\author{
UNIVERSIDADE DE SÃO PAULO \\ INSTITUTO DE QUÍMICA \\ DEPARTAMENTO DE QUÍMICA FUNDAMENTAL
}

\title{
ANÁLISE TÉRMICA APLICADA À SÍNTESE E CARACTERIZAÇÃO DE ÓXIDOS MISTOS DE NÍQUEL E TERRAS RARAS
}

Adélia Maria Lima da Silva

Tese de Doutorado

Prof. Dr. Jivaldo do Rosário Matos

Orientador

São Paulo 


\title{
"Análise Térmica Aplicada à Síntese e Caracterização de Óxidos Mistos de Níquel e Terras Raras".
}

\section{ADÉLIA MARIA LIMA DA SILVA}

Tese de Doutorado submetida ao Instituto de Química da Universidade de São Paulo como parte dos requisitos necessários à obtenção do grau de Doutor em Ciências - Área: Química Analítica.

Aprovada por:

\author{
Prof. Dr. JIVALDO DO ROSÁRIO MATOS \\ L - USP \\ (Orientador e Presidente)
Prof. Dr. GERALDO VICENTINI
IQ - USP
Prof. Dr. VALTER JOSÉ FERNANDES JUNIOR
UFRN \\ Prof. Dr. JOSÉ MARQUES LUIZ \\ FE - UNESP - Guaratinguetá \\ Profa. Dra. LUCI DIVA BROCARDO MACHADO \\ IPEN - SP \\ SÃO PAULO \\ 15 DE JANEIRO DE 1999.
}


Aos meus pais, Waldery e Raimunda, e meus irmãos Waldery Filho, Ana ,Waldenir, Walder e Andrea 
Ao Prof. Dr. Jivaldo do Rosário Matos, pelos ensinamentos, orientação, apoio $e$ oportunidade de desenvolver e finalizar este trabalho 


\section{SUMÁRIO}

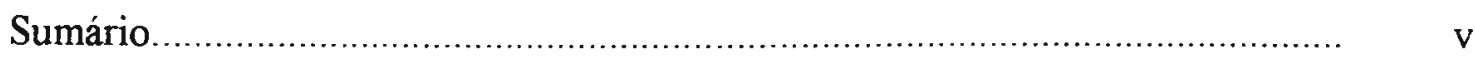

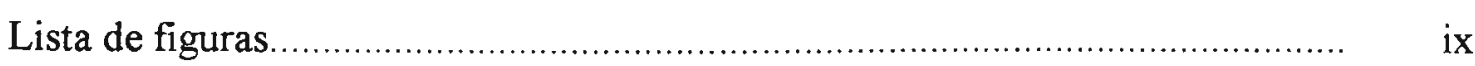

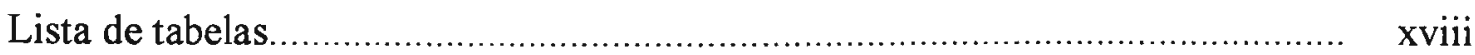

Lista de abreviaturas e siglas ............................................................. $\quad \mathrm{xx}$

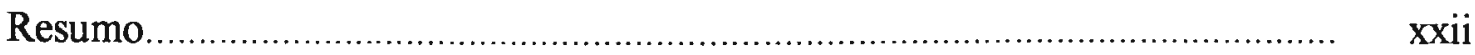

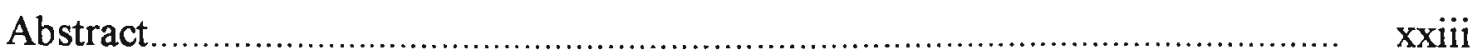

\section{Capítulo 1- INTRODUÇÃO, OBJETIVOS E REVISÃO BIBLIOGRÁFICA}

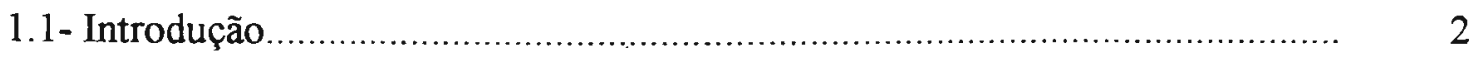

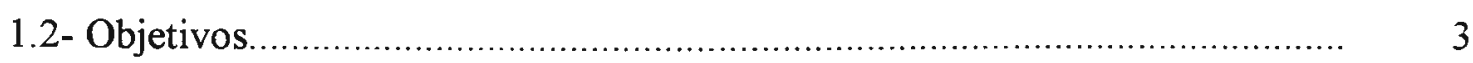

1.3- Revisão bibliográfica: considerações gerais............................................ 4

1.3.1- Análise térmica aplicada a óxidos mistos................................ 4

1.3.2- Niqquel........................................................................... 7

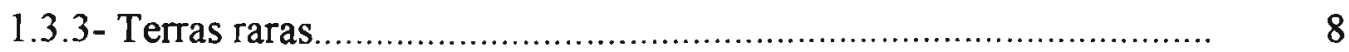

1.3.4- Estrutura cristalina dos óxidos mistos.................................... 9

1.3.5- Síntese dos óxidos mistos............................................... 13

1.3.6- Propriedades dos óxidos mistos.............................................. 14

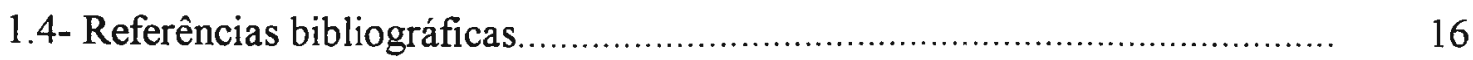

\section{Capítulo 2- PARTE EXPERIMENTAL}

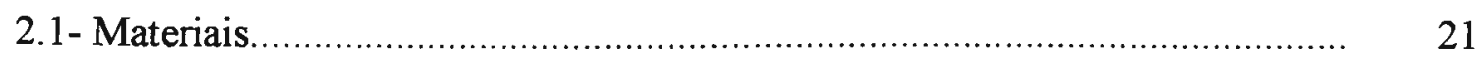

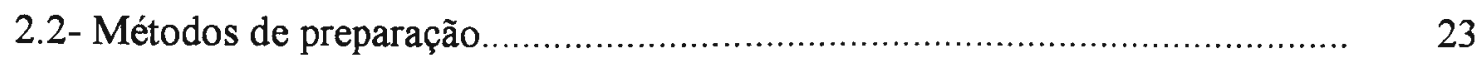

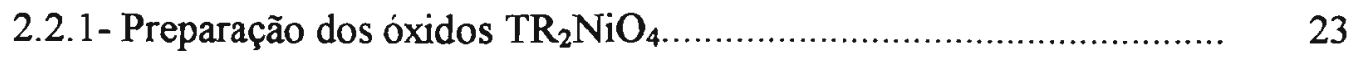

2.2.2- Preparação dos hidroxicarbonatos de terras raras.......................... 23

2.2.3- Preparação dos acetatos de terras raras.......................................... 24

2.2.4- Preparação dos acetatos binários de terras raras e níquel............... 25

2.2.4.1 - Mistura mecânica (M. M.)........................................... 25

2.2.4.2- Evaporação do solvente (E. S.).................................. 25

2.2.4.3- Cristalização por acetona (C. A.) ................................... 25

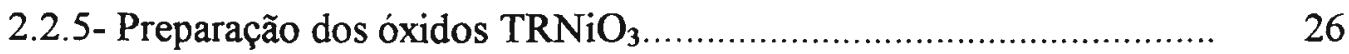


2.2.5.1- Mistura de óxidos (M. O.) .......................................... 26

2.2.5.2- Precipitação simultânea de hidróxidos (H. I.)................. 26

2.2.5.3- Processo sol-gel (S. G.) .............................................. 27

2.3- Tratamentos térmicos.................................................................. 30

2.4- Métodos de análise............................................................................ $\quad 31$

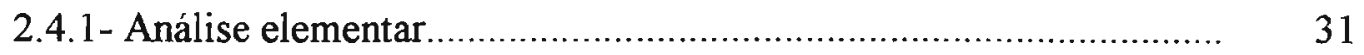

2.4.1.1- Determinação quantitativa de carbono e hidrogênio........ 31

2.4.1.2- Determinação quantitativa dos íons terras raras.............. 31

2.4.1.3- Determinação quantitativa do teor de água...................... 32

2.4.2- Espectroscopia de absorção na região do infravermelho (IR)........ 32

2.4.3- Difração de raios X (XRD) ....................................................... 32

2.4.4- Microscopia eletrônica de varredura (SEM)............................... 33

2.4.5- Resistividade elétrica............................................................. 33

2.4.6- Análise térmica.................................................................. 35

2.4.6.1 - Termogravimetria/termogravimetria derivada (TG/DTG).. $\quad 35$

2.4.6.2- Calorimetria exploratória diferencial (DSC).................. 36

2.4.6.3- Análise térmica diferencial (DTA)............................. 36

2.4.6.4- Termogravimetria/Análise térmica diferencial -

Cromatografia /espectrometria de massa (TG/DTA-GC/MS) 37

2.5- Propriedades: teste catalítico.......................................................... 38

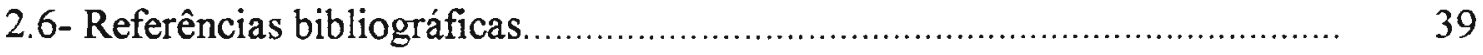

\section{Capítulo 3- RESULTADOS E DISCUSSÃO}

\section{Parte 1}

3.1- Hidroxicarbonatos de terras raras.............................................................

3.2- Acetatos de terras raras............................................................................ 45

3.2.1- Análise elementar................................................................. 45

3.2.2.- Espectroscopia de absorção na região do infravermelho............... 45

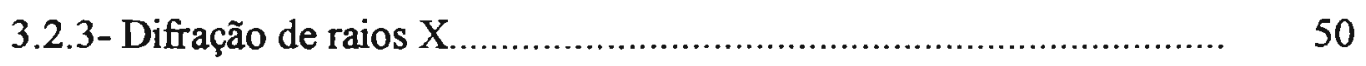

3.2.4- Análise térmica.................................................................... 52

3.2.4.1- Acetato de lantânio ..................................................... 52

3.2.4.2- Acetato de európio ...................................................... 59 
3.2.4.3- Acetato de ítrio....................................................... 64

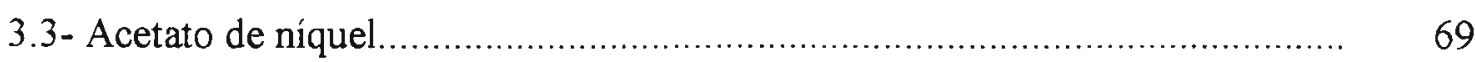

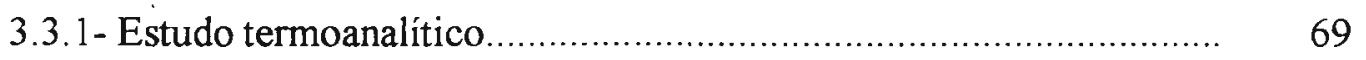

3.3.2- Caracterização ....................................................................... 73

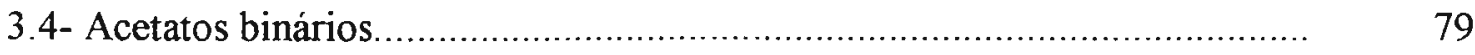

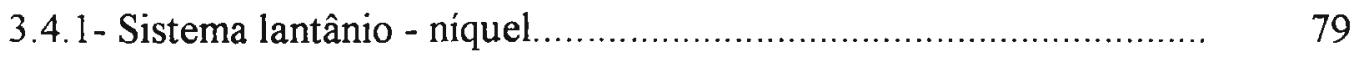

3.4.1.1- Análise elementar................................................ 79

3.4.1.2- Espectroscopia de absorção na região do infravermelho.. $\quad 80$

3.4.1.3- Difração de raios X ................................................... $\quad 80$

3.4.1.4- Análise térmica......................................................... $\quad 85$

3.4.1.5- Produtos sólidos da decomposição térmica dos acetatos binários de lantânio e níquel...................................... 94

3.4.1.6- Propriedades catalíticas: teste preliminar....................... $\quad 98$

3.4.2- Sistema európio - níquel............................................... 100

3.4.2.1- Análise elementar..................................................... 100

3.4.2.2- Espectroscopia de absorção na região do infravermelho.. 100

3.4.2.3- Difração de raios X.................................................... 103

3.4.2.4- Análise térmica........................................................ 106

3.4.2.5- Produtos sólidos da decomposição térmica dos acetatos binários de európio e níquel............................................ 114

3.4.3- Sistema ítrio - níquel........................................................ 118

3.4.3.1 - Análise elementar..................................................... 118

3.4.3.2- Espectroscopia de absorção na região do infravermelho.. 118

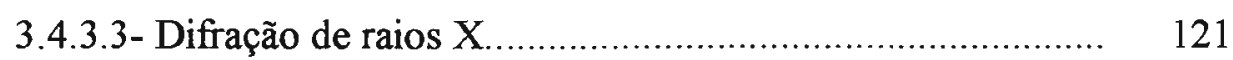

3.4.3.4- Análise térmica......................................................... 124

3.4.3.5-Produtos sólidos da decomposição térmica dos acetatos binários de ítrio e níquel.

\section{Parte 2}

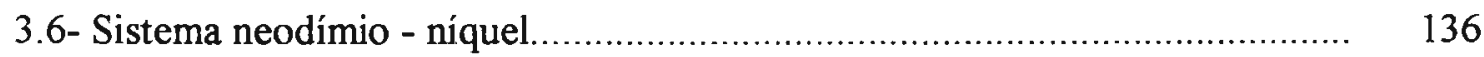

3.6.1 - Caracterização................................................................. 136

3.6.2- Propriedades................................................................ 141 


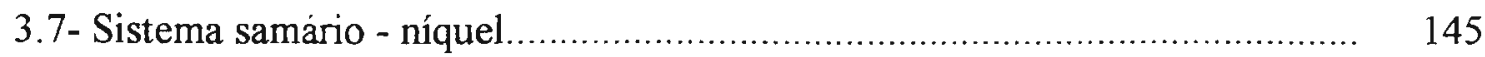

3.7.1- Caracterização...................................................................... 145

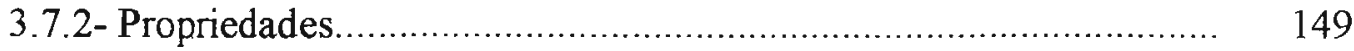

3.8- Sistema ítrio - níquel...................................................................... 152

3.8.1- Caracterização........................................................... 152

3.8.2- Propriedades............................................................... 153

3.9- Referências bibliográficas.......................................................... 156

Capítulo 4- CONSIDERAÇÕES FINAIS

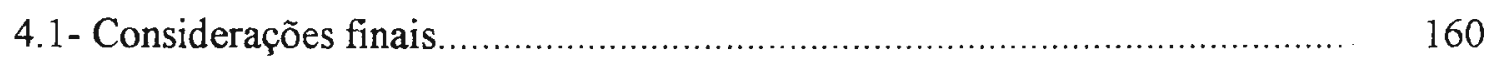

Capítulo 5- PERSPECTIVAS DE TRABALHOS FUTUROS

5.1- Perspectivas gerais....................................................................... 163

\section{Apêndice}

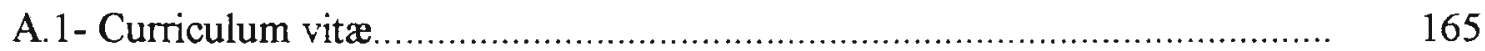




\section{LISTA DE FIGURAS}

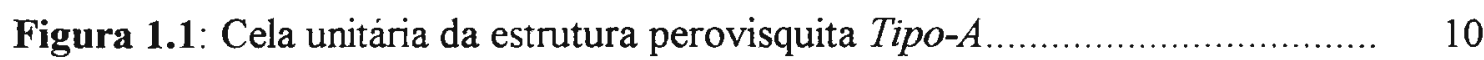

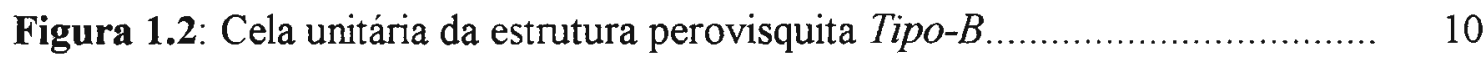

Figura 1.3: Estrutura perovisquita: (a) ortorrômbica (Pbnm)e (b) distorção romboédrica $(R 3 c)$

Figura 1.4: Dependência dos parâmetros de rede em função do fator de tolerância $t$ nas séries $\mathrm{TRNiO}_{3}$

Figura 1.5: (a) e (b) Estrutura tipo- $\mathrm{K}_{2} \mathrm{NiF}_{4}$ derivadas da cela unitária da estrutura perovisquita.

Figura 2.1: (a) Arranjo experimental construído com o tubo metálico de aço Inconel 600 acondicionado no interior da zona quente do forno Lindeberg; (b) Sistema de vedação da flange usando um anel de cobre.

Figura 2.2: Arranjo experimental montado no laboratório para medidas de $\rho(T)$ mostrando a configuração do porta amostra.

Figura 2.3: Representação esquemática do sistema TG/DTA-GC/MS

Figura 2.4: Esquema do microrreator catalítico de pulso acoplado a um cromatógrafo a gás.

Figura 3.1: Curvas TG/DTG do $\mathrm{LaOHCO}_{3}$ obtidas sob atmosfera dinâmica de ar $\left(50 \mathrm{~mL} \min ^{-1}\right)$, razão de aquecimento de $10^{\circ} \mathrm{C} \mathrm{min}^{-1}$, cadinho de platina e massa da amostra de 5,648 $\mathrm{mg}$.

Figura 3.2: Curvas TG/DTG do $\mathrm{EuOHCO}_{3}$ obtidas sob atmosfera dinâmica de ar $\left(50 \mathrm{~mL} \min ^{-1}\right)$, razão de aquecimento de $10^{\circ} \mathrm{C} \mathrm{min}^{-1}$, cadinho de platina e massa da amostra de 5,403 $\mathrm{mg}$.

Figura 3.3: Curvas TG/DTG do $\mathrm{YOHCO}_{3} \cdot \mathrm{H}_{2} \mathrm{O}$ obtidas sob atmosfera dinâmica de ar $\left(50 \mathrm{~mL} \mathrm{~min}^{-1}\right)$, razão de aquecimento de $10^{\circ} \mathrm{C} \min ^{-1}$, cadinho de platina e massa da amostra de 5,932 $\mathrm{mg}$.

Figura 3.4: Difratogramas de raios $\mathrm{X}$ (método do pó) dos intermediários da decomposição térmica isolados em $550^{\circ} \mathrm{C}$, sob atmosfera dinâmica de ar $(50 \mathrm{~mL}$ 
$\min ^{-1}$ ), razão de aquecimento de $10^{\circ} \mathrm{C} \mathrm{min}^{-1}$ e cadinho de platina dos compostos: (a) $\mathrm{LaOHCO}_{3}$; (b) $\mathrm{EuOHCO}_{3}$; (c) $\mathrm{YOHCO}_{3} \cdot \mathrm{H}_{2} \mathrm{O}$.

Figura 3.5: Representação das formas de coordenação do ânion acetato.

Figura 3.6: Espectros de absorção na região do infravermelho dos compostos: (a) $\mathrm{La}\left(\mathrm{CH}_{3} \mathrm{COO}\right)_{3} .1,5 \mathrm{H}_{2} \mathrm{O}$; (b) $\mathrm{Eu}\left(\mathrm{CH}_{3} \mathrm{COO}\right)_{3} .4 \mathrm{H}_{2} \mathrm{O}$; (c) $\mathrm{Y}\left(\mathrm{CH}_{3} \mathrm{COO}\right)_{3} .4 \mathrm{H}_{2} \mathrm{O} \ldots \ldots$.

Figura 3.7: Curvas TG/DTG do $\mathrm{La}\left(\mathrm{CH}_{3} \mathrm{COO}\right)_{3} .1,5 \mathrm{H}_{2} \mathrm{O}$ obtidas sob atmosfera dinâmica de ar $\left(50 \mathrm{~mL} \min ^{-1}\right)$, razão de aquecimento de $10^{\circ} \mathrm{C} \min ^{-1}$, cadinho de platina e massa da amostra de 5,463 $\mathrm{mg}$.

Figura 3.8: Curvas TG/DTG do $\mathrm{La}\left(\mathrm{CH}_{3} \mathrm{COO}\right)_{3} \cdot 1,5 \mathrm{H}_{2} \mathrm{O}$ obtidas sob atmosfera dinâmica de nitrogênio $\left(50 \mathrm{~mL} \min ^{-1}\right)$, razão de aquecimento de $10^{\circ} \mathrm{C} \min ^{-1}$, cadinho de platina e massa da amostra de 5,548 mg.

Figura 3.9: Curva DTA do $\mathrm{La}\left(\mathrm{CH}_{3} \mathrm{COO}\right)_{3} \cdot 1,5 \mathrm{H}_{2} \mathrm{O}$ obtida sob atmosfera dinâmica de ar $\left(50 \mathrm{~mL} \mathrm{~min}^{-1}\right)$, razão de aquecimento de $10^{\circ} \mathrm{C} \mathrm{min}^{-1}$, cadinho de alumina e massa da amostra de $18,36 \mathrm{mg}$.

Figura 3.10: Curva DSC do $\mathrm{La}\left(\mathrm{CH}_{3} \mathrm{COO}\right)_{3} \cdot 1,5 \mathrm{H}_{2} \mathrm{O}$ obtida sob atmosfera dinâmica de nitrogênio $\left(50 \mathrm{~mL} \min ^{-1}\right)$, razão de aquecimento de $10^{\circ} \mathrm{C} \min ^{-1}$, cápsula de alumínio aberta e massa da amostra de $2,328 \mathrm{mg}$.

Figura 3.11: Curvas DSC obtidas sob atmosfera dinâmica de nitrogênio $(50 \mathrm{~mL}$ $\min ^{-1}$ ), razão de aquecimento de $10^{\circ} \mathrm{C} \min ^{-1}$ e cápsula de alumínio das amostras: (a) $\mathrm{La}\left(\mathrm{CH}_{3} \mathrm{COO}\right)_{3} \cdot 1,5 \mathrm{H}_{2} \mathrm{O}$ (massa $=2,229 \mathrm{mg}$ ); (b) intermediário em $190^{\circ} \mathrm{C}$ (massa $=2,093 \mathrm{mg}$ ); (c) Reaquecimento do intermediário em $190^{\circ} \mathrm{C}$ (massa $=$ $2,00 \mathrm{mg}$ ); (d) intermediário em $260^{\circ} \mathrm{C}$ (massa $=2,00 \mathrm{mg}$ )

Figura 3.12: Difratogramas de raios $X$ (método do pó) das amostras: (a) $\mathrm{La}\left(\mathrm{CH}_{3} \mathrm{COO}\right)_{3} .1,5 \mathrm{H}_{2} \mathrm{O}$ (inserido $2 \theta=10$ a $70^{\circ}$, ampliado 15 vezes); (b) intermediário em $190^{\circ} \mathrm{C}$; (c) intermediário em $240^{\circ} \mathrm{C}$; (d) intermediário em $550^{\circ} \mathrm{C}$; (e) produto final em $900^{\circ} \mathrm{C}$. Os intermediários e o produto final da decomposição térmica foram obtidos sob atmosfera dinâmica de ar $\left(50 \mathrm{~mL} \mathrm{~min}{ }^{-1}\right)$, razão de aquecimento de $10^{\circ} \mathrm{C} \mathrm{min}^{-1}$, utilizando cadinho de platina.

Figura 3.13: Curvas $\mathrm{TG} / \mathrm{DTG}$ do $\mathrm{Eu}\left(\mathrm{CH}_{3} \mathrm{COO}\right)_{3} .4 \mathrm{H}_{2} \mathrm{O}$ obtidas sob atmosfera dinâmica de ar $\left(50 \mathrm{~mL} \mathrm{~min}^{-1}\right)$, razão de aquecimento de $10^{\circ} \mathrm{C} \mathrm{min}^{-1}$, cadinho de platina e massa da amostra de $5,784 \mathrm{mg}$

Figura 3.14: Curvas $\mathrm{TG} / \mathrm{DTG}$ do $\mathrm{Eu}\left(\mathrm{CH}_{3} \mathrm{COO}\right)_{3} \cdot 4 \mathrm{H}_{2} \mathrm{O}$ obtidas sob atmosfera 
dinâmica de nitrogênio $\left(50 \mathrm{~mL} \min ^{-1}\right)$, razão de aquecimento de $10^{\circ} \mathrm{C} \min ^{-1}$, cadinho de platina e massa da amostra de $5,791 \mathrm{mg}$.

Figura 3.15: Curva DTA do $\mathrm{Eu}\left(\mathrm{CH}_{3} \mathrm{COO}\right)_{3} \cdot 4 \mathrm{H}_{2} \mathrm{O}$ obtida sob atmosfera dinâmica de ar $\left(50 \mathrm{~mL} \mathrm{~min}{ }^{-1}\right)$, razão de aquecimento de $10^{\circ} \mathrm{C} \mathrm{min}^{-1}$, cadinho de alumina $\mathrm{e}$ massa da amostra de $18,04 \mathrm{mg}$.

Figura 3.16: Curva DSC do $\mathrm{Eu}\left(\mathrm{CH}_{3} \mathrm{COO}\right)_{3} \cdot 4 \mathrm{H}_{2} \mathrm{O}$ obtida sob atmosfera dinâmica de nitrogênio $\left(50 \mathrm{~mL} \min ^{-1}\right)$, razão de aquecimento de $10^{\circ} \mathrm{C} \mathrm{min}^{-1}$, cápsula de alumínio aberta e massa da amostra de $2,266 \mathrm{mg}$.

Figura 3.17: Difratogramas de raios $X$ (método do pó) das amostras: (a) $\mathrm{Eu}\left(\mathrm{CH}_{3} \mathrm{COO}\right)_{3} .4 \mathrm{H}_{2} \mathrm{O}$ (inserido $2 \theta=10$ a $70^{\circ}$, ampliado duas vezes); (b) intermediário em $200^{\circ} \mathrm{C}$; (c) intermediário em $500^{\circ} \mathrm{C}$; (d) produto final em $900^{\circ} \mathrm{C}$. Os intermediários e o produto final da decomposição térmica foram obtidos sob atmosfera dinâmica de ar $\left(50 \mathrm{~mL} \mathrm{~min}^{-1}\right)$, razão de aquecimento de $10^{\circ} \mathrm{C} \mathrm{min}^{-1}$, utilizando cadinho de platina

Figura 3.18: Curvas $\mathrm{TG} / \mathrm{DTG}$ do $\mathrm{Y}\left(\mathrm{CH}_{3} \mathrm{COO}\right)_{3} .4 \mathrm{H}_{2} \mathrm{O}$ obtidas sob atmosfera dinâmica de ar $\left(50 \mathrm{~mL} \mathrm{~min}{ }^{-1}\right)$, razão de aquecimento de $10^{\circ} \mathrm{C} \mathrm{min}{ }^{-1}$, cadinho de platina e massa da amostra de $5,367 \mathrm{mg}$.

Figura 3.19: Curvas $\mathrm{TG} / \mathrm{DTG}$ do $\mathrm{Y}\left(\mathrm{CH}_{3} \mathrm{COO}\right)_{3} .4 \mathrm{H}_{2} \mathrm{O}$ obtidas sob atmosfera dinâmica de nitrogênio $\left(50 \mathrm{~mL} \min ^{-1}\right)$, razão de aquecimento de $10^{\circ} \mathrm{C} \min ^{-1}$, cadinho de platina e massa da amostra de 5,064 mg.

Figura 3.20: Curva DTA do $\mathrm{Y}\left(\mathrm{CH}_{3} \mathrm{COO}\right)_{3} \cdot 4 \mathrm{H}_{2} \mathrm{O}$ obtida sob atmosfera dinâmica de ar $\left(50 \mathrm{~mL} \mathrm{~min}{ }^{-1}\right)$, razão de aquecimento de $10^{\circ} \mathrm{C} \min ^{-1}$, cadinho de alumina $\mathrm{e}$ massa da amostra de $17,58 \mathrm{mg}$.

Figura 3.21: Curva DSC do $\mathrm{Y}\left(\mathrm{CH}_{3} \mathrm{COO}\right)_{3} \cdot 4 \mathrm{H}_{2} \mathrm{O}$ obtida sob atmosfera dinâmica de nitrogênio $\left(50 \mathrm{~mL} \min ^{-1}\right.$ ), razão de aquecimento de $10^{\circ} \mathrm{C} \mathrm{min}{ }^{-1}$, cápsula de alumínio aberta e massa da amostra de $2,223 \mathrm{mg}$

Figura 3.22: Difratogramas de raios $X$ (método do pó) das amostras: (a) $\mathrm{Y}\left(\mathrm{CH}_{3} \mathrm{COO}\right)_{3} \cdot 4 \mathrm{H}_{2} \mathrm{O}$ (inserido $2 \theta=10$ a $70^{\circ}$, ampliado três vezes); (b) intermediário em $200^{\circ} \mathrm{C}$; (c) intermediário em $500^{\circ} \mathrm{C}$; (d) produto final em $900^{\circ} \mathrm{C}$. Os intermediários e o produto final da decomposição térmica foram obtidos sob atmosfera dinâmica de ar $\left(50 \mathrm{~mL} \mathrm{~min}^{-1}\right)$, razão de aquecimento de $10^{\circ} \mathrm{C} \min ^{-1}$, utilizando cadinho de platina......

Figura 3.23: Curvas TG/DTG do $\mathrm{Ni}\left(\mathrm{CH}_{3} \mathrm{COO}\right)_{2} \cdot 4 \mathrm{H}_{2} \mathrm{O}$ obtidas sob atmosfera 
dinâmica de ar $\left(50 \mathrm{~mL} \min ^{-1}\right)$, razão de aquecimento de $10^{\circ} \mathrm{C} \min ^{-1}$, cadinho de platina e massa da amostra de $4,745 \mathrm{mg}$.

Figura 3.24: Curvas TG/DTG do $\mathrm{Ni}\left(\mathrm{CH}_{3} \mathrm{COO}\right)_{2} \cdot 4 \mathrm{H}_{2} \mathrm{O}$ obtidas sob atmosfera dinâmica de nitrogênio $\left(50 \mathrm{~mL} \mathrm{~min}{ }^{-1}\right)$, razão de aquecimento de $10^{\circ} \mathrm{C} \mathrm{min}^{-1}$, cadinho de platina e massa da amostra de $4,326 \mathrm{mg}$.

Figura 3.25: Curva DTA do $\mathrm{Ni}\left(\mathrm{CH}_{3} \mathrm{COO}\right)_{2} \cdot 4 \mathrm{H}_{2} \mathrm{O}$ obtida sob atmosfera dinâmica de ar $\left(50 \mathrm{~mL} \mathrm{~min}^{-1}\right)$, razão de aquecimento de $10^{\circ} \mathrm{C} \mathrm{min}^{-1}$, cadinho de alumina e massa da amostra de $20,15 \mathrm{mg}$

Figura 3.26: Curva DSC do $\mathrm{Ni}\left(\mathrm{CH}_{3} \mathrm{COO}\right)_{2} .4 \mathrm{H}_{2} \mathrm{O}$ obtida sob atmosfera dinâmica de nitrogênio $\left(50 \mathrm{~mL} \mathrm{~min}^{-1}\right)$, razão de aquecimento de $10^{\circ} \mathrm{C} \mathrm{min}^{-1}$, cápsula de alumínio aberta e massa da amostra de $2,015 \mathrm{mg}$

Figura 3.27: Espectros de absorção na região do infravermelho dos compostos: (a) $\mathrm{Ni}\left(\mathrm{CH}_{3} \mathrm{COO}\right)_{2} \cdot 4 \mathrm{H}_{2} \mathrm{O}$; (b) Intermediário isolado em $200^{\circ} \mathrm{C}$

Figura 3.28: Difratogramas de raios $X$ (método do pó) das amostras: (a) $\mathrm{Ni}\left(\mathrm{CH}_{3} \mathrm{COO}\right)_{3} .4 \mathrm{H}_{2} \mathrm{O}$ (inserido $2 \theta=10$ a $70^{\circ}$, ampliado seis vezes); (b) intermediário em $200^{\circ} \mathrm{C}$; (c) intermediário em $450^{\circ} \mathrm{C}$; (d) intermediário em $570^{\circ} \mathrm{C}$; (e) produto final em $900^{\circ} \mathrm{C}$. Os intermediários e o produto final da decomposição térmica foram obtidos sob atmosfera dinâmica de nitrogênio (50 $\mathrm{mL} \min ^{-1}$ ), razão de aquecimento de $10^{\circ} \mathrm{C} \min ^{-1}$, utilizando cadinho de platina:......

Figura 3.29: Cromatograma total e os respectivos cromatogramas de massa dos voláteis libertados na decomposição térmica do $\mathrm{Ni}\left(\mathrm{CH}_{3} \mathrm{COO}\right)_{2} \cdot 4 \mathrm{H}_{2} \mathrm{O}$.

Figura 3.30: Espectros de massa dos voláteis da decomposição térmica do $\mathrm{Ni}\left(\mathrm{CH}_{3} \mathrm{COO}\right)_{2} .4 \mathrm{H}_{2} \mathrm{O}$ : (a) propanona e (b) ácido acético.

Figura 3.31: Espectros de absorção na região do infravermelho dos sistemas de $\begin{array}{llllll}\text { acetatos binários: (a) } \quad \mathrm{LaNi}\left(\mathrm{CH}_{3} \mathrm{COO}\right)_{5} .5,5 \mathrm{H}_{2} \mathrm{O} & \text { (M. } & \text { M.); } & \text { (b) }\end{array}$ $\mathrm{LaNi}\left(\mathrm{CH}_{3} \mathrm{COO}\right)_{5} .3 \mathrm{H}_{2} \mathrm{O}$ (E. S.); (c) $\mathrm{LaNi}\left(\mathrm{CH}_{3} \mathrm{COO}\right)_{5} .2,5 \mathrm{H}_{2} \mathrm{O}$ (C. A.).

Figura 3.32: Difratogramas de raios $X$ (método do pó) dos sistemas de acetatos binários de lantânio e níquel: (a) $\mathrm{LaNi}\left(\mathrm{CH}_{3} \mathrm{COO}\right)_{5} .5,5 \mathrm{H}_{2} \mathrm{O}, \mathrm{M}$. M.(inserido $2 \theta=$ 14 a $29^{\circ}$, ampliado seis vezes); (b) $\mathrm{LaNi}\left(\mathrm{CH}_{3} \mathrm{COO}\right)_{5} \cdot 3 \mathrm{H}_{2} \mathrm{O}, \mathrm{E}$. S. (inserido $2 \theta=$ 14 a $29^{\circ}$, ampliado dez vezes); (c) $\mathrm{LaNi}\left(\mathrm{CH}_{3} \mathrm{COO}\right)_{5} \cdot 2,5 \mathrm{H}_{2} \mathrm{O}, \mathrm{C}$. A. (inserido $2 \theta=$ 14 a $29^{\circ}$, ampliado duas vezes)

Figura 3.33: Curvas TG/DTG dos sistemas de acetatos binários de lantânio e níquel obtidas sob atmosfera dinâmica de ar $\left(50 \mathrm{~mL} \mathrm{~min}^{-1}\right)$, razão de aquecimento 
de $10^{\circ} \mathrm{C} \mathrm{min}^{-1}$ e cadinho de platina: (a) $\mathrm{LaNi}\left(\mathrm{CH}_{3} \mathrm{COO}\right)_{5} .5,5 \mathrm{H}_{2} \mathrm{O}$, M. M. $(\mathrm{m}=$ $5,009 \mathrm{mg})$; (b) $\mathrm{LaNi}\left(\mathrm{CH}_{3} \mathrm{COO}\right)_{5} \cdot 3 \mathrm{H}_{2} \mathrm{O}$, E. $\quad$ S. $(\mathrm{m}=6,413 \mathrm{mg}) ; \quad$ (c) $\mathrm{LaNi}\left(\mathrm{CH}_{3} \mathrm{COO}\right)_{5} .2,5 \mathrm{H}_{2} \mathrm{O}, \mathrm{C} . \mathrm{A} .(\mathrm{m}=4,990 \mathrm{mg})$.

Figura 3.34: Curvas TG/DTG dos sistemas de acetatos binários de lantânio e níquel obtidas sob atmosfera dinâmica de nitrogênio $\left(50 \mathrm{~mL} \mathrm{~min}^{-1}\right)$, razão de aquecimento de $10^{\circ} \mathrm{C} \mathrm{min}{ }^{-1}$ e cadinho de platina: (a) $\mathrm{LaNi}\left(\mathrm{CH}_{3} \mathrm{COO}\right)_{5}, 5,5 \mathrm{H}_{2} \mathrm{O}, \mathrm{M}$. M. $(\mathrm{m}=5,556 \mathrm{mg})$; (b) $\mathrm{LaNi}\left(\mathrm{CH}_{3} \mathrm{COO}\right)_{5} \cdot 3 \mathrm{H}_{2} \mathrm{O}$, E. S. $(\mathrm{m}=5,351 \mathrm{mg}$; (c) $\mathrm{LaNi}\left(\mathrm{CH}_{3} \mathrm{COO}\right)_{5} .2,5 \mathrm{H}_{2} \mathrm{O}, \mathrm{C} . \mathrm{A} .(\mathrm{m}=5,403 \mathrm{mg})$.

Figura 3.35: Curvas DTA dos sistemas de acetatos binários de lantânio e níquel obtidas sob atmosfera dinâmica de ar $\left(50 \mathrm{~mL} \mathrm{~min}^{-1}\right)$, razão de aquecimento de $10^{\circ} \mathrm{C} \mathrm{min}{ }^{-1}$ e cadinho de alumina: (a) $\mathrm{LaNi}\left(\mathrm{CH}_{3} \mathrm{COO}\right)_{3} .5,5 \mathrm{H}_{2} \mathrm{O}$, M. M. (m $=19,22$ $\mathrm{mg}) ; \quad$ (b) $\mathrm{LaNi}\left(\mathrm{CH}_{3} \mathrm{COO}\right)_{5} \cdot 3 \mathrm{H}_{2} \mathrm{O}$, E. $\quad \mathrm{S} . \quad(\mathrm{m}=17,50 \mathrm{mg}) ; \quad$ (c) $\mathrm{LaNi}\left(\mathrm{CH}_{3} \mathrm{COO}\right)_{5} \cdot 2,5 \mathrm{H}_{2} \mathrm{O}$, C. A. $(\mathrm{m}=18,30 \mathrm{mg})$.

Figura 3.36: Curvas DSC dos sistemas de acetatos binários de lantânio e níquel obtidas sob atmosfera dinâmica de nitrogênio $\left(50 \mathrm{~mL} \min ^{-1}\right)$, razão de aquecimento de $10^{\circ} \mathrm{C} \min ^{-1}$ e cápsula de alumínio aberta: (a) $\mathrm{LaNi}\left(\mathrm{CH}_{3} \mathrm{COO}\right)_{5} .5,5 \mathrm{H}_{2} \mathrm{O}$, M. M. (m=2,328 mg); (b) $\mathrm{LaNi}\left(\mathrm{CH}_{3} \mathrm{COO}\right)_{5} .3 \mathrm{H}_{2} \mathrm{O}, \mathrm{E}$. S. $(\mathrm{m}=2,260 \mathrm{mg}) ;(\mathrm{c}) \mathrm{LaNi}\left(\mathrm{CH}_{3} \mathrm{COO}\right)_{5} \cdot 2,5 \mathrm{H}_{2} \mathrm{O}, \mathrm{C}$. A. $(\mathrm{m}=2,096 \mathrm{mg})$.

Figura 3.37: Difratogramas de raios $X$ (método do pó) dos produtos da decomposição térmica a $900^{\circ} \mathrm{C}$, obtidos sob atmosfera dinâmica de ar $(50 \mathrm{~mL}$ $\min ^{-1}$ ), razão de aquecimento de $10^{\circ} \mathrm{C} \mathrm{min}^{-1}$ e cadinho de platina das amostras: (a) $\mathrm{La}\left(\mathrm{CH}_{3} \mathrm{COO}\right)_{3} .1,5 \mathrm{H}_{2} \mathrm{O}$; (b) $\mathrm{Ni}\left(\mathrm{CH}_{3} \mathrm{COO}\right)_{2} .4 \mathrm{H}_{2} \mathrm{O}$; (c) $\mathrm{LaNi}\left(\mathrm{CH}_{3} \mathrm{COO}\right)_{5} .5,5 \mathrm{H}_{2} \mathrm{O}$ (M. M.); (d)LaNi( $\left.\mathrm{CH}_{3} \mathrm{COO}\right)_{5} .3 \mathrm{H}_{2} \mathrm{O}$ (E. S.); (e) $\mathrm{LaNi}\left(\mathrm{CH}_{3} \mathrm{COO}\right)_{5} .2,5 \mathrm{H}_{2} \mathrm{O}$ (C. A.).

Figura 3.38: Difratogramas de raios $X$ (método do pó) dos produtos da decomposição térmica a $900^{\circ} \mathrm{C}$, obtidos sob atmosfera dinâmica de nitrogênio (50 $\left.\mathrm{mL} \min ^{-1}\right)$, razão de aquecimento de $10^{\circ} \mathrm{C} \min ^{-1}$ e cadinho de platina das amostras:

(a) $\mathrm{La}\left(\mathrm{CH}_{3} \mathrm{COO}\right)_{3} \cdot 1,5 \mathrm{H}_{2} \mathrm{O}$;

(b) $\mathrm{Ni}\left(\mathrm{CH}_{3} \mathrm{COO}\right)_{2} \cdot 4 \mathrm{H}_{2} \mathrm{O}$; $\mathrm{LaNi}\left(\mathrm{CH}_{3} \mathrm{COO}\right)_{5} .5,5 \mathrm{H}_{2} \mathrm{O}$ (M. M.); (d) $\mathrm{LaNi}\left(\mathrm{CH}_{3} \mathrm{COO}\right)_{5} .3 \mathrm{H}_{2} \mathrm{O}$ (E. S.); (e) $\mathrm{LaNi}\left(\mathrm{CH}_{3} \mathrm{COO}\right)_{5} .2,5 \mathrm{H}_{2} \mathrm{O}$ (C. A.)

Figura 3.39: Difratogramas de raios $X$ (método do pó) obtidos após tratamento térmico a $900^{\circ} \mathrm{C}$, sob atmosfera dinâmica de ar $\left(50 \mathrm{~mL} \min ^{-1}\right)$, razão de aquecimento de $10^{\circ} \mathrm{C} \min ^{-1}$ e cadinho de alumina das amostras: (a) $\mathrm{La}\left(\mathrm{CH}_{3} \mathrm{COO}\right)_{3} .1,5 \mathrm{H}_{2} \mathrm{O}$; (b) $\mathrm{Ni}\left(\mathrm{CH}_{3} \mathrm{COO}\right)_{2} \cdot 4 \mathrm{H}_{2} \mathrm{O}$; (c) $\mathrm{LaNi}\left(\mathrm{CH}_{3} \mathrm{COO}\right)_{5} .5,5 \mathrm{H}_{2} \mathrm{O}$ (M. M.); (d)LaNi(CH $\mathrm{LOO}_{5} .3 \mathrm{H}_{2} \mathrm{O}$ (E. S.); (e) $\mathrm{LaNi}\left(\mathrm{CH}_{3} \mathrm{COO}\right)_{5} .2,5 \mathrm{H}_{2} \mathrm{O}$ (C. A.). 
Figura 3.40: Espectros de absorção na região do infravermelho dos sistemas de acetatos binários: (a) $\quad \mathrm{EuNi}\left(\mathrm{CH}_{3} \mathrm{COO}\right)_{5} .8 \mathrm{H}_{2} \mathrm{O} \quad$ (M. $\quad$ M.); (b)

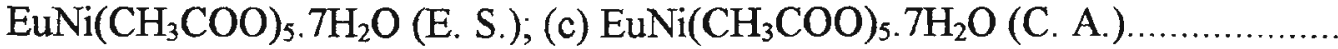

Figura 3.41: Difratogramas de raios $X$ (método do pó) dos sistemas de acetatos binários de európio e níquel: (a) $\mathrm{EuNi}\left(\mathrm{CH}_{3} \mathrm{COO}\right)_{5} .8 \mathrm{H}_{2} \mathrm{O}$, M. M. (inserido $2 \theta=14$ a $29^{\circ}$, ampliado seis vezes); (b) $\mathrm{EuNi}\left(\mathrm{CH}_{3} \mathrm{COO}\right)_{5} .5 \mathrm{H}_{2} \mathrm{O}$, E. S. (inserido $2 \theta=14$ a $29^{\circ}$, ampliado duas vezes); (c) $\mathrm{EuNi}\left(\mathrm{CH}_{3} \mathrm{COO}\right)_{5} .7 \mathrm{H}_{2} \mathrm{O}, \mathrm{C}$. A. (inserido $2 \theta=14 \mathrm{a}$ $29^{\circ}$, ampliado duas vezes)

Figura 3.42 : Curvas TG/DTG dos sistemas de acetatos binários de európio e níquel obtidas sob atmosfera dinâmica de ar $\left(50 \mathrm{~mL} \mathrm{~min}^{-1}\right)$, razão de aquecimento de $10^{\circ} \mathrm{C} \min ^{-1}$ e cadinho de platina: (a) $\operatorname{EuNi}\left(\mathrm{CH}_{3} \mathrm{COO}\right)_{5} .8 \mathrm{H}_{2} \mathrm{O}$, M. M. (m = $5,673 \mathrm{mg})$; (b) $\mathrm{EuNi}\left(\mathrm{CH}_{3} \mathrm{COO}\right)_{5} \cdot 5 \mathrm{H}_{2} \mathrm{O}$, E. S. (m $\left.=5,305 \mathrm{mg}\right) ;$ (c) $\mathrm{EuNi}\left(\mathrm{CH}_{3} \mathrm{COO}\right)_{5} .7 \mathrm{H}_{2} \mathrm{O}$, C. A. $(\mathrm{m}=4,519 \mathrm{mg})$

Figura 3.43 : Curvas TG/DTG dos sistemas de acetatos binários de európio e níquel obtidas sob atmosfera dinâmica de nitrogênio $\left(50 \mathrm{~mL} \mathrm{~min}{ }^{-1}\right)$, razão de aquecimento de $10^{\circ} \mathrm{C} \min ^{-1}$ e cadinho de platina: (a) $\mathrm{EuNi}\left(\mathrm{CH}_{3} \mathrm{COO}\right)_{5} .8 \mathrm{H}_{2} \mathrm{O}, \mathrm{M}$. M. $(\mathrm{m}=4,164 \mathrm{mg})$; (b) $\mathrm{EuNi}\left(\mathrm{CH}_{3} \mathrm{COO}\right)_{5} \cdot 5 \mathrm{H}_{2} \mathrm{O}$, E. S. $(\mathrm{m}=4,971 \mathrm{mg})$; (c) $\mathrm{EuNi}\left(\mathrm{CH}_{3} \mathrm{COO}\right)_{5} .7 \mathrm{H}_{2} \mathrm{O}, \mathrm{C} . \mathrm{A} .(\mathrm{m}=4,287 \mathrm{mg})$.

Figura 3.44: Curvas DTA dos sistemas de acetatos binários de európio e níquel obtidas sob atmosfera dinâmica de ar $\left(50 \mathrm{~mL} \min ^{-1}\right)$, razão de aquecimento de $10^{\circ} \mathrm{C} \min ^{-1}$ e cadinho de alumina: (a) EuNi $\left(\mathrm{CH}_{3} \mathrm{COO}\right)_{3} \cdot 8 \mathrm{H}_{2} \mathrm{O}, \mathrm{M} . \mathrm{M}$. (m $=19,50$ $\mathrm{mg}) ;$ (b) $\mathrm{EuNi}\left(\mathrm{CH}_{3} \mathrm{COO}\right)_{5} .5 \mathrm{H}_{2} \mathrm{O}, \quad$ E. S. $\quad(\mathrm{m}=18,68 \mathrm{mg}) ; \quad$ (c) $\mathrm{EuNi}\left(\mathrm{CH}_{3} \mathrm{COO}\right)_{5} .7 \mathrm{H}_{2} \mathrm{O}$, C. A. $(\mathrm{m}=17,02 \mathrm{mg})$.

Figura 3.45: Curvas DSC dos sistemas de acetatos binários de európio e níquel obtidas sob atmosfera dinâmica de nitrogênio $\left(50 \mathrm{~mL} \min ^{-1}\right)$, razão de aquecimento de $10^{\circ} \mathrm{C} \min ^{-1}$ e cápsula de alumínio aberta: (a)

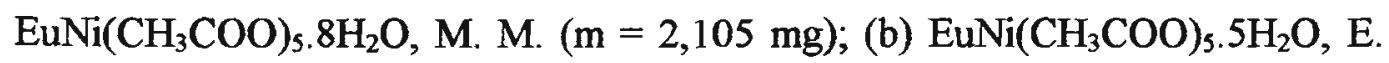
S. $(\mathrm{m}=2,305 \mathrm{mg})$; (c) $\mathrm{EuNi}\left(\mathrm{CH}_{3} \mathrm{COO}\right)_{5} .7 \mathrm{H}_{2} \mathrm{O}, \mathrm{C} . \mathrm{A} .(\mathrm{m}=2,225 \mathrm{mg})$.

Figura 3.46: Difratogramas de raios $X$ (método do pó) dos produtos da decomposição térmica a $900^{\circ} \mathrm{C}$, obtidos sob atmosfera dinâmica de ar $(50 \mathrm{~mL}$ $\min ^{-1}$ ), razão de aquecimento de $10^{\circ} \mathrm{C} \min ^{-1}$ e cadinho de platina das amostras: (a) $\mathrm{Eu}\left(\mathrm{CH}_{3} \mathrm{COO}\right)_{3} .4 \mathrm{H}_{2} \mathrm{O}$; (b) $\mathrm{Ni}\left(\mathrm{CH}_{3} \mathrm{COO}\right)_{2} .4 \mathrm{H}_{2} \mathrm{O}$; (c) $\mathrm{EuNi}\left(\mathrm{CH}_{3} \mathrm{COO}\right)_{5} .8 \mathrm{H}_{2} \mathrm{O}$ (M. M.); (d) $\mathrm{EuNi}\left(\mathrm{CH}_{3} \mathrm{COO}\right)_{5} .5 \mathrm{H}_{2} \mathrm{O}$ (E. S.); (e) $\mathrm{EuNi}\left(\mathrm{CH}_{3} \mathrm{COO}\right)_{5} .7 \mathrm{H}_{2} \mathrm{O}$ (C. A.).......... 
Figura 3.47: Difratogramas de raios $X$ (método do pó) dos produtos da decomposição térmica a $900^{\circ} \mathrm{C}$, obtidos sob atmosfera dinâmica de nitrogênio (50 $\mathrm{mL} \min ^{-1}$ ), razão de aquecimento de $10^{\circ} \mathrm{C} \min ^{-1}$ e cadinho de platina das amostras: (a) $\quad \mathrm{Eu}\left(\mathrm{CH}_{3} \mathrm{COO}\right)_{3} \cdot 4 \mathrm{H}_{2} \mathrm{O} ; \quad$ (b) $\mathrm{Ni}\left(\mathrm{CH}_{3} \mathrm{COO}\right)_{2} \cdot 4 \mathrm{H}_{2} \mathrm{O}$; $\quad$ (c) $\mathrm{EuNi}\left(\mathrm{CH}_{3} \mathrm{COO}\right)_{5 .} .8 \mathrm{H}_{2} \mathrm{O}$ (M. M.); (d) $\mathrm{EuNi}\left(\mathrm{CH}_{3} \mathrm{COO}\right)_{5} .5 \mathrm{H}_{2} \mathrm{O} \quad$ (E. S.); (e) $\mathrm{EuNi}\left(\mathrm{CH}_{3} \mathrm{COO}\right)_{5} .7 \mathrm{H}_{2} \mathrm{O}$ (C. A.)

Figura 3.48: Difratogramas de raios $X$ (método do pó) obtidos após tratamento térmico a $900^{\circ} \mathrm{C}$, obtidos sob atmosfera dinâmica de ar $\left(50 \mathrm{~mL} \mathrm{~min}^{-1}\right)$, razão de aquecimento de $10^{\circ} \mathrm{C} \min ^{-1}$ e cadinho de alumina das amostras: (a) $\mathrm{Eu}\left(\mathrm{CH}_{3} \mathrm{COO}\right)_{3} .4 \mathrm{H}_{2} \mathrm{O}$; (b) $\mathrm{Ni}\left(\mathrm{CH}_{3} \mathrm{COO}\right)_{2} .4 \mathrm{H}_{2} \mathrm{O}$; (c) $\mathrm{EuNi}\left(\mathrm{CH}_{3} \mathrm{COO}\right)_{5} .8 \mathrm{H}_{2} \mathrm{O}$ (M. M.); (d) $\mathrm{EuNi}\left(\mathrm{CH}_{3} \mathrm{COO}\right)_{5} .5 \mathrm{H}_{2} \mathrm{O}$ (E. S.); (e) $\mathrm{EuNi}\left(\mathrm{CH}_{3} \mathrm{COO}\right)_{5} .7 \mathrm{H}_{2} \mathrm{O}$ (C. A.).

Figura 3.49: Espectros de absorção na região do infravermelho dos sistemas de acetatos binários: (a) $\mathrm{YNi}\left(\mathrm{CH}_{3} \mathrm{COO}\right)_{5} .8 \mathrm{H}_{2} \mathrm{O}$ (M. M.); (b) $\mathrm{YNi}\left(\mathrm{CH}_{3} \mathrm{COO}\right)_{5} \cdot 2 \mathrm{H}_{2} \mathrm{O}$ (E. S.); (c) $\mathrm{YNi}\left(\mathrm{CH}_{3} \mathrm{COO}\right)_{5} .2 \mathrm{H}_{2} \mathrm{O}$ (C. A.).

Figura 3.50: Difratogramas de raios $X$ (método do pó) dos sistemas de acetatos binários de ítrio e níquel: (a) $\mathrm{YNi}\left(\mathrm{CH}_{3} \mathrm{COO}\right)_{5} .8 \mathrm{H}_{2} \mathrm{O}, \mathrm{M}$. $\mathrm{M}$. (inserido $2 \theta=14$ a $29^{\circ}$, ampliado cinco vezes); (b) $\mathrm{YNi}\left(\mathrm{CH}_{3} \mathrm{COO}\right)_{5} \cdot 3 \mathrm{H}_{2} \mathrm{O}, \mathrm{E}$. S. (inserido $2 \theta=14$ a $29^{\circ}$, ampliado duas vezes); (c) $\mathrm{YNi}\left(\mathrm{CH}_{3} \mathrm{COO}\right)_{5} \cdot 2 \mathrm{H}_{2} \mathrm{O}, \mathrm{C}$. A. (inserido $2 \theta=14$ a $29^{\circ}$, ampliado duas vezes)

Figura 3.51: Curvas TG/DTG dos sistemas de acetatos binários de ítrio e níquel obtidas sob atmosfera dinâmica de ar $\left(50 \mathrm{~mL} \mathrm{~min}^{-1}\right)$, razão de aquecimento de $10^{\circ} \mathrm{C} \min ^{-1}$ e cadinho de platina: (a) $\mathrm{YNi}\left(\mathrm{CH}_{3} \mathrm{COO}\right)_{5} \cdot 8 \mathrm{H}_{2} \mathrm{O}$, M. M. (m $=4,826$ $\mathrm{mg}$ ); (b) $\mathrm{YNi}\left(\mathrm{CH}_{3} \mathrm{COO}\right)_{5} \cdot 3 \mathrm{H}_{2} \mathrm{O}$, E. S. (m=4,070 mg); (c) $\mathrm{Y}\left(\mathrm{CH}_{3} \mathrm{COO}\right)_{5} \cdot 2 \mathrm{H}_{2} \mathrm{O}$, C. A. $(\mathrm{m}=4,931 \mathrm{mg})$

Figura 3.52: Curvas TG/DTG dos sistemas de acetatos binários de ítrio e níquel obtidas sob atmosfera dinâmica de nitrogênio (50 $\left.\mathrm{mL} \mathrm{min}^{-1}\right)$, razão de aquecimento de $10^{\circ} \mathrm{C} \min ^{-1}$ e cadinho de platina: (a) $\mathrm{YNi}\left(\mathrm{CH}_{3} \mathrm{COO}\right)_{5} 8 \mathrm{H}_{2} \mathrm{O}, \mathrm{M}$. M. $(\mathrm{m}=5,117 \mathrm{mg})$; (b) $\mathrm{YNi}\left(\mathrm{CH}_{3} \mathrm{COO}\right)_{5} \cdot 3 \mathrm{H}_{2} \mathrm{O}$, E. S. $(\mathrm{m}=4,075 \mathrm{mg})$; (c) $\mathrm{Y}\left(\mathrm{CH}_{3} \mathrm{COO}\right)_{5} .2 \mathrm{H}_{2} \mathrm{O}, \mathrm{C} . \mathrm{A} .(\mathrm{m}=5,073 \mathrm{mg})$.

Figura 3.53: Curvas DTA dos sistemas de acetatos binários de ítrio e níquel obtidas sob atmosfera dinâmica de ar $\left(50 \mathrm{~mL} \mathrm{~min}^{-1}\right)$, razão de aquecimento de $10^{\circ} \mathrm{C} \min ^{-1}$ e cadinho de alumina: (a) $\mathrm{YNi}\left(\mathrm{CH}_{3} \mathrm{COO}\right)_{3} \cdot 8 \mathrm{H}_{2} \mathrm{O}, \mathrm{M} . \mathrm{M} .(\mathrm{m}=19,22$ $\mathrm{mg})$; (b) $\mathrm{YNi}\left(\mathrm{CH}_{3} \mathrm{COO}\right)_{5} \cdot 3 \mathrm{H}_{2} \mathrm{O}$, E. $\quad$ S. $(\mathrm{m}=17,50 \mathrm{mg}) ; \quad$ (c) $\mathrm{YNi}\left(\mathrm{CH}_{3} \mathrm{COO}\right)_{5} .2 \mathrm{H}_{2} \mathrm{O}, \mathrm{C} . \mathrm{A} .(\mathrm{m}=18,30 \mathrm{mg})$. 
Figura 3.54: Curvas DSC dos sistemas de acetatos binários de ítrio e níquel obtidas sob atmosfera dinâmica de nitrogênio $\left(50 \mathrm{~mL} \min ^{-1}\right)$, razão de aquecimento de $10^{\circ} \mathrm{C} \min ^{-1}$ e cápsula de alumínio aberta: (a) $\mathrm{YNi}\left(\mathrm{CH}_{3} \mathrm{COO}\right)_{5} .8 \mathrm{H}_{2} \mathrm{O}$, M. M. (m=2,045 mg); (b) $\mathrm{YNi}\left(\mathrm{CH}_{3} \mathrm{COO}\right)_{5} .3 \mathrm{H}_{2} \mathrm{O}$, E. S. $(\mathrm{m}=2,021 \mathrm{mg})$; (c) $\mathrm{YNi}\left(\mathrm{CH}_{3} \mathrm{COO}\right)_{5} \cdot 2 \mathrm{H}_{2} \mathrm{O}$, C. A. $(\mathrm{m}=2,041 \mathrm{mg})$.

Figura 3.55: Difratogramas de raios $X$ (método do pó) dos produtos da decomposição térmica a $900^{\circ} \mathrm{C}$, obtidos sob atmosfera dinâmica de ar $(50 \mathrm{~mL}$ $\min ^{-1}$ ), razão de aquecimento de $10^{\circ} \mathrm{C} \mathrm{min}^{-1}$ e cadinho de platina das amostras: (a) $\mathrm{Y}\left(\mathrm{CH}_{3} \mathrm{COO}\right)_{3} .4 \mathrm{H}_{2} \mathrm{O}$; (b) $\mathrm{Ni}\left(\mathrm{CH}_{3} \mathrm{COO}\right)_{2} \cdot 4 \mathrm{H}_{2} \mathrm{O}$; (c) $\mathrm{YNi}\left(\mathrm{CH}_{3} \mathrm{COO}\right)_{5} .8 \mathrm{H}_{2} \mathrm{O}$ (M. M.); (d) $\mathrm{YNi}\left(\mathrm{CH}_{3} \mathrm{COO}\right)_{5} .3 \mathrm{H}_{2} \mathrm{O}$ (E. S.); (e) $\mathrm{YNi}\left(\mathrm{CH}_{3} \mathrm{COO}\right)_{5} .2 \mathrm{H}_{2} \mathrm{O}$ (C. A.).

Figura 3.56: Difratogramas de raios $X$ (método do pó) dos produtos da decomposição térmica a $900^{\circ} \mathrm{C}$, obtidos sob atmosfera dinâmica de nitrogênio (50 $\mathrm{mL} \min ^{-1}$ ), razão de aquecimento de $10^{\circ} \mathrm{C} \min ^{-1}$ e cadinho de platina das amostras: (a) $\quad \mathrm{Y}\left(\mathrm{CH}_{3} \mathrm{COO}\right)_{3} .4 \mathrm{H}_{2} \mathrm{O} ; \quad$ (b) $\mathrm{Ni}\left(\mathrm{CH}_{3} \mathrm{COO}\right)_{2} .4 \mathrm{H}_{2} \mathrm{O}$; (c) $\mathrm{YNi}\left(\mathrm{CH}_{3} \mathrm{COO}\right)_{5} .8 \mathrm{H}_{2} \mathrm{O}$ (M. M.); (d) $\mathrm{YNi}\left(\mathrm{CH}_{3} \mathrm{COO}\right)_{5} .3 \mathrm{H}_{2} \mathrm{O}$ (E. S.); (e) $\mathrm{YNi}\left(\mathrm{CH}_{3} \mathrm{COO}\right)_{5} .2 \mathrm{H}_{2} \mathrm{O}$ (C. A.).

Figura 3.57: Difratogramas de raios $X$ (método do pó) obtidos após tratamento térmico a $900^{\circ} \mathrm{C}$, durante uma hora de aquecimento, sob atmosfera dinâmica de ar $\left(50 \mathrm{~mL} \mathrm{~min}^{-1}\right)$, razão de aquecimento de $10^{\circ} \mathrm{C} \min ^{-1}$ e cadinho de alumina das amostras: (a) $\quad \mathrm{Y}\left(\mathrm{CH}_{3} \mathrm{COO}\right)_{3} .4 \mathrm{H}_{2} \mathrm{O}$; (b) $\mathrm{Ni}\left(\mathrm{CH}_{3} \mathrm{COO}\right)_{2} .4 \mathrm{H}_{2} \mathrm{O}$; $\quad$ (c) $\mathrm{YNi}\left(\mathrm{CH}_{3} \mathrm{COO}\right)_{5} .8 \mathrm{H}_{2} \mathrm{O}$ (M. M.); (d) $\mathrm{YNi}\left(\mathrm{CH}_{3} \mathrm{COO}\right)_{5} .3 \mathrm{H}_{2} \mathrm{O} \quad$ (E. S.); (e) $\mathrm{YNi}\left(\mathrm{CH}_{3} \mathrm{COO}\right)_{5} .2 \mathrm{H}_{2} \mathrm{O}$ (C. A.).

Figura 3.58: Comparação dos difratogramas de raios $X$ (método do pó) das amostras de $\mathrm{NdNiO}_{3}$, tratadas a $900^{\circ} \mathrm{C}$, sob pressão de 50 atm de oxigênio, durante $48 \mathrm{~h}$ de aquecimento e preparadas por: (a) misturas de óxidos; (b) hidróxidos binários; (c) processo sol-gel.

Figura 3.59: Comparação das micrografias das amostras de $\mathrm{NdNiO}_{3}$, tratadas a $900^{\circ} \mathrm{C}$, sob pressão de $50 \mathrm{~atm}$ de oxigênio, durante $48 \mathrm{~h}$ de aquecimento e preparadas por: (a) misturas de óxidos; (b) hidróxidos binários; (c) processo solgel.

Figura 3.60: Medidas de resistividade elétrica em função da temperatura das amostras $\mathrm{NdNiO}_{3}$ obtidas por: (a) mistura de óxidos; (b) hidróxidos binários; (c ) sol-gel. Detalhe da região próxima a transição de fase metal-isolante $\left(T_{M I}\right)$. 
Figura 3.61: Curvas DSC das amostras $\mathrm{NdNiO}_{3}$ obtidas sob atmosfera dinâmica de nitrogênio ( $50 \mathrm{~mL} \min ^{-1}$ ), razão de aquecimento de $2^{\circ} \mathrm{C} \min ^{-1}$ e cápsula de alumínio fechada: (a) mistura de óxidos; (b) hidróxidos binários; (c) processo solgel..

Figura 3.62: Comparação dos difratogramas de raios $\mathrm{X}$ (método do pó) das amostras de $\mathrm{SmNiO}_{3}$, tratadas a $1000^{\circ} \mathrm{C}$, sob pressão de 70 atm de oxigênio, durante $48 \mathrm{~h}$ de aquecimento preparadas por: (a) misturas de óxidos; (b) hidróxidos binários; (c) processo sol-gel.

Figura 3.63: Comparação das micrografias das amostras de $\mathrm{SmNiO}_{3}$, tratadas a $1000^{\circ} \mathrm{C}$, sob pressão de $70 \mathrm{~atm}$ de oxigênio, durante $48 \mathrm{~h}$ de aquecimento e preparadas por: (a) misturas de óxidos; (b) hidróxidos binários; (c) processo solgel.

Figura 3.64: Medidas de resistividade elétrica em função da temperatura das amostras de $\mathrm{SmNiO}_{3}$ obtidas por: (a) mistura de óxidos; (b) hidróxidos binários; (c) processo sol-gel.

Figura 3.65: Curvas DSC das amostras de $\mathrm{SmNiO}_{3}$ obtidas sob atmosfera dinâmica de nitrogênio $\left(50 \mathrm{~mL} \mathrm{~min}{ }^{-1}\right)$, razão de aquecimento e resfriamento de $10^{\circ} \mathrm{C} \min ^{-1}$ e cápsula de alumínio fechada: (a) mistura de óxidos; (b) hidróxidos binários; (c) processo sol-gel.

Figura 3.66: Comparação dos difratogramas de raios $\mathrm{X}$ (método do pó) das amostras de $\mathrm{PrNiO}_{3}$, tratadas a $1000^{\circ} \mathrm{C}$, sob pressão de 70 atm de oxigênio, durante $48 \mathrm{~h}$ de aquecimento e preparadas por: (a) misturas de óxidos; (b) hidróxidos binários; (c) processo sol-gel.

Figura 3.67: Medidas de resistividade elétrica em função da temperatura das amostras $\mathrm{PrNiO}_{3}$ obtidas por: (a) hidróxidos binários; (b) sol-gel. 


\section{LISTA DE TABELAS}

Tabela 2.1: Substâncias utilizadas.

Tabela 3.1: Dados percentuais referentes aos intermediários sólidos formados na decomposição térmica dos hidroxicarbonatos de terras raras.

Tabela 3.2: Resultados de análise elementar para os acetatos de terras raras

Tabela 3.3: Atribuição das bandas de absorção dos espectros IR dos acetatos de terras raras (número de onda, $\mathrm{cm}^{-1}$ ).

Tabela 3.4: Dados parciais de difração de raios $X$ para os acetatos de terras raras

Tabela 3.5: Dados percentuais dos intermediários sólidos e produto final obtidos na decomposição térmica do acetato de lantânio

Tabela 3.6: Dados percentuais dos intermediários sólidos e produto final obtidos na decomposição térmica do acetato de európio.

Tabela 3.7: Dados percentuais dos intermediários sólidos e produto final obtidos na decomposição térmica do acetato de ítrio

Tabela 3.8: Dados percentuais dos produtos sólidos da decomposição térmica do acetato de níquel tetraidratado.

Tabela 3.9: Atribuição das bandas de absorção dos espectros IR do acetato de níquel e intermediário isolado em $200^{\circ} \mathrm{C}$ (número de onda, $\mathrm{cm}^{-1}$ ).

Tabela 3.10: Dados parciais de difração de raios $\mathrm{X}$ para o acetato de níquel.

Tabela 3.11: Resultados de análise elementar para os sistemas de acetatos binários de lantânio e níquel.

Tabela 3.12: Atribuição das bandas de absorção dos espectros IR dos sistemas de acetatos binários de lantânio e níquel (número de onda, $\mathrm{cm}^{-1}$ ).

Tabela 3.13: Dados parciais de difração de raios $X$ para os sistemas de acetatos binários de lantânio e níquel.

Tabela 3.14: Dados percentuais dos produtos sólidos da decomposição térmica dos sistemas de acetatos binários de lantânio e níquel

Tabela 3.15: Dados de DSC para as etapas de desidratação e decomposição térmica dos sistemas de acetatos binários de lantânio e níquel. 
Tabela 3.16: Concentração molar (\%) dos produtos de reação em função do tempo obtidos do ensaio catalítico do $\mathrm{La}_{2} \mathrm{NiO}_{4}$

Tabela 3.17: Resultados de análise elementar para os sistemas de acetatos binários de európio e níquel.

Tabela 3.18: Atribuição das bandas de absorção dos espectros $\mathbb{R}$ dos sistemas de acetatos binários de európio e níquel (número de onda, $\mathrm{cm}^{-1}$ ).

Tabela 3.19: Dados parciais de difração de raios $X$ para os sistemas de acetatos binários de európio e níquel.

Tabela 3.20: Dados percentuais dos produtos sólidos da decomposição térmica dos sistemas de acetatos binários de európio e níquel.

Tabela 3.21: Dados de DSC para as etapas de desidratação e decomposição térmica dos sistemas de acetatos binários de európio e níquel.

Tabela 3.22: Resultados de análise elementar para os sistemas de acetatos binários de ítrio e níquel

Tabela 3.23: Atribuição das bandas de absorção dos espectros IR dos sistemas de acetatos binários de ítrio e níquel (número de onda, $\mathrm{cm}^{-1}$ )

Tabela 3.24: Dados parciais de difração de raios $X$ dos sistemas de acetatos binários de ítrio e níquel.

Tabela 3.25: Dados percentuais dos intermediários sólidos da decomposição térmica dos sistemas de acetatos binários de ítrio e níquel.

Tabela 3.26: Dados de DSC para as etapas de desidratação e decomposição térmica dos sistemas de acetatos binários de ítrio e níquel.

Tabela 3.27: Parâmetros de rede $a, b$ e $c$ calculados para as amostras $\mathrm{NdNiO}_{3}$ obtidas por diferentes métodos de síntese.

Tabela 3.28: Parâmetros de rede $a, b$ e $c$ calculados para as amostras $\mathrm{SmNiO}_{3}$ obtidas por diferentes métodos de síntese

Tabela 3.29: Parâmetros de rede $a, b$ e $c$ calculados para as amostras $\mathrm{PrNiO}_{3}$ obtidas por diferentes métodos de síntese. 


\section{LISTA DE ABREVIATURAS E SIGLAS}

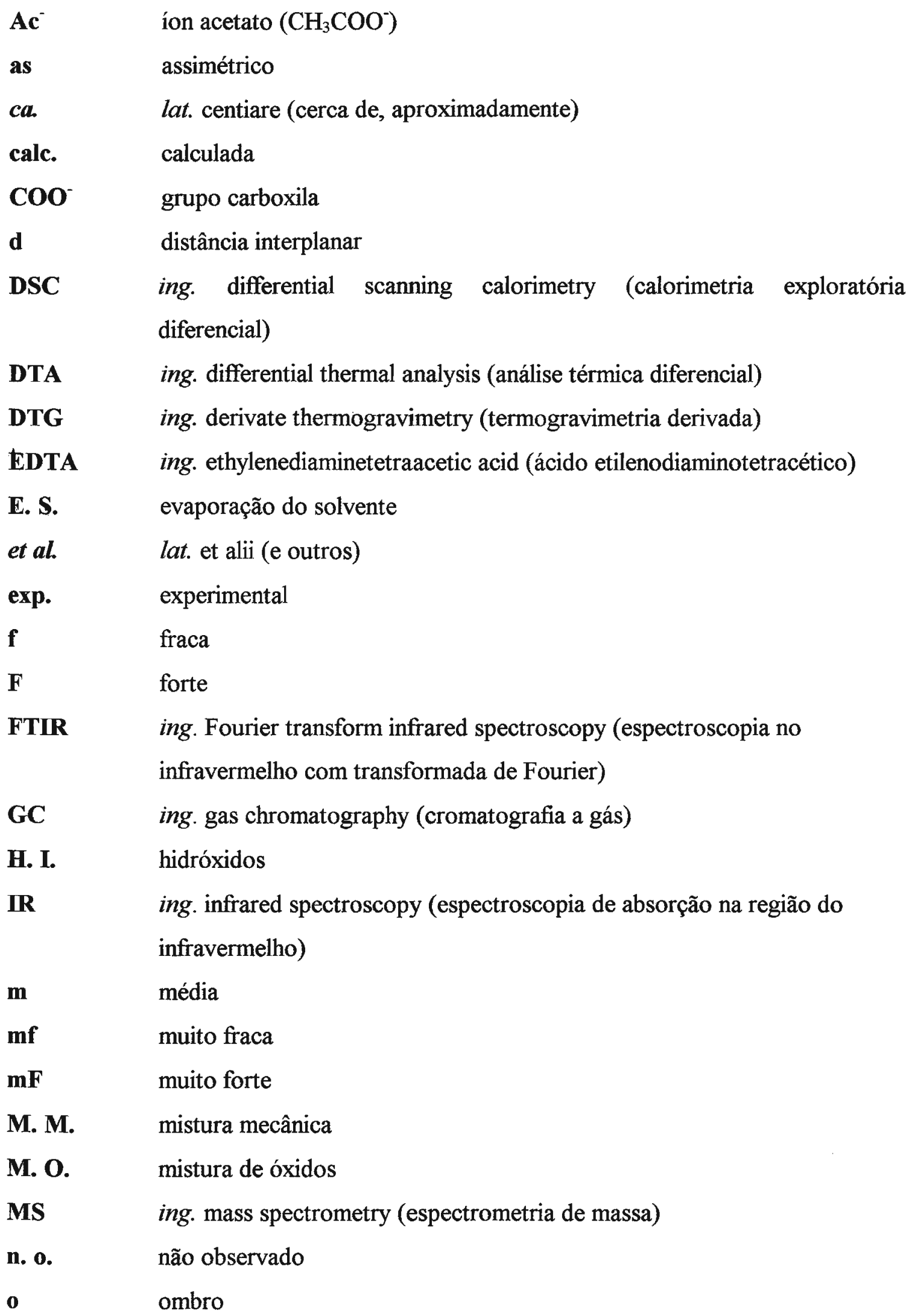


P. A. para análise

pH potencial hidrogeniônico

s simétrico

SEM ing. scanning electron microscopy (microscopia eletrônica de varredura)

S. G. sol-gel

$\mathbf{T}_{\mathrm{c}} \quad$ temperatura crítica

$\mathbf{T}_{\mathbf{e}} \quad$ temperatura de ebulição

$\mathbf{T}_{\text {endset }} \quad$ temperatura final

$\mathbf{T}_{\mathrm{f}}$ temperatura de fusão

TG ing. thermogravimetry (termogravimetria)

$\mathbf{T}_{\mathrm{MI}} \quad$ temperatura de transição de fase metal-isolante

$\mathbf{T}_{\mathbf{p}} \quad$ temperatura do pico

TR terras raras

U. A. unidade arbitrária

XRD ing. $\mathrm{X}$ ray diffraction (difração de raios $\mathrm{X}$ )

$\mathbf{Z} \quad$ número atômico 


\section{RESUMO}

Este trabalho apresenta um estudo sistemático sobre síntese, caracterização e análise térmica aplicada a óxidos mistos dos tipos $\mathrm{TR}_{2} \mathrm{NiO}_{4}[\mathrm{TR}=\mathrm{La}, \mathrm{Eu}$ e Y (III)] e $\mathrm{TRNiO}_{3}[\mathrm{TR}=\mathrm{Pr}, \mathrm{Nd}$ e $\mathrm{Sm}$ (II)]. Os primeiros óxidos foram obtidos a partir da decomposição térmica de acetatos de terras raras e níquel utilizando-se três métodos distintos: (1) mistura mecânica; (2) evaporação do solvente e (3) cristalização com acetona. Os acetatos simples e binários foram caracterizados por análise elementar, espectroscopia de absorção na região do infravermelho, difração de raios $\mathrm{X}, \mathrm{TG} / \mathrm{DTG}$, DSC e DTA. Os resultados revelaram a formação de sais binários quando utilizaram-se os métodos 2 e/ou 3. Os produtos da decomposição térmica foram basicamente os óxidos individuais e após tratamento térmico obteveram-se os óxidos desejados. Os

óxidos $\mathrm{TRNiO}_{3}$ foram preparados através de três métodos diferentes: (1) mistura de óxidos; (2) precipitação simultânea de hidróxidos e (3) processo sol-gel. Estas amostras foram sinterizadas em temperaturas $650 \leq \mathrm{T} \leq 1000^{\circ} \mathrm{C}$ e sob pressões de até $70 \mathrm{~atm}$ de $\mathrm{O}_{2}$, caracterizadas por difração de raios $\mathrm{X}$, resistividade elétrica, microscopia eletrônica de varredura e calorimetria exploratória diferencial. Os resultados indicaram que o método sol-gel produziu óxidos monofásicos. Os outros dois métodos, mistura de óxidos e hidróxidos, produziram a fase desejada e traços dos óxidos individuais. Desta forma, concluiu-se que a escolha do método a ser utilizado é fundamental para a obtenção do óxido misto desejado. 


\section{ABSTRACT}

This work reports a systematic study on the synthesis, characterization and thermal analysis applied of mixed oxides type- $\mathrm{TR}_{2} \mathrm{NiO}_{4}[\mathrm{TR}=\mathrm{La}$, Eu e Y (III)] e type$\mathrm{TRNiO}_{3}[\mathrm{TR}=\mathrm{Pr}, \mathrm{Nd}$ e $\mathrm{Sm}(\mathrm{III})]$. The first oxides were prepared through thermal decomposition of rare earth and nickel acetates, which were synthesized by three methods: (1) mechanical mixture; (2) solvent evaporation and (3) crystallization with addition of acetone. The simply and binary acetates were characterized by elementare analyses, infrared spectroscopy, $X$ ray diffraction, TG/DTG, DSC and DTA. The results revealed formation of binary salts when was used the second and/or third methods. The products of thermal decomposition were single oxides, but after thermal treatment were obtained the single phase of materials. The last oxides were prepared through three different methods: (1) mixture of oxides; (2) simultaneous precipitation of hydroxides and (3) sol-gel process. Samples were sintered at temperatures between $650 \leq \mathrm{T} \leq$ $1000^{\circ} \mathrm{C}$ and under oxygen pressures until $70 \mathrm{~atm}$, characterized by $\mathrm{X}$ ray diffraction, electrical resistivity, scanning electron microscopy and differential scanning calorimetry. The results revealed that the sol-gel method produced single phase oxides. The other two methods, mixture of oxides and hydroxides, led to have this phase with traces of single oxides. Therefore, it was concluded that the method used is fundamental to get the desired mixed oxides. 


\section{Capítulo}

\section{Introdução, objetivos e}

\section{revisão bibliográfica}

Este capítulo situa o trabalho dentro do contexto da síntese de óxidos mistos, a fim

de estabelecer os objetivos e a relevância do que foi executado. São feitas algumas considerações gerais sobre, análise térmica aplicada a óxidos mistos, níquel, terras raras, estrutura cristalina, síntese e propriedades dos óxidos mistos, reunindo na forma de revisão as principais referências bibliográficas.

\section{Introdução}

Objetivos

Revisão Bibliográfica

Referências Bibliográficas 


\section{1- INTRODUÇÃO, OBJETIVOS E REVISÃO BIBLIOGRÁFICA}

\section{1- Introdução}

Desde a descoberta de supercondutores de alta temperatura crítica $\left(\mathrm{T}_{\mathrm{c}}\right)$ numa série de óxidos de cobre [1], vários estudos têm sido realizados com outros sistemas [24]. Entre esses, podem-se citar os óxidos mistos de elementos terras raras (TR) e níquel. Apesar destes óxidos não apresentarem supercondutividade, eles exibem propriedades interessantes, tais como, catalíticas [5, 6], magnéticas [7, 8] e elétricas [7-10]. Estas propriedades dependem, fundamentalmente, da composição, da pureza dos reagentes, da homogeneidade e do método de síntese utilizado.

Para alcançar tais propriedades, vários métodos de síntese têm sido estudados [11-13]. O método a ser escolhido não depende somente da composição do óxido desejado, mas também da aplicação que será dada a este material.

Normalmente, os óxidos mistos têm sido preparados pelo método cerâmico, que consiste na mistura mecânica de óxidos ou carbonatos dos materiais constituintes e aquecimento em temperaturas e pressões elevadas, permitindo a interdifusão das espécies. As reações são geralmente lentas, devido a dificuldades no processo de difusão e nem sempre é possivel obter materiais monofásicos na estequiometria desejada [14].

Estudos recentes têm sido desenvolvidos com o objetivo de reduzir as distâncias de difusão, pela incorporação dos cátions numa mesma matriz, por exemplo utilizando o processo sol-gel [15]. Este método envolve várias etapas de processos físicos e químicos, tais como, hidrólise, polimerização, secagem e compactação. O nome sol-gel é dado ao processo devido ao aumento característico na viscosidade que ocorre em um ponto particular numa seqüência de etapas, ocasionado pela matriz coloidal, que se modifica de sol para gel. Um aumento abrupto na viscosidade é uma característica comum no processo sol-gel, indicando o início da formação do gel. A síntese de óxidos é realizada a partir de precursores inorgânicos ou organometálicos [12].

As características importantes do produto obtido pelo processo sol-gel, quando comparado ao método cerâmico, são maior homogeneidade, pureza e distribuição uniforme de fases em sistemas multicomponentes, menor temperatura de processamento, 
possibilidade de controle do tamanho e forma de novos materiais cristalinos e não cristalinos, inclusive para uso em filmes finos e revestimentos. Apesar destas vantagens, o processo sol-gel requer para a obtenção de uma determinada fase, temperaturas e pressões elevadas $[12,13]$.

Uma outra alternativa que tem sido utilizada, é o método do precursor. Por exemplo, vários óxidos mistos têm sido sintetizados pela decomposição térmica de compostos cristalinos de alta pureza, que contém os cátions misturados em escala atômica, facilitando o processo de difusão e obtenção de materiais monofásicos. $\mathrm{O}$ método envolve a cristalização de uma solução do composto precursor, a qual contém os metais desejados numa determinada proporção. A decomposição térmica do precursor produz uma mistura dos óxidos metálicos, que estão finamente divididos e intimamente ligados, facilitando assim o processo de difusão. No entanto, nem sempre é possível obter compostos precursores, para todas as composições desejadas de óxidos mistos [16, 17].

\section{2- Objetivos}

Este trabalho tem como objetivo geral o estudo sistemático de diferentes métodos de síntese (cerâmico, sol-gel e precursores de acetatos ou hidróxidos binários), utilizando-se das técnicas termoanalíticas, para a obtenção de óxidos mistos envolvendo elementos terras raras e níquel. Com o intuito de comparar as condições de tempo e temperatura de sinterização, microestrutura e morfologia dos materiais, utilizou-se diferentes tratamentos térmicos, variando-se parâmetros como a temperatura, pressão, tempo e atmosfera atuante.

O trabalho foi dividido em duas partes com estratégias específicas. Na primeira parte, escolheu-se o método precursor de acetatos binários para a obtenção de óxidos mistos do tipo $\mathrm{TR}_{2} \mathrm{NiO}_{4}$ [TR = La, Eu e Y (III)], utilizando-se três rotas de síntese: (1) mistura mecânica de acetatos de terras raras (TR) e acetato de níquel na proporção molar $1: 1$; (2) mistura de soluções aquosas equimolares dos acetatos, onde a cristalização foi por evaporação do solvente e (3) por adição de solvente orgânico (acetona). Nesta primeira parte procurou-se obter acetatos duplos, envolvendo 
elementos terras raras do início, meio e final da série lantanídica, fixando o metal de transição (níquel) e estudar, comparativamente, o comportamento térmico dos acetatos individuais e das suas misturas nas atmosferas de ar comprimido e nitrogênio.

A segunda parte foi desenvolvida, utilizando-se três métodos de síntese para a obtenção de óxidos mistos do tipo $\mathrm{TRNiO}_{3}$ [TR $=\mathrm{Pr}, \mathrm{Nd}$ e $\mathrm{Sm}$ (III)]: (1) mistura de óxidos (cerâmico); (2) precipitação simultânea de hidróxidos binários de $\mathrm{TR}^{3+} \mathrm{e} \mathrm{Ni}^{3+} \mathrm{e}$ (3) processo sol-gel. Nesta parte, procurou-se otimizar uma metodologia que fosse mais adequada para a síntese destes óxidos, em melhores condições de sinterização.

A caracterização dos materiais foi realizada utilizando-se técnicas de análise térmica, difração de raios $X$, espectroscopia de absorção na região do infravermelho, resistência elétrica em função da temperatura e observações por microscopia eletrônica de varredura, para comparar os diferentes métodos e identificar os possíveis óxidos mistos.

\section{3- Revisão bibliográfica: considerações gerais}

\subsection{1- Análise Térmica aplicada a óxidos mistos}

A análise térmica abrange um grupo de técnicas analíticas nas quais uma propriedade fisica de uma substância e/ou seus produtos de reação é medida em função da temperatura ou do tempo, enquanto a substância é submetida a um programa controlado de temperatura $[18,19]$.

As principais técnicas termoanalíticas usadas no estudo de óxidos mistos são a termogravimetria (TG), calorimetria exploratória diferencial (DSC) e análise térmica diferencial (DTA).

A termogravimetria mede a variação na massa de uma amostra, submetida a um programa de aquecimento ou resfriamento em função do tempo ou da temperatura. Esta técnica possibilita conhecer as alterações que o aquecimento pode causar na massa da amostra, permite estabelecer a faixa de temperatura em que a mesma adquire estabilidade térmica definida e a temperatura de início de decomposição. 
Três modos de termogravimetria são comumente usados: (i) isotérmica, em que a massa é registrada em função do tempo à temperatura constante; (ii) quasi-isotérmica, no qual o registro da massa é feito a uma certa razão de aquecimento, enquanto não há variação de massa e à temperatura constante, enquanto há variação de massa e (iii) dinâmica, no qual o registro de massa é feito a uma programação controlada de temperatura pré-estabelecida, geralmente linear.

As curvas geradas na termogravimetria, denominadas curvas TG, possibilitam obter informações quanto a estabilidade térmica da amostra, bem como da composição e estabilidade dos intermediários e do produto final. A curva termogravimétrica derivada (DTG) é a derivada primeira da curva TG. Nessa curva os degraus correspondentes às variações de massa observados na curva $T G$, são substituídos por picos que determinam áreas proporcionais às variações de massa. A curva DTG traz as mesmas informações que a curva TG, porém é possível separar reações sobrepostas, uma vez que as inflexões sutis da TG são enfatizadas [20].

Outra técnica de análise térmica muito utilizada na química do estado sólido, especialmente no estudo de óxidos mistos, é a calorimetria exploratória diferencial. Essa técnica mede a potência $(\Delta \mathrm{P}=\mathrm{d}(\Delta \mathrm{Q}) / \mathrm{dt})$ necessária para manter amostra e referência na mesma temperatura $(\Delta \mathrm{T}=0)$, quando submetidas a uma programação controlada de temperatura. A área referente aos picos na curva DSC corresponde à energia liberada ou absorvida numa reação. Através desta técnica, pode-se acompanhar e quantificar alterações físicas e químicas da amostra, por exemplo, mudança de estado físico (fusão, ebulição, solidificação, etc.), transições de fase (modificações na estrutura cristalina) ou reações de desidratação, decomposição, oxi-redução, etc. [20].

De acordo com o método de medida utilizado, tem-se o DSC com compensação de potência e o DSC com fluxo de calor. No primeiro, a amostra e a referência são aquecidas ou resfriadas em fornos separados. Isto torna possível manter a amostra e a referência em condições isotérmicas. Assim, se a amostra sofre alteração de temperatura devido a um evento endotérmico ou exotérmico em função do aquecimento ou resfriamento a que é submetida, ocorre uma modificação na potência de entrada do forno correspondente, de modo a se anular essa diferença. Quanto ao DSC com fluxo de calor, a amostra e a referência são colocadas em cadinhos idênticos, localizados sobre um disco termoelétrico e aquecidos por uma única fonte de calor. $\mathrm{O}$ calor é transferido através do 
disco para a amostra e referência, e o fluxo de calor diferencial entre os dois é controlado por termopares conectados abaixo dos cadinhos. Dessa forma, a diferença no fluxo de calor da amostra e da referência é diretamente proporcional a diferença de potência das junções dos termopares.

A grande diferença nos dois tipos de DSC consiste na apresentação dos resultados. No DSC com compensação de potência foi adotada a convenção da termodinâmica, onde um evento endotérmico $(\Delta H>0)$ é caracterizado por um pico ascendente na curva DSC, enquanto no DSC com fluxo de calor, esse mesmo evento é representado por um pico descendente [20].

A análise térmica diferencial é a técnica de análise térmica mais usada na química do estado sólido. O seu princípio é registrar a variação de temperatura $(\Delta \mathrm{T})$ entre a amostra e um material de referência termicamente estável, enquanto ambos são submetidos a uma programação controlada de temperatura. Essa técnica assemelha-se ao DSC. Quando a amostra sofre um processo endotérmico, a temperatura da amostra apresenta um decréscimo em relação a do material de referência, e o registro de $\Delta \mathrm{T}$ será negativo. Quando o processo é exotérmico ocorrerá o inverso [20].

As reações no estado sólido, geralmente, envolvem variações de massa e entalpia, as quais podem ser medidas pelas técnicas de análise térmica [21, 22]. No entanto, outros aspectos que dominam uma reação no estado sólido, tais como, efeitos de nucleação, processos de difusão e condução de calor, fatores macroscópicos (distribuição, tamanho e forma das partículas) e defeitos cristalinos não podem ser medidos por estas técnicas, mas por métodos de difração e espectroscópicos.

De maneira geral, a análise térmica associada com outras técnicas analíticas, por exemplo a difração de raios $X$, podem fornecer informações sobre a síntese de óxidos mistos, incluindo a decomposição de precursores, a formação e decomposição de fases intermediárias e a estequiometria do produto final. Além disso, pode-se estudar a decomposição em diferentes atmosferas, avaliar as suas características durante o resfriamento ou variações das propriedades e temperaturas de transições de fase.

O conhecimento da composição, arranjo atômico e propriedades físicas e químicas dos precursores e produtos finais são de grande importância, para a obtenção de bons materiais. Assim, a análise térmica vem sendo largamente usada como 
ferramenta, para auxiliar na definição das melhores condições de síntese de óxidos mistos [14].

Uma discussão mais detalhada sobre as técnicas TG/DTG, DTA e DSC envolvendo o desenvolvimento, instrumentação e aplicações encontram-se descritos nas referências de 23 a 28 . O avanço da análise térmica aplicada a óxidos mistos pode ser encontrado nas edições dos anos pares, mês de junho, do periódico Analytical Chemistry. Estas revisões vêm sendo apresentadas por Dollimore desde 1988 [29-34].

\subsection{2- Níquel}

O níquel (Ni) é um elemento químico da primeira série de transição, possui número atômico, $Z=28$, e configuração eletrônica no estado fundamental [Ar] $3 \mathrm{~d}^{8} 4 \mathrm{~s}^{2}$.

De um modo geral, o níquel é um metal bom condutor de calor e eletricidade. Apresenta altos pontos de fusão $\left(\mathrm{T}_{\mathrm{f}}=1453^{\circ} \mathrm{C}\right)$ e de ebulição $\left(\mathrm{T}_{\mathrm{e}}=2914^{\circ} \mathrm{C}\right)$, com entalpia de vaporização relativamente elevada $\left(\Delta H_{\mathrm{v}}=429,7 \mathrm{~kJ} \mathrm{~mol}^{-1}\right)$. Sob o ponto de vista termodinâmico, é um metal moderadamente ativo, isto é, seu potencial de redução $\left(\mathrm{E}^{\circ}=-0,24 \mathrm{~V}\right)$ indica que reage lentamente com soluções ácidas diluídas, dando origem a seus íons em solução aquosa, sendo que o seu estado de oxidação mais importante é o +2. Em solução aquosa, o $\mathrm{Ni}^{2+}$ hidratado é verde, e os sais são verdes ou azuis. No entanto, os estados +3 e +4 só aparecem em alguns compostos.

O níquel é resistente à corrosão, pois se apresenta protegido por uma camada de óxido, reagindo muito lentamente com agentes oxidantes. É quimicamente resistente sob condições alcalinas, e usado com muita freqüência na fabricação de recipientes ou eletrodos para uso em meio básico. Quando finamente dividido, o níquel pode absorver grandes quantidades de hidrogênio, que penetra na rede metálica na forma atômica. Como resultado, a esponja de níquel poroso é um excelente catalisador de hidrogenação de compostos orgânicos.

Geralmente, o níquel é encontrado na natureza sob a forma de sulfeto, NiS. A calcinação desse composto em ar produz o óxido $\mathrm{NiO}$, de coloração verde, que pode ser reduzido com carvão para produzir níquel metálico. Quando $\mathrm{Ni}(\mathrm{OH})_{2}$ é tratado com agentes oxidantes moderadamente fortes, como hipoclorito de sódio, forma-se um sólido 
preto cuja composição é próxima de $\mathrm{Ni}_{2} \mathrm{O}_{3} \cdot \mathrm{H}_{2} \mathrm{O}$. Dessa forma, é possível preparar óxidos de $\mathrm{Ni}(\mathrm{III})$, em condições brandas. Os óxidos de níquel são muito usados como catalisadores e em reações eletroquímicas [35].

\subsection{3- Terras raras}

As terras raras (TR) compreendem os elementos que vão do lantânio ao lutécio, ítrio e escândio.

Os elementos do cério $(Z=58)$ ao lutécio $(Z=71)$ pertencem ao sexto período da tabela periódica e apresentam o preenchimento gradativo dos orbitais do subnível $4 f$. $\mathrm{O}$ ítrio $(Z=39)$ e o lantânio $(Z=57)$ pertencem ao quinto e sexto período e suas estruturas eletrônicas são $[\mathrm{Kr}] 4 \mathrm{~d}^{1} 5 \mathrm{~s}^{2},[\mathrm{Xe}] 5 \mathrm{~d}^{1} 6 \mathrm{~s}^{2}$, respectivamente. Apesar desses elementos não apresentarem elétrons no subnível $4 f$, eles são incluídos nesta classe de elementos, pois apresentam propriedades fisicas e químicas semelhantes [36]. O escândio $(Z=21)$ pertence ao quarto período e apresenta configuração [Ar] $3 \mathrm{~d}^{1} 4 \mathrm{~s}^{2}$. Embora seja, significativamente, diferente em seu comportamento quando comparado com os demais elementos terras raras, sua inclusão na série é justificada com base nas suas propriedades químicas, como o estado de oxidação +3 , o raio iônico e muitas propriedades que podem ser previstas pela extrapolação nessa série [37].

Os elementos terras raras são metálicos e os únicos radioativos são o promécio $(Z=61)$, obtido artificialmente, e o isótopo 176 do lutécio $\left({ }^{176} \mathrm{Lu}\right)$ de ocorrência natural. Esses elementos formam cátions trivalentes $\left(\mathrm{TR}^{3+}\right)$, mas alguns podem apresentar estados de oxidação +2 e +4 , de menor estabilidade. Estes estados existem, quando o conjunto de orbitais do subnível $4 f$ encontra-se vazio no $\mathrm{Ce}^{4+}\left(f^{0}\right)$, semi-preenchido no $\mathrm{Tb}^{4+}$ e $\mathrm{Eu}^{2+}\left(f^{7}\right)$ ou totalmente preenchido no $\mathrm{Yb}^{2+}\left(f^{14}\right)$. Para os cátions trivalentes, que são os mais estáveis tanto no estado sólido como em solução, apresentam, geralmente a configuração eletrônica do xenônio, isto é, $4 f^{0}$ [37].

Os elementos terras raras são conhecidos como metais de transição interna, devido aos seus elétrons $f$ estarem internos e protegidos da interação direta com o meio, pelos elétrons que se encontram nos orbitais $5 s$ e $5 p$, localizados externamente. 
O preenchimento gradativo dos orbitais $4 f$ aumenta a carga nuclear, conduzindo ao decréscimo do raio atômico dos elementos. Este efeito é chamado de contração lantanídica, e é resultado da blindagem imperfeita da atração nuclear de um elétron $4 f$ por um outro elétron $4 f$. Observa-se que a redução do raio do íon $\mathrm{La}^{3+}$ ao $\mathrm{Lu}^{3+}$ é da

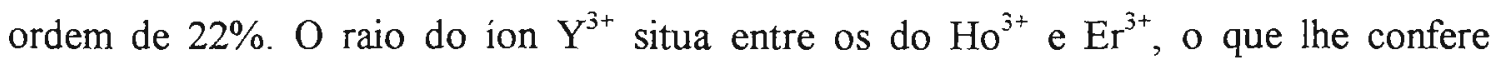
propriedades semelhantes aos lantanídeos. A contração lantanídica é caracterizada por um decréscimo gradual na atividade dos metais e basicidade dos $\mathrm{TR}^{3^{+}}$. Desta forma, lantânio é o mais básico da série, e lutécio o de menor basicidade [37]. A diferença na basicidade nas terras raras ao longo da série influencia diretamente a hidrólise dos ions, a solubilidade dos sais, a decomposição dos oxi-sais e a formação de espécies complexas [36].

Os íons terras raras, em seus diversos estados de oxidação, pertencem à classe do tipo $a$, de acordo com Ahrland et al. [38], ou podem ainda ser classificados como ácidos duros segundo o conceito de Pearson [39]. Íons desta classe coordenam-se preferencialmente a bases duras, especialmente àquelas contendo oxigênio ou nitrogênio como átomos doadores, e fracamente às bases moles contendo enxofre ou fósforo. As ligações são, predominantemente, de caráter eletrostático, dada a fraca sobreposição dos orbitais $f$ com aqueles dos ligantes e ainda, ao alto poder polarizante que os íons terras raras apresentam em função de sua carga e de seu raio iônico grande.

\subsection{4- Estrutura cristalina dos óxidos mistos}

Óxidos mistos são substâncias iônicas que possuem dois ou mais cátions na sua estrutura cristalina, que pode ser do tipo perovisquita, espinélio ou ilmenita [40]. Existem vários artigos de revisão que sumarizam a química interessante de óxidos mistos, principalmente os de estrutura perovisquita [41, 42].

Muitos óxidos mistos com a composição $\mathrm{ABO}_{3}$, incluindo o mineral perovisquita $\left(\mathrm{CaTiO}_{3}\right)$, cristalizam com esta estrutura. A soma das cargas de $\mathbf{A}$ e $\mathbf{B}$ deve ser igual a +6, por exemplo: cátions onde a soma dos estados de oxidação é $(1+5),(2+4)$ e $(3+3)$. Além destes, um grande número de óxidos com a composição $\mathrm{AB}_{0,5} \mathrm{~B}_{0,5} \mathrm{O}_{3}$ também 
apresentam esta estrutura, onde B e B' são o mesmo elemento químico com diferentes estados de oxidação.

As perovisquitas tipo- $A$ (com o átomo A no centro da cela unitária) é mostrada na Figura 1.1. O átomo central $\mathbf{A}$ está coordenado com oito átomos $\mathbf{B}$ nos vértices do cubo e com doze átomos de $\mathbf{O}$ nos pontos médios das arestas do cubo. A estrutura perovisquita pode ser igualmente representada movendo a origem da cela unitária para o centro do cubo, isto é, colocando os átomos $\mathbf{A}$ nos vértices, o átomo $\mathbf{B}$ no centro do cubo e os átomos de $\mathbf{O}$ no centro de cada face do cubo, obtém-se estrutura perovisquita tipo-B (Figura 1.2) [40].

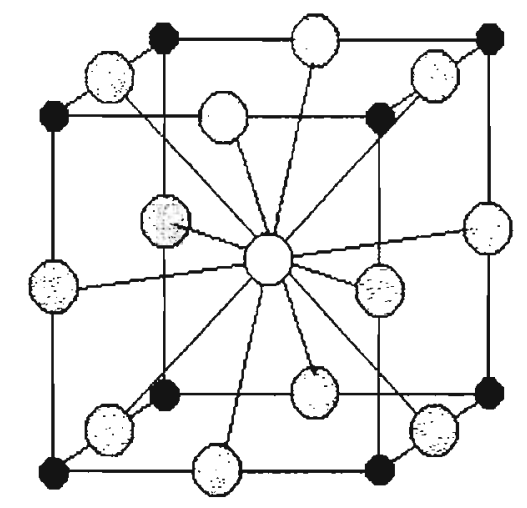

Figura 1.1: Cela unitária da estrutura perovisquita Tipo-A.
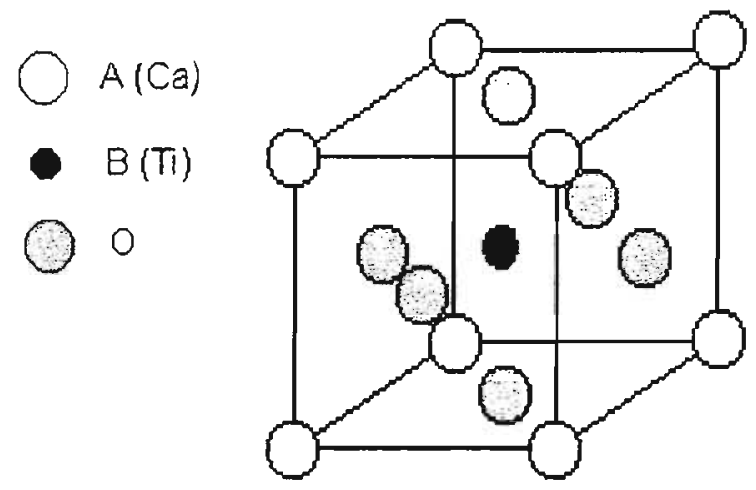

Figura 1.2: Cela unitária da estrutura perovisquita Tipo-B.

Na perovisquita ideal o cátion A localiza-se no centro da célula unitária (posição $1 / 2,1 / 2,1 / 2)$. Este cátion ajusta-se perfeitamente nesta posição se a relação entre as distâncias de A-O e B-O for:

$$
\mathrm{d}_{\mathrm{A}-\mathrm{O}}=\sqrt{2} \mathrm{~d}_{\mathrm{B}-\mathrm{O}}
$$

Os óxidos mistos $\mathrm{TRNiO}_{3}$ cristalizam-se na estrutura perovisquita. A estrutura cristalina consiste de um arranjo tridimensional de octaedros de $\mathrm{NiO}_{6}$ presentes nos vértices de uma rede cúbica simples distorcida. A magnitude desta distorção está relacionada com as distâncias relativas $d_{\mathrm{Ni}-\mathrm{O}}$ e $d_{\mathrm{TR}-\mathrm{O}}$, que pode ser discutida através do fator de tolerância $t$ [8], definido como:

$$
t=\mathrm{d}_{\mathrm{TR}-\mathrm{O}} / \sqrt{2} \mathrm{~d}_{\mathrm{Ni}-\mathrm{O}}
$$


Nestes óxidos os valores de $\boldsymbol{t}$ aproximam-se da unidade, o que resulta em uma estrutura perovisquita com distorção ortorrômbica do tipo $\mathrm{GdFeO}_{3}$, grupo espacial Pbnm [38] (Figura 1.3a). Nesta familia de óxidos, o composto $\mathrm{LaNiO}_{3}$ apresenta estrutura com simetria romboédrica, grupo espacial $R c 3$, diferentemente dos compostos $\mathrm{TRNiO}_{3}, \mathrm{TR} \neq \mathrm{La}$ (Figuras $1.3 \mathrm{~b}$ ) $[9,44]$. No entanto, resultados de análise térmica diferencial obtidos para os compostos $\mathrm{PrNiO}_{3}$ e $\mathrm{NdNiO}_{3}$, evidenciaram uma transição estrutural da simetria ortorrômbica $\mathrm{Pbnm}$ para a romboédrica $R 3 c$, em $500^{\circ} \mathrm{C}$ e $920^{\circ} \mathrm{C}$, respectivamente [9]

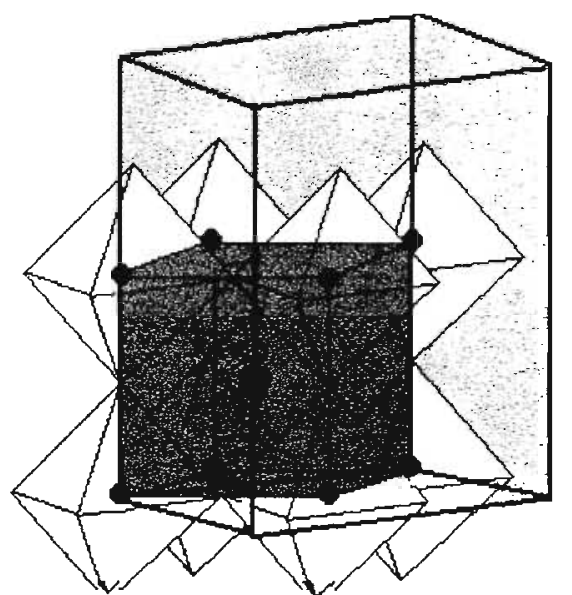

Nij

(a)

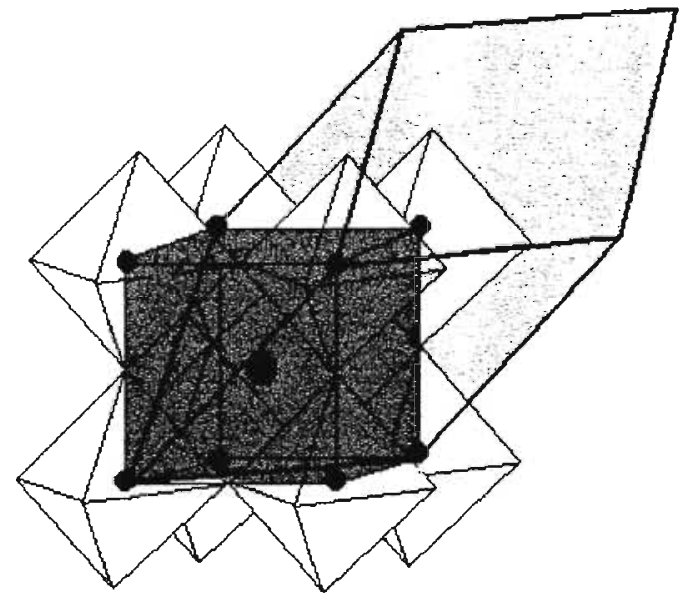

$T R$

(b)

Figura 1.3: Estrutura perovisquita: (a) ortorrômbica $(P b n m)$ e (b) distorção romboédrica $(R 3 c)$.

A Figura 1.4 representa a variação dos parâmetros de rede em função do fator de tolerância $\boldsymbol{t}$. Os valores de $\boldsymbol{t}$ foram calculados usando $\mathrm{d}_{\mathrm{Ni}-\mathrm{O}}$ igual a $1,94 \AA$ e as $\mathrm{d}_{\mathrm{TR}-\mathrm{O}}$ para íns terras raras trivalentes com número de coordenação doze [45]. A distorção ortorrômbica aumenta com o decréscimo do raio iônico das $\operatorname{TR}^{3+}$ e o valor de $t$ diminui de 0,975 (Pr) para 0,932 (Lu). No caso do $\mathrm{LaNiO}_{3}$, o valor de $\boldsymbol{t}$ aproxima-se da unidade $(t=0,986)$ e a estrutura apresenta distorção romboédrica [46]. 


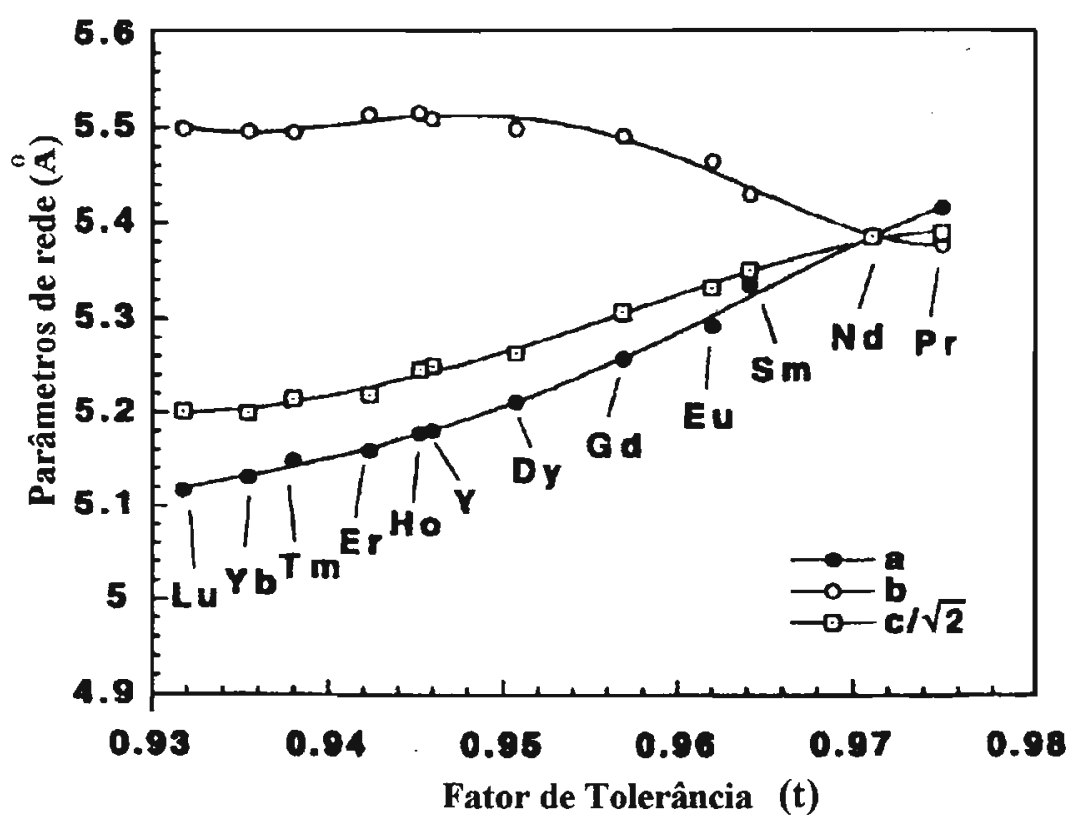

Figura 1.4: Dependência dos parâmetros de rede em função do fator de tolerância $t$ nas séries $\mathrm{TRNiO}_{3}$.

Os óxidos mistos de fórmula geral $\mathrm{TR}_{2} \mathrm{NiO}_{4}$ adotam estrutura tipo- $\mathrm{K}_{2} \mathrm{NiF}_{4}$. A cela unitária e as relações com a estrutura perovisquita estão ilustrados na Figura 1.5. A estrutura cristalina consiste de uma cela tetragonal de corpo-centrado. Dividindo-se a cela unitária em três seções ao longo da direção do eixo-c, pode-se verificar que a seção central é uma cela unitária do tipo- $B$ e de camadas alternadas de duas celas unitárias do tipo- $A$ da estrutura perovisquita [40].

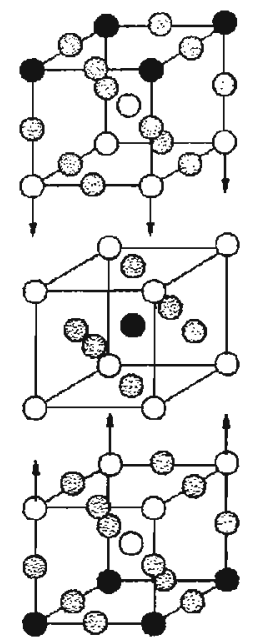

(a)

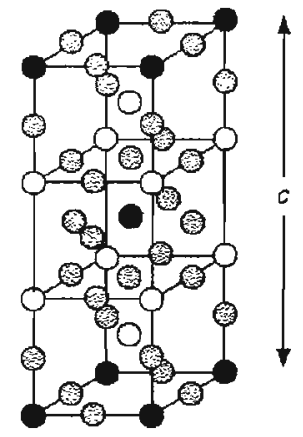

$O A(K)$

$B(N)$

(b)

Figura 1.5: (a) e (b) Estrutura tipo- $\mathrm{K}_{2} \mathrm{NiF}_{4}$ derivadas de cela unitária da estrutura perovisquita. 


\subsection{5- Síntese dos óxidos mistos}

As primeiras tentativas de preparar óxidos mistos, de níquel e terras raras, foram realizadas por Wold et al. [17]. A síntese envolveu misturas estequiométricas dos óxidos individuais, utilizando cadinho de ouro e tratamento térmico a $800^{\circ} \mathrm{C}$ por $72 \mathrm{~h}$. Nesses experimentos, os produtos obtidos consistiram basicamente da mistura dos óxidos, não sendo observado a formação de novas fases.

Demazeau et al. [44] foram os pioneiros a obter óxidos $\mathrm{TRNiO}_{3}$ [TR $=\mathrm{La}, \mathrm{Nd}$, $\mathrm{Sm}, \mathrm{Eu}, \mathrm{Gd}, \mathrm{Ho}, \mathrm{Tm}, \mathrm{Yb}, \mathrm{Lu}$ e Y (III)], os quais só voltaram a ser estudados vinte anos depois, devido a descoberta dos supercondutores de alta $T_{c}[1]$.

Estes materiais foram produzidos a partir da mistura dos óxidos de terras raras e níquel (II), utilizando $\mathrm{KClO}_{3}$ na proporção $1: 2: 1,5$, cadinho de platina e tratamento térmico a $950^{\circ} \mathrm{C}$, sob pressão de 60 atm de oxigênio por $12 \mathrm{~min}$. Nesse procedimento foi possível obter os óxidos desejados, mas em quantidades muito pequenas, impossibilitando a sua caracterização [44].

De forma geral, a preparação dos $\mathrm{TRNiO}_{3}$ envolve a seguinte reação:

$$
\mathrm{TR}_{2} \mathrm{O}_{3}+2 \mathrm{NiO}+1 / 2 \mathrm{O}_{2} \rightarrow 2 \mathrm{TRNiO}_{3}
$$

Estes materiais são difíceis de serem sintetizados, pois é necessário favorecer a presença de $\mathrm{Ni}^{3+}$, o qual ocorre apenas em condições extremas, ou seja, quando os precursores são submetidos simultaneamente a altas temperaturas $\left(\mathrm{T}>800^{\circ} \mathrm{C}\right) \mathrm{e}$ pressões de oxigênio $(\mathrm{P}>50 \mathrm{~atm})$.

A maioria dos procedimentos citados na literatura, para a obtenção de óxidos mistos, utiliza o método cerâmico $[4,9,10,17,44,46-47]$. Há também menção na literatura, sobre a síntese de óxidos mistos utilizando o processo sol-gel [13-16]. Por exemplo, Vassilou et al. [15] prepararam a partir da decomposição térmica de nitratos metálicos e sol-gel, $\mathrm{NdNiO}_{3}$ a $650^{\circ} \mathrm{C}$ sob pressão de 10 atm de oxigênio. Lacorre et al. [46] prepararam $\mathrm{TRNiO}_{3}(\mathrm{TR}=\mathrm{La}, \mathrm{Pr}, \mathrm{Nd}, \mathrm{Sm}$ e Eu$)$, utilizando o método cerâmico a $1000^{\circ} \mathrm{C}$ sob pressão de $150-200$ atm de oxigênio, por vários dias. Estes materiais não são obtidos de forma convencional, necessitando de condições especiais, tais como, equipamentos relativamente sofisticados, célula de alta pressão e tratamentos térmicos drásticos. 
No entanto, vários óxidos mistos foram preparados por decomposição térmica de precursores de acetatos, oxalatos e citratos duplos. Por exemplo, $\mathrm{BaTiO}_{3}$ pode ser preparado a partir do $\mathrm{Ba}\left[\mathrm{TiO}\left(\mathrm{C}_{2} \mathrm{O}_{4}\right)_{2}\right]$, enquanto que $\mathrm{LiCrO}_{2}$ pode ser obtido do $\mathrm{Li}\left[\mathrm{Cr}\left(\mathrm{C}_{2} \mathrm{O}_{4}\right)_{2}\left(\mathrm{H}_{2} \mathrm{O}\right)_{2}\right]$. Ferritas espinelas de fórmula geral $\mathrm{MFe}_{2} \mathrm{O}_{4}(\mathrm{M}=\mathrm{Mg}, \mathrm{Mn}, \mathrm{Ni}, \mathrm{Co})$ são preparadas pela decomposição térmica de precursores, do tipo $\mathrm{M}_{3} \mathrm{~F}_{3}\left(\mathrm{CH}_{3} \mathrm{COO}\right)_{17} \mathrm{O}_{3} \mathrm{OH} .12 \mathrm{C}_{5} \mathrm{H}_{5} \mathrm{~N}$ e cromitas, $\mathrm{MCr}_{2} \mathrm{O}_{4}$, são obtidas do $\left(\mathrm{NH}_{4}\right)_{2} \mathrm{M}\left(\mathrm{CrO}_{4}\right)_{2} \cdot 6 \mathrm{H}_{2} \mathrm{O}$. Outros óxidos foram preparados pela decomposição térmica de soluções sólidas de hidróxidos, nitratos e cianetos. Por exemplo, $\mathrm{LaCo}(\mathrm{CN})_{6} .5 \mathrm{H}_{2} \mathrm{O}$ e $\mathrm{LaFe}(\mathrm{CN})_{6} .6 \mathrm{H}_{2} \mathrm{O}$ produz sob atmosfera oxidante, $\mathrm{LaCoO}_{3}$ e $\mathrm{LaFeO}_{3}$, respectivamente. Compostos de fórmula geral $\mathrm{TR}_{1-\mathrm{x}} \mathrm{M}_{\mathrm{x}}(\mathrm{OH})_{3}$, onde $\mathrm{TR}=\mathrm{La}$ ou $\mathrm{Nd}$ e $\mathrm{M}=\mathrm{Al}, \mathrm{Cr}, \mathrm{Fe}, \mathrm{Co}$ ou Ni, e $\mathrm{TR}_{1-\mathrm{x}-\mathrm{y}} \mathrm{M}_{\mathrm{x}} \mathrm{M}^{\prime}{ }_{\mathrm{y}}(\mathrm{OH})_{3}$ onde $\mathrm{M}^{\prime}=\mathrm{Ni}$ e $\mathrm{M}^{\prime \prime}=\mathrm{Co}$ ou $\mathrm{Cu}$, cristalizam na estrutura do hidróxido de terra rara (III) e são decompostos em temperaturas relativamente baixas (em torno de $600^{\circ} \mathrm{C}$ ) para produzir $\mathrm{LaNiO}_{3}, \mathrm{NdNiO}_{3}, \mathrm{LaNi}_{1-\mathrm{x}} \mathrm{Co}_{\mathrm{x}} \mathrm{O}_{3}, \mathrm{LaNi}_{1-\mathrm{x}} \mathrm{Cu}_{\mathrm{x}} \mathrm{O}_{3}$, etc. [48].

\subsection{6- Propriedades dos óxidos mistos}

As propriedades elétricas e magnéticas de óxidos mistos, $\mathrm{TRNiO}_{3}$ e $\mathrm{TR}_{2} \mathrm{NiO}_{4}$, têm sido extensivamente investigadas [7-10, 46, 48, 53-55]. Uma comparação rigorosa das propriedades destes materiais somente é possível, quando mantém-se o mesmo estado de oxidação do metal de transição, neste caso o níquel.

Os compostos $\mathrm{TRNiO}_{3}$ pertencem a família de óxidos que possuem comportamento metálico. Medidas de resistividade elétrica em função da temperatura nos $\mathrm{TRNiO}_{3}$, onde $\mathrm{TR}=\mathrm{Pr}, \mathrm{Nd}, \mathrm{Sm}$ e Eu, revelaram que estes compostos apresentam uma transição de fase de primeira ordem do tipo metal-isolante (MI) nas temperaturas $\mathrm{T}_{\mathrm{MI}}=-138,-73,127$ e $207^{\circ} \mathrm{C}$, respectivamente $[8,46,53,54] . \mathrm{O}$ aumento da $\mathrm{T}_{\mathrm{MI}}$ está relacionado com o decréscimo do raio iônico da terra rara e com o grau de distorção da estrutura ideal da perovisquita. Este comportamento também depende do ângulo de ligação Ni-O-Ni. Para o $\mathrm{LaNiO}_{3}$, este ângulo se aproxima de $180^{\circ}$ e não se observa nenhuma alteração no seu comportamento metálico, até temperaturas tão baixas quanto $-271^{\circ} \mathrm{C}[8-10,54]$. 
Adicionalmente às propriedades elétricas, estes compostos apresentam propriedades magnéticas interessantes. Por exemplo, nos compostos $\mathrm{PrNiO}_{3}$ e $\mathrm{NdNiO}_{3}$, os spins dos íons $\mathrm{Ni}^{3+}$ apresentam ordem magnética a baixas temperaturas, porém com uma estrutura magnética não convencional [49]. Observa-se também que este ordenamento magnético desaparece com o aumento da temperatura, exatamente na temperatura $\mathrm{T}_{\mathrm{MI}}$.

Estudos teóricos acerca da estrutura eletrônica destes compostos sugerem a existência de uma diferença de energia típica de transferência de carga, entretanto, até hoje, há controvérsias quanto ao mecanismo responsável por esta transição de fase [8]. Isto ocorre especialmente nos compostos $\mathrm{PrNiO}_{3}$ e $\mathrm{NdNiO}_{3}$, nos quais a transição de fase é acompanhada por mudanças magnéticas, eletrônicas e estruturais.

Os $\mathrm{TRNiO}_{3}$ são óxidos estequiométricos, enquanto os $\mathrm{TR}_{2} \mathrm{NiO}_{4+\delta}$ são óxidos não-estequiométricos. Os primeiros apresentam transição metal-isolante em função da temperatura. Os últimos são metálicos e apresentam propriedades similares ao sistema La-Ba-Cu-O, mas não comportamento supercondutor [56-58].

As propriedades magnéticas e elétricas dos $\mathrm{TR}_{2} \mathrm{NiO}_{4+\delta}$ são influenciadas pela distribuição geométrica. As distâncias relativas das ligação TR-O e Ni-O resultam no estiramento da TR-O e compressão da $\mathrm{Ni}-\mathrm{O}$, relativos aos valores encontrados pelos óxidos individuais. As distorções estruturais são funções tanto do oxigênio nãoestequiométrico $(\delta)$ quanto da temperatura $(T)$. No entanto, ainda não está estabelecido se a falta de estequiometria está associado com a presença de vacâncias em proporções estequiométricas, isto é $\left(\mathrm{TR}_{2} \mathrm{Ni}\right)_{1-\mathrm{r}} \mathrm{O}_{4}$, ou com a presença de oxigênio intersticial na rede, ou seja, $\mathrm{TR}_{2} \mathrm{NiO}_{4+\delta}$. [59-60]. 


\section{4- Referências Bibliográficas}

1- J. G. Bednorz, K. A. Müller, Z. Phys. B 64, 189 (1986).

2- M. A. Subramanian, C. C. Torardi, D. C. Johnson, J. Pannetier, A. W. Sleight, J. Solid State Chem. 72, 24 (1988).

3- J. Jung, J. Töpfer, A. Feltz, J. Thermal. Anal. 36, 1505 (1990).

4- M. Verelst, N. Rangavittal, C. N. R. Rao, A. Rousset, J. Solid State Chem. 104, 74 (1993).

5- E. Ruckenstein, Y. H. Hu, J. Catal. 161, 55 (1996).

6- Z. Zhao, X. Yang, Y. Wu, Appl. Catal. B 8, 281 (1996).

7- J. Basco, J. García, J. Phys.: Condens. Matter 6, 10759 (1994).

8- $\quad$ M. L. Medarde, J. Phys.: Condens. Matter 9, 1679 (1997).

9- J. L. García-Muñoz, J. Rodríguez-Carvajal, P. Lacorre, J. B. Torrance, Phys. Rev. $B$ 46, 4414 (1992).

10- J. L. Garcia-Muñoz, M. Suaidi, M. J. Martínez-Lope, J. A. Alonso, Phys. Rev. B 52, 13563 (1995).

11- A. Wold, J. Chem. Educ. 57, 531 (1980).

12- C. N. R. Rao, J. Gopalakrishnan, Acc. Chem. Res. 20, 228 (1987).

13- C. N. R. Rao, Mater. Sci. Eng. B 18, 1 (1993).

14- C. N. R. Rao, J. Gopalakrishnan, New Directions in Solid State Chemistry (1986). Cambridge University Press, New York.

15- J. K. Vassilou, M. Hornsboste, R. Ziebarth, F. J. Disalvo, J. Solid State Chem. 81, 208 (1989).

16- V. Vidyassagar, J. Gopalakrishnan, C. N. R. Rao, J. Solid State Chem. 58, 29 (1985).

17- A. Wold, B. Post, E. Banks, J. Am. Chem. Soc. 79, 4911 (1957).

18- M. Ionashiro, I. Giolito, Cerâmica 26, 17 (1980).

19- I. Giolito, M. Ionashiro, Cerâmica 34, 163 (1988). 
20- W. W. Wendlandt, Thermal Analysis, $3^{\text {rd }}$. Ed. (1986). Wiley, New York.

21- M. E. Brown, D. Dollimore, A. K. Galwey, Reactions in the Solid State, vol. 22 (1980). Elsevier, Amsterdan.

22- Sesták, Thermophysical Properties of Solids, vol. XII, part D (1984). Elsevier, Amsterdan.

23- $\quad$ P. J. Haines, Thermal Methods of Analysis: Principles, Applications and Problems (1995). Black Academic and Professional, Glasgow.

24- International Confederation for Thermal Analysis- ICTA, J. Thermal Anal. 4, 343 (1972).

25- International Confederation for Thermal Analysis- ICTA, J. Thermal Anal. 6, 241 (1974).

26- International Confederation for Thermal Analysis- ICTA, J. Thermal Anal. 8, 197 (1975).

27- M. E. Brown, Introduction to Thermal Analysis: Tecniques and Applications (1988). Chapman and Hall, London.

28- C. J. Keath, D. Dollimore, An Introduction to Thermogravimetry (1975). Heyden, London.

29- D. Dollimore, Anal. Chem. 60, 274R (1988).

30- D. Dollimore, Anal. Chem. 62, 44R (1990).

31- D. Dollimore, Anal. Chem. 64, 147R (1992)

32- D. Dollimore, Anal. Chem. 66, 17R (1994).

33- D. Dollimore, Anal. Chem. 68, 63R (1996).

34- D. Dollimore, S. Lerdkanchanaporn, Anal. Chem. 70, 27R (1998).

35- F. A. Cotton, G. Wikinson, Advanced Inorganic Chemistry, $4^{\text {th }}$. Ed. (1980). Wiley, New York.

36- T. Moller, The Chemistry of the Lanthanides, (1975). Pergamon Press, New York.

37- A. Abrão, Química e Tecnologia das Terras Raras (1994). Centro de Tecnologia Mineral (CETEM)/CNPq. 
38- S. Arhland, J. Chatt, N. R. Davies, Quart. Rev. Chem. Soc. 12, 265 (1958)

39- R. G. Pearson, J. Am. Chem. Soc. 85, 3533 (1963).

40- L. Smart, E. Moore, Solid State Chemistry: An Introduction (1985). Chapman and Hall, London.

41- R. Ward, Progress in Inorganic Chemistry, vol. 1 (1959). Interscience, New York.

42- F. S. Galasso, Structure, Properties and Preparation of Perovskite-Type Compounds (1969). Pergamon, Oxford.

43- J. B. Goodenough, J. M. Longo, Crystallographic and Magnetic Properties of Peroviskites and Peroviskite-Related Compounds, vol. 4A (1970). LandoltBörnstein Group III.

44- G. Demazeau, A. Marbeuf, M. Pouchard, P. Hagenmuller, J. Solid State Chem. 3, $582(1971)$.

45- P. Poix, C. R. Acad, Crystallogr. Sec. A 31, 756 (1975).

46- P. Lacorre, J. B. Torrance, J. Pannetier, A I. Nazzal, P. W. Wang, C. Huang, J. Solid State Chem. 91, 225 (1991).

47- M. Medarde, A. Fontaine, J. L. García-Muñoz, J. L. Rodríguez-Carvajal, M. Santis, M. Sacchi, G. Rossi, P. Lacorre, Phys. Rev. B 46, 14975 (1992).

48- C. N. R. Rao, Solid State Chemistry, vol. 4 (1995). World Scientific Series in $20^{\text {th }}$ Century Chemistry.

49- C. N. R. Rao, G. V. Subba Rao, Phys. Status Solidi (A) 1, 597 (1970).

50- J. B. Goodenough, Prog. Solid State Chem. 5, 145 (1972).

51- C. N. R. Rao, J. Indian Chem. Soc. 51, 979 (1974).

52- P. Ganguly, Om Parkash, C. N. R. Rao, Phys. Status Solidi (A) 36, 339 (1976).

53- V. Vidyassagar, J. Gopalakrishnan, C. N. R. Rao, Inorg. Chem. 23, 1206 (1984).

54- J. B. Torrance, P. Lacorre, A. I. Nazzal, E. J. Ansaldo, Ch. Niedermayer, Phys. Rev. B 45, 8209 (1992).

55- J. A. Alonso, M. J. Martínez-Lope, I. Rasines, J. Solid State Chem. 120, 170 (1995). 
56- J. Blasco, J. García, M. G. Proietti, R. L. Chaboy, Solid State Ion. 63, 585 (1993).

57- J. B. Torrance, P. Lacorre, C. Asavaroengchai, R. Metzger, J. Solid State Chem. 81, 208 (1989).

58- J. D. Axe, A. H. Moudden, D. Hohlwein, D. E. Cox, K. M. Mohanty, A. R. Moodenbaugh, Y. Xu; Phys. Rev. Lett. 62, 2751 (1989).

59- C. N. R. Rao, D. J. Buttrey, N. Otsuka, P. Ganguly, H. R. Harrison, C. J. Sandrerg, J. M. Honig, J. Solid State Chem. 52, 266 (1984).

60- D. J. Buttrey, J. M. Homig, C. N. R. Rao, J. Solid State Chem. 64, 287 (1986). 


\section{Capítulo}

\section{Parte Experimental}

Neste capítulo são apresentados os procedimentos de síntese, as técnicas e as condições experimentais utilizados na caracterização dos compostos.

São apresentadas as três rotas de síntese para a obtenção dos óxidos $\mathrm{TR}_{2} \mathrm{NiO}_{4}[\mathrm{TR}=\mathrm{La}$, Eu e Y (III) $]$ e $\mathrm{TRNiO}_{3}[\mathrm{TR}=\mathrm{Pr}, \mathrm{Nd}$ e $\mathrm{Sm}$ (III)].

\section{Materiais}

Métodos de Preparação

Tratamentos Térmicos

Métodos de Análises

\section{Propriedades}

Referências Bibliográficas 


\section{2- PARTE EXPERIMENTAL}

\section{1- Materiais}

Na Tabela 2.1 estão apresentadas as substâncias empregadas como reagentes, solventes ou materiais em geral, com sua aplicação direta, procedência e grau de pureza.

Tabela 2.1: Substâncias utilizadas

\begin{tabular}{|c|c|c|c|}
\hline REAGENTES & APLICAÇÃO DIRETA & PROCEDÊNCIA & PUREZA \\
\hline Acetato de níquel & Síntese de acetatos binários & Carlo Erba & P.A. ${ }^{a}$ \\
\hline Acetato de sódio & Titulação complexométrica & Merck & P.A. \\
\hline Ácido acético glacial & $\begin{array}{l}\text { Preparação dos acetatos de } \mathrm{TR}^{\mathbf{b}} \\
\text { e titulação complexométrica }\end{array}$ & Merck & P.A. \\
\hline Ácido clorídrico & Solubilização dos óxidos de TR & Merck & P.A. \\
\hline Ácido cítrico & Processo sol-gel & Aldrich & $99,5 \%$ \\
\hline Ácido nítrico & Teste qualitativo para cloreto & Merck & P.A. \\
\hline Ácido oxálico & Teste qualitativo para TR & Ecibra & $99 \%$ \\
\hline $\begin{array}{l}\text { Alaranjado de } \\
\text { ortoxilenol }\end{array}$ & Titulação complexométrica & J.G.Baker & $99 \%$ \\
\hline Brometo de potássio & $\begin{array}{l}\text { Pastilhas para obtenção dos } \\
\text { espectros no infravermelho }\end{array}$ & Aldrich & $99 \%$ \\
\hline Carbonato de níquel & $\begin{array}{l}\text { Preparação dos hidróxidos } \\
\text { binários }\end{array}$ & Fluka & P.A. \\
\hline Cloreto de cálcio & Agente secante & Aldrich & $99 \%$ \\
\hline Dimetilglioxima & Teste qualitativo para $\mathrm{Ni}^{2+}$ & Aldrich & $99 \%$ \\
\hline $\mathrm{EDTA}^{\mathrm{c}}$ & Titulação complexométrica & Merck & P.A. \\
\hline Etileno glicol & Processo sol-gel & Aldrich & $99 \%$ \\
\hline Hidróxido de sódio & $\begin{array}{l}\text { Preparação dos hidróxidos } \\
\text { binários }\end{array}$ & Aldrich & $99 \%$ \\
\hline Hidróxido de amônio & $\begin{array}{l}\text { Preparação dos } \\
\text { hidroxicarbonatos de TR }\end{array}$ & Aldrich & P.A. \\
\hline
\end{tabular}




\begin{tabular}{|c|c|c|c|}
\hline REAGENTES & APLICAÇÃO DIRETA & PROCEDÊNCIA & PUREZA \\
\hline Hipoclorito de sódio & $\begin{array}{l}\text { Preparação dos hidróxidos } \\
\text { binários }\end{array}$ & Synth & $10-12 \%$ \\
\hline Índio metálico & Calibração do DSC & Perkin-Elmer & $99,99 \%$ \\
\hline $\begin{array}{l}\text { Nitratos de TR } \\
(\mathrm{TR}=\mathrm{Nd}, \mathrm{Sm} \text { e } \mathrm{Pr})\end{array}$ & Processo sol-gel & Aldrich & P.A. \\
\hline Nitrato de prata & Teste qualitativo para cloreto & Aldrich & P.A. \\
\hline Nitrato de níquel & Processo sol-gel & Aldrich & $99,9 \%$ \\
\hline $\begin{array}{l}\text { Óxidos de TR (TR = } \\
\text { La, Pr, Nd, Sm, Eu e } \\
\text { Y) }\end{array}$ & $\begin{array}{l}\text { Preparação dos } \\
\text { hidroxicarbonatos; mistura de } \\
\text { óxidos; hidróxidos binários }\end{array}$ & $\begin{array}{l}\text { Sigma Chemical } \\
\text { Company Inc. }\end{array}$ & $99,9 \%$ \\
\hline Óxido de níquel & Mistura de óxidos & Merck & $99,99 \%$ \\
\hline $\begin{array}{l}\text { Oxalato de cálcio } \\
\text { monoidrato }\end{array}$ & $\begin{array}{l}\text { Verificação dos parâmetros de } \\
\text { massa e temperatura das } \\
\text { termobalanças }\end{array}$ & Sintetizado & P.A. \\
\hline Piridina & Titulação complexométrica & Reagen & P.A. \\
\hline Uréia & $\begin{array}{l}\text { Preparação dos } \\
\text { hidroxicarbonatos de TR }\end{array}$ & Merck & P.A. \\
\hline Zinco metálico & $\begin{array}{l}\text { Calibração dos equipamentos } \\
\text { de DSC e DTA }\end{array}$ & Perkin-Elmer & $99,99 \%$ \\
\hline
\end{tabular}

\footnotetext{
${ }^{\mathrm{a}}$ P.A.: para análise; ${ }^{\mathrm{b}}$ TR: terras raras; ${ }^{\mathrm{c}}$ EDTA: ácido etilenodiaminotetracético
} 


\section{2- Métodos de preparação}

\subsection{1- Preparação dos óxidos $\mathrm{TR}_{2} \mathrm{NiO}_{4}$}

Os óxidos $\mathrm{TR}_{2} \mathrm{NiO}_{4}[\mathrm{TR}=\mathrm{La}, \mathrm{Eu}$ e $\mathrm{Y}(\mathrm{III})]$ foram obtidos como produtos da decomposição térmica de acetatos binários de terras raras e níquel, os quais foram sintetizados utilizando-se o método precursor, empregando três rotas distintas: (a) mistura mecânica; (b) evaporação do solvente e (c) cristalização com acetona.

Inicialmente, foram preparados os hidroxicarbonatos de terras raras como materiais de partida, para obtenção dos respectivos acetatos de terras raras. $\mathrm{O}$ acetato de níquel foi obtido comercialmente (Tabela 2.1). Os detalhes referentes aos métodos de preparação estão apresentados a seguir.

\subsection{2- Preparação dos hidroxicarbonatos de terras raras}

Os hidroxicarbonatos de terras raras, especificamente La, Eu e Y (III), foram preparados a partir da precipitação em meio homogêneo utilizando uréia [1].

$\mathrm{O}$ método consistiu no tratamento de uma suspensão aquosa de $10,0 \mathrm{~g}$ dos respectivos óxidos de terras raras, com ácido clorídrico concentrado adicionado gota a gota até dissolução total. A solução resultante foi diluída até $800 \mathrm{~mL}$ e o pH mantido entre 2 e 3, quando necessário ajustou-se o pH, utilizando solução diluída de hidróxido de amônio. A solução resultante foi levada à ebulição e adicionaram-se pequenas quantidades de uréia, sempre verificando o $\mathrm{pH}$. A precipitação do hidroxicarbonato iniciou-se em $\mathrm{pH}$ próximo de 5 e completou-se em $\mathrm{pH}$ igual a 7 . A precipitação completa foi verificada qualitativamente, tomando-se uma alíquota do sobrenadante e tratando-a com solução diluída de ácido oxálico.

Após precipitação completa, os hidroxicarbonatos foram separados por filtração e lavados repetidamente com água deionizada, a quente, até total remoção de ions cloreto $\left(\mathrm{Cl}^{-}\right)$adsorvidos superficialmente. A ausência de $\mathrm{Cl}^{-}$foi verificada nas águas de lavagens e no precipitado, qualitativamente, com nitrato de prata em meio de ácido nítrico diluído. Os precipitados foram secos a vácuo, armazenados em frascos de vidro e mantidos em dessecador contendo $\mathrm{CaCl}_{2}$. 
Entre os hidroxicarbonatos de terras raras, o de ítrio apresentou maior grau de contaminação por $\mathrm{Cl}^{-}$, não sendo possível eliminá-lo mesmo após inúmeras lavagens. Dessa forma, uma nova rota de preparação foi estabelecida, com o objetivo de diminuir o grau de contaminação.

O óxido de ítrio foi solubilizado com ácido clorídrico, nas mesmas condições anteriores, porém eliminou-se o excesso de ácido por sucessivas evaporações, antes de elevar o volume da solução a $800 \mathrm{~mL}$. Por meio de uma bureta foram adicionados volumes sucessivos de $2 \mathrm{~mL}$ de uma solução de uréia $1,0 \mathrm{~mol} \mathrm{~L}^{-1}$, em intervalos de tempo de $10 \mathrm{~min}$, sob agitação e temperatura controlada a $80^{\circ} \mathrm{C}$, sempre verificando o pH. O término da reação ocorreu em pH 7. Após verificação da precipitação completa, a suspensão foi submetida a banhos de ultra-som [2], em intervalos de duas horas consecutivas, num total de oito horas por dia e filtrada a vácuo, utilizando-se cadinhos de placa porosa de vidro sinterizado (malha 3). O precipitado apresentou-se finamente dividido e foi lavado com água deionizada a quente, até remoção total de íons cloretos. Em seguida, foi seco a vácuo, armazenado em frasco de vidro e mantido em dessecador contendo $\mathrm{CaCl}_{2}$.

\subsection{3- Preparação dos acetatos de terras raras}

Os acetatos de terras raras, especificamente La, Eu e Y (III), foram preparados pela dissolução dos respectivos hidroxicarbonatos, com ácido acético glacial, em proporções estequiométricas.

O método consistiu no tratamento de uma suspensão do hidroxicarbonato de terra rara, em quantidade necessária para formação de $c a .5,0 \mathrm{~g}$ do respectivo acetato. Adicionou-se ácido acético glacial, lentamente, sob agitação e aquecimento, observandose o desprendimento de $\mathrm{CO}_{2}$. Após dissolução completa, adicionou-se uma pequena quantidade de hidroxicarbonato, com o objetivo de garantir um pequeno excesso do mesmo e a ausência de ácido acético livre. $\mathrm{O}$ pH final foi igual a 5. Filtrou-se a solução para eliminar o excesso de hidroxicarbonato e lavou-se o resíduo com pequenos volumes de água deionizada. O filtrado foi evaporado em banho-maria até a obtenção de um sólido cristalino. Os cristais obtidos foram dissolvidos em água deionizada $\mathrm{e}$ recristalizados por da água, secos a vácuo, armazenados em frascos de vidro e mantidos em dessecador contendo $\mathrm{CaCl}_{2}$ 


\subsection{4- Preparação dos acetatos binários de terras raras e níquel}

A preparação dos acetatos binários foi realizada por meio de três rotas distintas: (a) mistura mecânica de acetatos de terras raras e níquel; (b) evaporação do solvente (água) e (c) cristalização por acetona.

Os detalhes referentes aos métodos de síntese estão descritos a seguir e foram resumidos no Fluxograma 1.

\subsubsection{1- Mistura mecânica (M. M.)}

Os acetatos de terras raras [La, Eu e Y (III)] e níquel (II) foram misturados mecanicamente na proporção molar 1:1, utilizando-se um almofariz de ágata. A mistura resultante dos constituintes foi armazenada em frascos de vidro e mantidos em dessecador contendo $\mathrm{CaCl}_{2}$.

\subsubsection{2- Evaporação do solvente (E. S.)}

Soluções aquosas dos acetatos de terras raras [La, Eu e Y (III)] e níquel (II), na proporção molar $1: 1$, foram misturadas sob agitação e aquecimento moderado $\left(70^{\circ} \mathrm{C}\right)$. A solução resultante, com $\mathrm{pH}$ igual 7 , foi aquecida quase à secura e a cristalização finalizada evaporando-se lentamente a água, em banho-maria. Os cristais obtidos foram dissolvidos em água deionizada e novamente cristalizados por evaporação do solvente, secos a vácuo, armazenados em frascos de vidro e mantidos em dessecador contendo $\mathrm{CaCl}_{2}$.

\subsubsection{3- Cristalização com acetona (C. A.)}

Soluções aquosas dos acetatos de terras raras [La, Eu e Y (III)] e níquel (II), na proporção molar $1: 1$, foram misturadas sob agitação e aquecimento moderado $\left(70^{\circ} \mathrm{C}\right)$. $\AA$ solução resultante, com $\mathrm{pH}$ igual a 7 , adicionou-se acetona para promover a cristalização. Os cristais formados foram filtrados a vácuo e lavados com pequenos volumes de acetona. As águas de lavagens foram tratadas com solução diluída de ácido 
oxálico e dimetilglioxima, para confirmar se a cristalização foi total para os íons $\mathrm{TR}^{3+} \mathrm{e}$ $\mathrm{Ni}^{2+}$, respectivamente. Os cristais foram secos a vácuo, armazenados em frascos de vidro e mantidos em dessecador contendo $\mathrm{CaCl}_{2}$.

\subsection{5- Preparação dos óxidos $\mathrm{TRNiO}_{3}$}

Os óxidos $\mathrm{TRNiO}_{3}[\mathrm{TR}=\mathrm{Pr}, \mathrm{Nd}$ e $\mathrm{Sm}$ (III)] foram obtidos por três métodos diferentes: (1) mistura de óxidos de terras raras e de níquel; (2) precipitação simultânea de hidróxidos de $\mathrm{TR}^{3+}$ e $\mathrm{Ni}^{3+} \mathrm{e}(3)$ processo sol-gel. Os detalhes referentes aos métodos estão descritos a seguir e resumidos no Fluxograma 2

\subsubsection{1- Mistura de óxidos (M. O.)}

As amostras de $\mathrm{TRNiO}_{3}[\mathrm{TR}=\mathrm{Pr}, \mathrm{Nd}$ e $\mathrm{Sm}(\mathrm{III})]$ foram preparadas por mistura mecânica dos respectivos óxidos de terras raras $\left(\mathrm{TR}_{2} \mathrm{O}_{3}\right)$ e níquel $(\mathrm{NiO})$. Após pesagem dos óxidos em proporções estequiométricas, os mesmos foram misturados utilizando um almofariz de ágata, até obter-se uma mistura visualmente homogênea. Em seguida, as misturas foram submetidas a moagem utilizando um moinho de bolas, em intervalos de tempo de duas horas. O material obtido foi inicialmente submetido a tratamentos térmicos em fluxo de ar sintético, por $24 \mathrm{~h}$ a $500^{\circ} \mathrm{C}$, com interrupções para moagens intermediárias por duas horas. Ao final deste processo, as amostras apresentaram colorações desde o verde claro ao marrom, dependendo da terra rara envolvida. Em seguida foram armazenadas em frascos de vidro e mantidas em dessecador contendo $\mathrm{CaCl}_{2}$.

\subsubsection{2- Precipitação simultânea de hidróxidos (H. I.)}

Os hidróxidos binários de terras raras $[\mathrm{Pr}, \mathrm{Nd}$ e $\mathrm{Sm}$ (III)] e níquel foram preparados misturando-se quantidades estequiométricas dos óxidos de terras raras $\left(\mathrm{TR}_{2} \mathrm{O}_{3}\right)$ e carbonato de níquel $\left(\mathrm{NiCO}_{3}\right)$. A esta mistura adicionou-se ácido clorídrico concentrado gota a gota, até dissolução completa. À solução clorídrica foi adicionada simultaneamente uma mistura de soluções de hipoclorito de sódio $(10 \%)$ e hidróxido de 
sódio $\left(1,0 \mathrm{~mol} \mathrm{~L}^{-1}\right)$, gota a gota em excesso, até $\mathrm{pH}$ igual a 12. Nestas condições acredita-se que dois processos ocorram simultaneamente: (1) oxidação do $\mathrm{Ni}^{2+}$ a $\mathrm{Ni}^{3+} \mathrm{e}$ (2) precipitação simultânea de hidróxidos metálicos de $\mathrm{TR}^{3+} \mathrm{e} \mathrm{Ni}^{3+}$.

Para o sistema envolvendo o praseodímio, adotou-se o seguinte procedimento. Pesou-se, separadamente, as quantidades estequiométricas de $\operatorname{Pr}_{6} \mathrm{O}_{11}$ e $\mathrm{NiCO}_{3}$. Fez-se suspensões aquosas e adicionou-se ácido clorídrico concentrado gota a gota até dissolução total. Para a solução clorídrica de níquel, adicionou-se hipoclorito de sódio $(10 \%)$ lentamente, gota a gota, para promover a oxidação de $\mathrm{Ni}^{2+} \mathrm{a} \mathrm{Ni}^{3+}$. Para a solução clorídrica de praseodímio, adicionou-se peróxido de hidrogênio $(30 \%)$ gota a gota em excesso, para reduzir $\operatorname{Pr}^{4+}$ a $\operatorname{Pr}^{3+}$. Em seguida misturou-se as duas soluções de $\mathrm{Ni}^{3+} \mathrm{e}$ $\operatorname{Pr}^{3+}$, e adicionou-se solução de hidróxido de sódio $1,0 \mathrm{~mol} \mathrm{~L}{ }^{-1}$, lentamente sob agitação e aquecimento, até $\mathrm{pH}$ igual a 12. Os precipitados formados de coloração preta, apresentaram-se finamente dividido. Estes foram separados por filtração à vácuo, lavados exaustivamente com água deionizada a quente até remoção total de íons cloreto (teste qualitativo com nitrato de prata em meio de ácido nítrico diluído). Em seguida foram submetidos a secagem a vácuo, armazenados em frascos de vidro e mantidos em dessecador contendo $\mathrm{CaCl}_{2}$.

\subsubsection{3- Processo sol-gel (S. G.)}

Os materiais iniciais utilizados foram os nitratos de terras raras, $\mathrm{TR}\left(\mathrm{NO}_{3}\right)_{3} \cdot 6 \mathrm{H}_{2} \mathrm{O}$ $(\mathrm{TR}=\mathrm{Pr}, \mathrm{Nd}$ e $\mathrm{Sm}(\mathrm{III}))$ e de níquel, $\mathrm{Ni}\left(\mathrm{NO}_{3}\right)_{2} \cdot 6 \mathrm{H}_{2} \mathrm{O}$. Estes materiais foram misturados em quantidades estequiométricas e dissolvidos em $200 \mathrm{~mL}$ de água destilada. Adicionou-se ácido cítrico, para promover a formação de citratos metálicos, e em seguida etileno glicol em excesso. A solução de coloração verde foi submetida a aquecimento e agitação magnética por duas horas. Durante esta etapa várias reações ocorrem: decomposição dos nitratos com liberação de gases nitrosos; condensação e polimerização da solução e finalmente a formação do gel. Em seguida, o gel obtido foi transferido para um cadinho de alumina e levado ao forno a $300^{\circ} \mathrm{C}$. Nestas condições, o material foi desidratado adquirindo coloração marrom, e submetido a outro tratamento térmico a $500^{\circ} \mathrm{C}$ sob atmosfera de ar. Em seguida foi armazenado em frascos de vidro e mantidos em dessecador contendo $\mathrm{CaCl}_{2}$. 
Fluxograma 1: Etapas de preparação dos óxidos $\mathrm{TR}_{2} \mathrm{NiO}_{4}(\mathrm{TR}=\mathrm{La}, \mathrm{Eu}$ e $\mathrm{Y})$

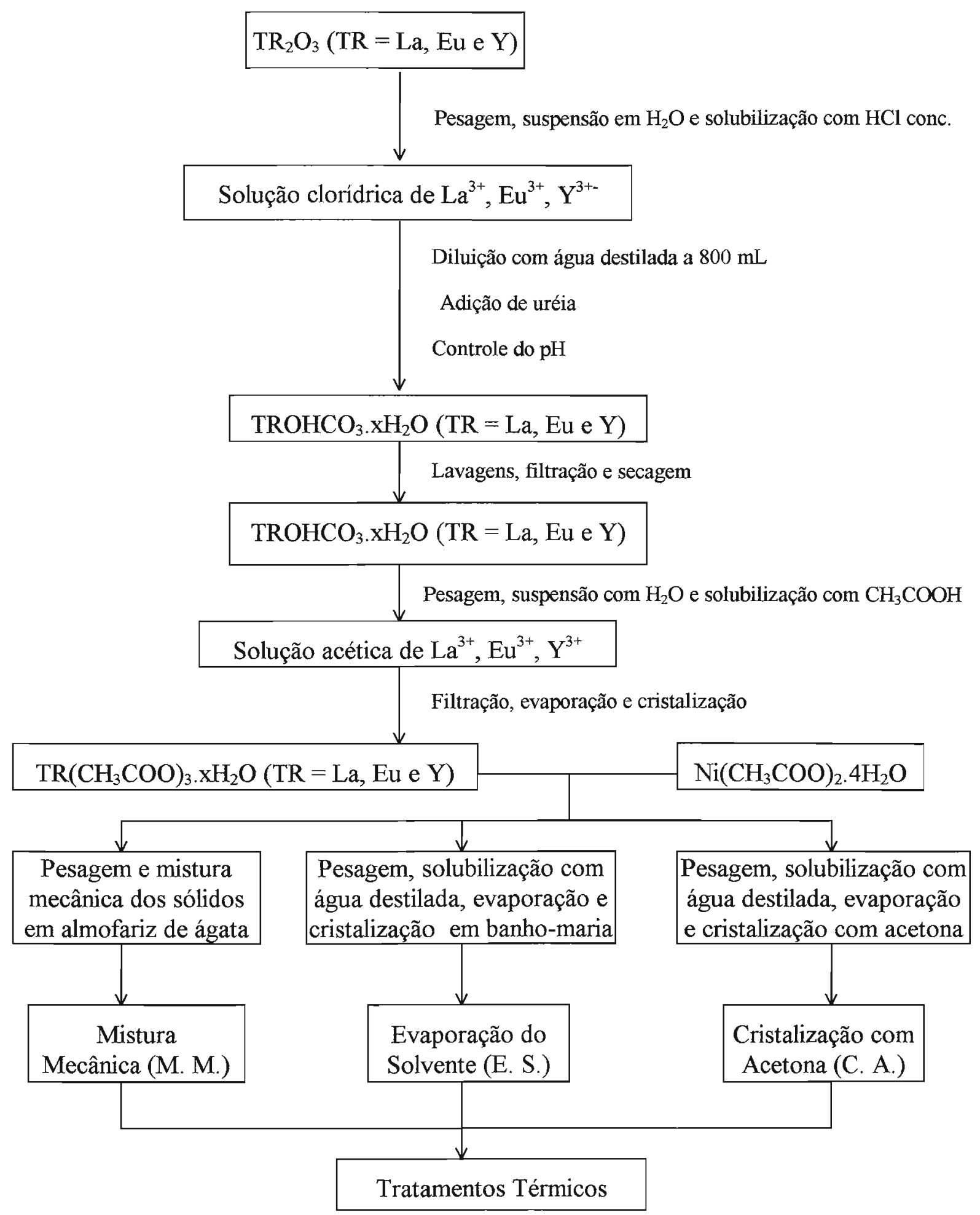




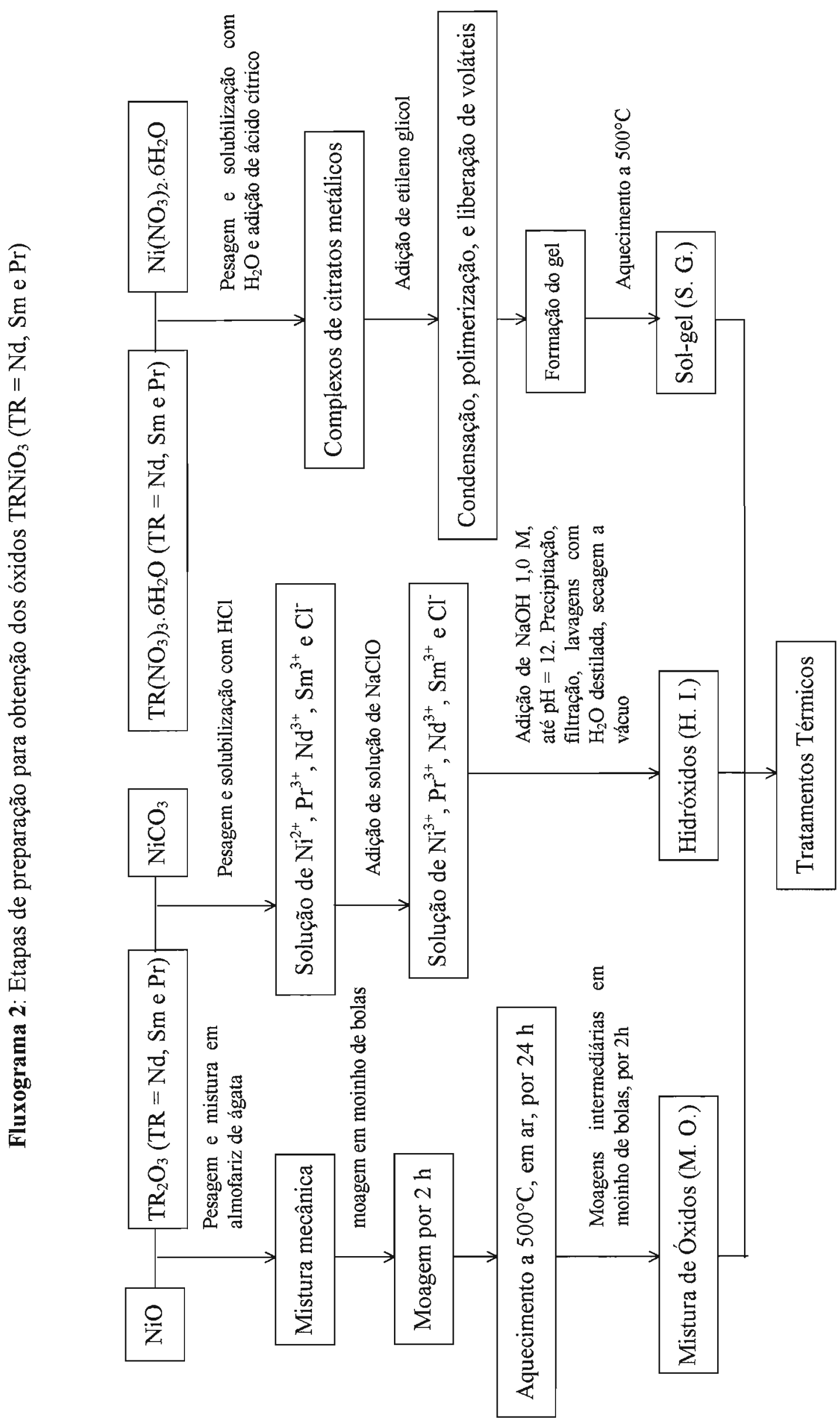




\section{3- Tratamentos térmicos}

Os materiais precursores foram inicialmente tratados termicamente em uma mufla, sob atmosfera de ar, em temperaturas de 300 e $500^{\circ} \mathrm{C}$, para calcinação primária. Em seguida, as amostras foram submetidas a diversos tratamentos térmicos, em temperaturas de $650 \leq \mathrm{T} \leq 1000^{\circ} \mathrm{C}$ e pressões de até 70 atm de oxigênio. Estes tratamentos foram efetuados em intervalos de tempo de $48 \mathrm{~h}$, utilizando razões de aquecimento e resfriamento de $10^{\circ} \mathrm{C} \mathrm{min}^{-1}$. Utilizou-se um forno resistivo tubular Lindberg, equipado com controlador - programador de temperatura. No forno foi instalado um tubo metálico Inconel 600 , que possibilitou realizar os tratamentos térmicos em altas temperaturas e sob pressões de oxigênio relativamente elevadas (Figura 2.1).

(a)

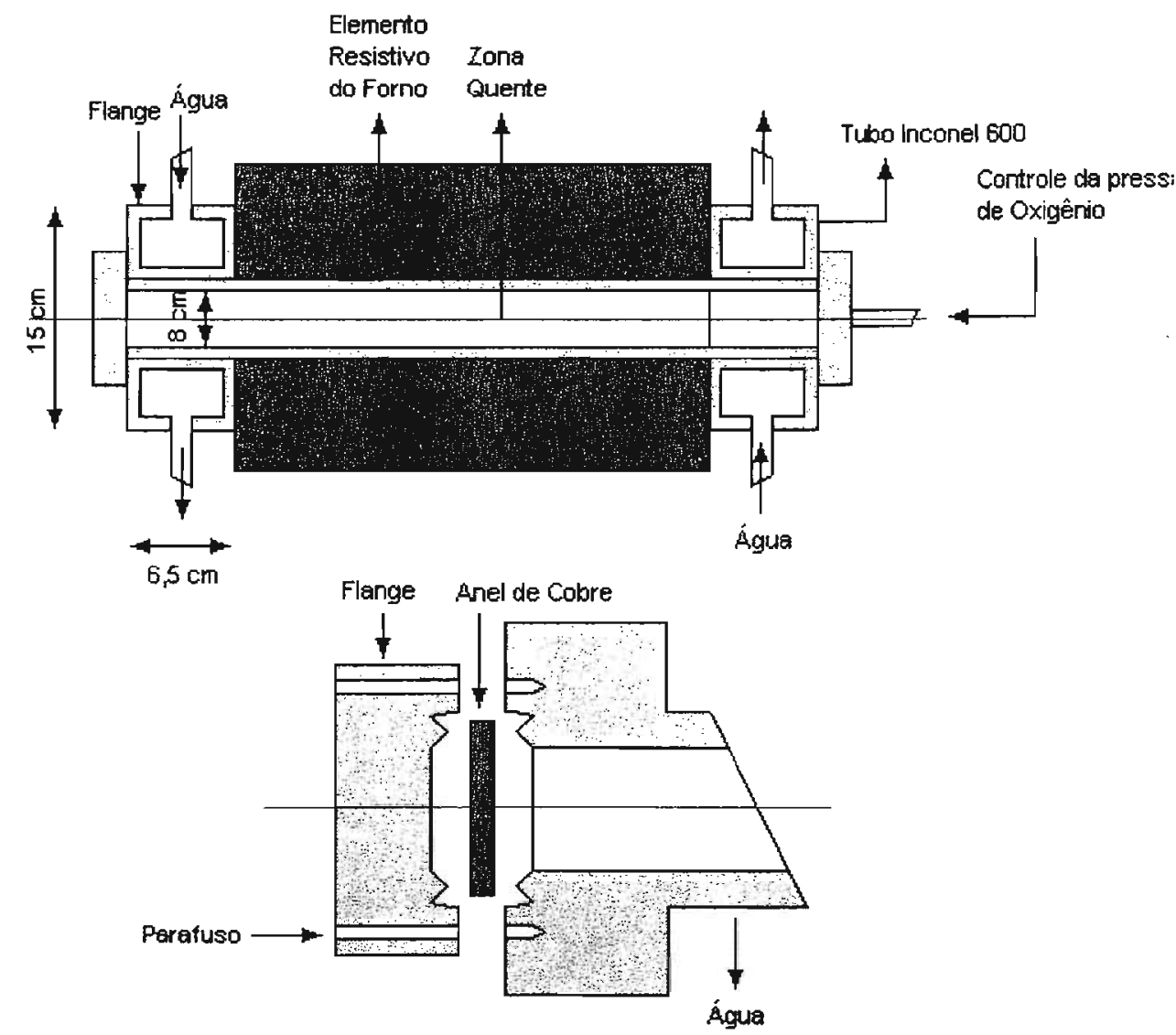

Figura 2.1: (a) Arranjo experimental construído com o tubo metálico aço de Inconel 600 acondicionado no interior da zona quente do forno Lindeberg; (b) Sistema de vedação da flange usando um anel de cobre. 


\section{4- Métodos de análise}

\subsection{1- Análise elementar}

\subsubsection{1- Determinação quantitativa de carbono e hidrogênio}

O teor de carbono e hidrogênio foi determinado no Laboratório da Central Analítica do IQ-USP, utilizando o equipamento Elemental Analyser $2400 \mathrm{CHN}$ (PerkinElmer).

\subsubsection{2- Determinação quantitativa dos íons terras raras}

O teor dos íons terras raras dos acetatos simples foi determinado por complexometria, utilizando-se solução de EDTA como agente complexante $0,01 \mathrm{~mol} \mathrm{~L}^{-1}$, em meio tamponado com solução de ácido acético/acetato de sódio $(\mathrm{pH}=5,8)$, uma gota de piridina e indicador alaranjado de ortoxilenol, segundo método sugerido por Korbl e Pribil [3], Kinnunen e Wennerstrand [4] e estudado por Lyle e Rahman [5].

Os teores destes elementos também foram determinados por termogravimetria (TG). Baseando-se nos cálculos de perda de massa, pode-se determinar a estequiometria dos acetatos, uma vez que o produto final da decomposição térmica são os respectivos óxidos.

O teor dos íons terras raras e níquel nos sistemas binários e óxidos foi determinado por espectrometria de emissão atômica com plasma de argônio indutivamente acoplado (ICP-AES), utilizando o espectrômetro modelo Spectral Flame Modula.

Para os sistemas binários de acetatos de $\mathrm{La}: \mathrm{Ni}$ e Eu:Ni, os teores dos metais também foram determinados por termogravimetria. 


\subsubsection{3- Determinação quantitativa do teor de água}

O grau de hidratação nos hidroxicarbonatos, acetatos de terras raras e acetatos binários, foi determinado por termogravimetria, no intervalo aproximado de 25 a $200^{\circ} \mathrm{C}$. Esta técnica mostra-se adequada no estudo dos processos de desidratação, uma vez que as curvas TG registram as variações de massa correspondentes a esses processos continuamente.

\subsection{2- Espectroscopia de absorção na região do infravermelho (IR)}

Os espectros de absorção na região do infravermelho para os acetatos simples e binários foram registrados na faixa espectral de 4000 a $400 \mathrm{~cm}^{-1}$, resolução de $4 \mathrm{~cm}^{-1} \mathrm{e}$ amostras diluídas em $\mathrm{KBr}$ na forma de pastilhas.

Os espectros foram obtidos no Laboratório da Central Analítica do IQ-USP, utilizando-se o espectrofotômetro modelo FTIR 510 (Nicolet).

\subsection{3- Difração de raios X (XRD)}

Os acetatos simples e binários, precursores obtidos por mistura de óxidos, hidróxidos binários, sol-gel e todos os produtos de calcinação foram caracterizados por difração de raios $X$ (método do pó).

Os difratogramas de raios $\mathrm{X}$ foram obtidos no Laboratório de Caracterização Tecnológica da Escola Politécnica da USP, utilizando o difratômetro equipado com monocromador e filtro de Ni, de marca Philips PW-1710, nas seguintes condições: radiação de $\operatorname{CuK} \alpha, K \alpha_{1}=1,54050 \AA$ e $K \alpha_{2}=1,54439 \AA$; intervalo de 2,5<2 $2080^{\circ}$; passo angular de $0,02^{\circ}$ e tempo de exposição de até $10 \mathrm{~s}$.

As amostras na forma de pó foram fixadas com cola ou graxa de silicone em um porta amostra de vidro. Este possui uma cavidade rasa na superficie, a qual foi preenchida com a cola e a amostra pulverizada. 
A análise dos resultados de difração de raios $\mathrm{X}$ foi realizada a partir de comparações com as fichas do banco de dados, correspondentes a cada composto [6].

\subsection{4- Microscopia eletrônica de varredura (SEM)}

Os óxidos $\mathrm{TRNiO}_{3}[\mathrm{TR}=\mathrm{Pr}, \mathrm{Nd}$ e $\mathrm{Sm}$ (III) $]$ obtidos por mistura de óxidos, precipitação de hidróxidos binários e processo sol-gel, foram caracterizados por observações em microscópio de varredura.

As micrografias foram obtidas no Laboratório de Caracterização Tecnológica da Escola Politécnica da USP, utilizando o equipamento Leica Cambrige modelo S-440, com potência de $20 \mathrm{kV}$ e distância de trabalho de $10 \mathrm{~mm}$.

As amostras foram coladas em um porta amostra metálico com fita adesiva de carbono e recobertas com um filme fino de ouro de $25 \AA$ de espessura. Este filme foi crescido através de volatilização utilizando o equipamento Bal-Tec modelo SCD-050 (Sputter Coated), no vácuo de $2 \times 10^{-2}$ torr e tempo de recobrimento de $120 \mathrm{~s}$. O sistema foi preso a um outro porta amostra de geometria circular que comporta até oito amostras. Nestas observações, as regiões das amostras foram fotografadas utilizando-se aumentos de 300 a 2400 vezes.

\subsection{5- Resistividade elétrica}

Os óxidos $\mathrm{TRNiO}_{3}[\mathrm{TR}=\mathrm{Pr}, \mathrm{Nd}$ e $\mathrm{Sm}$ (III)] obtidos por mistura de óxidos, precipitação de hidróxidos binários e processo sol-gel, foram caracterizados por medidas de resistividade elétrica em função da temperatura $\rho(\mathrm{T})$ utilizando o método de quatro pontas $d c(4 \mathrm{dc})$.

As amostras foram submetidas a $650^{\circ} \mathrm{C}$ e pressão de 50 atm de oxigênio para adquirir resistência mecânica. Em seguida, foram cortadas em pequenos paralelepípedos regulares de volume conhecido. Nestes foram afixados, paralelamente, quatro fios de cobre, utilizando-se uma resina com prata finamente dividida. 
As medidas foram obtidas utilizando um arranjo experimental montado no Laboratório de Física de Materias do IF-USP (Figura 2.2). Este sistema consiste de um frasco de aço inox, dentro do qual a amostra é inserida juntamente com o termômetro de platina. Esta configuração na presença de líquidos criogênicos, permite que a temperatura do sistema varie de -156 a $177^{\circ} \mathrm{C}$.

Para a determinação de R e T foram utilizados duas fontes de corrente Keithley, modelos 220 e 224, um nanovoltímetro Keithley modelo 182 e um multímetro digital Keithley modelo 196. Foi montado um sistema de aquisição de dados através de um microcomputador com interface GPIB, que registra as variações de potencial referentes à amostra e ao termômetro com a variação da temperatura.

As medidas foram obtidas utilizando correntes descontínuas de excitação $\left(\mathrm{I}_{\mathrm{ex}}\right)$, variando de 0,1 a $10 \mathrm{~mA}$ para as amostras e $0,1 \mathrm{~mA}$ para o termômetro. Introduzindo nitrogênio líquido no frasco de aço inox, o sistema é resfriado a $-156^{\circ} \mathrm{C}$. Nestas condições, inicia-se a obtenção dos dados, variando-se a diferença de potencial da amostra $\left(\mathrm{V}_{\mathrm{A}}\right)$ e do termômetro $\left(\mathrm{V}_{\mathrm{T}}\right)$ com a variação da temperatura (através da evaporação do nitrogênio líquido ou do aquecimento via resistor, presente no suporte da amostra). Para medidas de $\mathrm{R}(\mathrm{T})$ acima da temperatura ambiente, a amostra e o termômetro foram retirados do frasco de aço inox, sofrendo aquecimento. Neste caso o sistema pode atingir temperaturas de até $177^{\circ} \mathrm{C}$.

A partir destes dados obtém-se a variação da resistência elétrica $R(T)$ das amostras como função da temperatura, usando a Lei de Ohm:

$$
\begin{aligned}
& V(T)=R(T) I \\
& R(T)=V(T) / I
\end{aligned}
$$

Conhecida a geometria da amostra, calcula-se a resistividade elétrica $\rho(\mathrm{T})$ :

$$
\rho(\mathrm{T})=\mathrm{R}(\mathrm{T}) A / l
$$

Onde, $\boldsymbol{A}$ é a seção transversal da amostra sujeita a corrente de excitação I e $\boldsymbol{l}$ é o comprimento da amostra onde se extrai a diferença de potencial. 


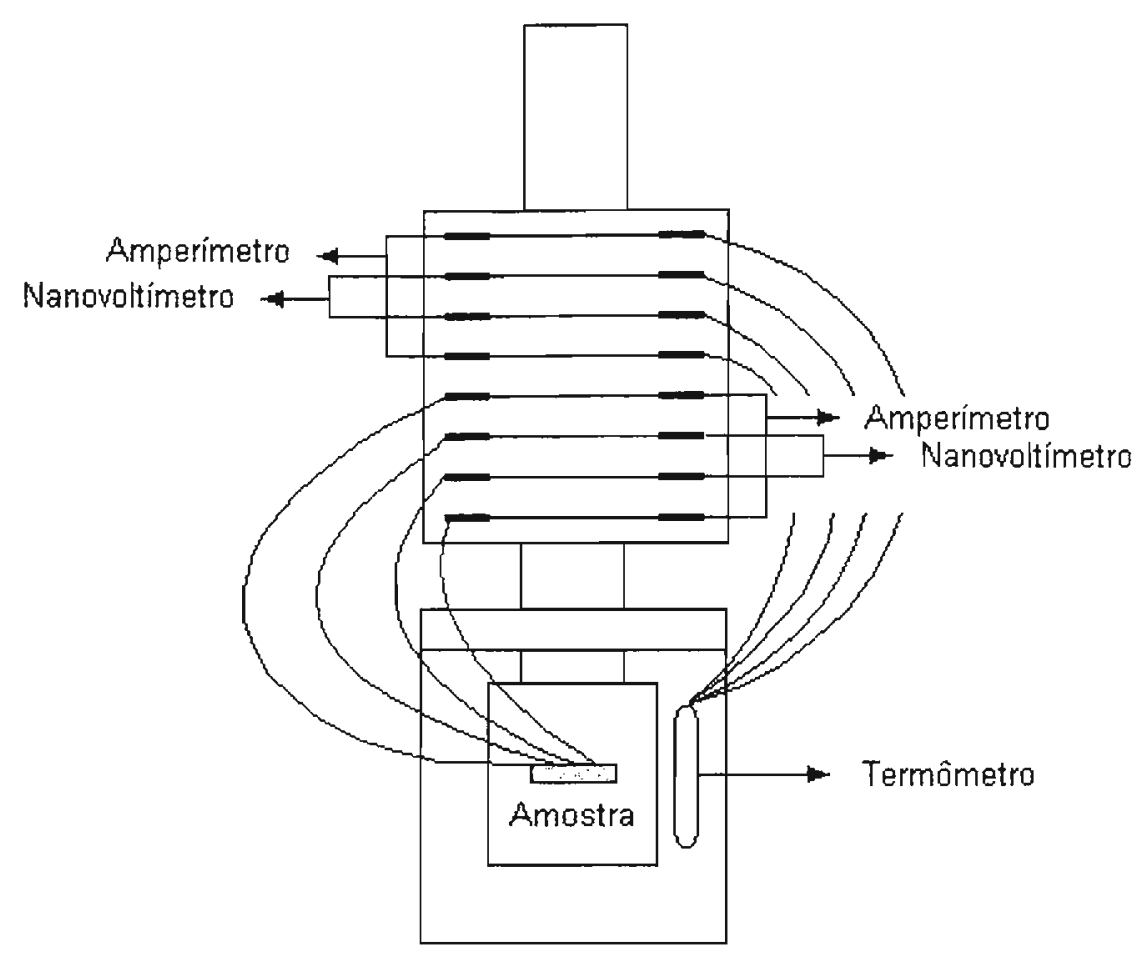

Figura 2.2: Arranjo experimental montado no laboratório para medidas de $\rho(\mathrm{T})$ mostrando a configuração do porta amostra.

\subsection{6- Análise térmica}

\subsubsection{1- Termogravimetria/Termogravimetria derivada (TG/DTG)}

As curvas TG/DTG foram obtidas no Laboratório de Análise Térmica Prof. Dr. Ivo Giolito do IQ-USP, utilizando uma termobalança modelo TGA-50 (Shimadzu), de 25 a $900^{\circ} \mathrm{C}$, sob atmosferas dinâmicas de ar e nitrogênio, com vazão de $50 \mathrm{~mL} \mathrm{~min}^{-1}$, massa de amostra de aproximadamente $5 \mathrm{mg}$, cadinho de platina e razão de aquecimento de $10^{\circ} \mathrm{C} \mathrm{min}^{-1}$.

As curvas DTG foram obtidas calculando-se a derivada primeira das curvas TG.

A termobalança foi periodicamente calibrada em massa (padrão de $100 \mathrm{mg}$ ), de acordo com as especificações do fabricante [7].

A calibração foi confirmada utilizando-se uma amostra padrão de $\mathrm{CaC}_{2} \mathrm{O}_{4} \cdot \mathrm{H}_{2} \mathrm{O}$, que apresenta três etapas de perdas de massa em intervalos de temperatura bem definidos [8]. 


\subsubsection{2- Calorimetria exploratória diferencial (DSC)}

As curvas DSC foram obtidas no Laboratório de Análise Térmica Prof. Dr. Ivo Giolito do IQ-USP, utilizando os equipamentos modelo DSC-50 do sistema TA 4000 (Mettler) ou DSC-50 da (Shimadzu), nas seguintes condições:

(a) De 25 a $600^{\circ} \mathrm{C}$, atmosfera dinâmica de nitrogênio $\left(50 \mathrm{~mL} \mathrm{~min}{ }^{-1}\right)$, massa de amostra de aproximadamente $2 \mathrm{mg}$, cápsula de alumínio aberta e/ou fechada, e razão de aquecimento de $10^{\circ} \mathrm{C} \mathrm{min}^{-1}$;

(b) De -100 a $25^{\circ} \mathrm{C}$, atmosfera dinâmica de nitrogênio ( $50 \mathrm{~mL} \mathrm{~min}^{-1}$ ), massa de amostra de aproximadamente $20 \mathrm{mg}$, cápsula de alumínio fechada e razões de aquecimento e resfriamento de $10^{\circ} \mathrm{C} \mathrm{min}^{-1}$. Para estas medidas utilizou-se o sistema LTC-50 (shimadzu), que permite operar em intervalos de temperaturas mais baixos (-150 a $300^{\circ} \mathrm{C}$ );

(c) De 25 a $200^{\circ} \mathrm{C}$, atmosfera dinâmica de nitrogênio $\left(50 \mathrm{~mL} \mathrm{~min}{ }^{-1}\right)$, massa de amostra de aproximadamente $20 \mathrm{mg}$, cápsula de alumínio fechada e razões de aquecimento e resfriamento de $10^{\circ} \mathrm{C} \mathrm{min}^{-1}$.

Ambos os equipamentos foram calibrados, periodicamente, utilizando-se índio metálico de pureza $99,99 \%$, o qual apresenta temperatura de fusão $\left(T_{f}\right)$ em $156,6^{\circ} \mathrm{C}$ e valor de entalpia de fusão $\left(\Delta \mathrm{H}_{\mathrm{f}}\right)$ igual a $28,45 \mathrm{~J} \mathrm{~g}^{-1}$. $\mathrm{O}$ procedimento utilizado foi o recomendado pelos fabricantes $[9,10]$.

\subsubsection{3- Análise térmica diferencial (DTA)}

As curvas DTA para os acetatos simples e binários foram obtidas no Laboratório de Geologia Geral do IG-USP, utilizando o sistema SDT 2960 (TA Instruments), nas seguintes condições: de 25 a $1350^{\circ} \mathrm{C}$, sob atmosfera dinâmica de ar $\left(50 \mathrm{~mL} \mathrm{~min}{ }^{-1}\right)$, massas de amostra e referência $\left(\alpha-\mathrm{Al}_{2} \mathrm{O}_{3}\right.$ altamente sinterizada) de aproximadamente 20 $\mathrm{mg}$, cadinhos de cerâmica e razão de aquecimento de $10^{\circ} \mathrm{C} \min ^{-1}$.

O equipamento foi calibrado, periodicamente, utilizando-se índio e zinco metálicos de pureza $99,99 \%$, que apresentam temperatura de fusão em 156,6 e $419,7^{\circ} \mathrm{C}$, respectivamente. $O$ procedimento utilizado foi o recomendado pelo fabricante [11]. 


\subsubsection{4- Termogravimetria/análise térmica diferencial - cromatografia gasosa/espectrometria de massa (TG/DTA-GC/MS)}

A análise dos produtos voláteis libertados na decomposição térmica do acetato de níquel tetraidratado, foi executada no Laboratónio de Análise Térmica Prof. Dr. Ivo Giolito do IQ-USP, utilizando o equipamento DTG-GC/MS (Shimadzu). Este equipamento corresponde ao sistema simultâneo de TG/DTA (modelo DTG-50H) acoplado ao sistema de cromatografia a gás (modelo GC-14B) e espectrometria de massa (modelo QP-5000). A Figura 2.3 mostra a configuração geral deste sistema. Nesta análise utilizou-se as seguintes condições experimentais:

(a) TG/DTA: de 25 a $900^{\circ} \mathrm{C}$, atmosfera dinâmica de $\mathrm{He}\left(50 \mathrm{~mL} \mathrm{~min}{ }^{-1}\right)$, massas de amostra e referência de aproximadamente $0,3 \mathrm{mg}$, cadinhos de alumina e razão de aquecimento de $40^{\circ} \mathrm{C} \mathrm{min}^{-1}$;

(b) GC/MS: de $80^{\circ} \mathrm{C}$ (mantida por $2 \mathrm{~min}$ ) a $250^{\circ} \mathrm{C}$ (mantida por $10 \mathrm{~min}$ ), vazão de $\mathrm{He}$ (50 $\left.\mathrm{mL} \mathrm{min}^{-1}\right)$, coluna cromatográfica empacotada, contendo como fase estacionária o adsorvente tipo Tenax TA (60/80 mesh), razão de aquecimento de $40^{\circ} \mathrm{C} \mathrm{min}^{-1} \mathrm{e}$ relação massa/carga de 20 a 200

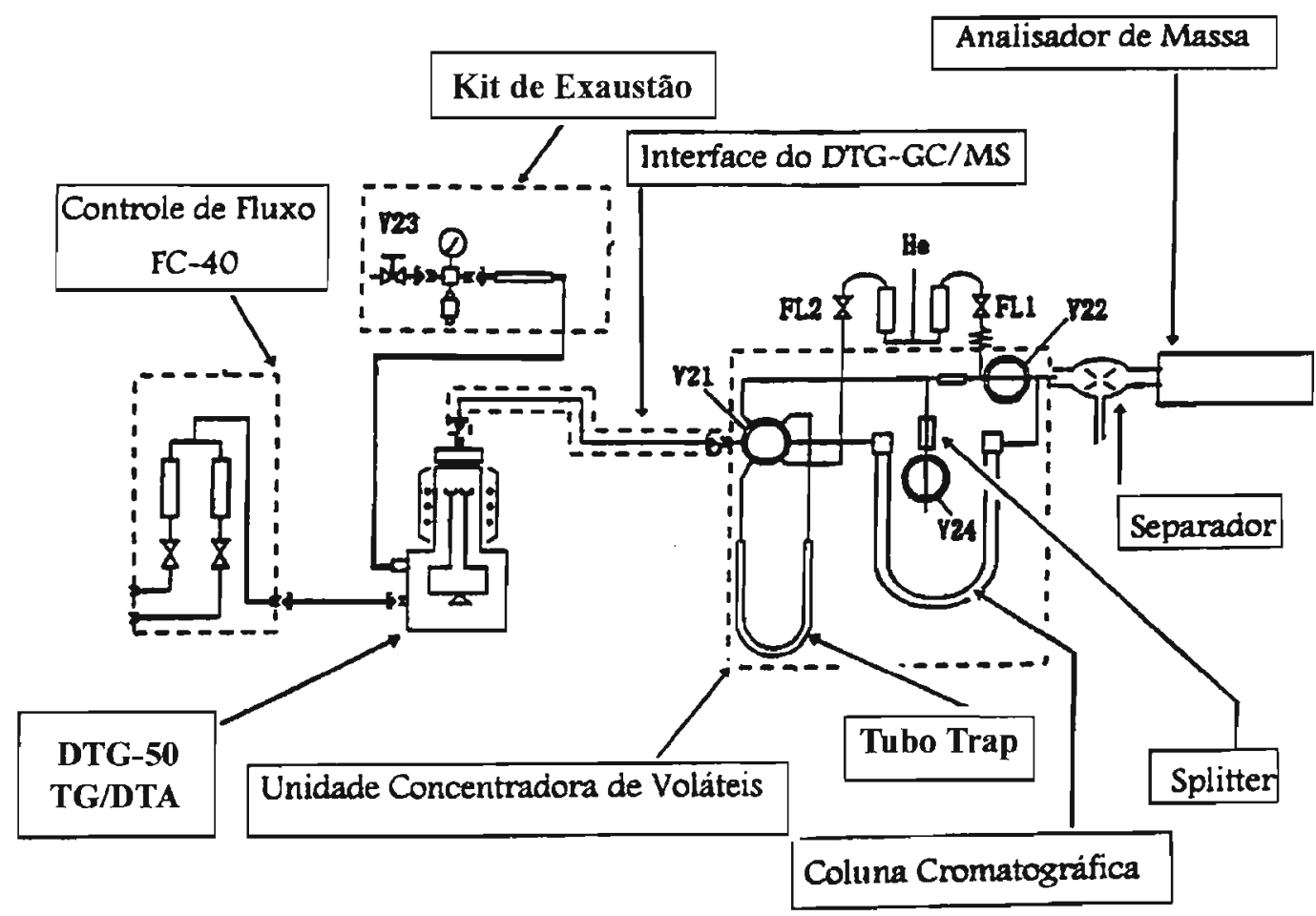

Figura 2.3: Representação esquemática do sistema TG/DTA-GC/MS 


\section{5- PROPRIEDADES: Teste Catalítico}

A atividade catalítica de uma amostra de $\mathrm{La}_{2} \mathrm{NiO}_{4}$ foi avaliada por meio de reação modelo, de desidratação e/ou desidrogenação do isopropanol.

Este ensaio foi realizado no Laboratório de Catálise do Departamento de Química da UFRN, utilizando um microrreator catalítico de pulso (Figura 2.5). As condições experimentais foram: massa de amostra de 25,0 mg; vapor de isopropanol carregado por um fluxo de nitrogênio; velocidade espacial (WHSV) de 2,5 $\mathrm{h}^{-1}$; temperatura de $300^{\circ} \mathrm{C}$ e tempo de reação de $5,15,30,45,60,75$ e $90 \mathrm{~min}$.

A taxa de formação dos produtos foi monitorada utilizando um fluxímetro de bolhas. As concentrações dos produtos foram determinadas por cromatografia a gás, utilizando o cromatógrafo modelo CG-25, com detector de condutividade térmica, empregando-se uma coluna empacotada utilizando fase estacionária, Carbowax 10\% suportada em Chromossorb $\mathrm{P}$, utilizando nitrogênio como gás de arraste $\left(30 \mathrm{~mL} \mathrm{~min}^{-1}\right)$.

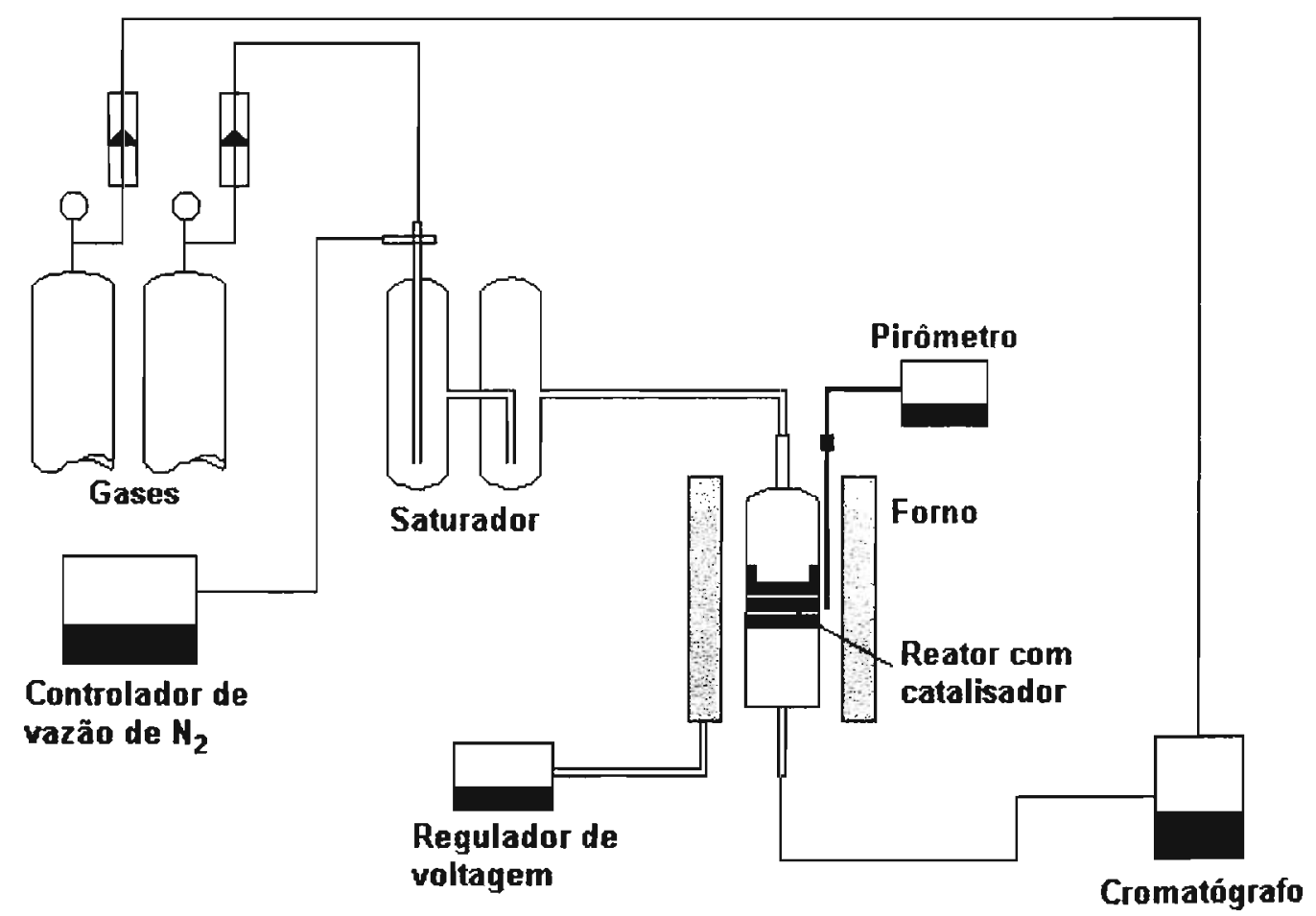

Figura 2.4: Esquema do microrreator catalítico de pulso acoplado a um cromatógrafo a gás. 


\section{6- Referências bibliográficas}

1- J. M. Luiz, "Hidroxicarbonatos de terras raras: estudo termoanalítico de sistemas simples e binários". Tese de Doutoramento - Instituto de Química - USP, 1995.

2- N. Purdie, M. M. Farrow, Coord. Chem. Rev. 11, 189 (1973).

3- J. Korbl, R. Pribil, Chemist Analyst 45, 102 (1956).

4- J. Kinnunen, B. Wennerstrand, Chemist Analyst 46, 92 (1957)

5- $\quad$ S. L. Lyle, M. M. Rahman, Talanta 10, 1177 (1963).

6- Powder Diffraction File of the Joint Commitee on Powder Diffraction Data (International Centre for Diffraction Data, Swarthmore, PA, 1996).

7- Shimadzu Corporation, Thermogravimetric Analyser TGA-50, Manual de Instruções.

8- W. W. Wendlandt, Thermal Analysis, $3^{\text {rd }}$ edition (1985). Wiley, New York.

9- Mettler TA 4000 System - DSC 50, Manual de Instruções.

10- Shimadzu Corporation, Differential Scanning Calorimetry - DSC 50, Manual de Instruções.

11- TA Instruments - STD 2960, Manual de Instruções. 


\section{Capítulo}

\section{Resultados e Discussão}

Neste capítulo são apresentados os resultados juntamente com as discussões pertinentes, com o objetivo de tornar o trabalho mais inteligível e sequenciado. Ele foi divido em duas partes: (i) resultados para a obtenção dos óxidos $\mathrm{TR}_{2} \mathrm{NiO}_{4}[\mathrm{TR}=\mathrm{La}, \mathrm{Eu}$ e Y (III)] e (ii) resultados para a obtenção dos óxidos $\mathrm{TRNiO}_{3}[\mathrm{TR}=\mathrm{Pr}, \mathrm{Nd}$ e Sm (III) $]$.

\section{Parte 1}

- Hidroxicarbonatos de terras raras

- Acetatos de terras raras

- Acetato de niquel

- Acctatos bintirios

\section{Parte 2}

- Sistema Nd:Ni

- Sistema Sm:Ni

- Sistema Pr:Ni

Referências Biblioggáficas 


\section{PARTE 1}

\section{1- Hidroxicarbonatos de terras raras}

Vários estudos sobre a caracterização dos hidroxicarbonatos de terras raras, TROHCO $3 . \mathrm{xH}_{2} \mathrm{O}$, foram realizados por técnicas de espectroscopia de absorção na região do infravermelo, difração de raios $X$ e análise térmica [1-7]. No presente trabalho, os $\mathrm{TROHCO}_{3} \cdot \mathrm{xH}_{2} \mathrm{O}[\mathrm{TR}=\mathrm{La}, \mathrm{Eu}$ e $\mathrm{Y}$ (III)] foram preparados para serem usados como precursores dos respectivos acetatos. A caracterização foi realizada apenas por termogravimetria, com os objetivos de determinar o grau de hidratação e estudar a estabilidade térmica.

Baseando-se nos cálculos de variação de massa observados nas curvas TG/DTG, foi possivel determinar a estequiometria dos hidroxicarbonatos de terras raras (Tabela 3.1), uma vez que os produtos finais da decomposição térmica são os respectivos óxidos. As pequenas diferenças observadas, maior para o composto de ítrio, podem ser atribuídas a diversos fatores, tais como acidez do ín terra rara, granulometria da amostra, umidade relativa, e ainda pode ocorrer a formação de hidroxicarbonatos em que a relação estequiométrica entre os íons $\mathrm{OH}$ e $\mathrm{CO}_{3}{ }^{2-}$ seja diferente de $1: 1$ [7].

Tabela 3.1: Dados percentuais referentes aos intermediários sólidos formados na decomposição térmica dos hidroxicarbonatos de terras raras

\begin{tabular}{l|c|c|c|c|c|c}
\hline \multirow{2}{*}{$\mathrm{TROHCO}_{3} \cdot \mathrm{xH}_{2} \mathrm{O}$} & \multicolumn{2}{|c|}{$\mathrm{TROHCO}_{3}$} & \multicolumn{2}{c|}{$\mathrm{TR}_{2} \mathrm{O}_{2} \mathrm{CO}_{3}$} & \multicolumn{3}{c}{$\mathrm{TR}_{2} \mathrm{O}_{3}$} \\
\cline { 2 - 7 } & $\%$ calc. & $\%$ exp. & \% calc. & $\%$ exp. & \% calc. & $\%$ exp. \\
\cline { 2 - 7 } & - & - & 85,12 & 84,7 & 75,61 & 75,0 \\
$\mathrm{LaOHCO}_{3}$ & - & - & 86,46 & 86,0 & 76,85 & 77,1 \\
$\mathrm{YOHCO}_{3} \cdot \mathrm{H}_{2} \mathrm{O}$ & 90,21 & 89,5 & n. o. & n. o. & 61,38 & 61,0 \\
\hline
\end{tabular}

TR: terras raras; calc.: calculada; exp.: experimental; n. o.: não observado

A Figura 3.1 apresenta as curvas TG/DTG do $\mathrm{LaOHCO}_{3}$. Este sal foi obtido anidro e apresentou-se termicamente estável até $420^{\circ} \mathrm{C}$. A decomposição térmica ocorreu em duas etapas bem definidas, com temperaturas de pico na curva DTG em 481 e $698^{\circ} \mathrm{C}$, para formar o $\mathrm{La}_{2} \mathrm{O}_{2} \mathrm{CO}_{3}$ e o produto final $\mathrm{La}_{2} \mathrm{O}_{3}$, respectivamente. 


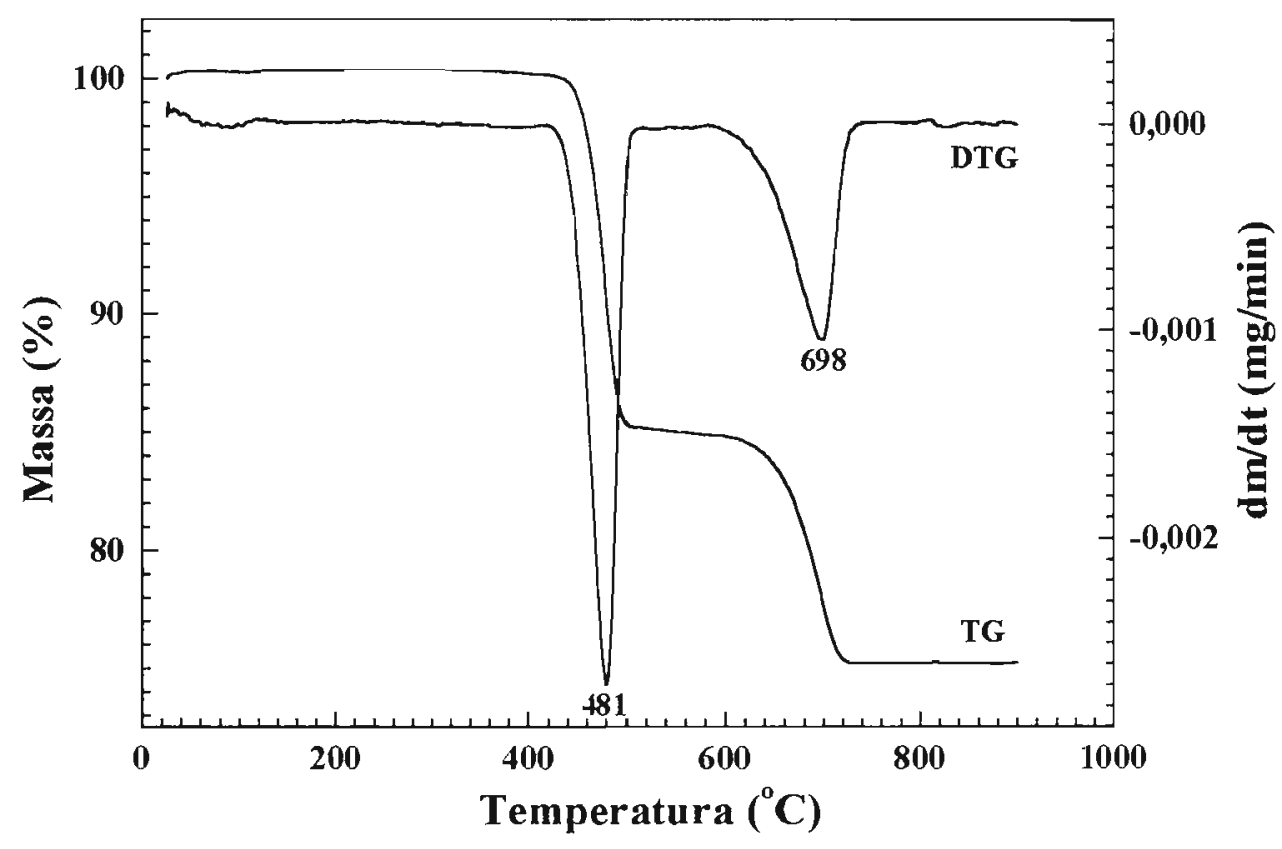

Figura 3.1: Curvas TG/DTG do $\mathrm{LaOHCO}_{3}$ obtidas sob atmosfera dinâmica de ar $\left(50 \mathrm{~mL} \mathrm{~min}{ }^{-1}\right)$, razão de aquecimento de $10^{\circ} \mathrm{C} \mathrm{min}^{-1}$, cadinho de platina e massa da amostra de 5,648 $\mathrm{mg}$.

A Figura 3.2 apresenta as curvas TG/DTG do $\mathrm{EuOHCO}_{3}$. Este sal, similarmente ao $\mathrm{LaOHCO}_{3}$, foi obtido anidro e apresentou-se termicamente estável até $420^{\circ} \mathrm{C}$. Observou-se que a decomposição ocorreu em três etapas, com temperaturas de picos na curva DTG em 508,605 e $672^{\circ} \mathrm{C}$, formando $\mathrm{Eu}_{2} \mathrm{O}_{2} \mathrm{CO}_{3}$ em $540^{\circ} \mathrm{C}$ e $\mathrm{Eu}_{2} \mathrm{O}_{3}$ a partir de $700^{\circ} \mathrm{C}$.

A Figura 3.3 apresenta o processo de decomposição térmica do $\mathrm{YOHCO}_{3} \cdot \mathrm{H}_{2} \mathrm{O}$. As curvas TG/DTG evidenciaram uma perda de massa entre 25 e $200^{\circ} \mathrm{C}$, relativa à desidratação do sal. $\mathrm{O} \mathrm{YOHCO}_{3}$ apresentou baixa estabilidade térmica, decompondo-se gradativamente até $600^{\circ} \mathrm{C}$, quando a decomposição térmica tornou-se mais rápida. Não foi possível observar por TG/DTG a formação do intermediário $\mathrm{Y}_{2} \mathrm{O}_{2} \mathrm{CO}_{3}$, pois a estabilidade térmica dos dioxicarbonatos de terras raras decresce, à medida que diminui o raio do íon terra rara $\left(\mathrm{TR}^{3+}\right)$. A partir de $840^{\circ} \mathrm{C}$, os cálculos de variação de massa sugeriram a formação de $\mathrm{Y}_{2} \mathrm{O}_{3}$. Estes resultados foram confirmados por XRD. Na Figura 3.4 a, b, c estão apresentados os difratogramas de raios $\mathrm{X}$, relativos aos intermediários sólidos, da decomposição térmica dos hidroxicarbonatos isolados em $500^{\circ} \mathrm{C}$. Os resultados confirmaram a formação dos compostos $\mathrm{La}_{2} \mathrm{O}_{2} \mathrm{CO}_{3}, \mathrm{Eu}_{2} \mathrm{O}_{2} \mathrm{CO}_{3} \mathrm{e}$, provavelmente, $\mathrm{Y}_{2} \mathrm{O}_{2} \mathrm{CO}_{3}$, respectivamente [8]. 


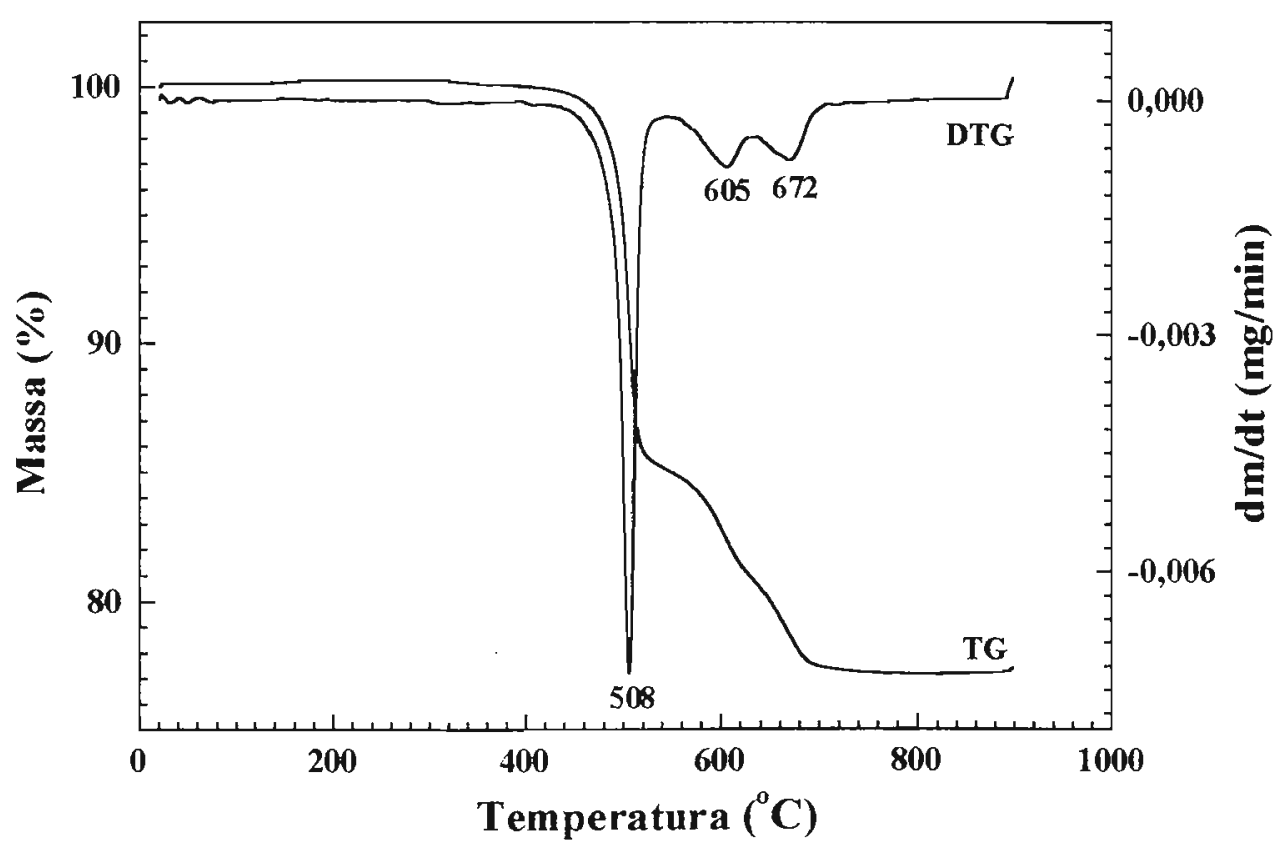

Figura 3.2: Curvas TG/DTG do $\mathrm{EuOHCO}_{3}$ obtidas sob atmosfera dinâmica de ar $\left(50 \mathrm{~mL} \mathrm{~min}^{-1}\right)$, razão de aquecimento de $10^{\circ} \mathrm{C} \mathrm{min}^{-1}$, cadinho de platina e massa da amostra de $5,403 \mathrm{mg}$.

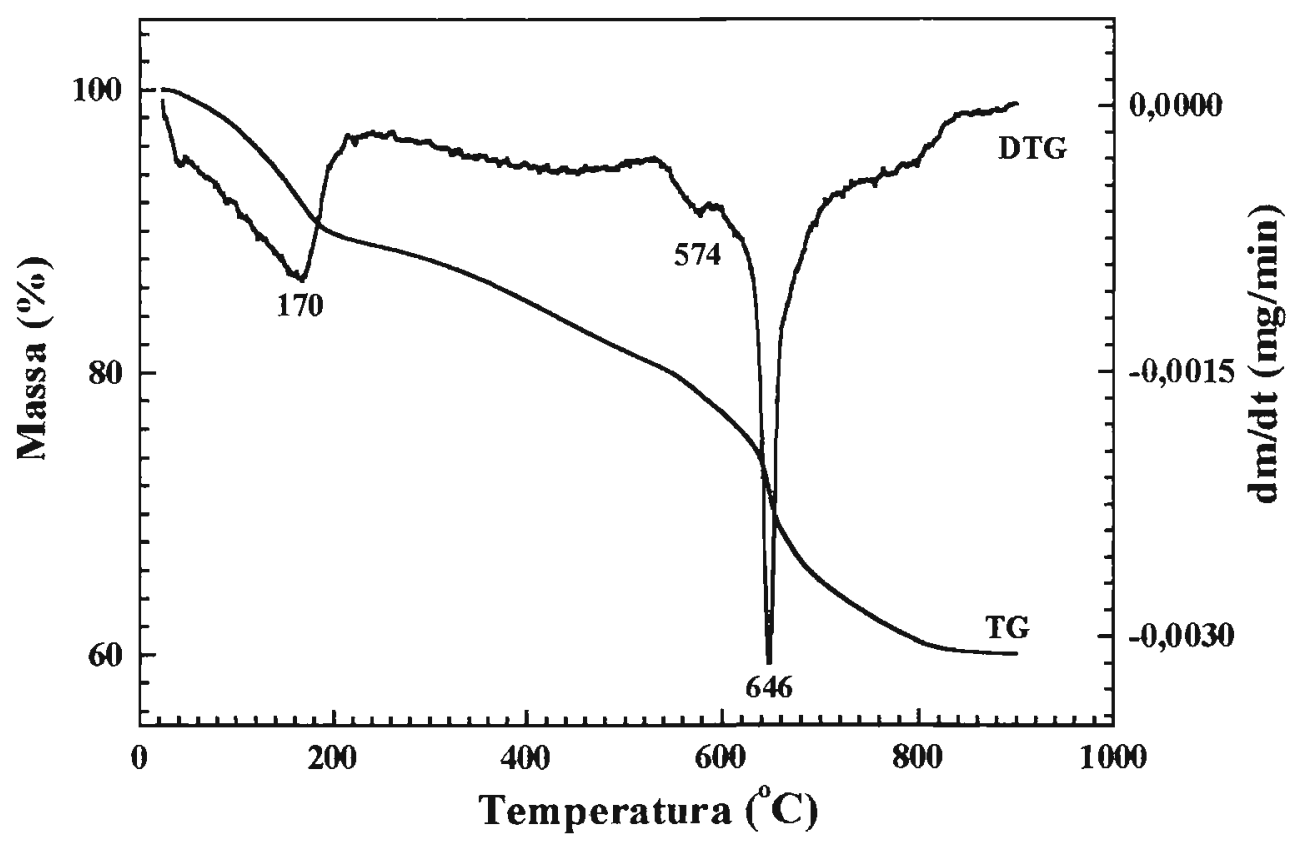

Figura 3.3: Curvas TG/DTG do $\mathrm{YOHCO}_{3} \cdot \mathrm{H}_{2} \mathrm{O}$ obtidas sob atmosfera dinâmica de ar $(50 \mathrm{~mL}$ $\min ^{-1}$ ), razão de aquecimento de $10^{\circ} \mathrm{C} \mathrm{min}^{-1}$, cadinho de platina e massa da amostra de $5,932 \mathrm{mg}$. 


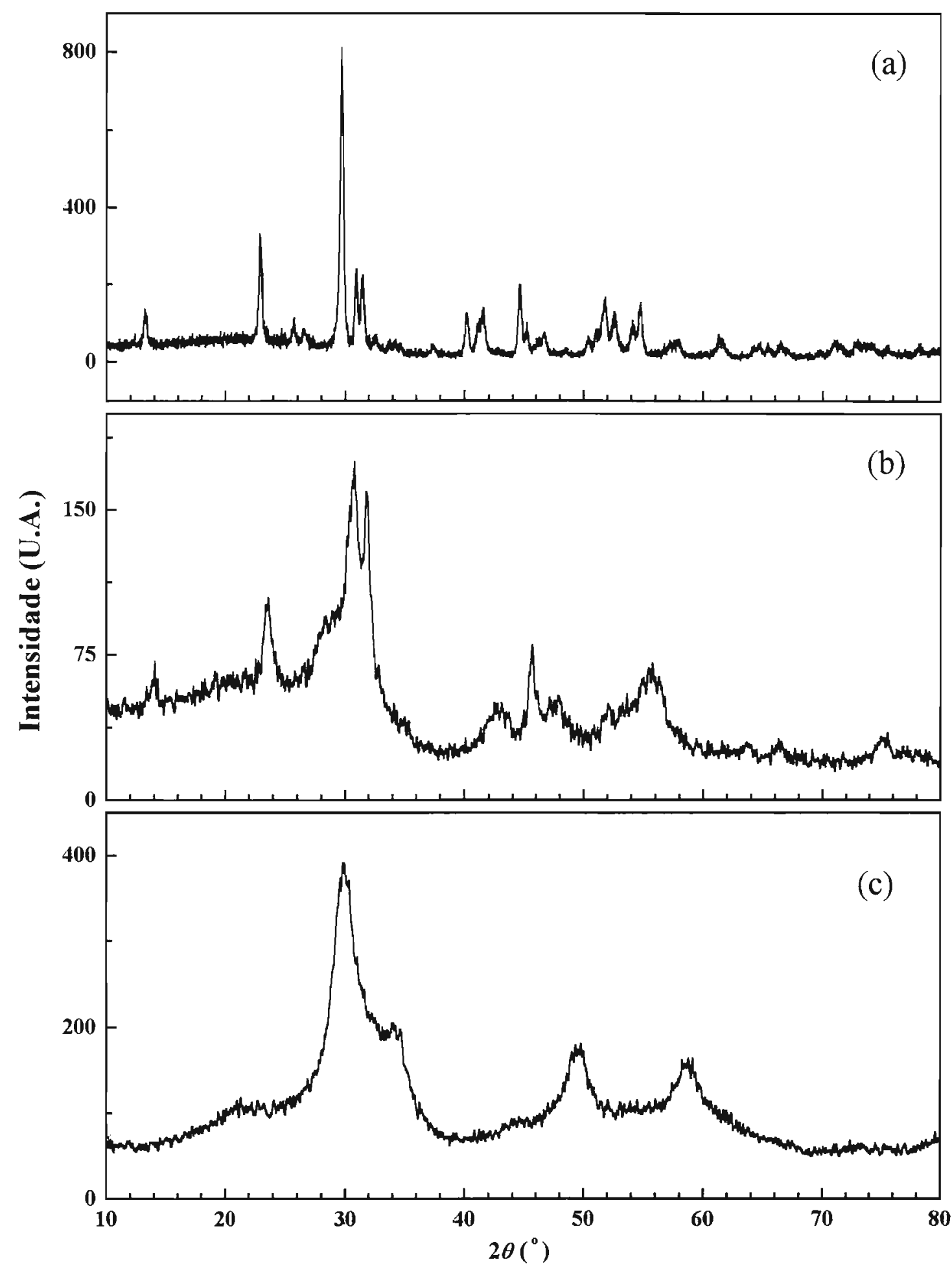

Figura 3.4: Difratogramas de raios $X$ (método do pó) para os intermediários da decomposição térmica isolados em $550^{\circ} \mathrm{C}$, sob atmosfera dinâmica de ar $\left(50 \mathrm{~mL} \mathrm{~min}^{-1}\right)$, razão de aquecimento de $10^{\circ} \mathrm{C} \mathrm{min}^{-1}$ e cadinho de platina dos compostos: (a) $\mathrm{LaOHCO}_{3}$; (b) $\mathrm{EuOHCO}_{3}$; (c) $\mathrm{YOHCO}_{3} \cdot \mathrm{H}_{2} \mathrm{O}$. 


\section{2- Acetatos de terras raras}

$\mathrm{Na}$ literatura existem vários estudos envolvendo, síntese, propriedades físicoquímicas e estrutura dos acetatos de terras raras [9-23], assim como estudos sobre o comportamento térmico que utilizam as técnicas de análise térmica, TG/DTG, DTA e DSC $[14,22,24-26]$. No entanto, a caracterização e o estudo termoanalítico dos acetatos de terras raras, $\mathrm{TR}\left(\mathrm{CH}_{3} \mathrm{COO}\right)_{3} \cdot \mathrm{xH}_{2} \mathrm{O}$ [TR $=\mathrm{La}, \mathrm{Eu}$ e Y (III)], e acetato de níquel, $\mathrm{Ni}\left(\mathrm{CH}_{3} \mathrm{COO}\right)_{2} \cdot 4 \mathrm{H}_{2} \mathrm{O}$, tornaram-se fundamentais neste trabalho, pois possibilitaram uma melhor interpretação dos dados relativos aos sistemas binários.

\subsection{1- Análise elementar}

Os acetatos de terras raras, $\mathrm{TR}\left(\mathrm{CH}_{3} \mathrm{COO}\right)_{3} \cdot \mathrm{xH}_{2} \mathrm{O}[\mathrm{TR}=\mathrm{La}$, Eu e Y (III)], foram obtidos como sais hidratados. Os resultados de análise elementar $(\mathrm{C}, \mathrm{H}, \mathrm{TR})$ revelaram a estequiometria dos sais e estão apresentados na Tabela 3.2. Os teores de terras raras foram obtidos a partir da complexometria com EDTA e das curvas TG/DTG.

Tabela 3.2: Resultados de análise elementar para os acetatos de terras raras

\begin{tabular}{l|c|c|c|c|c|c|c}
\hline \multirow{2}{*}{$\begin{array}{l}\text { COMPOSTO } \\
\text { TR(Ac) })_{3} \cdot \mathbf{x H}_{2} \mathbf{O}\end{array}$} & \multicolumn{3}{|c|}{ \% CALCULADA } & \multicolumn{4}{c}{ \% EXPERIMENTAL } \\
\cline { 2 - 8 } & $\mathbf{C}$ & $\mathbf{H}$ & $\mathbf{T R}$ & $\mathbf{C}$ & $\mathbf{H}$ & $\mathbf{T R}^{\mathbf{a}}$ & $\mathbf{T R}^{\mathrm{b}}$ \\
\hline $\mathrm{La}(\mathrm{Ac})_{3} \cdot 1,5 \mathrm{H}_{2} \mathrm{O}$ & 21,00 & 3,53 & 40,49 & 20,6 & 3,5 & 39,5 & 40,3 \\
$\mathrm{Eu}(\mathrm{Ac})_{3} .4 \mathrm{H}_{2} \mathrm{O}$ & 17,96 & 4,27 & 37,88 & 17,9 & 4,2 & 38,5 & 38,0 \\
$\mathrm{Y}(\mathrm{Ac})_{3} .4 \mathrm{H}_{2} \mathrm{O}$ & 21,31 & 5,07 & 26,30 & 21,3 & 5,0 & 26,1 & 25,8 \\
\hline
\end{tabular}

TR: terra rara; Ac: íon acetato $\left(\mathrm{CH}_{3} \mathrm{COO}^{-}\right)$; $\mathbf{x}$ : grau de hidratação; ${ }^{2}$ obtido por complexometria; b obtido por TG/DTG (valor médio).

\subsection{2- Espectroscopia de absorção na região do infravermelho}

$\mathrm{O}$ íon acetato livre tem simetria $\mathrm{C}_{2 \mathrm{v}}$ e apresenta 15 modos fundamentais ativos no infravermelho, dos quais os modos assimétricos (as.) e simétricos (s.) do grupo carboxila $\left(\mathrm{COO}^{-}\right)$tem sido empregados para estudos estruturais. 
No estado sólido, os acetatos metálicos têm sido estudados por difração de raios $\mathrm{X}$ e espectroscopia de absorção na região do infravermelho, mostrando que o grupo acetato pode agir como ânion não coordenado (iônico), ligante monodentado, bidentado quelato (formando um anel de quatro membros) ou ponte entre dois átomos metálicos (com possibilidade de formar ligação metal-metal) e como ligante polimérico (Figura $3.5)$.

Iônico

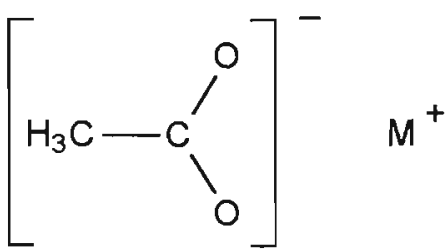

Monodentado<smiles>[M]OC(C)=O</smiles><smiles>[M]OC(C)O[M]</smiles>

Polimérico

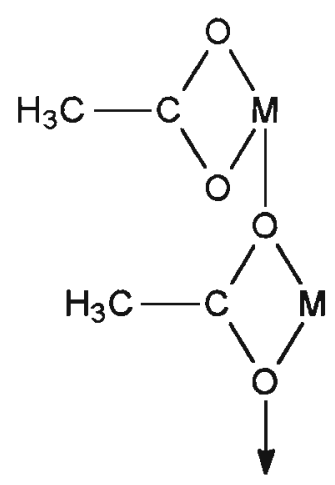

Figura 3.5: Representação das formas de coordenação do ânion acetato.

Nakamoto discute o uso da diferença entre as freqüências de estiramento assimétrico e simétrico do grupo carboxila $\left(\Delta v=v_{\text {as. }}-v_{\mathrm{s}}\right)$, para determinar o tipo de ligação presente no acetato metálico [23]. 
A aplicação desta correlação para a identificação do modo de coordenação, nos acetatos metálicos tem sido muito discutida $[12,14,17]$. Três fatores têm sido sugeridos serem fundamentais na determinação dos valores delta para os acetatos no estado sólido, são a polaridade da ligação metal-oxigênio, o tamanho do cátion e o ângulo da ligação $\mathrm{O}-\mathrm{C}-\mathrm{O}[12,19]$.

Em 1980, Deacon e Phillips [20] estudaram cerca de setenta complexos de acetatos metálicos, dos quais eram conhecidos os dados de infravermelho e raios $\mathrm{X}$, necessários para avaliar os valores de $\Delta v$, na determinação da natureza da coordenação do acetato. Eles concluíram que valores de $\Delta v$ substancialmente maiores do que o valor iônico $\left(\Delta v=164 \mathrm{~cm}^{-1}\right)$ indicavam coordenação monodentada para o acetato, enquanto que valores delta significativamente menores do que o valor iônico, indicavam coordenação bidentada ou polimérica, embora o inverso não seja verdadeiro. Isto sugere que a correlação básica somente pode ser válida sob condições especiais e a relação entre a coordenação do grupo acetato e as freqüências do grupo carboxilato podem não ser facilmente explicadas.

Estudos anteriores sugeriram para os acetatos de terras raras leves (La-Eu) o modo de coordenação bidentado, onde os valores de $\Delta v$ observados eram significativamente menores que o valor iônico, enquanto coordenação monodentada foi sugerida para os acetatos de terras raras pesados (Dy-Lu e Y), os quais exibiram valores de $\Delta v$ muito maiores que o valor iônico [16]. Em adição, Karraker [18] sugeriu que o desdobramento da banda $v_{\mathrm{s}}$ da carboxila era indicativo de diferentes modos de coordenação do grupo acetato.

Neste estudo, os espectros IR dos acetatos de terras raras foram obtidos com o objetivo de estudar a natureza da ligação metal-acetato e auxiliar na caracterização dos sistemas binários. Na Tabela 3.3 estão apresentadas as freqüências de absorção e as atribuições das bandas dos espectros IR, que foram designadas de acordo com Karraker [18].

A Figura 3.6 apresenta os espectros $\mathbb{R}$ dos acetatos de terras raras. As principais diferenças observadas foram as seguintes:

(a) As vibrações de deformação de ângulo das moléculas de água coordenada ( $\delta \mathrm{OH})$ apareceram em $1683 \mathrm{~cm}^{-1}$ para o acetato de lantânio e em 1678 e $1680 \mathrm{~cm}^{-1}$ para os 
acetatos de európio e ítrio (média dos valores). Estas absorções evidenciam que os sais foram obtidos hidratados;

(b) As vibrações de $v_{\text {as. }}\left(\mathrm{COO}^{-}\right)$e $v_{\mathrm{s}}\left(\mathrm{COO}^{-}\right)$ocorreram, respectivamente, em 1563 e 1451-1428 $\mathrm{cm}^{-1}$ para o acetato de lantânio; em 1544 e $1456 \mathrm{~cm}^{-1}$ para o acetato de európio; em 1550 e $1459 \mathrm{~cm}^{-1}$ para o acetato de ítrio;

(c) As vibrações $\rho\left(\mathrm{CH}_{3}\right)$ foram observadas em 1054 e $1018 \mathrm{~cm}^{-1}$ para o acetato de lantânio; em 1051 e $1022 \mathrm{~cm}^{-1}$ para os acetatos de európio e ítrio.

Tabela 3.3: Atribuição das bandas de absorção dos espectros IR dos acetatos de terras raras (número de onda, $\mathrm{cm}^{-1}$ ) *

\begin{tabular}{|c|c|c|c|}
\hline ATRIBUIÇÃO & $\mathrm{La}(\mathrm{Ac})_{3} .1,5 \mathrm{H}_{2} \mathrm{O}$ & $\mathrm{Eu}(\mathrm{Ac})_{3 .} \mathbf{4} \mathrm{H}_{2} \mathrm{O}$ & 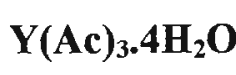 \\
\hline$v(\mathrm{O}-\mathrm{H})$ & $3323(\mathrm{~m})$ & $3330(\mathrm{mF})$ & $3312(\mathrm{mF})$ \\
\hline$\nu_{\text {as. }}(\mathrm{C}-\mathrm{H})$ & $3011(0)$ & $3050(0)$ & $3040(0)$ \\
\hline$\nu_{\text {s. }}(\mathrm{C}-\mathrm{H})$ & $2940(0)$ & 2944 (o) & $2944(0)$ \\
\hline$\delta(\mathrm{OH})$ & $1683(f)$ & $\begin{array}{l}1695(\mathrm{~m}) \\
1661(\mathrm{~m})\end{array}$ & $\begin{array}{l}1698(\mathrm{~m}) \\
1662(\mathrm{~m})\end{array}$ \\
\hline$v_{\text {as. }}\left(\mathrm{COO}^{\prime}\right)$ & $1563(f)$ & $1544(\mathrm{mF})$ & $1550(\mathrm{mF})$ \\
\hline$v_{\mathrm{s}}\left(\mathrm{COO}^{\circ}\right)$ & $\begin{array}{l}1451(\mathrm{mF}) \\
1428(\mathrm{mF})\end{array}$ & $1456(\mathrm{mF})$ & $1459(\mathrm{mF})$ \\
\hline$\delta_{\text {as. }}\left(\mathrm{CH}_{3}\right)$ & $1407(\mathrm{~F})$ & $1418(\mathrm{mF})$ & $1418(\mathrm{~F})$ \\
\hline$\delta_{\mathrm{s} .}\left(\mathrm{CH}_{3}\right)$ & $\begin{array}{l}1351(\mathrm{o}) \\
1337(\mathrm{~m})\end{array}$ & $1354(\mathrm{~m})$ & $1354(\mathrm{~m})$ \\
\hline$\rho\left(\mathrm{CH}_{3}\right)$ & $\begin{array}{l}1054(f) \\
1018(f)\end{array}$ & $\begin{array}{c}1051(\mathrm{f}) \\
1022(\mathrm{~m})\end{array}$ & $\begin{array}{l}1052(\mathrm{~m}) \\
1023(\mathrm{~m})\end{array}$ \\
\hline$v(\mathrm{C}-\mathrm{C})$ & 944 (f) & $\begin{array}{l}961(\mathrm{f}) \\
940(\mathrm{~m})\end{array}$ & $\begin{array}{c}967(\mathrm{f}) \\
945(\mathrm{~m})\end{array}$ \\
\hline$\delta\left(\mathrm{COO}^{-}\right)$ & $669(f)$ & $\begin{array}{l}737(F) \\
682(F)\end{array}$ & $\begin{array}{l}742(\mathrm{~F}) \\
686(\mathrm{~F})\end{array}$ \\
\hline$\rho(\mathrm{COO}-)_{\text {fora do plano }}$ & $613(f)$ & $610(\mathrm{~m})$ & $611(\mathrm{~m})$ \\
\hline$\pi(\mathrm{COO}-)_{\text {no plano }}$ & $\begin{array}{l}540(\mathrm{mf}) \\
470(\mathrm{mf})\end{array}$ & $470(f)$ & $470(\mathrm{mf})$ \\
\hline
\end{tabular}

* Nomenclatura das bandas segundo Nakamoto [23]; Ac: ion acetato $\left(\mathrm{CH}_{3} \mathrm{COO}^{-}\right)$; mf: muito fraca $(100-85 \%)$; f: fraca $(85-60 \%)$; m: média $(60-30 \%)$; F: forte (30-10\%); mF: muito forte (10-0 \%); o: ombro 


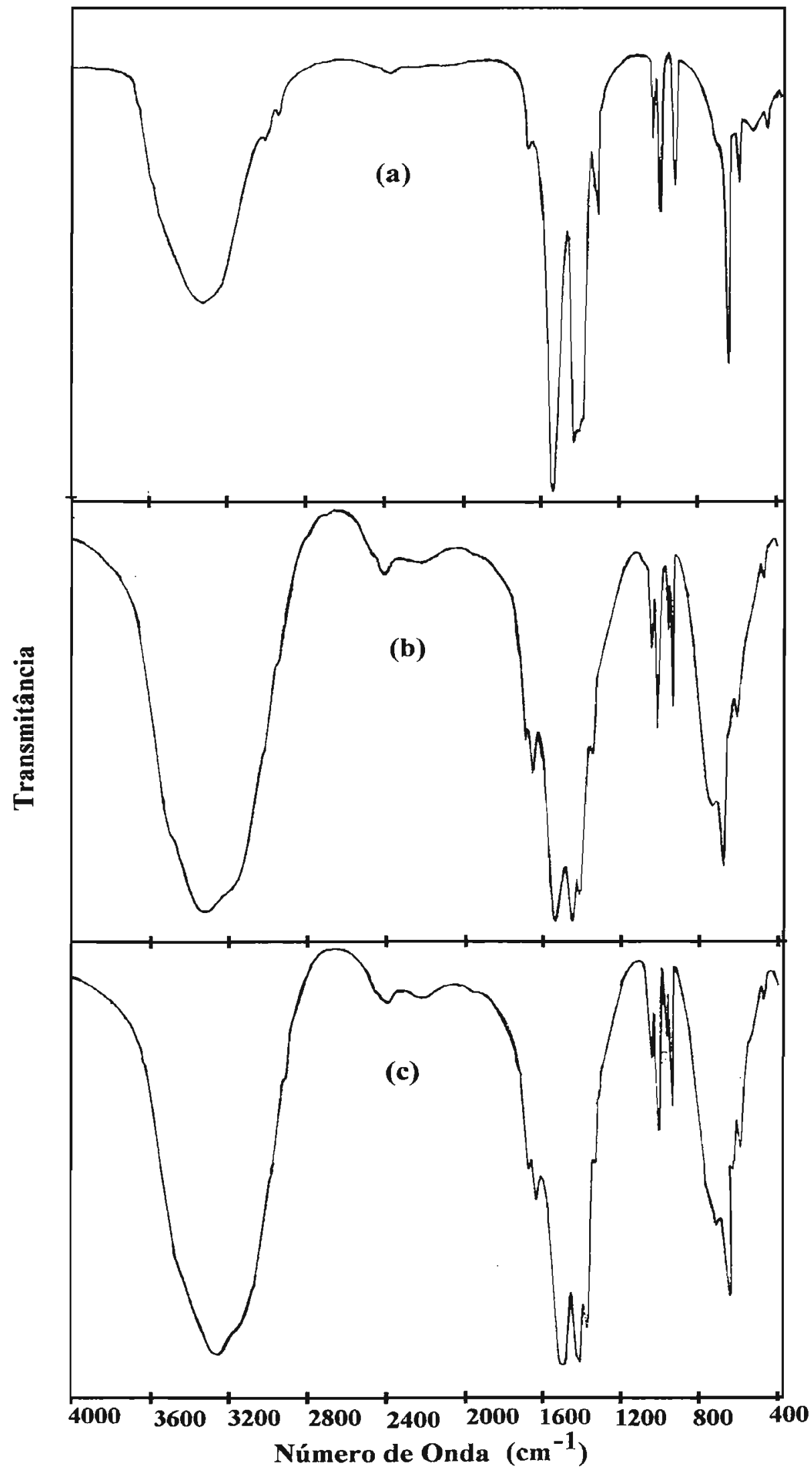

Figura 3.6: Espectros de absorção na região do infravermelho dos compostos:

(a) $\mathrm{La}\left(\mathrm{CH}_{3} \mathrm{COO}\right)_{3} .1,5 \mathrm{H}_{2} \mathrm{O}$; (b) $\mathrm{Eu}\left(\mathrm{CH}_{3} \mathrm{COO}\right)_{3} .4 \mathrm{H}_{2} \mathrm{O}$; (c) $\mathrm{Y}\left(\mathrm{CH}_{3} \mathrm{COO}\right)_{3} .4 \mathrm{H}_{2} \mathrm{O}$ 
Observou-se que os valores de $\Delta v$ para os acetatos de európio e ítrio tetraidratado foram de 87 e $91 \mathrm{~cm}^{-1}$, respectivamente, indicando coordenação bidentada. Para o acetato de lantânio hidratado, o aparecimento de um desdobramento de $v_{\mathrm{s}}$ da carboxila, indicou a presença de dois modos de coordenação. Os valores de $\Delta v$ foram de $111 \mathrm{e} 135 \mathrm{~cm}^{-1}$, indicando coordenação bidentada e polimérica, respectivamente.

\subsection{3- Difração de raios $X$}

A difração de raios X é uma técnica fundamental na caracterização de materiais.

De forma geral, as etapas para a caracterização de um composto são: (i) determinar as principais posições angulares (20), as distâncias interplanares (d) e as intensidades relativas $\left(\mathrm{I} / \mathrm{L}_{0}\right)$ dos picos observados nos difratogramas de raios $\mathrm{X}$; (ii) selecionar as linhas mais intensas e (iii) comparar estes valores com difratogramas ou fichas padrões de um banco de dados. A coincidência dos valores conduz à possível identificação do composto. No entanto, podem aparecer linhas estranhas que podem ser atribuídas a impurezas ou a linhas do próprio composto que, neste caso, não constam na ficha padrão. Essa análise deve ser realizada cuidadosamente, pois, muitas vezes a identificação não é trivial.

A partir desta análise é possível determinar os dados cristalográficos, isto é, sistema cristalino, grupo espacial e índices de Miller de um composto conhecido.

Neste estudo foi utilizado o método do pó, com o objetivo de caracterizar os $\mathrm{TR}\left(\mathrm{CH}_{3} \mathrm{COO}\right)_{3} \cdot \mathrm{xH}_{2} \mathrm{O}[\mathrm{TR}=\mathrm{La}, \mathrm{Eu}$ e $\mathrm{Y}(\mathrm{III})]$, intermediários e produtos sólidos da decomposição térmica, por meio de comparações com fichas padrões do banco de dados JCPDS [8].

A análise dos dados permitiu identificar o sistema triclínico para os três acetatos, grupo espacial $P_{1}$ (2) para $\mathrm{La}\left(\mathrm{CH}_{3} \mathrm{COO}\right)_{3} .1,5 \mathrm{H}_{2} \mathrm{O}$ e $P_{I}(1)$ para $\mathrm{Eu}\left(\mathrm{CH}_{3} \mathrm{COO}\right)_{3} \cdot 4 \mathrm{H}_{2} \mathrm{O}$ e $\mathrm{Y}\left(\mathrm{CH}_{3} \mathrm{COO}\right)_{3} \cdot 4 \mathrm{H}_{2} \mathrm{O}[27,28]$. As comparações com as fichas padrões estão apresentadas na Tabela 3.4. 


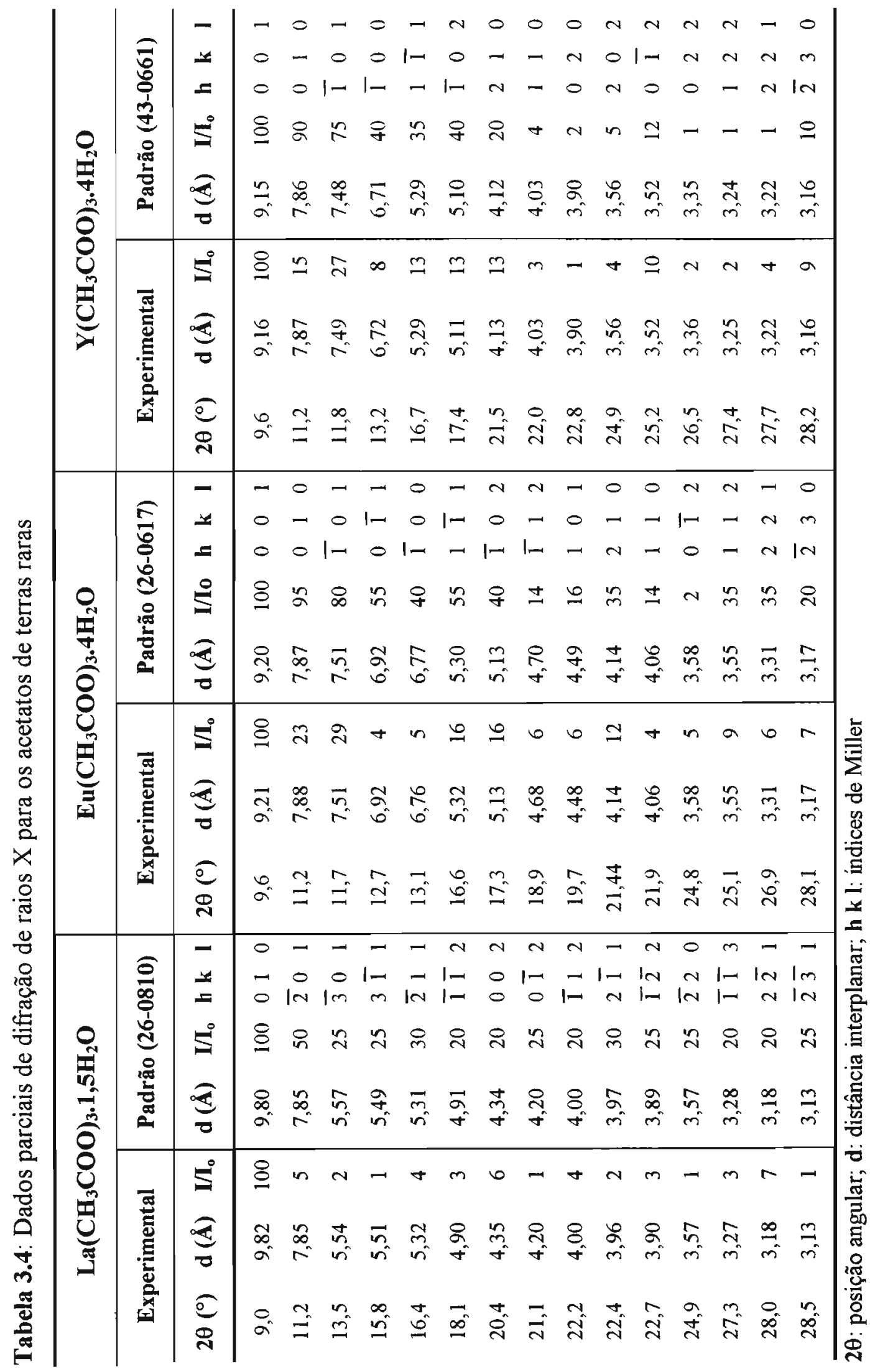




\subsection{4- Análise térmica}

Um estudo termoanalítico preliminar foi realizado utilizando uma amostra de $\mathrm{La}\left(\mathrm{CH}_{3} \mathrm{COO}\right)_{3.1} 1,5 \mathrm{H}_{2} \mathrm{O}$, com o objetivo de definir as melhores condições experimentais para a obtenção das curvas TG/DTG. Nesse estudo definiu-se os parâmetros como razão de aquecimento, vazão de gás, tipo de cadinho e massa de amostra. As condições operacionais foram: $10^{\circ} \mathrm{C} \mathrm{min}^{-1}, 50 \mathrm{~mL} \mathrm{~min}$, platina e $5 \mathrm{mg}$, respectivamente.

\subsubsection{1- Acetato de lantânio}

$\mathrm{O}$ acetato de lantânio foi obtido com estequiometria $\mathrm{La}\left(\mathrm{CH}_{3} \mathrm{COO}\right)_{3} \cdot 1,5 \mathrm{H}_{2} \mathrm{O}$ (Tabela 3.2)

Nas Figuras 3.7 e 3.8 estão apresentadas as curvas TG/DTG, obtidas nas atmosferas dinâmicas de ar e nitrogênio, respectivamente. Estas curvas não evidenciaram diferenças significativas no comportamento térmico do acetato de lantânio, ao mudar a atmosfera atuante.

O processo de decomposição térmica ocorreu em várias etapas. As duas primeiras perdas de massa, com temperaturas de pico nas curvas DTG em 60 e $160^{\circ} \mathrm{C}$, corresponderam, respectivamente, à libertação de $0,5 \mathrm{~mol}(2,63 \%)$ e $1 \mathrm{~mol}$ de água coordenada $(5,25 \%)$. Estas etapas estão representadas pelas equações 3.1 e 3.2 , respectivamente.

$$
\begin{aligned}
& \mathrm{La}\left(\mathrm{CH}_{3} \mathrm{COO}\right)_{3} \cdot 1,5 \mathrm{H}_{2} \mathrm{O}(\mathrm{s}) \rightarrow \mathrm{La}\left(\mathrm{CH}_{3} \mathrm{COO}\right)_{3} \cdot \mathrm{H}_{2} \mathrm{O}(\mathrm{s})+0,5 \mathrm{H}_{2} \mathrm{O}(\mathrm{g}) \\
& \mathrm{La}\left(\mathrm{CH}_{3} \mathrm{COO}\right)_{3} \cdot \mathrm{H}_{2} \mathrm{O}(\mathrm{s}) \rightarrow \mathrm{La}\left(\mathrm{CH}_{3} \mathrm{COO}\right)_{3}(\mathrm{~s})+\mathrm{H}_{2} \mathrm{O}(\mathrm{g})
\end{aligned}
$$

O sal anidro, $\mathrm{La}\left(\mathrm{CH}_{3} \mathrm{COO}\right)_{3}$, apresentou-se termicamente estável entre $180 \mathrm{e}$ $300^{\circ} \mathrm{C}$. Independente da atmosfera atuante, o processo de decomposição deste intermediário ocorreu em três etapas rápidas e consecutivas. Em torno de $400^{\circ} \mathrm{C}$, os cálculos de perda de massa sugeriram a formação do intermediário $\mathrm{La}_{2} \mathrm{O}\left(\mathrm{CO}_{3}\right)_{2}$, o qual apresentou baixa estabilidade térmica. Em seguida, observou-se uma perda de massa de $6,51 \%$ e formação do intermediário $\mathrm{La}_{2} \mathrm{O}_{2} \mathrm{CO}_{3}$ em $500^{\circ} \mathrm{C}$. A etapa de decomposição térmica entre 300 e $500^{\circ} \mathrm{C}$ está representada pela equação 3.3 .

$$
2 \mathrm{La}\left(\mathrm{CH}_{3} \mathrm{COO}\right)_{3}(\mathrm{~s}) \rightarrow \mathrm{La}_{2} \mathrm{O}_{2} \mathrm{CO}_{3}(\mathrm{~s})+3 \mathrm{CH}_{3} \mathrm{COCH}_{3}(\mathrm{~g})+2 \mathrm{CO}_{2}(\mathrm{~g})
$$


A última etapa da decomposição térmica, com temperatura do pico nas curvas DTG em torno de $715^{\circ} \mathrm{C}$, correspondeu à libertação de $\mathrm{CO}_{2}$, proveniente do $\mathrm{La}_{2} \mathrm{O}_{2} \mathrm{CO}_{3} \mathrm{e}$ formação do óxido $\mathrm{La}_{2} \mathrm{O}_{3}$ a partir de $740^{\circ} \mathrm{C}$, conforme ilustra a equação 3.4.

$$
2 \mathrm{La}_{2} \mathrm{O}_{2} \mathrm{CO}_{3}(\mathrm{~s}) \rightarrow \mathrm{La}_{2} \mathrm{O}_{3}(\mathrm{~s})+\mathrm{CO}_{2}(\mathrm{~g})
$$

$\mathrm{Na}$ Tabela 3.5 estão apresentados os valores percentuais calculados e experimentais, dos intermediários sólidos e produto final da decomposição térmica do acetato de lantânio.

Tabela 3.5: Dados percentuais dos intermediários sólidos e do produto final obtidos na decomposição térmica do acetato de lantânio

\begin{tabular}{l|c|c|c}
\hline \multirow{2}{*}{ COMPOSTO } & \multirow{2}{*}{ \% CALCULADA } & \multicolumn{2}{|c}{ \% EXPERIMENTAL } \\
\cline { 2 - 4 } & & AR & $\mathbf{N}_{\mathbf{2}}$ \\
\hline $\mathrm{La}(\mathrm{Ac})_{3} \cdot \mathrm{H}_{2} \mathrm{O}$ & 97,37 & 97,5 & 97,5 \\
$\mathrm{La}(\mathrm{Ac})_{3}$ & 92,12 & 91,5 & 91,8 \\
$\mathrm{La}_{2} \mathrm{O}\left(\mathrm{CO}_{3}\right)_{2}$ & 60,31 & 59,8 & 60,1 \\
$\mathrm{La}_{2} \mathrm{O}_{2} \mathrm{CO}_{3}$ & 53,90 & 53,5 & 54,6 \\
$\mathrm{La}_{2} \mathrm{O}_{3}$ & 47,49 & 47,0 & 47,3 \\
\hline
\end{tabular}

Ac: íon acetato $\left(\mathrm{CH}_{3} \mathrm{COO}^{-}\right)$

As curvas DTA e DSC foram obtidas, paralelamente, com o objetivo de obter informações sobre a energia liberada ou absorvida durante o processo de decomposição. A técnica DTA mede diferenças de temperatura entre a amostra e referência, sendo qualitativa, mas permite obter informações do comportamento térmico da amostra sob altas temperaturas $\left(\mathrm{T}=1400^{\circ} \mathrm{C}\right)$. Por outro lado, a técnica DSC só permite obter dados até $600^{\circ} \mathrm{C}$, mas apresenta a vantagem de ser quantitativa, em relação ao calor envolvido num evento térmico. As diferenças observadas nos valores das temperaturas dos eventos foram devidas à massa de amostra utilizada em cada experimento, pois, quando se utiliza massa de amostra alta, no caso da curva DTA, os eventos são deslocados para temperaturas mais elevadas. 
Nas Figuras 3.9 e 3.10 estão apresentadas as curvas DTA e DSC para o acetato de lantânio.

A desidratação do $\mathrm{La}\left(\mathrm{CH}_{3} \mathrm{COO}\right)_{3} .1,5 \mathrm{H}_{2} \mathrm{O}$ foi evidenciada na curva DTA por dois eventos endotérmicos, com temperatura de pico em 70 e $161^{\circ} \mathrm{C}$. No entanto, a curva DSC evidenciou três eventos endotérmicos. O primeiro evento, em $64^{\circ} \mathrm{C}$, correspondeu à libertação de $0,5 \mathrm{~mol}$ de água e formação do $\mathrm{La}\left(\mathrm{CH}_{3} \mathrm{COO}\right)_{3} \cdot \mathrm{H}_{2} \mathrm{O}\left(\Delta H=13 \mathrm{~kJ} \mathrm{~mol}^{-1}\right)$. $\mathrm{O}$ segundo e terceiro eventos, em 115 e $131^{\circ} \mathrm{C}$, ocorreram simultaneamente, indicando que a libertação da molécula de água ocorre em duas etapas. O valor total de $\Delta H$ foi igual a $66 \mathrm{~kJ} \mathrm{~mol}^{-1}$.

Nas curvas TG/DTG foi evidenciado que o sal anidro, $\mathrm{La}\left(\mathrm{CH}_{3} \mathrm{COO}\right)_{3}$, apresentou-se termicamente estável entre 180 e $300^{\circ} \mathrm{C}$. Neste intervalo de temperatura, observou-se tanto na curva DTA $\left(\mathrm{T}_{\mathrm{p}}=204^{\circ} \mathrm{C}\right)$, quanto na curva DSC $\left(\mathrm{T}_{\mathrm{p}}=230^{\circ} \mathrm{C}\right)$, um evento exotérmico característico de uma transição de fase $\left(\Delta H=-10 \mathrm{~kJ} \mathrm{~mol}^{-1}\right)$. Foram realizados outros experimentos de DSC, com o objetivo de estudar a reversibilidade deste evento, o qual apresentou-se não reversível (Figura 3.11 b, c). Em suporte aos resultados acima, foram isoladas amostras de $\mathrm{La}\left(\mathrm{CH}_{3} \mathrm{COO}\right)_{3}$ em temperatura inferior a $190^{\circ} \mathrm{C}$ e superior a $240^{\circ} \mathrm{C}$, e submetidos à caracterização por XRD. Os difratogramas de raios $\mathrm{X}$ indicaram uma perda significante na cristalinidade do sal hidratado e mudança de fase do sal anidro (Figura $3.12 \mathrm{a}, \mathrm{b}, \mathrm{c}$ ) [26].

Em seguida, observou-se nas curvas DTA $\left(\mathrm{T}_{\mathrm{p}}=325^{\circ} \mathrm{C}\right)$ e DSC $\left(\mathrm{T}_{\mathrm{p}}=330^{\circ} \mathrm{C}\right)$, um evento endotérmico característico de fusão do $\mathrm{La}\left(\mathrm{CH}_{3} \mathrm{COO}\right)_{3}\left(\Delta H=20 \mathrm{~kJ} \mathrm{~mol}^{-1}\right)$. A decomposição térmica deste sal ocorreu simultaneamente ao processo de fusão, em duas etapas extremamente exotérmicas, para produzir $\mathrm{La}_{2} \mathrm{O}_{2} \mathrm{CO}_{3}\left(\Delta H=-182 \mathrm{~kJ} \mathrm{~mol}^{-1}\right)$.

A última etapa da decomposição térmica observada nas curvas TG/DTG, relativas a formação do $\mathrm{La}_{2} \mathrm{O}_{3}$ foi endotérmica, como evidenciou a curva DTA $\left(\mathrm{T}_{\mathrm{p}}=\right.$ $\left.739^{\circ} \mathrm{C}\right)$.

Os intermediários sólidos da decomposição térmica foram isolados em $550 \mathrm{e}$ $900^{\circ} \mathrm{C}$, sob atmosfera de ar e submetidos à caracterização por XRD (Figura 3.12). Os difratogramas de raios $\mathrm{X}$ confirmaram, respectivamente, a formação do $\mathrm{La}_{2} \mathrm{O}_{2} \mathrm{CO}_{3}$ (ASTM 23-320) e $\mathrm{La}_{2} \mathrm{O}_{3}$ (ASTM 5-602) [8]. 


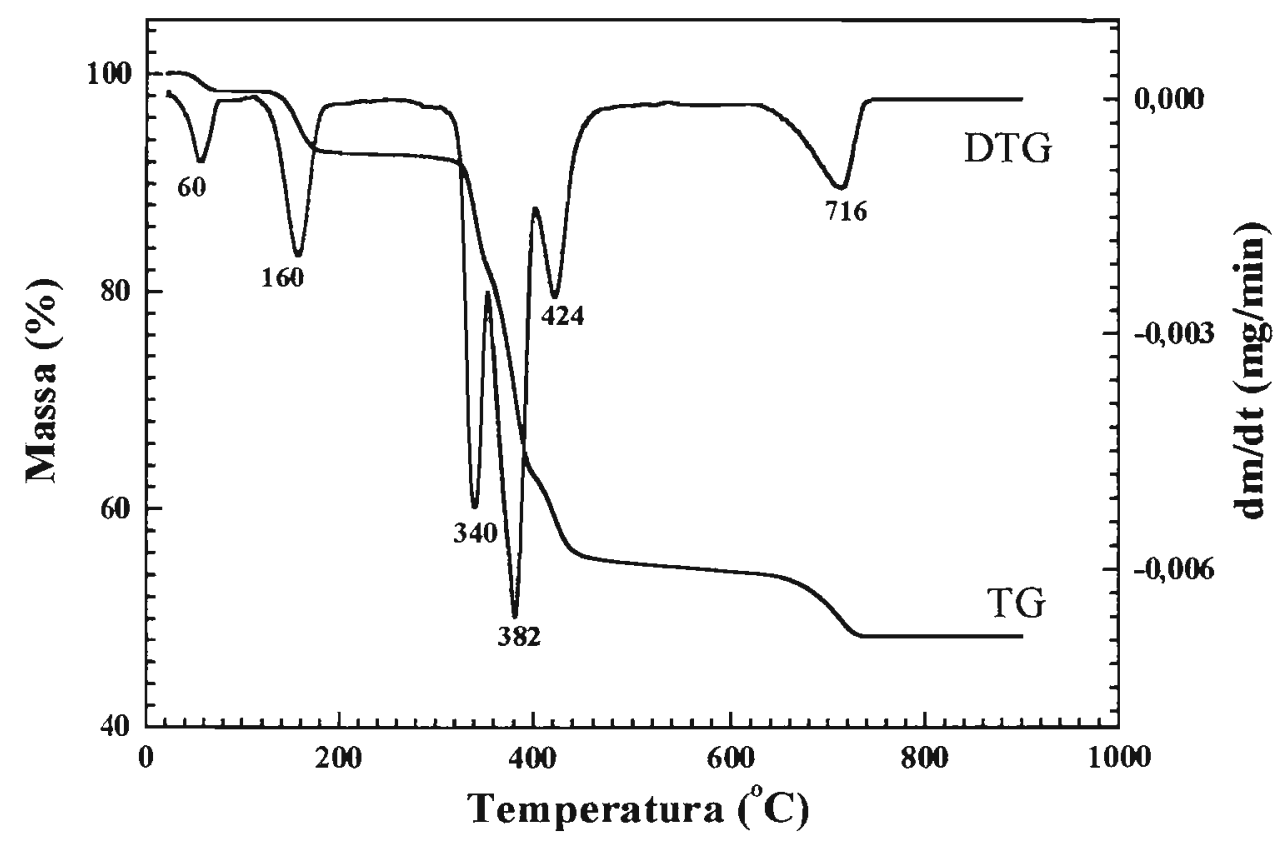

Figura 3.7: Curvas TG/DTG do $\mathrm{La}\left(\mathrm{CH}_{3} \mathrm{COO}\right)_{3} \cdot 1,5 \mathrm{H}_{2} \mathrm{O}$ obtidas sob atmosfera dinâmica de ar $\left(50 \mathrm{~mL} \mathrm{~min}^{-1}\right)$, razão de aquecimento de $10^{\circ} \mathrm{C} \mathrm{min}^{-1}$, cadinho de platina e massa da amostra de $5,463 \mathrm{mg}$.

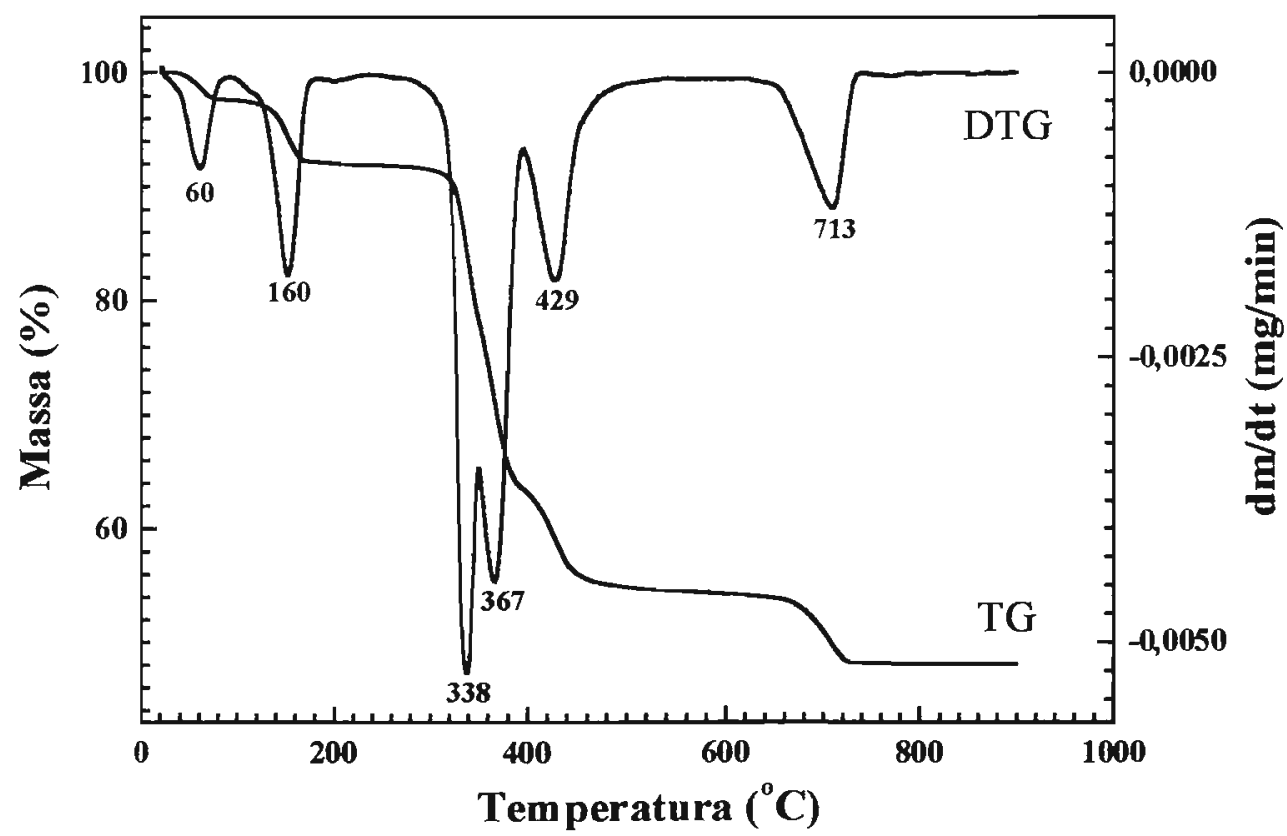

Figura 3.8: Curvas TG/DTG do $\mathrm{La}\left(\mathrm{CH}_{3} \mathrm{COO}\right)_{3} \cdot 1,5 \mathrm{H}_{2} \mathrm{O}$ obtidas sob atmosfera dinâmica de nitrogênio $\left(50 \mathrm{~mL} \mathrm{~min}{ }^{-1}\right)$, razão de aquecimento de $10^{\circ} \mathrm{C} \mathrm{min}{ }^{-1}$, cadinho de platina e massa da amostra de $5,548 \mathrm{mg}$. 


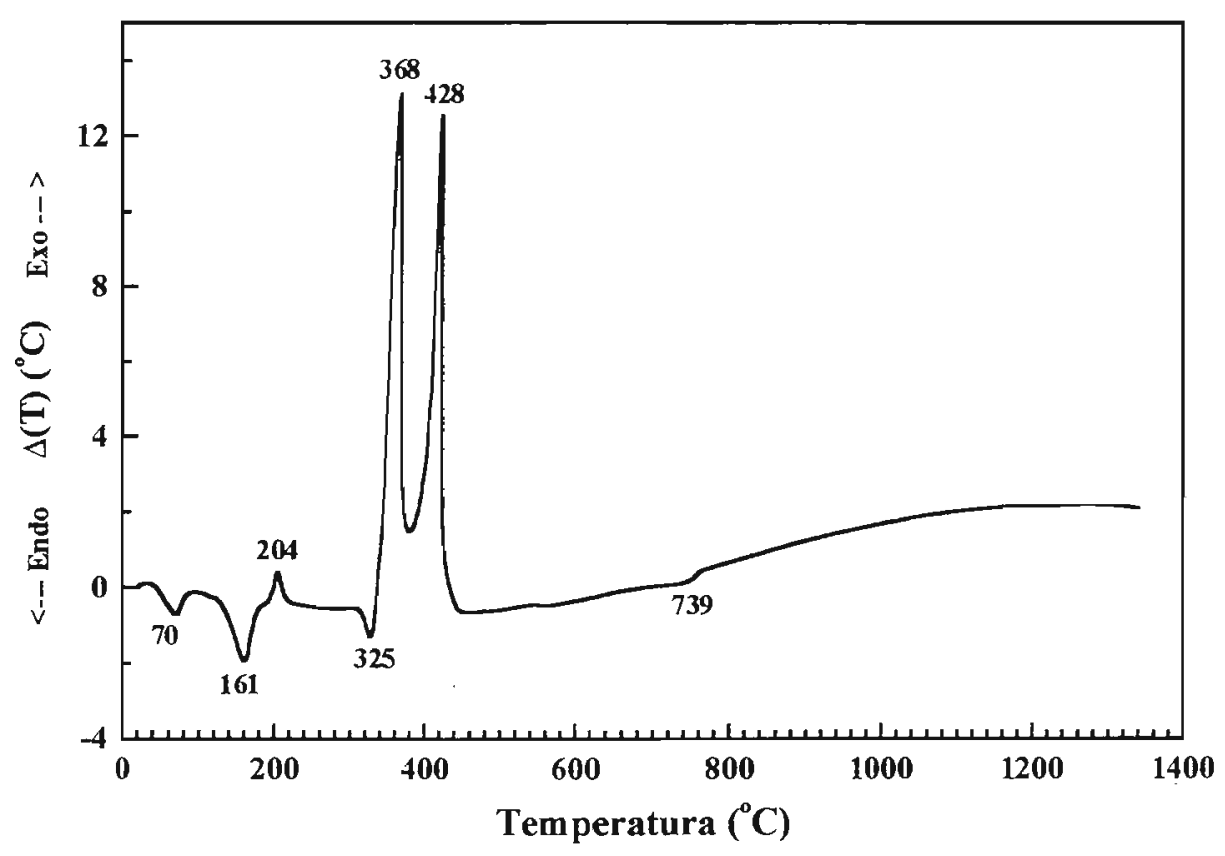

Figura 3.9: Curva DTA do $\mathrm{La}\left(\mathrm{CH}_{3} \mathrm{COO}\right)_{3} \cdot 1,5 \mathrm{H}_{2} \mathrm{O}$ obtida sob atmosfera dinâmica de ar $(50 \mathrm{~mL}$ $\min ^{-1}$ ), razão de aquecimento de $10^{\circ} \mathrm{C} \mathrm{min}^{-1}$, cadinho de alumina e massa da amostra de 18,36 mg.

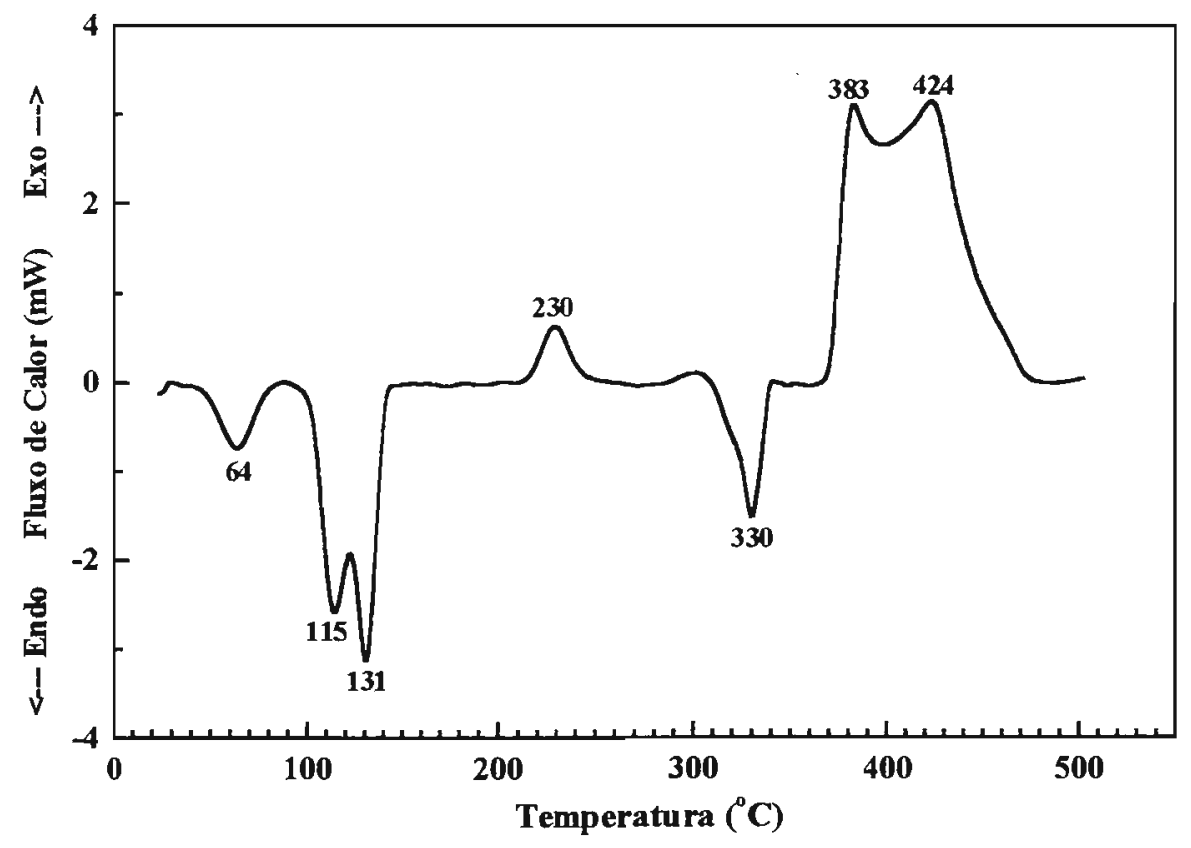

Figura 3.10: Curva DSC do $\mathrm{La}\left(\mathrm{CH}_{3} \mathrm{COO}\right)_{3} \cdot 1,5 \mathrm{H}_{2} \mathrm{O}$ obtida sob atmosfera dinâmica de nitrogênio $\left(50 \mathrm{~mL} \mathrm{~min}{ }^{-1}\right)$, razão de aquecimento de $10^{\circ} \mathrm{C} \mathrm{min}^{-1}$, cápsula de alumínio aberta e massa da amostra de $2,328 \mathrm{mg}$. 


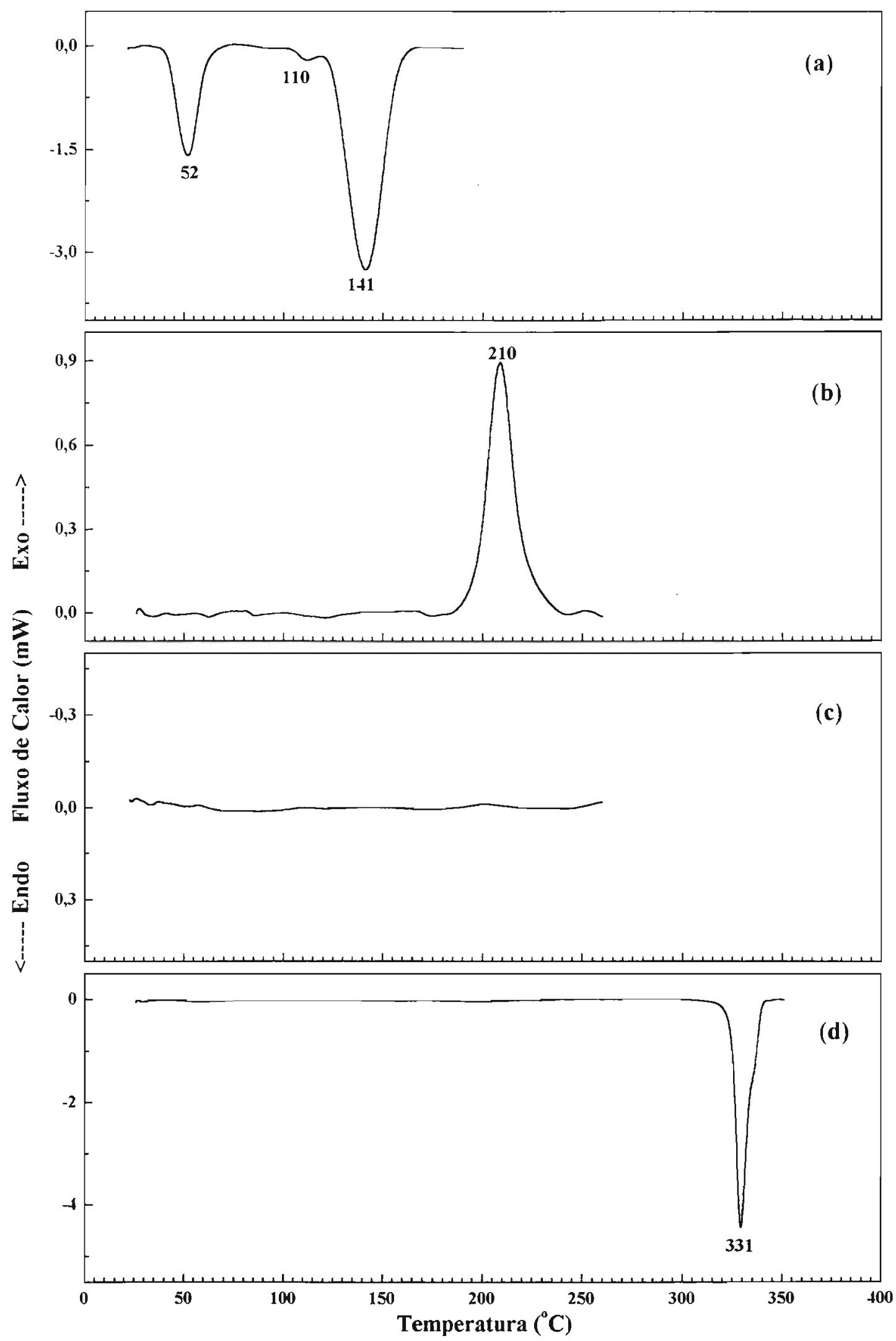

Figura 3.11: Curvas DSC obtidas sob atmosfera dinâmica de nitrogênio $\left(50 \mathrm{~mL} \mathrm{~min}{ }^{-1}\right)$, razão de aquecimento de $10^{\circ} \mathrm{C} \mathrm{min}^{-1}$ e cápsula de alumínio das amostras:

(a) $\mathrm{La}\left(\mathrm{CH}_{3} \mathrm{COO}\right)_{3} \cdot 1,5 \mathrm{H}_{2} \mathrm{O}$ (massa $=2,229 \mathrm{mg}$ ); (b) intermediário isolado em $190^{\circ} \mathrm{C}$ (massa $=$ $2,093 \mathrm{mg}$ ); (c) Reaquecimento do intermediário isolado em $190^{\circ} \mathrm{C}$ (massa $=2,023 \mathrm{mg}$ ); (d) intermediário isolado em $260^{\circ} \mathrm{C}$ (massa $=2,000 \mathrm{mg}$ ). 


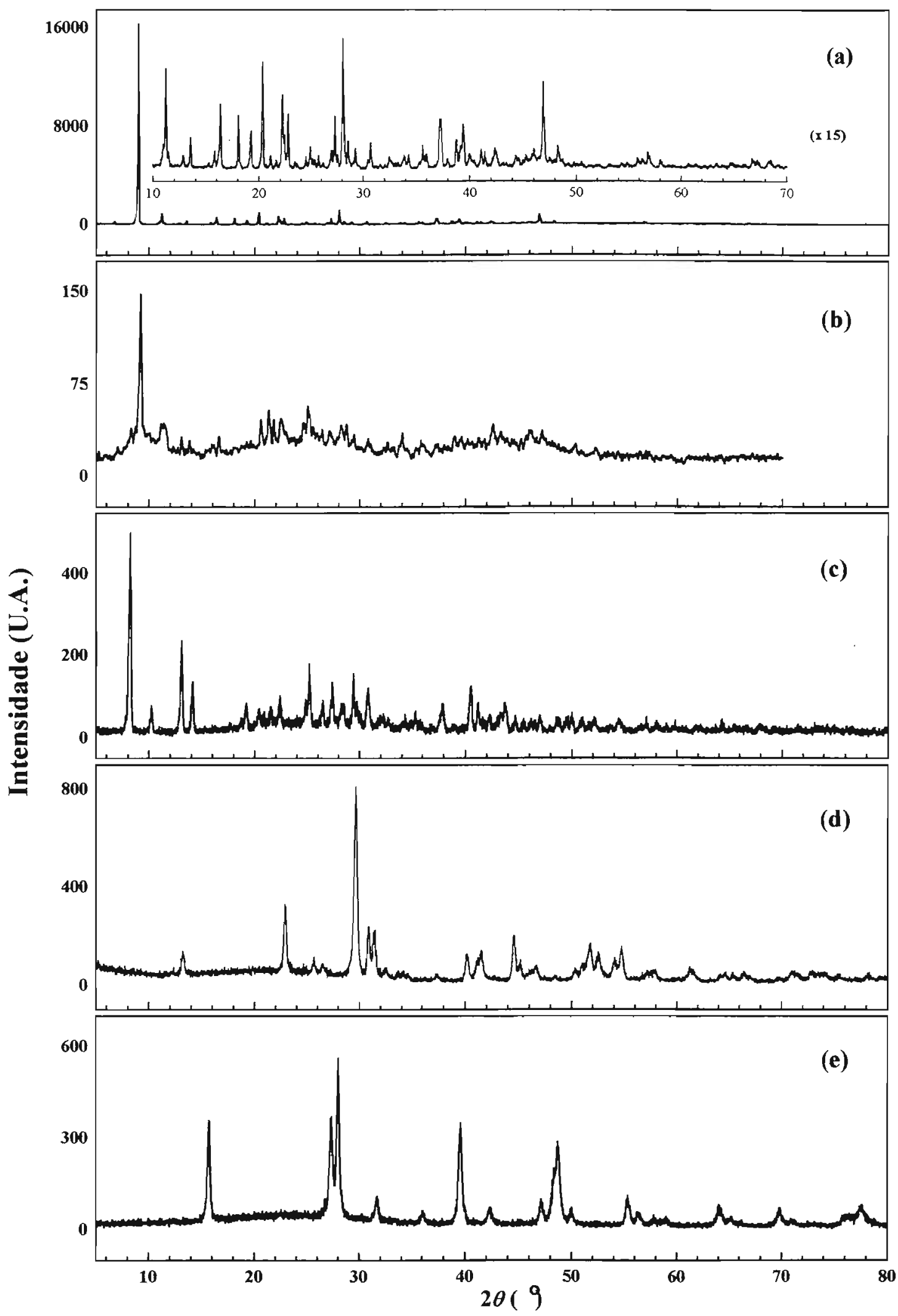

Figura 3.12: Difratogramas de raios $X$ (método do pó) das amostras: (a) $\mathrm{La}\left(\mathrm{CH}_{3} \mathrm{COO}\right)_{3} .1,5 \mathrm{H}_{2} \mathrm{O}$ (inserido $2 \theta=10$ a $70^{\circ}$, ampliado 15 vezes); (b) intermediário em $190^{\circ} \mathrm{C}$; (c) intermediário em $240^{\circ} \mathrm{C}$; (d) intermediário em $550^{\circ} \mathrm{C}$; (e) produto final em $900^{\circ} \mathrm{C}$. Os intermediários e o produto final da decomposição térmica foram obtidos sob atmosfera dinâmica de $\operatorname{ar}\left(50 \mathrm{~mL} \mathrm{~min}^{-1}\right)$, razão de aquecimento de $10^{\circ} \mathrm{C} \mathrm{min}{ }^{-1}$, utilizando cadinho de platina. 


\subsubsection{2- Acetato de európio}

$\mathrm{O}$ acetato de európio foi obtido com estequiometria $\mathrm{Eu}\left(\mathrm{CH}_{3} \mathrm{COO}\right)_{3} \cdot 4 \mathrm{H}_{2} \mathrm{O}$ (Tabela 3.2).

Nas Figuras 3.13 e 3.14 estão apresentadas as curvas TG/DTG obtidas nas atmosferas dinâmicas de ar e nitrogênio, respectivamente. Estas curvas mostraram que o processo de decomposição térmica ocorreu em três etapas, não sendo observado diferenças significativas no comportamento ao mudar a atmosfera atuante.

A primeira variação de massa observada nas curvas TG correspondeu à libertação de moléculas de água de cristalização. As curvas DTG indicaram uma etapa em atmosfera de ar e duas etapas em nitrogênio. A variação de massa total, entre 25 e $200^{\circ} \mathrm{C}$, foi de $27,96 \%$, relativo a $4 \mathrm{~mol}$ de água. A etapa de desidratação está representada pela equação de reação 3.5 .

$$
\mathrm{Eu}\left(\mathrm{CH}_{3} \mathrm{COO}\right)_{3} .4 \mathrm{H}_{2} \mathrm{O}(\mathrm{s}) \rightarrow \mathrm{Eu}\left(\mathrm{CH}_{3} \mathrm{COO}\right)_{3}(\mathrm{~s})+4 \mathrm{H}_{2} \mathrm{O}(\mathrm{g})
$$

$\mathrm{Eu}\left(\mathrm{CH}_{3} \mathrm{COO}\right)_{3}$ apresentou-se termicamente estável até $230^{\circ} \mathrm{C}$. Sob atmosfera dinâmica de ar, a decomposição térmica ocorreu em duas etapas rápidas e consecutivas, com temperatura dos picos na curva DTG em 353 e $384^{\circ} \mathrm{C}$. No entanto, sob atmosfera dinâmica de nitrogênio a decomposição térmica ocorreu de forma lenta e gradativa. Em ambas atmosferas, os cálculos de perda de massa, em $500^{\circ} \mathrm{C}$, indicaram a formação do $\mathrm{Eu}_{2} \mathrm{O}_{2} \mathrm{CO}_{3}$. A etapa de decomposição térmica entre 300 e $500^{\circ} \mathrm{C}$ está representada na equação 3.6 .

$$
2 \mathrm{Eu}\left(\mathrm{CH}_{3} \mathrm{COO}\right)_{3}(\mathrm{~s}) \rightarrow \mathrm{Eu}_{2} \mathrm{O}_{2} \mathrm{CO}_{3}(\mathrm{~s})+3 \mathrm{CH}_{3} \mathrm{COCH}_{3}(\mathrm{~g})+2 \mathrm{CO}_{2}(\mathrm{~g})
$$

A última etapa da decomposição térmica correspondeu a libertação de $\mathrm{CO}_{2}$ e formação do $\mathrm{Eu}_{2} \mathrm{O}_{3}$, a partir de $630^{\circ} \mathrm{C}$ (equação de reação 3.7).

$$
\mathrm{Eu}_{2} \mathrm{O}_{2} \mathrm{CO}_{3}(\mathrm{~s}) \rightarrow \mathrm{Eu}_{2} \mathrm{O}_{3}(\mathrm{~s})+\mathrm{CO}_{2}(\mathrm{~g})
$$

Na Tabela 3.6 estão apresentados os valores percentuais calculados e experimentais, dos intermediários sólidos e produto final da decomposição térmica do acetato de európio. 
Tabela 3.6: Dados percentuais dos intermediários sólidos e produto final obtidos na decomposição térmica do acetato de európio

\begin{tabular}{l|c|c|c}
\hline \multirow{2}{*}{ COMPOSTO } & \multirow{2}{*}{ \% CALCULADA } & \multicolumn{2}{|c}{ \% EXPERIMENTAL } \\
\cline { 3 - 4 } & & $\mathbf{A R}$ & $\mathbf{N}_{\mathbf{2}}$ \\
\hline $\mathrm{Eu}(\mathrm{Ac})_{3}$ & 82,04 & 81,9 & 82,0 \\
$\mathrm{Eu}_{2} \mathrm{O}_{2} \mathrm{CO}_{3}$ & 49,35 & 49,1 & 49,4 \\
$\mathrm{Eu}_{2} \mathrm{O}_{3}$ & 43,86 & 44,3 & 43,7 \\
\hline
\end{tabular}

Ac: íon acetato $\left(\mathrm{CH}_{3} \mathrm{COO}^{-}\right)$

Nas Figuras 3.15 e 3.16 estão representadas as curvas DTA e DSC para o acetato de európio, respectivamente. Similarmente ao acetato de lantânio, observaram-se diferenças nos valores das temperaturas de picos nestas curvas, em virtude da massa de amostra usada em cada experimento.

A desidratação do $\mathrm{Eu}\left(\mathrm{CH}_{3} \mathrm{COO}\right)_{3} \cdot 4 \mathrm{H}_{2} \mathrm{O}$ foi evidenciada por dois eventos endotérmicos, tanto na curva DTA $\left(\mathrm{T}_{\mathrm{p}}=109\right.$ e $\left.184^{\circ} \mathrm{C}\right)$, quanto na curva DSC $\left(\mathrm{T}_{\mathrm{p}}=81 \mathrm{e}\right.$ $184^{\circ} \mathrm{C}$ ). Os resultados são concordantes aos obtidos por TG/DTG, sob atmosfera de nitrogênio, onde foi verificado um pequeno pico na curva DTG em $152^{\circ} \mathrm{C}$. Dessa forma, pode-se sugerir que as moléculas de água estão ligadas de diferentes formas, pois a libertação ocorre separadamente como evidenciaram estes experimentos. $\mathrm{O}$ valor total de $\Delta H$ obtido por DSC, foi igual a $252 \mathrm{~kJ} \mathrm{~mol}^{-1}$, relativo a libertação de $4 \mathrm{~mol}$ de água.

A decomposição do acetato de európio anidro, $\mathrm{Eu}\left(\mathrm{CH}_{3} \mathrm{COO}\right)_{3}$, ocorreu com liberação de energia, sendo evidenciada na curva DTA por dois picos em 363 e $382^{\circ} \mathrm{C}$, enquanto que na curva DSC, esses eventos foram observados em 339 e $383^{\circ} \mathrm{C}(\Delta H=-$ $331 \mathrm{~kJ} \mathrm{~mol}^{-1}$ ).

A curva DTA evidenciou um evento endotérmico em $673^{\circ} \mathrm{C}$, relativo a última etapa da decomposição térmica, que corresponde à libertação de $\mathrm{CO}_{2}$ proveniente do $\mathrm{Eu}_{2} \mathrm{O}_{2} \mathrm{CO}_{3}$ e formação do $\mathrm{Eu}_{2} \mathrm{O}_{3}$.

Os intermediários sólidos em 200 e $500^{\circ} \mathrm{C}$ e o produto final da decomposição térmica em $190^{\circ} \mathrm{C}$ foram isolados e submetidos à caracterização por XRD (Figura 3.17). $\mathrm{O}$ difratograma de raios $\mathrm{X}$ do intermediário isolado em $200^{\circ} \mathrm{C}$ evidenciou baixa cristalinidade do sal anidro, sugerindo que as moléculas de água coordenadas são fundamentais para a cristalinidade do acetato de európio. Para o intermediário isolado em $500^{\circ} \mathrm{C}$ e o produto final em $900^{\circ} \mathrm{C}$, os difratogramas de raios $\mathrm{X}$ confirmaram as formações do dioxicarbonato (ASTM 43-0603) e óxido de európio (ASTM 34-0392), respectivamente [8]. 


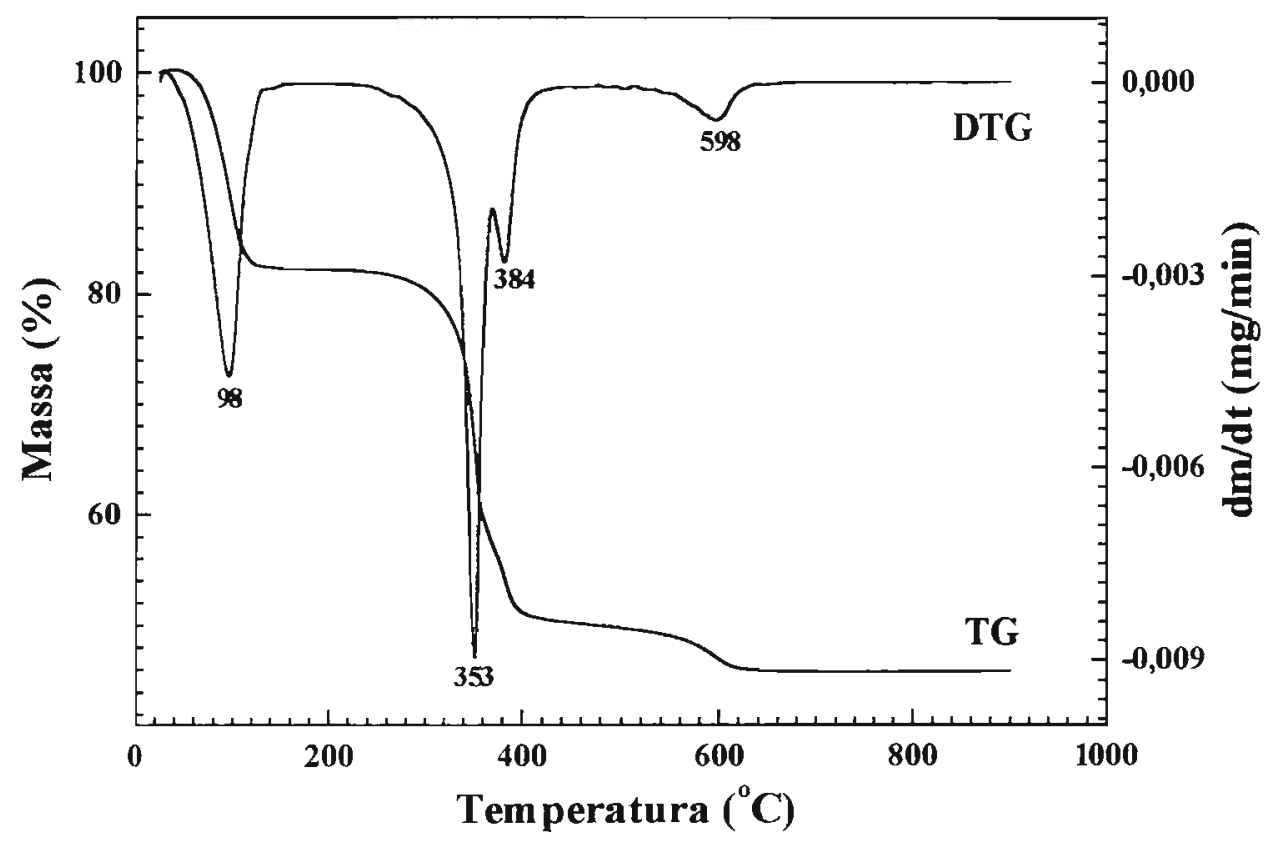

Figura 3.13: Curvas TG/DTG do $\mathrm{Eu}\left(\mathrm{CH}_{3} \mathrm{COO}\right)_{3} \cdot 4 \mathrm{H}_{2} \mathrm{O}$ obtidas sob atmosfera dinâmica de ar (50 $\mathrm{mL} \min ^{-1}$ ), razão de aquecimento de $10^{\circ} \mathrm{C} \mathrm{min}^{-1}$, cadinho de platina e massa da amostra de 5,784 mg.

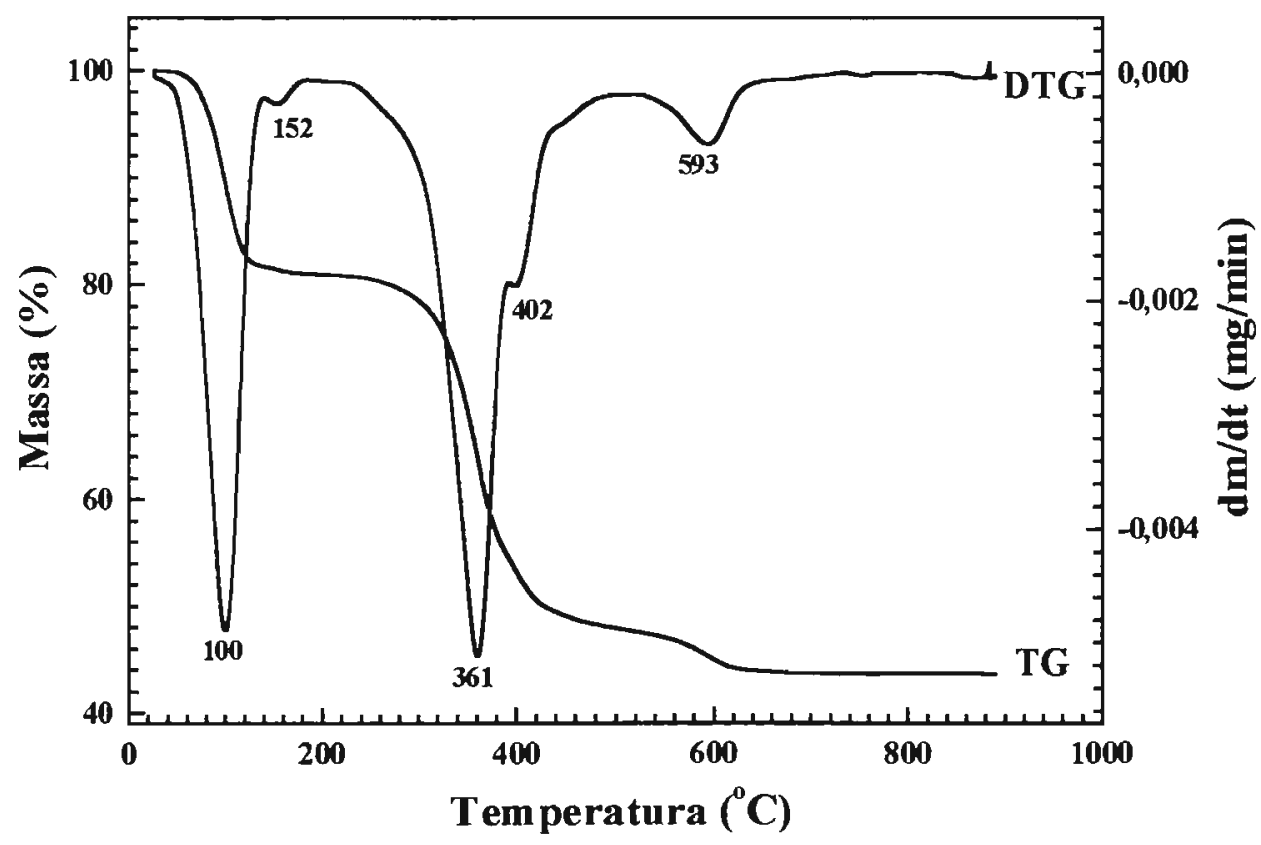

Figura 3.14: Curvas TG/DTG do $\mathrm{Eu}\left(\mathrm{CH}_{3} \mathrm{COO}\right)_{3} \cdot 4 \mathrm{H}_{2} \mathrm{O}$ obtidas sob atmosfera dinâmica de nitrogênio $\left(50 \mathrm{~mL} \mathrm{~min}{ }^{-1}\right)$, razão de aquecimento de $10^{\circ} \mathrm{C} \mathrm{min}^{-1}$, cadinho de platina e massa da amostra de 5,791 mg. 


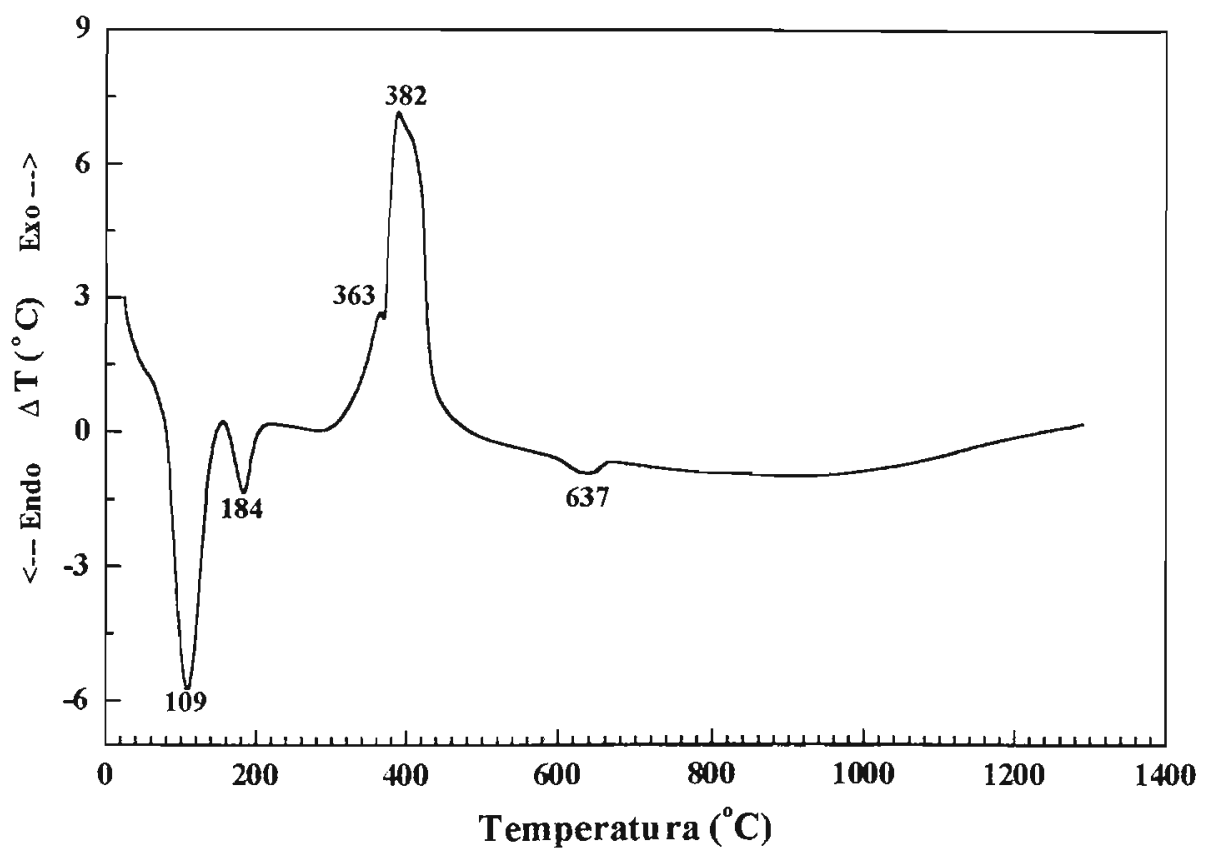

Figura 3.15: Curva DTA do $\mathrm{Eu}\left(\mathrm{CH}_{3} \mathrm{COO}\right)_{3} .4 \mathrm{H}_{2} \mathrm{O}$ obtida sob atmosfera dinâmica de ar $(50 \mathrm{~mL}$ $\min ^{-1}$ ), razão de aquecimento de $10^{\circ} \mathrm{C} \mathrm{min}^{-1}$, cadinho de alumina e massa da amostra de 18,04 mg.

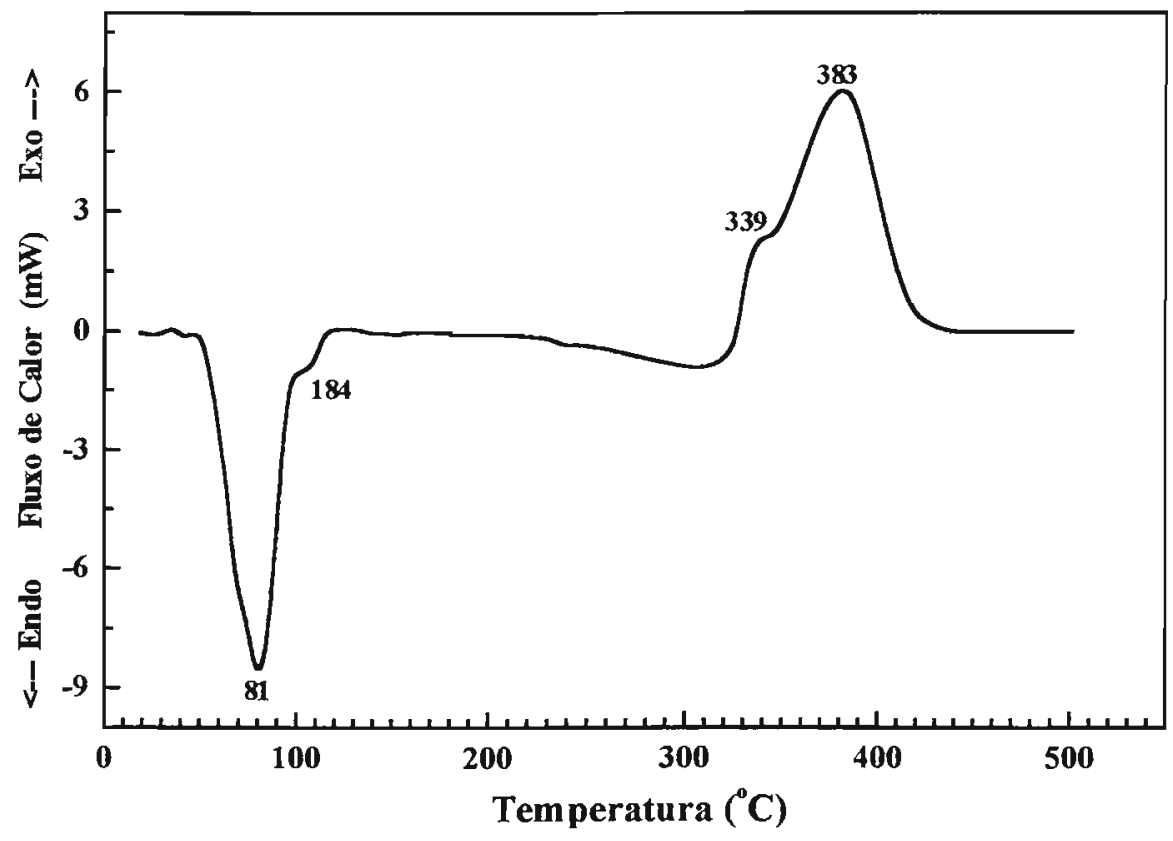

Figura 3.16: Curva DSC do $\mathrm{Eu}\left(\mathrm{CH}_{3} \mathrm{COO}\right)_{3} .4 \mathrm{H}_{2} \mathrm{O}$ obtida sob atmosfera dinâmica de nitrogênio $\left(50 \mathrm{~mL} \mathrm{~min}{ }^{-1}\right)$, razão de aquecimento de $10^{\circ} \mathrm{C} \min ^{-1}$, cápsula de alumínio aberta e massa da amostra de $2,266 \mathrm{mg}$. 


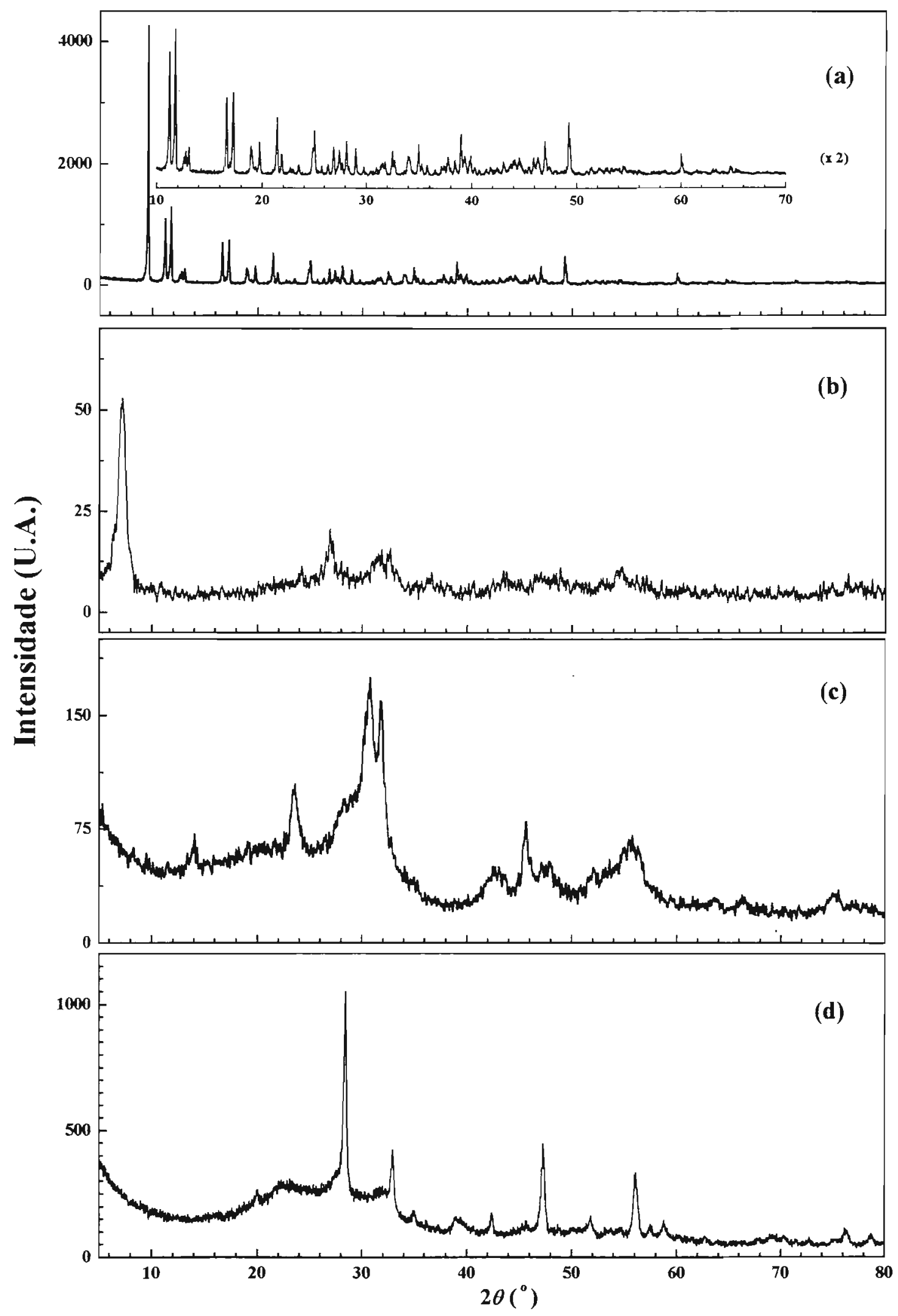

Figura 3.17: Difratogramas de raios $\mathrm{X}$ (método do pó) das amostras: (a) $\mathrm{Eu}\left(\mathrm{CH}_{3} \mathrm{COO}\right)_{3} .4 \mathrm{H}_{2} \mathrm{O}$ (inserido $2 \theta=10$ a $70^{\circ}$, ampliado duas vezes); (b) intermediário em $200^{\circ} \mathrm{C}$; (c) intermediário em $500^{\circ} \mathrm{C}$; (d) produto final em $900^{\circ} \mathrm{C}$. Os intermediários e o produto final da decomposição térmica foram obtidos sob atmosfera dinâmica de ar $\left(50 \mathrm{~mL} \mathrm{~min}{ }^{-1}\right)$, razão de aquecimento de $10^{\circ} \mathrm{C} \mathrm{min}^{-1}$, utilizando cadinho de platina. 


\subsubsection{3- Acetato de ítrio}

$\mathrm{O}$ acetato de ítrio foi obtido com estequiometria $\mathrm{Y}\left(\mathrm{CH}_{3} \mathrm{COO}\right)_{3} \cdot 4 \mathrm{H}_{2} \mathrm{O}$ (Tabela 3.2).

Nas Figuras 3.18 e 3.19 estão apresentadas as curvas TG/DTG obtidas sob atmosferas dinâmicas de ar e nitrogênio, respectivamente. Essas curvas mostraram que o processo de decomposição térmica ocorreu em três etapas, não sendo observadas diferenças significativas aos mudar a atmosfera atuante

A primeira variação de massa observada nas curvas TG/DTG correspondeu à libertação de moléculas de água de cristalização. Independente da atmosfera, observouse uma variação de massa no intervalo de 25 a $200^{\circ} \mathrm{C}$, relativa a perda de 4 mol de água $(22,31 \%)$. A etapa de desidratação está representada pela equação 3.8 .

$$
\mathrm{Y}\left(\mathrm{CH}_{3} \mathrm{COO}\right)_{3} .4 \mathrm{H}_{2} \mathrm{O}(\mathrm{s}) \rightarrow \mathrm{Y}\left(\mathrm{CH}_{3} \mathrm{COO}\right)_{3}(\mathrm{~s})+4 \mathrm{H}_{2} \mathrm{O}(\mathrm{g})
$$

Em ambas atmosferas, isto é, ar e nitrogênio, a decomposição térmica do $\mathrm{Y}\left(\mathrm{CH}_{3} \mathrm{COO}\right)_{3}$ ocorreu em uma etapa, produzindo, possivelmente o intermediário $\mathrm{Y}_{2} \mathrm{O}_{2} \mathrm{CO}_{3}$ em $500^{\circ} \mathrm{C}$. Esse intermediário apresentou baixa estabilidade térmica, decompondo-se gradativamente a $\mathrm{Y}_{2} \mathrm{O}_{3}$. Estas etapas estão representadas pelas equações 3.9 e 3.10 .

$$
\begin{aligned}
& 2 \mathrm{Y}\left(\mathrm{CH}_{3} \mathrm{COO}\right)_{3}(\mathrm{~s}) \rightarrow \mathrm{Y}_{2} \mathrm{O}_{2} \mathrm{CO}_{3}(\mathrm{~s})+3 \mathrm{CH}_{3} \mathrm{COCH}_{3}(\mathrm{~g})+2 \mathrm{CO}_{2}(\mathrm{~g}) \\
& \mathrm{Y}_{2} \mathrm{O}_{2} \mathrm{CO}_{3}(\mathrm{~s}) \rightarrow \mathrm{CO}_{2}(\mathrm{~g})+\mathrm{Y}_{2} \mathrm{O}_{3}(\mathrm{~s})
\end{aligned}
$$

Os valores percentuais calculados e experimentais, dos intermediários sólidos e produto final da decomposição térmica do acetato de ítrio, estão apresentados na Tabela 3.7 .

Nas Figuras 3.18 e 3.19 estão apresentadas as curvas DTA e DSC para o acetato de ítrio, respectivamente.

Similarmente aos acetatos de lantânio e európio, observaram-se diferenças nos valores das temperaturas dos picos dessas curvas, em virtude da massa de amostra usada em cada experimento. 
A desidratação do $\mathrm{Y}\left(\mathrm{CH}_{3} \mathrm{COO}\right)_{3} \cdot 4 \mathrm{H}_{2} \mathrm{O}$ foi evidenciada por um evento endotérmico na curva DTA $\left(\mathrm{T}_{\mathrm{p}}=110^{\circ} \mathrm{C}\right)$, enquanto que na curva DSC evidenciou-se dois eventos endotérmicos, em 93 e $121^{\circ} \mathrm{C}$. A separação dos picos na curva DSC, possivelmente, se deve ao fato da quantidade de massa de amostra usada no experimento, ou seja, foi utilizado $c a .5 \mathrm{mg}$, enquanto que na curva DTA foi $c a .18 \mathrm{mg}$. A utilização de pequena quantidade de amostra facilita a degradação e consequentemente, podem-se distinguir eventos sobrepostos. Esse resultado sugere que as moléculas de água estão ligadas de diferentes formas no acetato de ítrio. $\mathrm{O}$ valor total de $\Delta H$, obtido por DSC, foi igual a $252 \mathrm{~kJ} \mathrm{~mol}^{-1}$.

Para a decomposição térmica do acetato de ítrio, $\mathrm{Y}\left(\mathrm{CH}_{3} \mathrm{COO}\right)_{3}$, observou-se na curva DTA um evento endotérmico em $371^{\circ} \mathrm{C}$, seguido de um forte evento exotérmico em $400^{\circ} \mathrm{C}$. No entanto, a curva DSC obtida sob atmosfera inerte, foi observado somente um evento exotérmico em $391^{\circ} \mathrm{C}\left(\Delta H=-249 \mathrm{~kJ} \mathrm{~mol}^{-1}\right)$.

Os intermediários em 200 e $500^{\circ} \mathrm{C}$ e o produto final em $900^{\circ} \mathrm{C}$ da decomposição térmica foram isolados e submetidos à caracterização por XRD (Figura 3.22). O difratograma de raios $\mathrm{X}$ do intermediário isolado em $200^{\circ} \mathrm{C}$, evidenciou baixa cristalinidade para o sal anidro. Para o intermediário em $500^{\circ} \mathrm{C}$, o difratograma de raios $\mathrm{X}$ não apresentou boa resolução, provavelmente devido à pequena quantidade de amostra usada no experimento, o que dificultou a identificação do intermediário. No entanto, os valores de perda de massa sugeriram a formação do $\mathrm{Y}_{2} \mathrm{O}_{2} \mathrm{CO}_{3}$. Finalmente, o difratograma de raios $\mathrm{X}$ do produto final em $900^{\circ} \mathrm{C}$, confirmou a formação do $\mathrm{Y}_{2} \mathrm{O}_{3}$ (ASTM 5-0574) [8].

Tabela 3.7: Dados percentuais dos intermediários sólidos e produto final da decomposição térmica do acetato de ítrio

\begin{tabular}{l|c|c|c}
\hline \multirow{2}{*}{ COMPOSTO } & \multirow{2}{*}{ \% CALCULADA } & \multicolumn{2}{|c}{ \% EXPERIMENTAL } \\
\cline { 3 - 4 } & & AR & $\mathbf{N}_{\mathbf{2}}$ \\
\hline $\mathrm{Y}(\mathrm{Ac})_{3}$ & 79,69 & 78,8 & 78,6 \\
$\mathrm{Y}_{2} \mathrm{O}_{2} \mathrm{CO}_{3}$ & 39,90 & n. o. & n. o. \\
$\mathrm{Y}_{2} \mathrm{O}_{3}$ & 33,39 & 33,6 & 33,3 \\
\hline
\end{tabular}

Ac: íon acetato $\left(\mathrm{CH}_{3} \mathrm{COO}^{-}\right)$; n. o.: não observado 


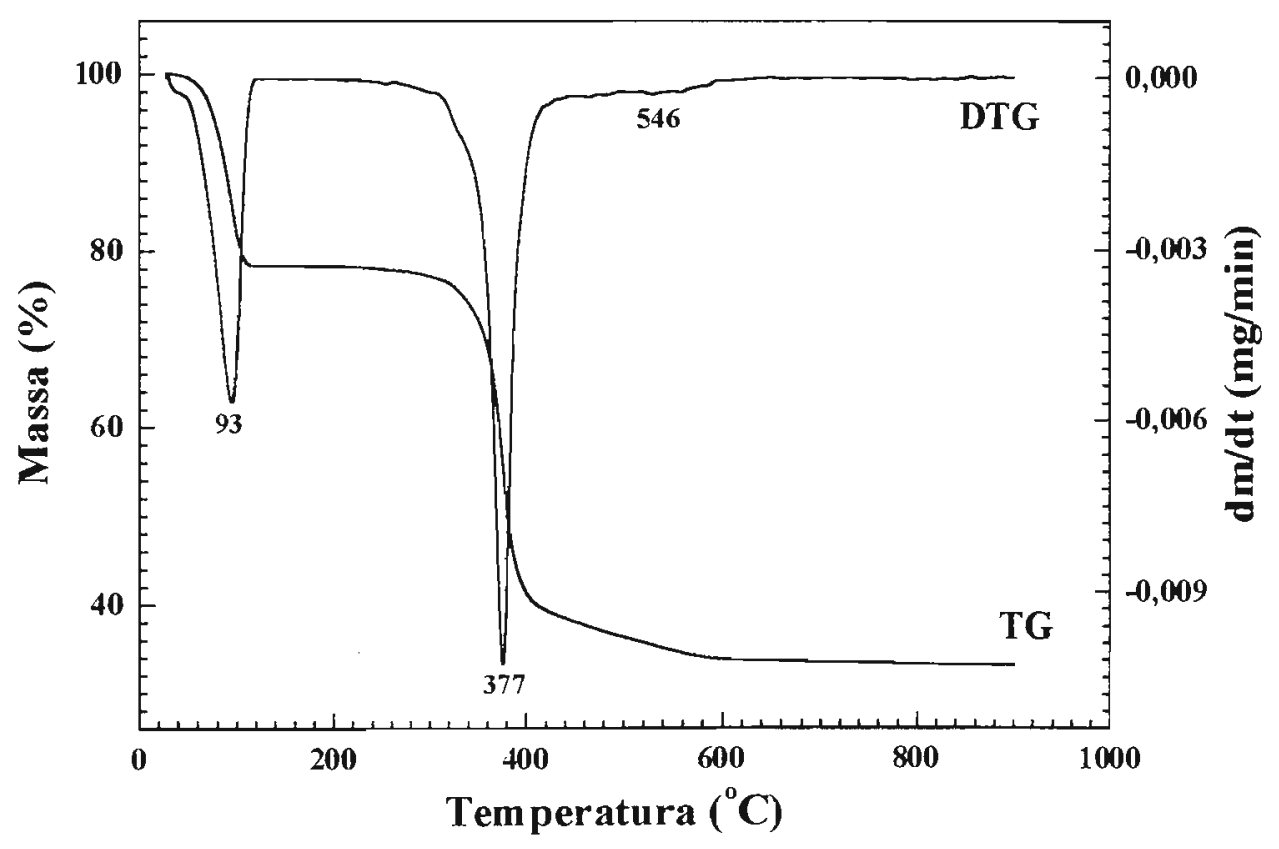

Figura 3.18: Curvas TG/DTG do $\mathrm{Y}\left(\mathrm{CH}_{3} \mathrm{COO}\right)_{3} \cdot 4 \mathrm{H}_{2} \mathrm{O}$ obtidas sob atmosfera dinâmica de ar $(50$ $\mathrm{mL} \mathrm{min}{ }^{-1}$ ), razão de aquecimento de $10^{\circ} \mathrm{C} \mathrm{min}^{-1}$, cadinho de platina e massa da amostra de 5,367 $\mathrm{mg}$.

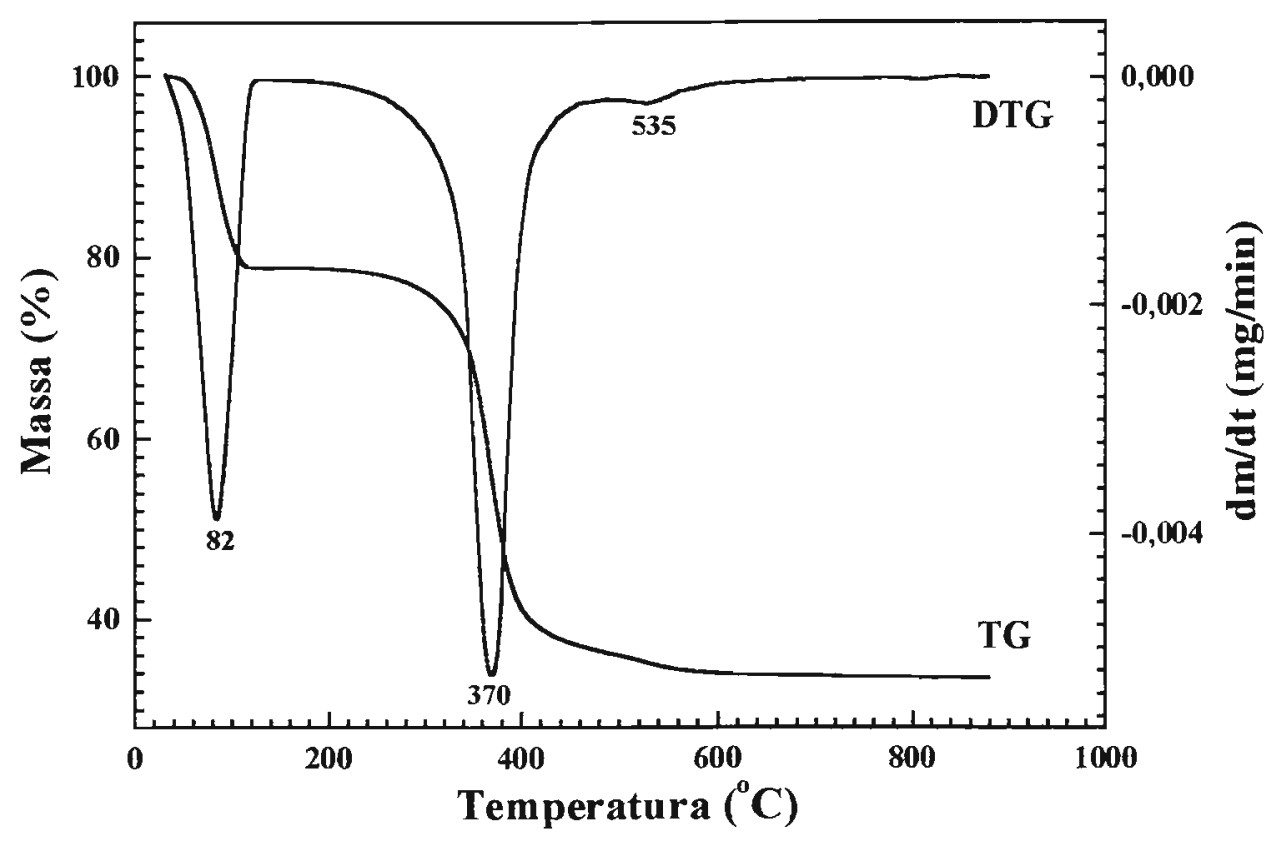

Figura 3.19: Curvas TG/DTG do $\mathrm{Y}\left(\mathrm{CH}_{3} \mathrm{COO}\right)_{3} \cdot 4 \mathrm{H}_{2} \mathrm{O}$ obtidas sob atmosfera dinâmica de nitrogênio $\left(50 \mathrm{~mL} \mathrm{~min}{ }^{-1}\right)$, razão de aquecimento de $10^{\circ} \mathrm{C} \min ^{-1}$, cadinho de platina e massa da amostra de $5,064 \mathrm{mg}$. 


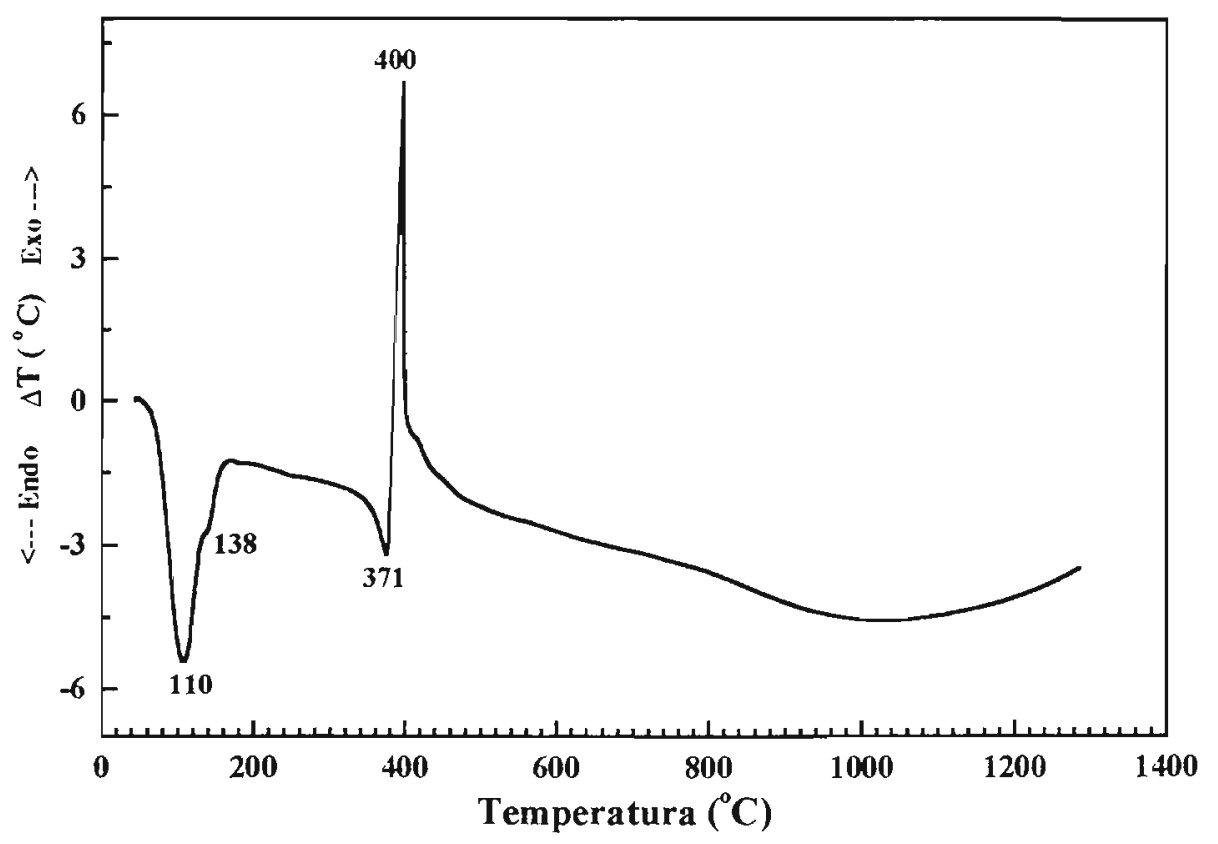

Figura 3.20: Curva DTA do $\mathrm{Y}\left(\mathrm{CH}_{3} \mathrm{COO}\right)_{3} \cdot 4 \mathrm{H}_{2} \mathrm{O}$ obtida sob atmosfera dinâmica de ar $(50 \mathrm{~mL}$ $\min ^{-1}$ ), razão de aquecimento de $10^{\circ} \mathrm{C} \mathrm{min}^{-1}$, cadinho de alumina e massa da amostra de 17,58 mg.

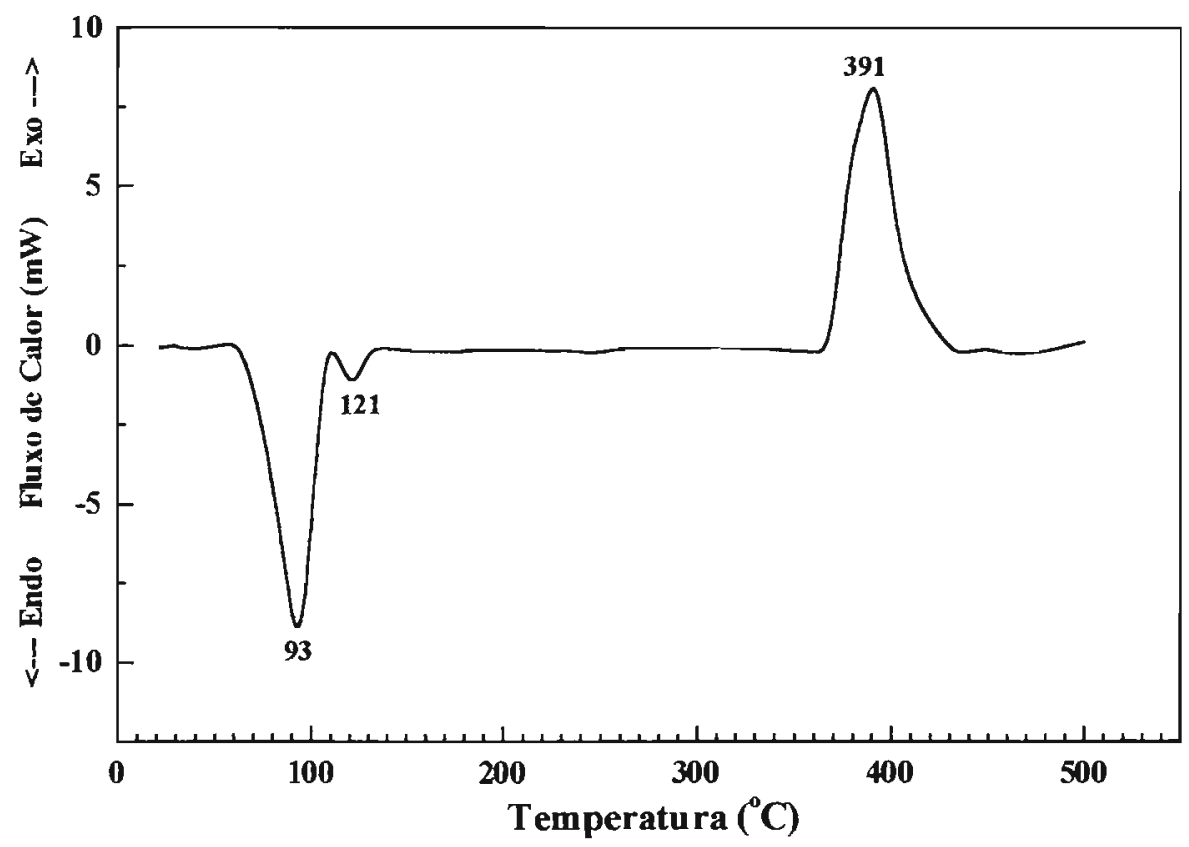

Figura 3.21: Curva DSC do $\mathrm{Y}\left(\mathrm{CH}_{3} \mathrm{COO}\right)_{3} \cdot 4 \mathrm{H}_{2} \mathrm{O}$ obtida sob atmosfera dinâmica de nitrogênio $\left(50 \mathrm{~mL} \mathrm{~min}{ }^{-1}\right)$, razão de aquecimento de $10^{\circ} \mathrm{C} \mathrm{m^{-1 }}$, cápsula de alumínio aberta e massa da amostra de $2,223 \mathrm{mg}$. 


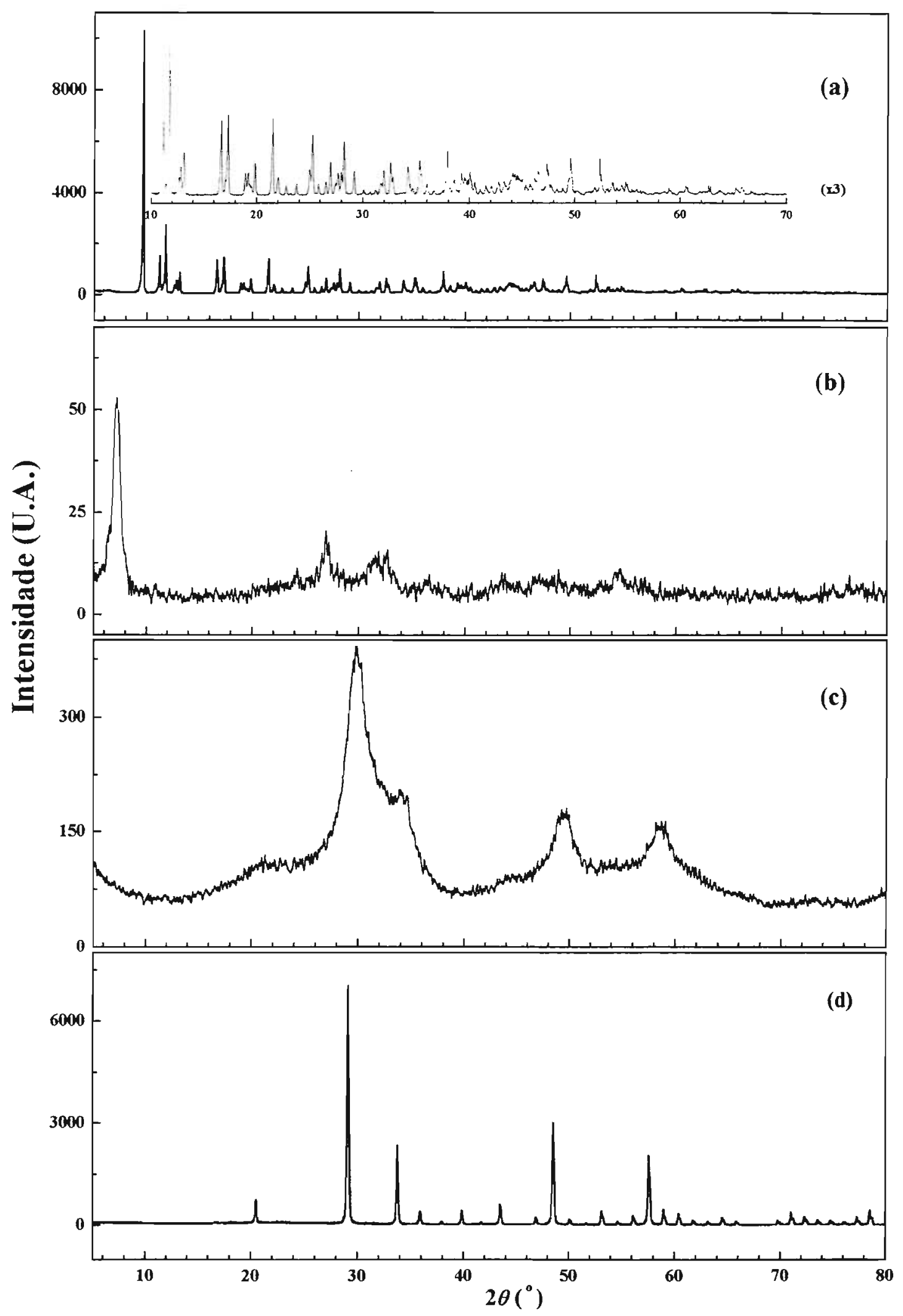

Figura 3.22: Difratogramas de raios $\mathrm{X}$ (método do pó) das amostras: (a) $\mathrm{Y}\left(\mathrm{CH}_{3} \mathrm{COO}\right)_{3} .4 \mathrm{H}_{2} \mathrm{O}$ (inserido $2 \theta=10$ a $70^{\circ}$, ampliado três vezes); (b) intermediário em $200^{\circ} \mathrm{C}$; (c) intermediário em $500^{\circ} \mathrm{C}$; (d) produto final em $900^{\circ} \mathrm{C}$. Os intermediários e o produto final da decomposição térmica foram obtidos sob atmosfera dinâmica de ar $\left(50 \mathrm{~mL} \mathrm{~min}^{-1}\right)$, razão de aquecimento de $10^{\circ} \mathrm{C} \mathrm{min}^{-1}$, utilizando cadinho de platina. 


\section{3- Acetato de níquel}

$\mathrm{Na}$ literatura existe vários estudos envolvendo síntese, propriedades físicoquímicas, estrutura cristalina e decomposição térmica do acetato de níquel [29-39]. Apesar deste sal ser bastante conhecido, a sua caracterização e o estudo termoanalítico foram necessários neste trabalho, pois, o acetato de níquel foi utilizado como material de partida, na síntese de sistemas binários precursores dos óxidos mistos, $\mathrm{TR}_{2} \mathrm{NiO}_{4}[\mathrm{TR}=$ La, Eu e Y (III)].

\subsection{1- Estudo termoanalítico}

$\mathrm{O}$ acetato de níquel tetraidratado, $\mathrm{Ni}\left(\mathrm{CH}_{3} \mathrm{COO}\right)_{2} .4 \mathrm{H}_{2} \mathrm{O}$, foi obtido comercialmente (Tabela 2.1).

Nas Figuras 3.23 e 3.24 estão representadas as curvas TG/DTG, obtidas nas atmosferas dinâmicas de ar comprimido e nitrogênio, respectivamente.

$\mathrm{Ni}\left(\mathrm{CH}_{3} \mathrm{COO}\right)_{2} \cdot 4 \mathrm{H}_{2} \mathrm{O}$ apresentou-se termicamente estável até $60^{\circ} \mathrm{C}$. A primeira variação de massa observada nas curvas TG/DTG correspondeu à libertação de moléculas de água de cristalização, em uma etapa, independente da atmosfera utilizada. Observou-se em $200^{\circ} \mathrm{C}$, uma diferença de $3,54 \%$ entre o valor médio experimental $(32,50 \%)$ e o calculado $(28,96 \%)$, para a libertação de quatro mol de água. Esta diferença foi devido a hidrólise de grupos acetatos, que conduziu na libertação de ácido acético livre na fase gasosa e formação de acetato básico de níquel [40]. Os dados de perda de massa estimaram a formação do $(1-\mathrm{y}) \mathrm{Ni}\left(\mathrm{CH}_{3} \mathrm{COO}\right)_{2}+\mathrm{y} \mathrm{Ni}(\mathrm{OH})_{2}$, com valor de $\mathrm{y} \approx 0,10$ (Tabela 3.8). Estas etapas são representadas pelas equações 3.11 e 3.12 .

$$
\begin{aligned}
& \mathrm{Ni}\left(\mathrm{CH}_{3} \mathrm{COO}\right)_{2} \cdot 4 \mathrm{H}_{2} \mathrm{O}(\mathrm{s}) \rightarrow \mathrm{Ni}\left(\mathrm{CH}_{3} \mathrm{COO}\right)_{2}(\mathrm{~s})+4 \mathrm{H}_{2} \mathrm{O}(\mathrm{g}) \\
& \mathrm{CH}_{3} \mathrm{COO}^{-}+\mathrm{H}_{2} \mathrm{O}(\mathrm{g}) \rightarrow \mathrm{OH}^{-}+\mathrm{CH}_{3} \mathrm{COOH}(\mathrm{g}) \quad\left(\mathrm{K}_{\mathrm{h}}=5,4 \quad 10^{-10}\right)
\end{aligned}
$$

Sob atmosfera de ar, a decomposição térmica do intermediário em $200^{\circ} \mathrm{C}$ ocorreu em uma etapa rápida, com temperatura de pico na curva DTG em $356^{\circ} \mathrm{C}$. A partir de $370^{\circ} \mathrm{C}$ foi formado $\mathrm{NiO}$, o qual manteve-se termicamente estável até $900^{\circ} \mathrm{C}$. No entanto, sob atmosfera de nitrogênio, a decomposição térmica deste intermediário ocorreu em duas etapas, com temperatura de picos na curva DTG em 365 e $426^{\circ} \mathrm{C}$, 
libertando uma mistura gasosa de ácido acético e propanona, e formação de um resíduo preto em $440^{\circ} \mathrm{C}$, constituído de níquel metálico [40]. A partir desta temperatura foi observado um pequeno ganho de massa $(1,48 \%)$, relativo à oxidação do níquel metálico a óxido. A oxidação deve-se, possivelmente, a existência de impurezas no gás de purga, tais como traços de oxigênio e água, ou devido a atmosfera gerada na decomposição térmica do acetato, ou ainda, entrada de ar nas imediações da saída do forno da termobalança. Os resultados de variação de massa indicaram a formação de $\mathrm{NiO}$ em $900^{\circ} \mathrm{C}$.

Os valores percentuais calculados e experimentais do intermediário em $200^{\circ} \mathrm{C} \mathrm{e}$ do óxido de níquel, obtidos na decomposição térmica do acetato de níquel, estão apresentados na Tabela 3.8 .

Tabela 3.8: Dados percentuais dos produtos sólidos da decomposição térmica do acetato de níquel tetraidratado

\begin{tabular}{l|c|c|c}
\hline \multirow{2}{*}{ COMPOSTO } & \multirow{2}{*}{ \% CALCULADA } & \multicolumn{2}{|c}{ \% EXPERIMENTAL } \\
\cline { 3 - 4 } & & AR & $\mathbf{N}_{\mathbf{2}}$ \\
\hline $0,90 \mathrm{Ni}(\mathrm{Ac})_{2} \cdot 0,10 \mathrm{Ni}(\mathrm{OH})_{2}{ }^{*}$ & 67,66 & 67,4 & 67,4 \\
$\mathrm{NiO}$ & 30,02 & 29,7 & 29,6 \\
\hline
\end{tabular}

Ac: ín acetato $\left(\mathrm{CH}_{3} \mathrm{COO}^{-}\right) ;{ }^{*}$ intermediário isolado em $200^{\circ} \mathrm{C}$

Nas Figuras 3.25 e 3.26 estão representadas, respectivamente, as curvas DTA e DSC para o acetato de níquel. Similarmente aos acetatos de terras raras, as diferenças observadas nos valores de temperatura dos picos foram em virtude da massa de amostra usada em cada experimento.

A etapa de desidratação foi evidenciada por um evento endotérmico, tanto na curva DTA $\left(\mathrm{T}_{\mathrm{p}}=116^{\circ} \mathrm{C}\right)$, quanto na curva DSC $\left(\mathrm{T}_{\mathrm{p}}=99^{\circ} \mathrm{C}\right)$. O valor total de $\Delta H$, obtido por DSC, foi igual a $21 \mathrm{~kJ} \mathrm{~mol}^{-1}$, relativo a libertação das moléculas de água de cristalização e hidrólise de grupos acetatos, simultaneamente.

A decomposição térmica do intermediário em $200^{\circ} \mathrm{C}$, sob atmosfera de ar comprimido, foi evidenciada na curva DTA por dois eventos exotérmicos, rápidos e consecutivos em 322 e $364^{\circ} \mathrm{C}$. No entanto, sob atmosfera de nitrogênio a curva DSC evidenciou um evento endotérmico em $310^{\circ} \mathrm{C}\left(\Delta H=16 \mathrm{~kJ} \mathrm{~mol}^{-1}\right)$ seguidos de dois exotérmicos em 383 e $400^{\circ} \mathrm{C}\left(\Delta H=-116 \mathrm{~kJ} \mathrm{~mol}^{-1}\right)$. 


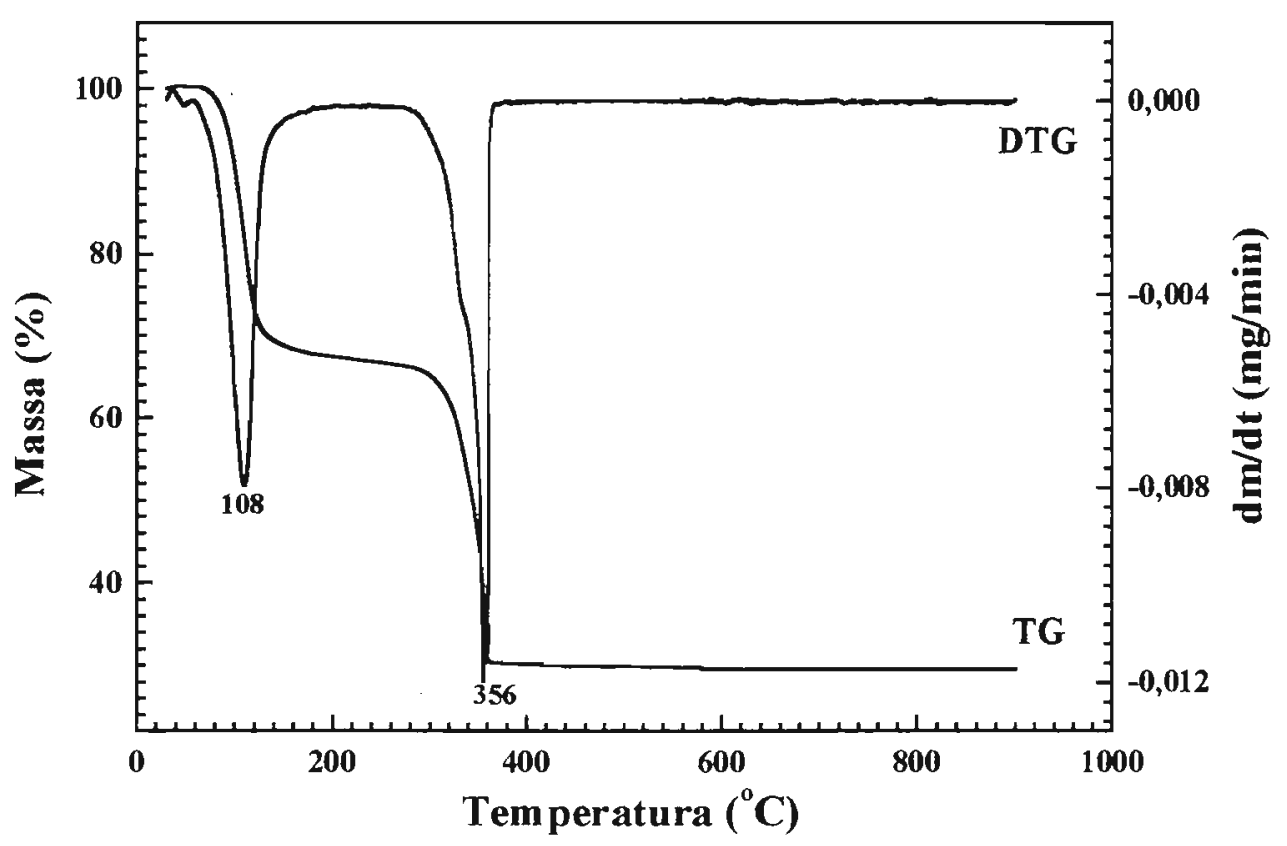

Figura 3.23: Curvas TG/DTG do $\mathrm{Ni}\left(\mathrm{CH}_{3} \mathrm{COO}\right)_{2} \cdot 4 \mathrm{H}_{2} \mathrm{O}$ obtidas sob atmosfera dinâmica de ar (50 $\mathrm{mL} \min ^{-1}$ ), razão de aquecimento de $10^{\circ} \mathrm{C} \mathrm{min}^{-1}$, cadinho de platina e massa da amostra de 4,745 mg.

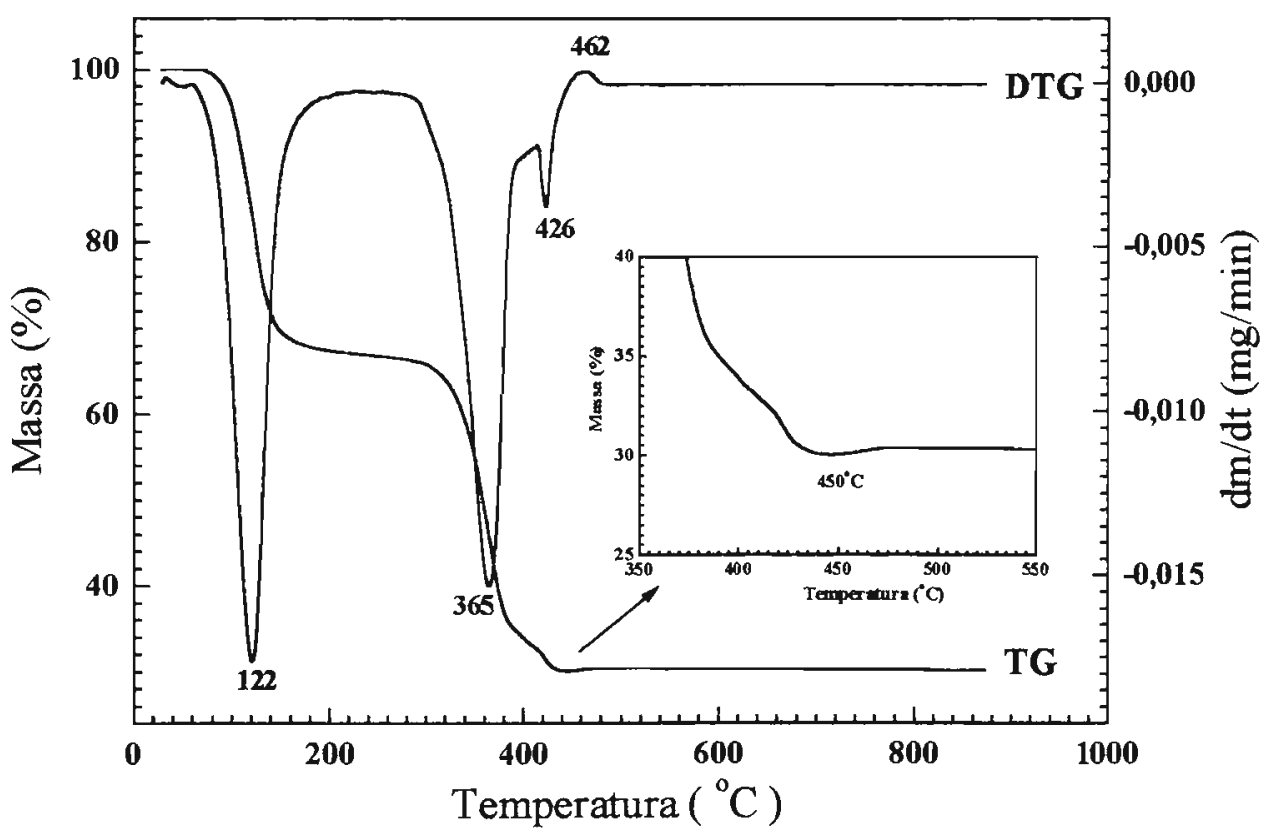

Figura 3.24: Curvas TG/DTG do $\mathrm{Ni}\left(\mathrm{CH}_{3} \mathrm{COO}\right)_{2} \cdot 4 \mathrm{H}_{2} \mathrm{O}$ obtidas sob atmosfera dinâmica de nitrogênio $\left(50 \mathrm{~mL} \mathrm{~min}{ }^{-1}\right)$, razão de aquecimento de $10^{\circ} \mathrm{C} \mathrm{min}^{-1}$, cadinho de platina e massa da amostra de $4,326 \mathrm{mg}$. 


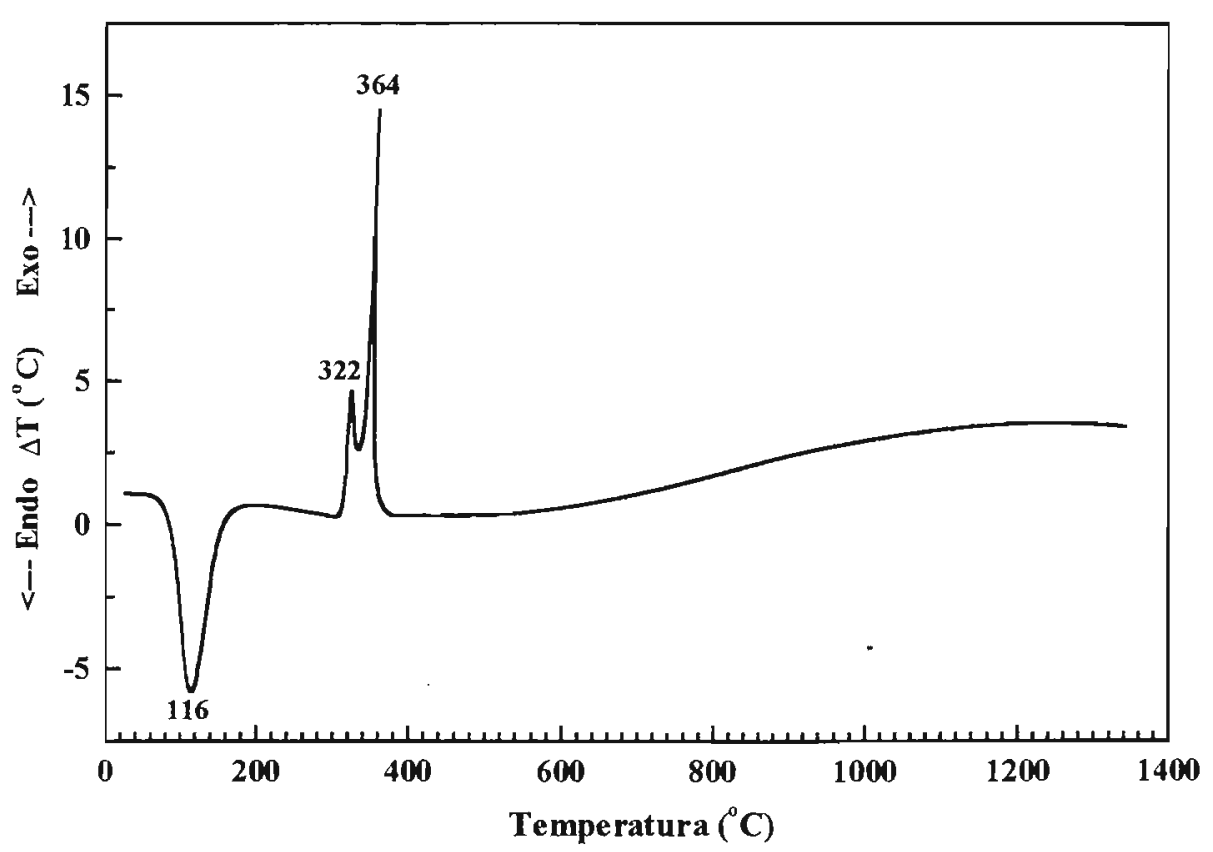

Figura 3.25: Curva DTA do $\mathrm{Ni}\left(\mathrm{CH}_{3} \mathrm{COO}\right)_{2} .4 \mathrm{H}_{2} \mathrm{O}$ obtida sob atmosfera dinâmica de ar $(50 \mathrm{~mL}$ $\mathrm{min}^{-1}$ ), razão de aquecimento de $10^{\circ} \mathrm{C} \mathrm{min}^{-1}$, cadinho de alumina e massa da amostra de 20,15 mg.

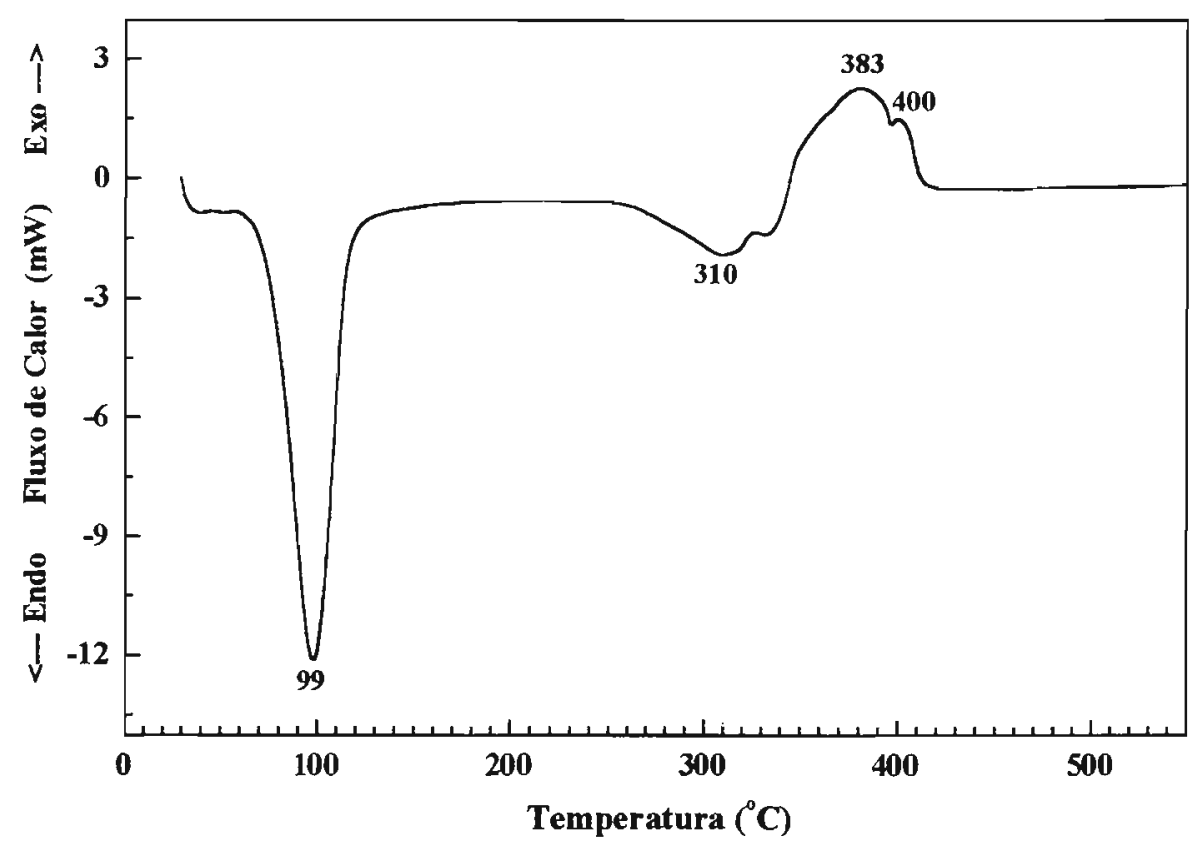

Figura 3.26: Curva DSC do $\mathrm{Ni}\left(\mathrm{CH}_{3} \mathrm{COO}\right)_{2} \cdot 4 \mathrm{H}_{2} \mathrm{O}$ obtida sob atmosfera dinâmica de nitrogênio $(50 \mathrm{~mL} \mathrm{~min}-1)$, razão de aquecimento de $10^{\circ} \mathrm{C} \mathrm{min}^{-1}$, cápsula de alumínio aberta e massa da amostra de 2,015 mg. 


\subsection{2- Caracterização}

A caracterização do $\mathrm{Ni}\left(\mathrm{CH}_{3} \mathrm{COO}\right)_{2} \cdot 4 \mathrm{H}_{2} \mathrm{O}$ e do intermediário isolado em $200{ }^{\circ} \mathrm{C}$ foi realizada por espectroscopia de absorção na região do infravermelho e difração de raios X. Na Figura 3.27 estão apresentados os espectros IR para estes compostos.

Para o intermediário isolado em $200^{\circ} \mathrm{C}$, observou-se o desaparecimento das bandas de absorção, relativas às vibrações das moléculas de água de cristalização. No entanto, as bandas características do grupo acetato continuam presentes. Na Tabela 3.9 estão apresentadas as freqüências de absorção e as atribuições das bandas dos espectros $\mathrm{R}$, para o $\mathrm{Ni}\left(\mathrm{CH}_{3} \mathrm{COO}\right)_{2} .4 \mathrm{H}_{2} \mathrm{O}$ e intermediário isolado em $200^{\circ} \mathrm{C}$.

Tabela 3.9: Atribuição das bandas de absorção dos espectros IR do acetato de níquel e intermediário isolado em $200^{\circ} \mathrm{C}$ (número de onda, $\mathrm{cm}^{-1}$ ) *

\begin{tabular}{|c|c|c|}
\hline ATRIBUIÇÃO & $\mathrm{Ni}\left(\mathrm{CH}_{3} \mathrm{COO}\right)_{2} \cdot 4 \mathrm{H}_{2} \mathrm{O}$ & INTERMEDIÁRIO EM $200^{\circ} \mathrm{C}$ \\
\hline$v(\mathrm{O}-\mathrm{H})$ & $\begin{array}{l}3477(\mathrm{mF}) \\
3139(\mathrm{mF})\end{array}$ & 3400 \\
\hline$\nu_{\text {as. }}(\mathrm{C}-\mathrm{H})$ & $3025(0)$ & 3047 (o) \\
\hline$v_{\mathrm{s} .}(\mathrm{C}-\mathrm{H})$ & n. 0 . & $2961(\mathrm{o})$ \\
\hline$v_{\text {as. }}\left(\mathrm{COO}^{-}\right)$ & $1536(\mathrm{mF})$ & $1564(\mathrm{mF})$ \\
\hline$v_{\mathrm{s} .}\left(\mathrm{COO}^{-}\right)$ & $1421(\mathrm{mF})$ & $1422(\mathrm{~F})$ \\
\hline$\delta_{\text {s. }}\left(\mathrm{CH}_{3}\right)$ & $1353(\mathrm{~m})$ & $1346(\mathrm{~m})$ \\
\hline$\rho\left(\mathrm{CH}_{3}\right)$ & $\begin{array}{l}1058(\mathrm{~m}) \\
1030(\mathrm{~m})\end{array}$ & $1029(f)$ \\
\hline$v(\mathrm{C}-\mathrm{C})$ & $964(f)$ & $962(0)$ \\
\hline$\rho\left(\mathrm{H}_{2} \mathrm{O}\right)_{\text {rock }}$ ** & $908(\mathrm{~m})$ & n. $o$. \\
\hline$\beta\left(\mathrm{H}_{2} \mathrm{O}\right)_{t w i s t} \star \star$ & $820(\mathrm{~m})$ & n. $o$. \\
\hline$\gamma\left(\mathrm{H}_{2} \mathrm{O}\right)_{w a g} * *$ & $752(\mathrm{~m})$ & n. o. \\
\hline$\delta\left(\mathrm{COO}^{-}\right)$ & $678(\mathrm{~F})$ & $682(\mathrm{~F})$ \\
\hline$\rho\left(\mathrm{COO}^{-}\right)_{\text {fora do plano }}$ & $628(\mathrm{~m})$ & $619(\mathrm{~m})$ \\
\hline$\pi\left(\mathrm{COO}^{-}\right)_{\text {no plano }}$ & $552(\mathrm{f})$ & $534(\mathrm{f})$ \\
\hline
\end{tabular}


A partir dos dados de espectroscopia no $\mathbb{R}$, pode-se confirmar que 0 $\mathrm{Ni}\left(\mathrm{CH}_{3} \mathrm{COO}\right)_{2} \cdot 4 \mathrm{H}_{2} \mathrm{O}$ apresentou coordenação monodentada do ligante acetato $[29,30]$. Quanto ao intermediário isolado em $200^{\circ} \mathrm{C}$, o modo de coordenação pode ser bidentado, pois o valor de $\Delta v=142 \mathrm{~cm}^{-1}$, é indicativo de tal coordenação. No entanto, esse intermediário é uma mistura de acetato de níquel anidro e hidróxido de níquel, e o modo de coordenação torna-se dificil de ser definido.

Os resultados de difração de raios $\mathrm{X}$ para o $\mathrm{Ni}\left(\mathrm{CH}_{3} \mathrm{COO}\right)_{2} .4 \mathrm{H}_{2} \mathrm{O}$, Figura 3.28 a, permitiram identificar o sistema monoclínico e grupo espacial $P 2_{l} / c$ [29]. Na Tabela 3.10 estão apresentadas as principais distâncias interplanares $d(\AA)$, posições angulares $2 \theta\left(^{\circ}\right)$ e intensidade relativa $\left(\mathrm{I} / \mathrm{I}_{0}\right)$ das principais linhas observadas no difratograma de raios $\mathrm{X}$, comparadas com aquelas da ficha padrão (ASTM 25-0901) do acetato de níquel [8].

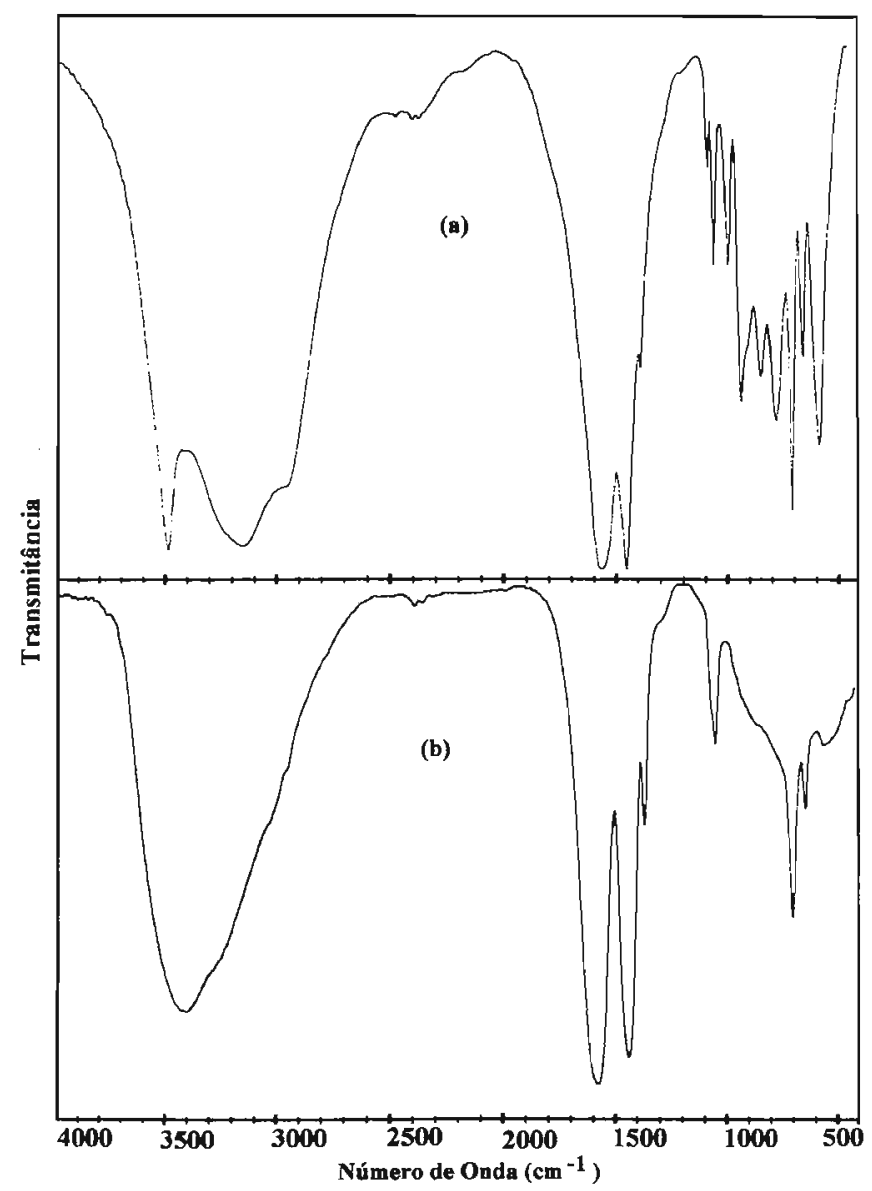

Figura 3.27: Espectros de absorção na região do infravermelho dos compostos:

(a) $\mathrm{Ni}\left(\mathrm{CH}_{3} \mathrm{COO}\right)_{2} .4 \mathrm{H}_{2} \mathrm{O}$; (b) Intermediário isolado em $200^{\circ} \mathrm{C}$ 
Tabela 3.10: Dados parciais de difração de raios $\mathrm{X}$ para o acetato de níquel

\begin{tabular}{|c|c|c|c|c|c|c|c|}
\hline \multicolumn{8}{|c|}{$\mathrm{Ni}\left(\mathrm{CH}_{3} \mathrm{COO}\right)_{2 .} \cdot 4 \mathrm{H}_{2} \mathrm{O}$} \\
\hline \multicolumn{3}{|c|}{ Experimental } & \multicolumn{5}{|c|}{ Padrão (25-0901) } \\
\hline $2 \theta\left(^{\circ}\right)$ & d $(\AA)$ & $\mathbf{I} / \mathbf{I}_{\mathbf{o}}$ & d $(\AA)$ & $\mathbf{I} / \mathbf{I}_{\mathbf{0}}$ & $\mathbf{h}$ & $\mathbf{k}$ & 1 \\
\hline 12,9 & 6,85 & 100 & 6,87 & 100 & 1 & 1 & 0 \\
\hline 15,0 & 5,89 & 2 & 5,90 & 3 & 0 & 2 & 0 \\
\hline 18,6 & 4,77 & 1,5 & 4,77 & 15 & 0 & 0 & 1 \\
\hline 21,1 & 4,21 & 11 & 4,22 & 20 & 2 & 0 & 0 \\
\hline 22,1 & 4,02 & 2 & 4,02 & 6 & 1 & 1 & 1 \\
\hline 22,4 & 3,96 & 4 & 3,97 & 6 & 2 & 1 & 0 \\
\hline 23,3 & 3,82 & 1 & 3,82 & 3 & 1 & 1 & 1 \\
\hline 25,0 & 3,56 & 4 & 3,56 & 6 & 1 & 3 & 0 \\
\hline 28,3 & 3,15 & 4 & 3,15 & 15 & 2 & 1 & 1 \\
\hline 30,9 & 2,90 & 1 & 2,89 & 3 & 1 & 3 & 1 \\
\hline 31,1 & 2,87 & 4 & 2,87 & 4 & 2 & 3 & 0 \\
\hline 35,8 & 2,51 & 2 & 2,50 & 3 & 0 & 4 & 1 \\
\hline
\end{tabular}

20: posição angular; d: distância interplanar; $\mathbf{h} \mathbf{k}$ l: índices de Miller

Para os intermediários sólidos da decomposição térmica do $\mathrm{Ni}\left(\mathrm{CH}_{3} \mathrm{COO}\right)_{2} \cdot 4 \mathrm{H}_{2} \mathrm{O}$, isolados na atmosfera de nitrogênio em $200,450,570$ e $900^{\circ} \mathrm{C}$, a caracterização foi realizada por XRD. A análise dos difratogramas de raios $\mathrm{X}$ (Figura 3.28) permitiu concluir que: (i) o intermediário em $200^{\circ} \mathrm{C}$ apresentou natureza não cristalina, sugerindo que as moléculas de água coordenadas são fundamentais para a cristalinidade do $\mathrm{Ni}\left(\mathrm{CH}_{3} \mathrm{COO}\right)_{2} .4 \mathrm{H}_{2} \mathrm{O}$; (ii) o intermediário em $450^{\circ} \mathrm{C}$ correspondeu ao níquel metálico (ASTM 4-850), não sendo observado as reflexões pertinentes ao $\mathrm{NiO}$; (iii) em $570^{\circ} \mathrm{C}$ as reflexões relativas ao níquel metálico começaram a desaparecer e surgiram as reflexões relativas ao óxido; (iv) com o aumento da temperatura observou-se a completa oxidação do níquel metálico a óxido. Em $900^{\circ} \mathrm{C}$ foi produzido NiO (preto) (ASTM 4-835) [8]. 


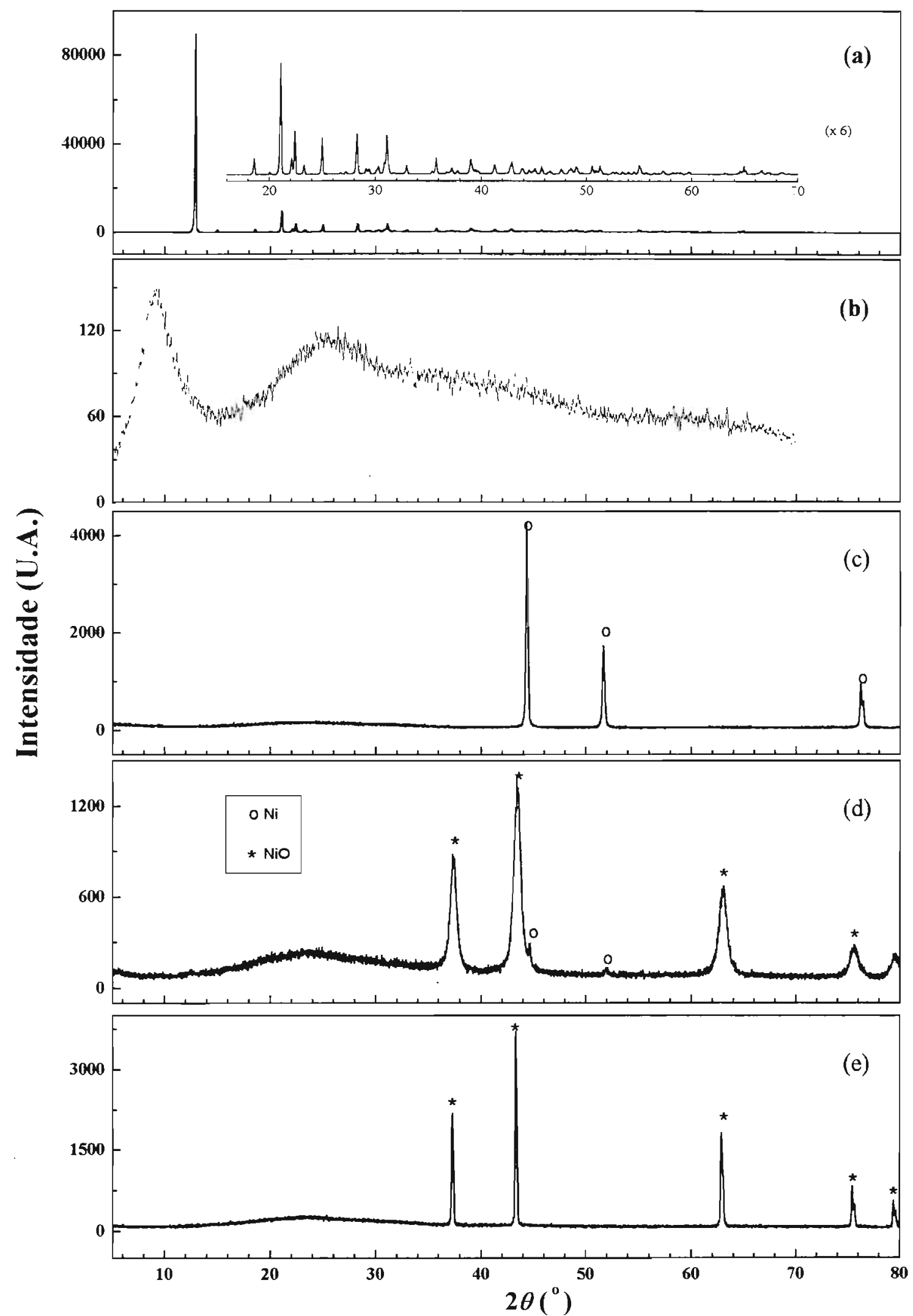

Figura 3.28: Difratogramas de raios $X$ (método do pó) das amostras: (a) $\mathrm{Ni}\left(\mathrm{CH}_{3} \mathrm{COO}\right)_{3} \cdot 4 \mathrm{H}_{2} \mathrm{O}$ (inserido $2 \theta=16$ a $70^{\circ}$, ampliado seis vezes); (b) intermediário em $200^{\circ} \mathrm{C}$; (c) intermediário em $450^{\circ} \mathrm{C}$; (d) intermediário em $570^{\circ} \mathrm{C}$; (e) produto final em $900^{\circ} \mathrm{C}$. Os intermediários e o produto final foram obtidos sob atmosfera dinâmica de nitrogênio $\left(50 \mathrm{~mL} \mathrm{~min}^{-1}\right)$, razão de aquecimento de $10^{\circ} \mathrm{C} \mathrm{min}^{-1}$, utilizando cadinho de platina. 
Utilizando um sistema simultâneo e acoplado TG/DTA-GC/MS, foi possível detectar e identificar os voláteis provenientes da decomposição térmica do $\mathrm{Ni}\left(\mathrm{CH}_{3} \mathrm{COO}\right)_{2} \cdot 4 \mathrm{H}_{2} \mathrm{O}$, sob atmosfera de hélio ultra puro. Neste sistema, a amostra foi submetida a uma razão de aquecimento linear, proporcionando a sua decomposição. Os voláteis libertados foram conduzidos para um tubo concentrador e, em seguida, carreados para uma coluna cromatográfica, os quais foram separados por ordem de polaridade e detectados pelo espectrômetro de massa.

O cromatograma total e os respectivos cromatogramas de massa de cada pico, correspondentes aos voláteis identificados estão apresentados na Figura 3.29. A partir da comparação dos espectros de massa obtidos com os respectivos padrões (contidos na biblioteca do banco de dados), foi possível identificar os voláteis, propanona e ácido acético, como principais produtos gasosos, da decomposição térmica do acetato de níquel (Figura 3.30).

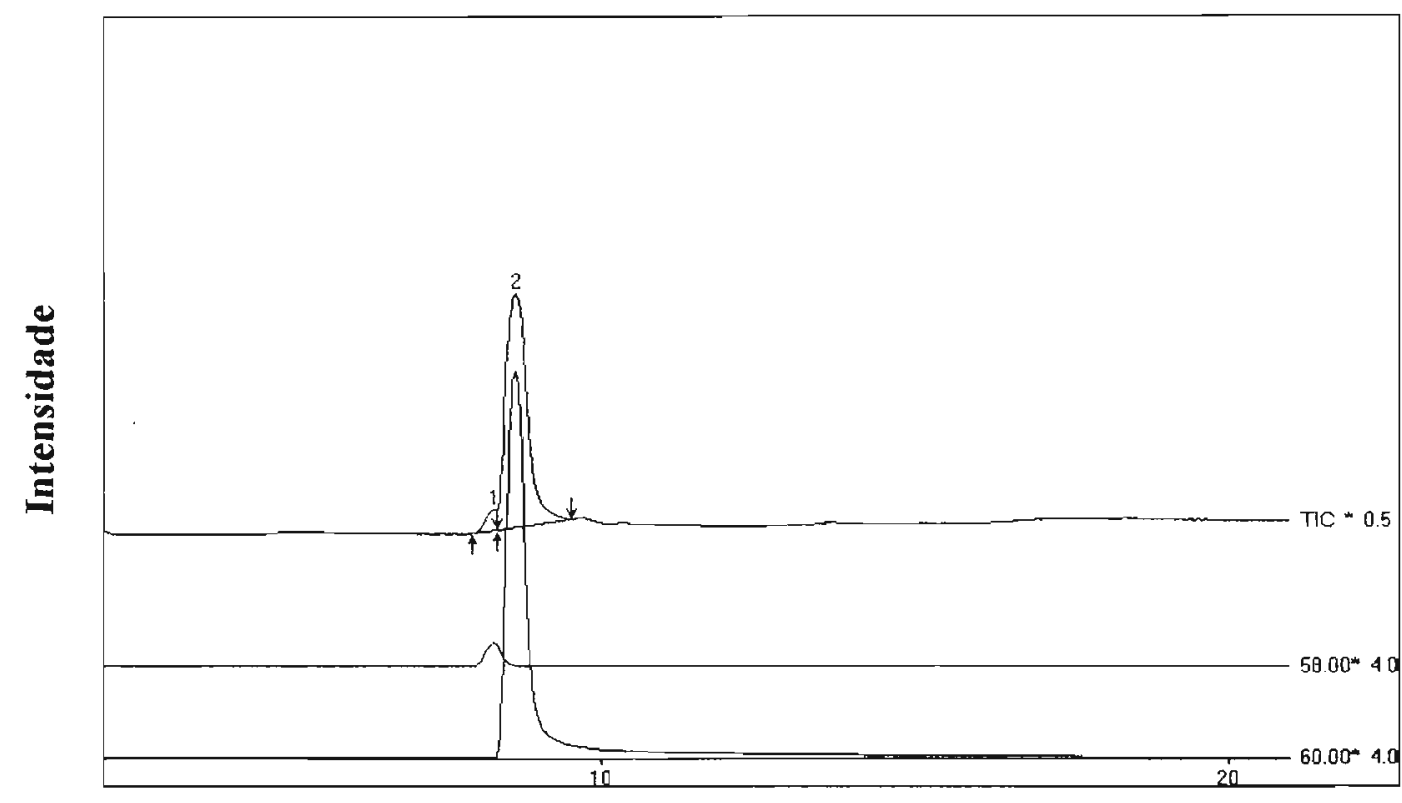

Tempo de Retenção (min)

Figura 3.29: Cromatograma total e os respectivos cromatogramas de massa dos voláteis libertados na decomposição térmica do $\mathrm{Ni}\left(\mathrm{CH}_{3} \mathrm{COO}\right)_{2} \cdot 4 \mathrm{H}_{2} \mathrm{O}$. 

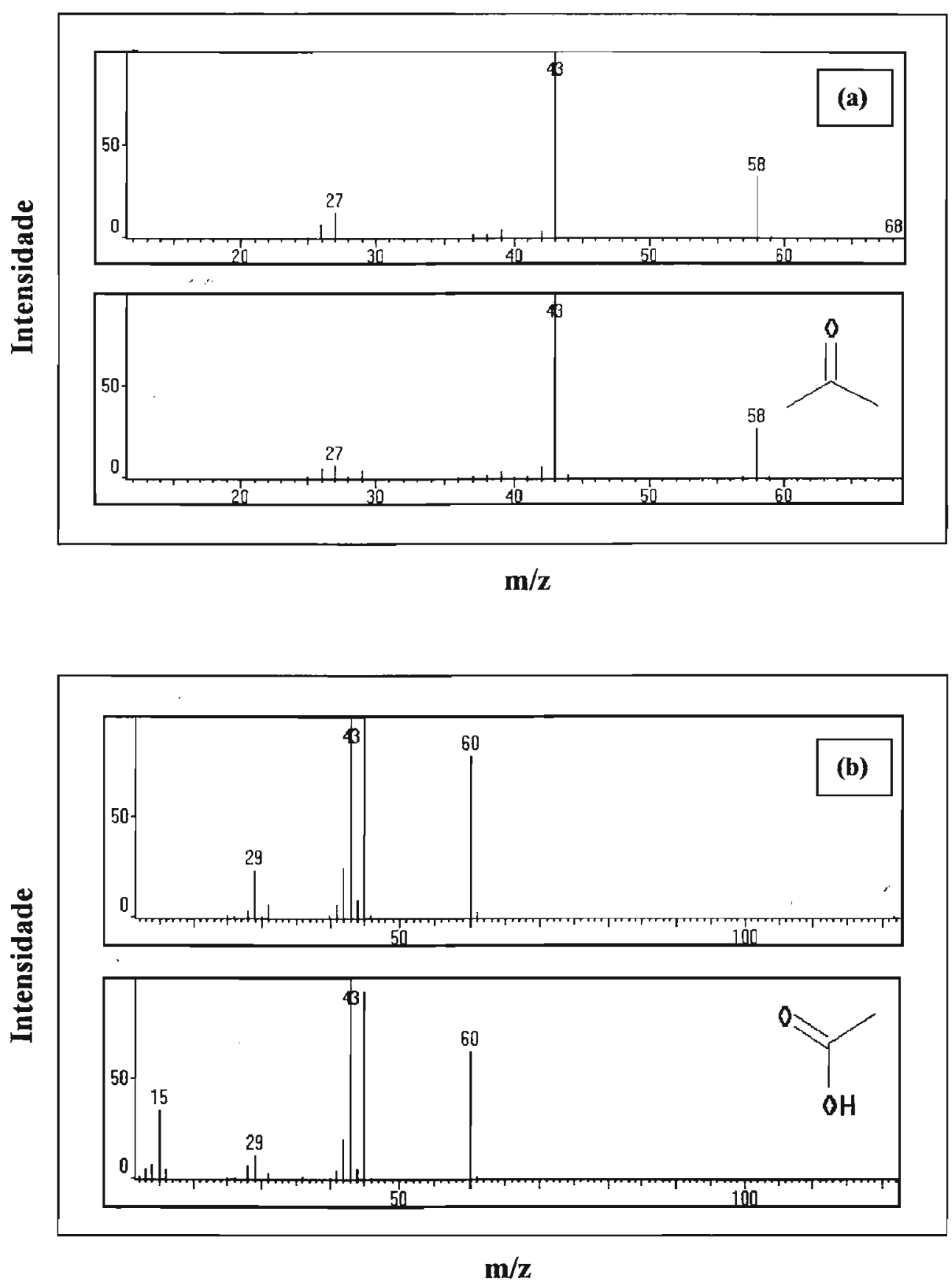

Figura 3.30: Espectros de massa dos voláteis da decomposição térmica do $\mathrm{Ni}\left(\mathrm{CH}_{3} \mathrm{COO}\right)_{2} \cdot 4 \mathrm{H}_{2} \mathrm{O}$ : (a) propanona e (b) ácido acético. 


\section{4- Acetatos binários}

Os acetatos binários de terras raras e níquel, TRNi $\left(\mathrm{CH}_{3} \mathrm{COO}\right)_{5} \cdot \mathrm{xH}_{2} \mathrm{O}[\mathrm{TR}=\mathrm{La}$, Eu e Y (III)], foram sintetizados por três métodos: (1) mistura mecânica; (2) evaporação do solvente e (3) cristalização com acetona. Os métodos 2 e 3 foram utilizados, com o objetivo de obter acetatos duplos e compará-los com a mistura fisica (método 1). A partir da decomposição térmica desses precursores, utilizando diferentes atmosferas atuantes, tentou-se otimizar as condições para a obtenção de óxidos mistos do tipo $\mathrm{TR}_{2} \mathrm{NiO}_{4}$.

\subsection{1- Sistema lantânio - níquel}

Os sistemas de acetatos binários de lantânio (III) e níquel (II) foram obtidos hidratados, cristalinos e solúveis em água.

\subsubsection{1- Análise elementar}

Os teores de carbono e hidrogênio foram determinados por procedimentos microanalíticos, enquanto que os teores de lantânio e níquel foram obtidos a partir de cálculos de variação de massa registrados, diretamente, nas curvas TG/DTG sob atmosfera de ar comprimido. Os resultados revelaram a estequiometria dos acetatos binários e estão apresentados na Tabela 3.11.

Tabela 3.11: Resultados de análise elementar para os sistemas de acetatos binários de lantânio e níquel

\begin{tabular}{l|c|c|c|c|c|c|c|c}
\hline \multirow{2}{*}{ ACETATOS BINÁRIOS } & \multicolumn{4}{c|}{ \% CALCULADA } & \multicolumn{3}{c}{ \% EXPERIMENTAL } \\
\cline { 2 - 9 } & $\mathbf{C}$ & $\mathbf{H}$ & $\mathbf{L a}$ & $\mathbf{N i}$ & $\mathbf{C}$ & $\mathbf{H}$ & $\mathbf{L a}$ & $\mathbf{N i}$ \\
\hline $\mathrm{LaNi}(\mathrm{Ac})_{5} .5,5 \mathrm{H}_{2} \mathrm{O}^{\mathrm{a}}$ & 20,29 & 4,43 & 23,47 & 9,92 & 20,15 & 4,29 & 23,02 & 9,83 \\
$\mathrm{LaNi}(\mathrm{Ac})_{5}, 3 \mathrm{H}_{2} \mathrm{O}^{b}$ & 21,96 & 3,87 & 25,40 & 10,73 & 21,61 & 3,67 & 25,00 & 10,56 \\
$\mathrm{LaNi}(\mathrm{Ac})_{5} .2,5 \mathrm{H}_{2} \mathrm{O}^{\mathrm{c}}$ & 22,33 & 3,75 & 25,82 & 10,91 & 22,27 & 3,44 & 25,56 & 10,80 \\
\hline
\end{tabular}

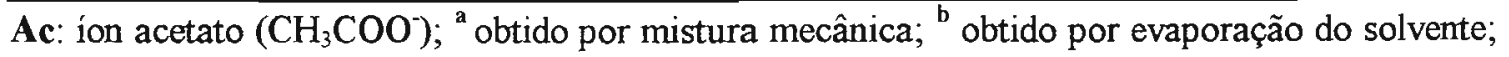
${ }^{c}$ obtido por cristalização com acetona 


\subsubsection{2- Espectroscopia de absorção na região do infravermelho}

Os espectros de absorção na região do infravermelho para os acetatos binários de lantânio e níquel estão apresentados na Figura 3.31. Os sistemas obtidos por evaporação do solvente, $\mathrm{LaNi}\left(\mathrm{CH}_{3} \mathrm{COO}\right)_{5} .3 \mathrm{H}_{2} \mathrm{O}$, e por cristalização com acetona, $\mathrm{LaNi}\left(\mathrm{CH}_{3} \mathrm{COO}\right)_{5} .2,5 \mathrm{H}_{2} \mathrm{O}$, apresentaram espectros IR similares. As bandas de absorção foram observadas nas mesmas freqüências relativas ao $\mathrm{La}\left(\mathrm{CH}_{3} \mathrm{COO}\right)_{3} \cdot 1,5 \mathrm{H}_{2} \mathrm{O}$. Esse resultado indicou que os sais cristalizaram, possivelmente, com a mesma estrutura cristalina. No entanto, para o sistema obtido por mistura mecânica, $\mathrm{LaNi}\left(\mathrm{CH}_{3} \mathrm{COO}\right)_{5} .5,5 \mathrm{H}_{2} \mathrm{O}$, o espectro IR apresentou o somatório das bandas de absorção relativas aos acetatos simples.

Na Tabela 3.12 estão apresentadas as atribuições das bandas de absorção dos espectros IR para os sistemas de acetatos binários de lantânio e níquel.

\subsubsection{3- Difração de raios $X$}

Os difratogramas de raios X, Figura 3.32, dos acetatos binários de lantânio e níquel, foram obtidos com o objetivo de verificar a cristalinidade e observar a formação de novas fases. As análises foram realizadas por meio de comparações, entre as linhas de reflexão dos sistemas binários com as dos acetatos simples (Tabela 3.13).

Similarmente aos resultados de infravermelho, foi observado que o difratograma de raios $\mathrm{X}$ do sistema obtido por mistura mecânica, $\mathrm{LaNi}\left(\mathrm{CH}_{3} \mathrm{COO}\right)_{5} .5,5 \mathrm{H}_{2} \mathrm{O}$, correspondeu a mistura dos acetatos simples, evidenciado pelas linhas de reflexão mais intensas do $\mathrm{La}\left(\mathrm{CH}_{3} \mathrm{COO}\right)_{3} \cdot 1,5 \mathrm{H}_{2} \mathrm{O}$ e $\mathrm{Ni}\left(\mathrm{CH}_{3} \mathrm{COO}\right)_{3} \cdot 4 \mathrm{H}_{2} \mathrm{O}$, em $2 \theta=9,0$ e $12,9^{\circ}$, respectivamente. Para os sistemas obtidos por evaporação do solvente, $\mathrm{LaNi}\left(\mathrm{CH}_{3} \mathrm{COO}\right)_{5} .3 \mathrm{H}_{2} \mathrm{O}$, e por cristalização com acetona, $\mathrm{LaNi}\left(\mathrm{CH}_{3} \mathrm{COO}\right)_{5}, 2,5 \mathrm{H}_{2} \mathrm{O}$, os difratogramas de raios $\mathrm{X}$ apresentaram algumas linhas de reflexão não observadas nos acetatos simples e diferentes em relação ao $\mathrm{LaNi}\left(\mathrm{CH}_{3} \mathrm{COO}\right)_{5} .5,5 \mathrm{H}_{2} \mathrm{O}$.

Quanto à cristalinidade dos compostos, foi observado que o método de síntese utilizado, influenciou na cristalinidade, aumentando na seguinte ordem: mistura mecânica $>$ evaporação do solvente $>$ cristalização com acetona. 
Tabela 3.12: Atribuição das bandas de absorção dos espectros $\mathbb{R}$ dos sistemas de acetatos binários de lantânio e níquel (número de onda, $\mathrm{cm}^{-1}$ ) *

\begin{tabular}{|c|c|c|c|}
\hline ATRIBUIÇÃO & $\mathrm{LaNi}(\mathrm{Ac})_{5}, 5,5 \mathrm{H}_{2} \mathrm{O}^{\mathrm{a}}$ & $\mathrm{LaNi}(\mathrm{Ac})_{5} \cdot 3 \mathrm{H}_{2} \mathrm{O}^{b}$ & $\mathrm{LaNi}(\mathrm{Ac})_{5} .2,5 \mathrm{H}_{2} \mathrm{O}$ \\
\hline$v(\mathrm{O}-\mathrm{H})$ & $\begin{array}{l}3477(\mathrm{~F}) \\
3210(\mathrm{~F})\end{array}$ & $3335(\mathrm{~F})$ & $3336(\mathrm{~F})$ \\
\hline$v_{\text {as. }}(C-H)$ & n. $o$. & $3012(0)$ & $3012(0)$ \\
\hline$v_{\text {s. }}(\mathrm{C}-\mathrm{H})$ & $2940(0)$ & $2940(0)$ & $2940(0)$ \\
\hline$\delta(\mathrm{OH})$ & $1680(0)$ & $1681(0)$ & $1681(\mathrm{o})$ \\
\hline$\nu_{\text {as. }}\left(\mathrm{COO}^{-}\right)$ & $1561(\mathrm{mF})$ & $1563(\mathrm{mF})$ & $1563(\mathrm{~F})$ \\
\hline$v_{\mathrm{s} .}\left(\mathrm{COO}^{-}\right)$ & $\begin{array}{c}1440(\mathrm{o}) \\
1421(\mathrm{mF})\end{array}$ & $\begin{array}{l}1450(\mathrm{mF}) \\
1427(\mathrm{mF})\end{array}$ & $\begin{array}{c}1450(\mathrm{f}) \\
1427(\mathrm{mF})\end{array}$ \\
\hline$\delta_{\text {as. }}\left(\mathrm{CH}_{3}\right)$ & $1407(\mathrm{mF})$ & $1407(\mathrm{mF})$ & 1406 \\
\hline$\delta_{\mathrm{s}}\left(\mathrm{CH}_{3}\right)$ & $\begin{array}{l}1351(\mathrm{~m}) \\
1339(\mathrm{~m})\end{array}$ & $\begin{array}{l}1349(\mathrm{~m}) \\
1338(\mathrm{~m})\end{array}$ & $\begin{array}{l}1351(\mathrm{~m}) \\
1337(\mathrm{~m})\end{array}$ \\
\hline$\rho\left(\mathrm{CH}_{3}\right)$ & $\begin{array}{c}1055(\mathrm{f}) \\
1020(\mathrm{~m})\end{array}$ & $\begin{array}{c}1053(\mathrm{f}) \\
1019(\mathrm{~m})\end{array}$ & $\begin{array}{l}1054(\mathrm{f}) \\
1018(\mathrm{f})\end{array}$ \\
\hline$v(\mathrm{C}-\mathrm{C})$ & $944(\mathrm{~m})$ & $944(\mathrm{~m})$ & $944(f)$ \\
\hline$\rho\left(\mathrm{H}_{2} \mathrm{O}\right)_{\text {rock }}$ * & $908(\mathrm{~m})$ & $908(\mathrm{mf})$ & $908(\mathrm{mf})$ \\
\hline$\beta\left(\mathrm{H}_{2} \mathrm{O}\right)_{\text {twist }}$ ** & $818(\mathrm{~m})$ & n. $o$. & n. $o$. \\
\hline$\gamma\left(\mathrm{H}_{2} \mathrm{O}\right)_{\text {wag }}$ * * & $750(\mathrm{~m})$ & n. $o$. & n. $o$. \\
\hline$\delta\left(\mathrm{COO}^{-}\right)$ & $672(\mathrm{~F})$ & $669(f)$ & $669(\mathrm{~m})$ \\
\hline$\rho\left(\mathrm{COO}^{\circ}\right)_{\text {fora do plano }}$ & $626(\mathrm{~m})$ & $613(\mathrm{~m})$ & $614(f)$ \\
\hline$\pi\left(\mathrm{COO}^{-}\right)_{\text {no plano }}$ & $\begin{array}{c}552(\mathrm{~m}) \\
472(\mathrm{f})\end{array}$ & $\begin{array}{l}540(f) \\
470(f)\end{array}$ & $\begin{array}{l}540(f) \\
471(f)\end{array}$ \\
\hline
\end{tabular}

* Nomenclatura das bandas segundo Nakamoto [23]; ** segundo Raghuvanshi et al. [32]; Ac: íon acetato $\left(\mathrm{CH}_{3} \mathrm{COO}^{-}\right) ;{ }^{a}$ obtido por mistura mecânica; ${ }^{\mathbf{b}}$ obtido por evaporação do solvente; c obtido por cristalização com acetona; mf: muito fraca (100-85\%); f: fraca (85-60\%); m: média (60-30\%); F: forte (30-10\%); mF: muito forte (10-0 \%); $\mathbf{0}$ : ombro; $\mathbf{n} . \mathbf{0 . :}$ não observado 


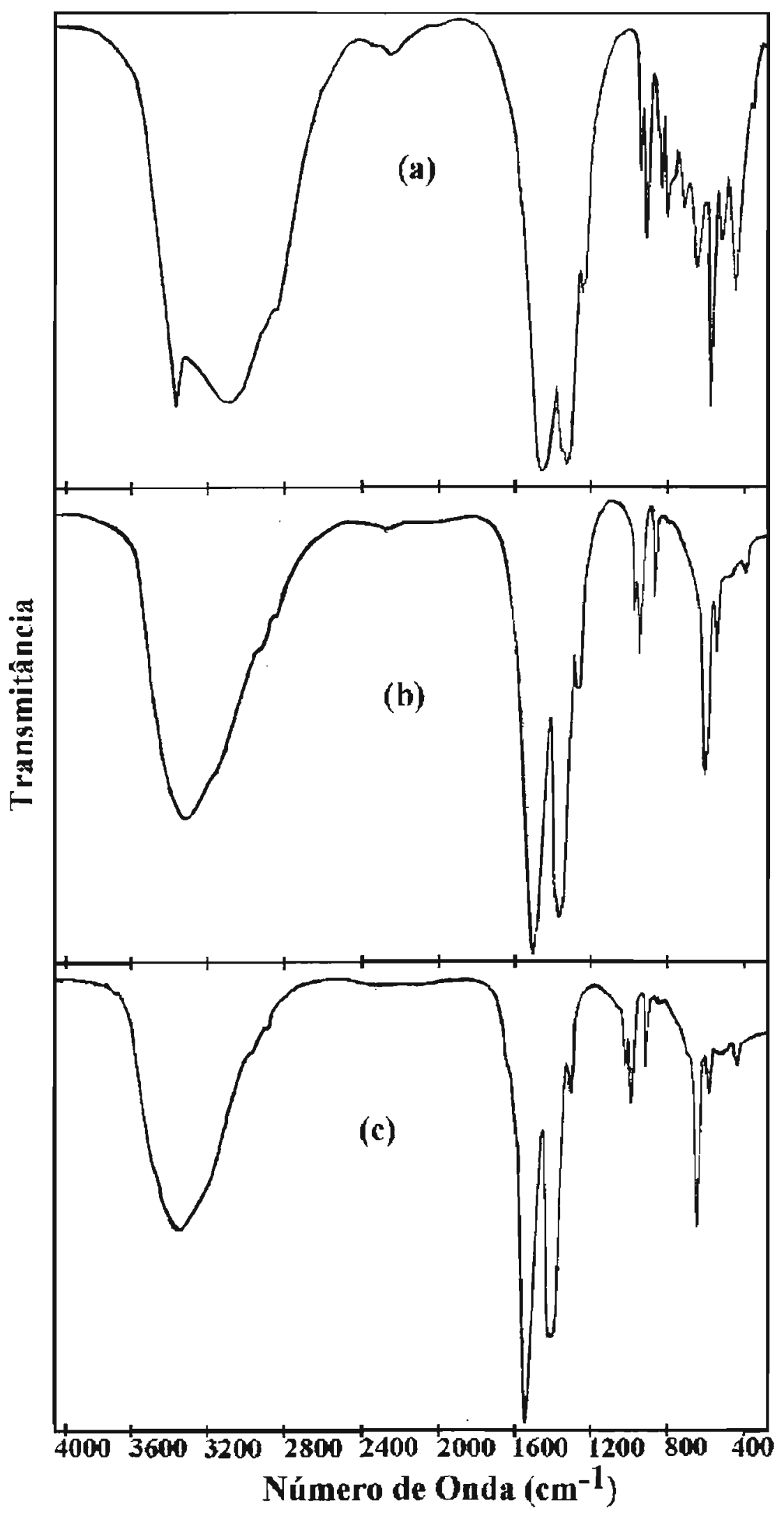

Figura 3.31: Espectros de absorção na região do infravermelho dos sistemas de acetatos binários: (a) $\mathrm{LaNi}\left(\mathrm{CH}_{3} \mathrm{COO}\right)_{5} .5,5 \mathrm{H}_{2} \mathrm{O}$ (M . M.); (b) $\mathrm{LaNi}\left(\mathrm{CH}_{3} \mathrm{COO}\right)_{5} .3 \mathrm{H}_{2} \mathrm{O}$ (E. S.); (c) $\mathrm{LaNi}\left(\mathrm{CH}_{3} \mathrm{COO}\right)_{5} .2,5 \mathrm{H}_{2} \mathrm{O}$ (C. A.). 
Tabela 3.13: Dados parciais de difração de raios $X$ para os sistemas de acetatos binários de lantânio e níquel

\begin{tabular}{|c|c|c|c|c|c|c|c|c|}
\hline \multicolumn{3}{|c|}{$\operatorname{LaNi}(\mathrm{Ac})_{5} .5,5 \mathrm{H}_{2} \mathrm{O}^{\mathrm{a}}$} & \multicolumn{3}{|c|}{$\mathrm{LaNi}(\mathrm{Ac})_{5} \cdot 3 \mathrm{H}_{2} \mathrm{O}^{b}$} & \multicolumn{3}{|c|}{$\mathrm{LaNi}(\mathrm{Ac})_{5} \cdot 2,5 \mathrm{H}_{2} \mathrm{O}^{\mathrm{c}}$} \\
\hline $2 \theta\left({ }^{\circ}\right)$ & d $(\AA)$ & I/Io & $2 \theta$ & d $(\AA)$ & I/Io & $2 \theta$ & d $(\AA)$ & I/Io \\
\hline 9,0 & 9,78 & 100 & 8,9 & 9,87 & 100 & 9,0 & 9,80 & 100 \\
\hline n. o. & n. o. & n. $o$ & n. o. & n. o. & n. o. & 10,9 & 8,07 & 13 \\
\hline 11,2 & 7,87 & 2 & 11,2 & 7,92 & 9 & 11,2 & 7,89 & 22 \\
\hline n. o. & n. o. & n. o. & n. $o$ & n. o. & n. o. & 11,5 & 7,69 & 11 \\
\hline 12,9 & 6,84 & 69 & 12,8 & 6,91 & 2 & 12,9 & 6,86 & 9 \\
\hline 13,5 & 6,52 & 2 & 13,5 & 6,56 & 2 & 13,5 & 6,52 & 7 \\
\hline 15,1 & 5,87 & 1 & 15,2 & 5,83 & 1 & 15,3 & 5,79 & 4 \\
\hline 15,8 & 5,58 & 1 & 15,7 & 5,62 & 2 & 15,8 & 5,60 & 8 \\
\hline 16,4 & 5,39 & 3 & 16,1 & 5,43 & 5 & 16,4 & 5,40 & 19 \\
\hline 18,1 & 4,89 & 2 & 18,0 & 4,91 & 3 & 18,0 & 4,90 & 2 \\
\hline 18,7 & 4,75 & 1 & n. $o$. & n. o. & n. o. & n. o. & n. $o$. & n. $o$. \\
\hline 19,3 & 4,59 & 2 & 19,2 & 4,62 & 2 & 19,2 & 4,60 & 4 \\
\hline 20,4 & 4,34 & 5 & 20,3 & 4,37 & 6 & 20,4 & 4,34 & 23 \\
\hline 21,1 & 4,21 & 11 & 21,1 & 4,21 & 2 & 21,1 & 4,20 & 10 \\
\hline n. o. & n. o. & n. $o$ & 21,6 & 4,10 & 1 & 21,6 & 4,10 & 6 \\
\hline 22,2 & 3,99 & 3 & 22,1 & 4,01 & 5 & 22,2 & 3,99 & 20 \\
\hline 22,5 & 3,96 & 5 & 22,4 & 3,97 & 3 & 22,4 & 3,95 & 11 \\
\hline 22,8 & 3,89 & 2 & 22,7 & 3,91 & 4 & 22,7 & 3,90 & 11 \\
\hline 23,3 & 3,82 & 1 & 23,6 & 3,76 & 1 & n. o. & n. o. & n. $o$. \\
\hline 24,5 & 3,63 & 2 & 24,4 & 3,64 & 2 & 24,5 & 3,62 & 7 \\
\hline 25,0 & 3,55 & 3 & 24,8 & 3,58 & 4 & 24,8 & 3,57 & 15 \\
\hline 25,7 & 3,46 & 1 & 25,6 & 3,47 & 1 & 25,7 & 3,46 & 5 \\
\hline 26,2 & 3,41 & 1 & 26,1 & 3,42 & 1 & 26,1 & 3,41 & 6 \\
\hline 26,9 & 3,30 & 1 & 26,9 & 3,32 & 3 & 26,9 & 3,31 & 15 \\
\hline 27,3 & 3,26 & 2 & 27,2 & 3,27 & 3 & n. o. & n. $o$ & n. 0. \\
\hline 28,1 & 3,18 & 4 & 27,9 & 3,18 & 8 & 28,0 & 3,18 & 16 \\
\hline 28,4 & 3,14 & 3 & 28,5 & 3,13 & 3 & 28,6 & 3,12 & 14 \\
\hline
\end{tabular}

Ac: ín acetato $\left(\mathrm{CH}_{3} \mathrm{COO}^{-}\right)$; n. o.: não observado; ${ }^{a}$ : obtido por mistura mecânica; ${ }^{b}$ : obtido por evaporação do solvente; ' : obtido por cristalização com acetona; $2 \theta$ : posição angular; d: distância interplanar. 


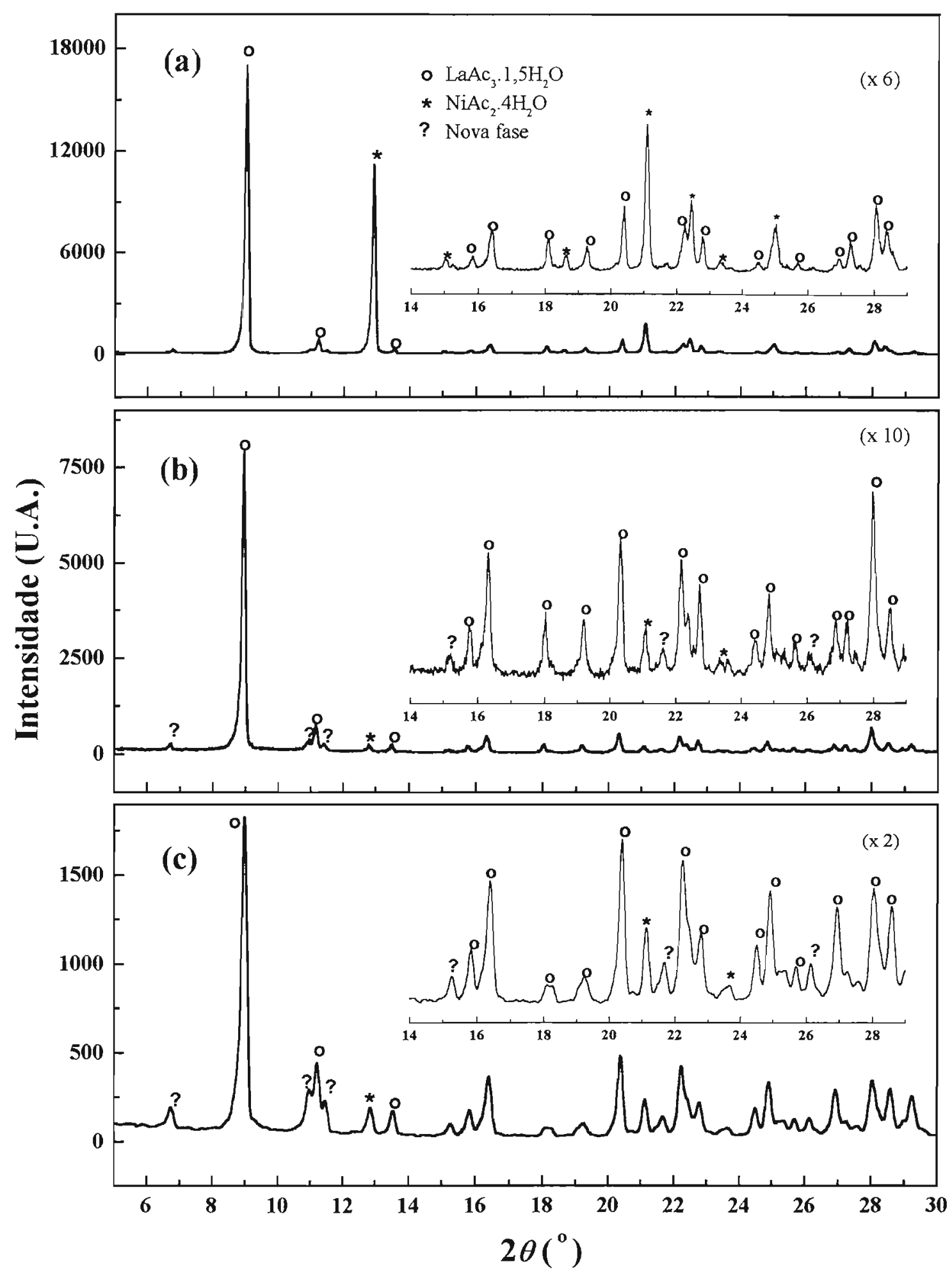

Figura 3.32: Difratogramas de raios $\mathrm{X}$ (método do pó) dos sistemas de acetatos binários de lantânio e níquel:

(a) $\mathrm{LaNi}\left(\mathrm{CH}_{3} \mathrm{COO}\right)_{5} .5,5 \mathrm{H}_{2} \mathrm{O}, \mathrm{M}$. M. (inserido $2 \theta=14$ a $29^{\circ}$, ampliado seis vezes);

(b) $\mathrm{LaNi}\left(\mathrm{CH}_{3} \mathrm{COO}\right)_{5} \cdot 3 \mathrm{H}_{2} \mathrm{O}$, E. S. (inserido $2 \theta=14$ a $29^{\circ}$, ampliado dez vezes);

(c) $\mathrm{LaNi}\left(\mathrm{CH}_{3} \mathrm{COO}\right)_{5} .2,5 \mathrm{H}_{2} \mathrm{O}, \mathrm{C}$. A. (inserido $2 \theta=14$ a $29^{\circ}$, ampliado duas vezes). 


\subsubsection{4- Análise térmica}

De uma maneira geral, o comportamento térmico dos sistemas de acetatos binários de lantânio e niquel, independente do método de síntese, envolveu três eventos principais: desidratação, decomposição e formação da mistura $\mathrm{La}_{2} \mathrm{O}_{2} \mathrm{CO}_{3}$ e $\mathrm{NiO}$, e produção da mistura de óxidos $\mathrm{La}_{2} \mathrm{O}_{3}$ e $\mathrm{NiO}$. Nas Figuras 3.33 e 3.34 estão apresentadas as curvas TG/DTG, obtidas nas atmosferas dinâmicas de ar e nitrogênio, respectivamente

A desidratação dos sais ocorreu no intervalo de temperatura de 25 a $200^{\circ} \mathrm{C}$, independente da atmosfera atuante. Nas Figuras 3.33 (a) e 3.34 (a) estão apresentadas as curvas TG/DTG para o sistema $\mathrm{LaNi}\left(\mathrm{CH}_{3} \mathrm{COO}\right)_{5.5}, 5 \mathrm{H}_{2} \mathrm{O}$. A desidratação ocorreu em três etapas, com temperatura de pico na curva DTG em 46,102 e $152^{\circ} \mathrm{C}$. Essas etapas corresponderam, respectivamente, à libertação de $0,5 \mathrm{~mol}(1,52 \%)$ e 4,5 mol de água $(13,70 \%)$ e novamente de $0,5 \mathrm{~mol}$ de água $(1,52 \%)$. No entanto, para o sistema $\mathrm{LaNi}\left(\mathrm{CH}_{3} \mathrm{COO}\right)_{5} \cdot 3 \mathrm{H}_{2} \mathrm{O}$, a desidratação ocorreu em duas etapas lentas e consecutivas, com temperatura de picos nas curvas DTG em 66 e $154^{\circ} \mathrm{C}$. A variação de massa total foi de $9,89 \%$, correspondente à libertação de $3 \mathrm{~mol}$ de água, conforme ilustrado nas Figuras 3.33 (b) e 3.34 (b). Similarmente, o sistema $\mathrm{LaNi}\left(\mathrm{CH}_{3} \mathrm{COO}\right)_{5} \cdot 2,5 \mathrm{H}_{2} \mathrm{O}$ apresentou a desidratação em duas etapas lentas e consecutivas, com temperatura de picos nas curva DTG em 64 e $130^{\circ} \mathrm{C}$, sendo que a variação de massa total foi de $8,38 \%$, relativo à libertação de 2,5 mol de água, o que pode ser observado nas Figuras 3.33 (c) e 3.34 (c).

Para todos os sistemas, observou-se uma pequena perda de massa lenta e gradativa, até $250^{\circ} \mathrm{C}$. Os dados de perda de massa observados nesta temperatura, foram maiores que os esperados para a desidratação dos sais. Esses resultados indicaram que, similarmente ao acetato de níquel, possivelmente, ocorre hidrólise de grupos acetatos, com formação de acetatos básicos de lantânio e níquel. A perda de massa total dos voláteis até $250^{\circ} \mathrm{C}$, observada nas curvas $\mathrm{TG}$ dos sistemas foi de:

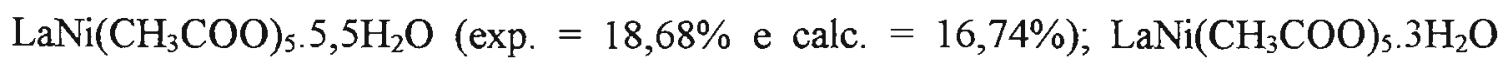
$($ exp. $=11,22 \%$ e calc. $=9,89 \%)$ e $\mathrm{LaNi}\left(\mathrm{CH}_{3} \mathrm{COO}\right)_{5} \cdot 2,5 \mathrm{H}_{2} \mathrm{O}($ exp. $=9,40 \%$ e calc. $=$ $8,38 \%$ ). O valor experimental é a média aritmética dos valores observados nas atmosferas de ar e nitrogênio. 
A decomposição térmica dos intermediários em $250^{\circ} \mathrm{C}$ foi influenciada pela atmosfera atuante. De forma geral, sob atmosfera de ar, a análise das curvas TG/DTG evidenciou uma perda de massa rápida e um pico agudo em torno de $345^{\circ} \mathrm{C}$, característico de pirólise. Para os sistemas obtidos por mistura mecânica e evaporação do solvente, a decomposição ocorreu em duas etapas rápidas, Figuras 3.33 (a) e (b). Para o sistema obtido por cristalização com acetona, a decomposição ocorreu em três etapas, como evidenciou a curva DTG, Figura 3.33 (c)

Sob atmosfera de nitrogênio, as curvas TG/DTG mostram que a decomposição ocorre lentamente e em várias etapas. Para o sistema obtido por mistura mecânica, a decomposição ocorreu em três etapas, com temperatura de picos na curva DTG em 360 , 400 e $462^{\circ} \mathrm{C}$, Figura 3.34 (a). O sistema obtido por evaporação do solvente decompõese em temperatura inferior ao obtido por mistura mecânica, isto é a partir de $280^{\circ} \mathrm{C}$. A decomposição também ocorreu em quatro etapas, com temperatura de picos na curva DTG em $307,358,390$ e $437^{\circ} \mathrm{C}$, Figura 3.34 (b). No entanto, o sistema obtido por cristalização com acetona foi o que apresentou menor estabilidade térmica, ou seja, a sua decomposição iniciou a partir de $240^{\circ} \mathrm{C}$, em quatro etapas consecutivas, em 230,360 , 386 e $445^{\circ} \mathrm{C}$, Figura 3.34 (o). Para todos os sistemas binários, os valores de perda de massa calculados a partir das curvas TG/DTG até $600^{\circ} \mathrm{C}$, sugeriram a formação da mistura de $\mathrm{La}_{2} \mathrm{O}_{2} \mathrm{CO}_{3}$ e $\mathrm{NiO}$

A última etapa de perda de massa observada nas curvas TG/DTG, independentemente da atmosfera, correspondeu à libertação de $\mathrm{CO}_{2}$ proveniente do $\mathrm{La}_{2} \mathrm{O}_{2} \mathrm{CO}_{3}$ e consequentemente, a formação da mistura de $\mathrm{La}_{2} \mathrm{O}_{3}$ e $\mathrm{NiO}$ em $900^{\circ} \mathrm{C}$. O sistema obtido por evaporação do solvente apresentou menor temperatura de formação dos óxidos $\left(\mathrm{T}_{\text {endset }}=760^{\circ} \mathrm{C}\right)$, seguido do obtido por cristalização com acetona $\left(\mathrm{T}_{\text {endset }}=\right.$ $\left.770^{\circ} \mathrm{C}\right)$ e mistura mecânica $\left(\mathrm{T}_{\text {endset }}=780^{\circ} \mathrm{C}\right)$.

Por meio desta etapa foi possivel estimar os teores de lantânio e níquel, presentes nos acetatos binários, utilizando-se cálculos estequiométricos. Os valores percentuais calculados e experimentais, dos produtos sólidos da decomposição térmica, formados nas atmosferas de ar comprimido e nitrogênio estão apresentados na Tabela 3.14. 
Tabela 3.14: Dados percentuais dos produtos sólidos da decomposição térmica dos sistemas de acetatos binários de lantânio e níquel

\begin{tabular}{|c|c|c|c|}
\hline \multirow{2}{*}{ COMPOSTO } & \multirow{2}{*}{ \% CALCULADA } & \multicolumn{2}{|c|}{ \% EXPERIMENTAL } \\
\hline & & $\mathbf{A R}$ & $\mathbf{N}_{2}$ \\
\hline $\mathrm{LaNi}(\mathrm{Ac})_{5} .5,5 \mathrm{H}_{2} \mathrm{O}^{\mathrm{a}}$ & 100,00 & 100,0 & 100,0 \\
\hline $\mathrm{LaNi}(\mathrm{Ac})_{5} .5 \mathrm{H}_{2} \mathrm{O}$ & 98,48 & 98,7 & 98,1 \\
\hline $\mathrm{LaNi}(\mathrm{Ac})_{5} .0,5 \mathrm{H}_{2} \mathrm{O}$ & 84,78 & 84,3 & 84,7 \\
\hline $\mathrm{LaNi}(\mathrm{Ac})_{5}$ & 83,26 & 81,7 & 81,0 \\
\hline $\mathrm{La}_{2} \mathrm{O}_{2} \mathrm{CO}_{3}, \mathrm{NiO}$ & 43,06 & 43,0 & 42,6 \\
\hline $\mathrm{La}_{2} \mathrm{O}_{3} \cdot \mathrm{NiO}$ & 40,14 & 39,8 & 39,0 \\
\hline $\mathrm{LaNi}(\mathrm{Ac})_{5} \cdot 3 \mathrm{H}_{2} \mathrm{O}^{b}$ & 100,00 & 100,0 & 100,0 \\
\hline $\mathrm{LaNi}(\mathrm{Ac})_{5}$ & 90,11 & 88,7 & 88,7 \\
\hline $\mathrm{La}_{2} \mathrm{O}_{2} \mathrm{CO}_{3} \cdot \mathrm{NiO}$ & 46,77 & 46,7 & 46,8 \\
\hline $\mathrm{La}_{2} \mathrm{O}_{3} \cdot \mathrm{NiO}$ & 43,96 & 42,8 & 42,9 \\
\hline $\mathrm{LaNi}(\mathrm{Ac})_{5} \cdot 2,5 \mathrm{H}_{2} \mathrm{O}^{\mathrm{c}}$ & 100,00 & 100,0 & 100,0 \\
\hline $\mathrm{LaNi}(\mathrm{Ac})_{5}$ & 91,62 & 90,7 & 90,5 \\
\hline $\mathrm{La}_{2} \mathrm{O}_{2} \mathrm{CO}_{3} \cdot \mathrm{NiO}$ & 48,26 & 47,8 & 47,6 \\
\hline $\mathrm{La}_{2} \mathrm{O}_{3} \cdot \mathrm{NiO}$ & 44,17 & 43,7 & 44,0 \\
\hline
\end{tabular}

Ac: ín acetato $\left(\mathrm{CH}_{3} \mathrm{COO}^{-}\right)$; ${ }^{\text {a }}$ : obtido por mistura mecânica; ${ }^{\text {b: }}$ obtido por evaporação do solvente; ${ }^{\mathbf{c}}$ : obtido por cristalização com acetona

Nas Figuras 3.35 e 3.36 estão apresentadas as curvas DTA e DSC para os sistemas de acetatos binários de lantânio e níquel, respectivamente. Similarmente aos acetatos de terras raras e acetato de níquel, os valores das temperaturas dos picos observados dessas curvas estão deslocados para valores menores (curvas DSC) e maiores (curvas DTA), em relação aos picos das curvas DTG.

Para o sistema $\mathrm{LaNi}\left(\mathrm{CH}_{3} \mathrm{COO}\right)_{5} .5,5 \mathrm{H}_{2} \mathrm{O}$, a curva DTA, Figura 3.35 (a), evidenciou três eventos endotérmicos em 65,109 e $159^{\circ} \mathrm{C}$, relativos as etapas de desidratação. No entanto, para o sistema $\mathrm{LaNi}\left(\mathrm{CH}_{3} \mathrm{COO}\right)_{5} \cdot 3 \mathrm{H}_{2} \mathrm{O}$, a desidratação foi evidenciada por dois 
eventos endotérmicos em 80 e $156^{\circ} \mathrm{C}$, Figura 3.35 (b). Similarmente, no sistema $\mathrm{LaNi}\left(\mathrm{CH}_{3} \mathrm{COO}\right)_{5} .2,5 \mathrm{H}_{2} \mathrm{O}$, a desidratação também foi evidenciada por dois eventos endotérmicos, em 98 e $145^{\circ} \mathrm{C}$, Figura 3.35 (c).

Todas as amostras apresentaram um evento exotérmico, no intervalo de 180 a $220^{\circ} \mathrm{C}$, característico de transição cristalina, provavelmente, devido ao acetato de lantânio [26]. As temperaturas dos picos nas curvas DTA, para os sistemas obtidos por mistura mecânica, evaporação do solvente e cristalização com acetona foram, respectivamente, 198,212 e $203^{\circ} \mathrm{C}$.

De maneira geral, após desidratação e transição cristalina os sistemas apresentaram um evento exotérmico, caracterizado por um pico agudo, entre 300 a $400^{\circ} \mathrm{C}$, o que pode estar associado ao fenômeno de pirólise. Este fenômeno é uma indicação que a decomposição térmica dos acetatos binários é rápida, o que facilita a formação do óxido misto em temperaturas mais baixas. O mesmo foi observado nas curvas TG/DTG obtidas na atmosfera de ar. Estes precursores mostraram-se vantajosos em relação aos citados na literatura, uma vez que o próprio processo de decomposição auxilia na sinterização do produto desejado.

A última etapa da decomposição térmica, relativo à libertação de $\mathrm{CO}_{2}$, proveniente do $\mathrm{La}_{2} \mathrm{O}_{2} \mathrm{CO}_{3}$ e formação da mistura $\mathrm{La}_{2} \mathrm{O}_{3}$. NiO, somente foi perceptivel para o sistema obtido por mistura mecânica. A curva DTA, Figura 3.35 (a), apresentou um pequeno pico em $723^{\circ} \mathrm{C}$, caracterizando uma reação endotérmica para esta etapa da decomposição térmica. Para os sistemas obtidos por evaporação do solvente e cristalização com acetona, este evento não foi evidenciado, Figuras 3.35 (b) e (c). Estes resultados sugerem que a formação da mistura dos óxidos ou do oxido misto, foi favorecida para estes dois métodos.

Na Figura 3.36 estão apresentadas as curvas DSC, obtidas sob atmosfera de nitrogênio, dos acetatos binários de lantânio e níquel. Estas curvas são concordantes com as curvas DTA, para as etapas de desidratação e transição cristalina.

De maneira geral, a desidratação dos sistemas foi evidenciada por eventos endotérmicos. Em virtude da pequena massa de amostra usada nos experimentos, $c a$. 2 mg, observou-se que estes eventos ocorreram em temperaturas inferiores, em relação as curvas DTA. Quanto à transição cristalina, esta foi observada, aproximadamente, na mesma temperatura, independentemente do método de síntese utilizado. 
No entanto, a decomposição térmica foi influenciada pela atmosfera atuante. Nas curvas DTA foi observado pirólise. Porém, nas curvas DSC foi observado em torno de $330^{\circ} \mathrm{C}$ processo de fusão, seguido de decomposição, caracterizada por um ou dois picos largos e consecutivos.

Os perfis das curvas DSC permitiram calcular as entalpias de reação $(\Delta H)$ referentes às etapas de desidratação e decomposição dos sistemas binários. Na Tabela 3.15 estão apresentados os resultados de $\mathrm{DSC}$, para os $\mathrm{LaNi}\left(\mathrm{CH}_{3} \mathrm{COO}\right)_{5} \cdot \mathrm{xH}_{2} \mathrm{O}$, sintetizados pelos três métodos em estudo.

Tabela 3.15: Dados de DSC para as etapas de desidratação e decomposição térmica dos sistemas de acetatos binários de lantânio e níquel

\begin{tabular}{|c|c|c|c|c|c|c|}
\hline \multirow{2}{*}{ EVENTOS } & \multicolumn{2}{|c|}{$\mathrm{LaNi}(\mathrm{Ac})_{5} .5,5 \mathrm{H}_{2} \mathrm{O}^{\mathrm{a}}$} & \multicolumn{2}{|c|}{$\mathrm{LaNi}(\mathrm{Ac})_{5} \cdot 3 \mathrm{H}_{2} \mathrm{O}^{\mathrm{b}}$} & \multicolumn{2}{|c|}{$\operatorname{LaNi}(\mathrm{Ac})_{5} \cdot 2,5 \mathrm{H}_{2} \mathrm{O}^{\mathrm{c}}$} \\
\hline & $\mathrm{T}_{\mathrm{p}}\left({ }^{\circ} \mathrm{C}\right)$ & $\Delta H\left(\mathrm{~kJ} \mathrm{~mol}{ }^{-1}\right)$ & $\mathrm{T}_{\mathrm{p}}\left({ }^{\circ} \mathrm{C}\right)$ & $\Delta H\left(\mathrm{~kJ} \mathrm{~mol}^{-1}\right)$ & $\mathrm{T}_{\mathrm{p}}\left({ }^{\circ} \mathrm{C}\right)$ & $\Delta H\left(\mathrm{~kJ} \mathrm{~mol}^{-1}\right)$ \\
\hline \multirow{3}{*}{ Desidratação } & 46 & 16 & 53 & 55 & 56 & 51 \\
\hline & 60 & 213 & 110 & 3 & 108 & 3 \\
\hline & 133 & 42 & 137 & 41 & 136 & 44 \\
\hline Transição cristalina & 211 & -15 & 212 & -10 & 213 & -10 \\
\hline Fusão & 324 & 24 & 331 & 23 & 325 & 18 \\
\hline Decomposição & $\begin{array}{l}365 \\
390\end{array}$ & -633 & $\begin{array}{l}380 \\
418\end{array}$ & -341 & 400 & -489 \\
\hline
\end{tabular}

Ac: íon acetato $\left(\mathrm{CH}_{3} \mathrm{COO}\right)$; ${ }^{\mathbf{a}}$ : obtido por mistura mecânica; ${ }^{\mathbf{b}}$ : obtido por evaporação do solvente; ': obtido por cristalização com acetona; $\mathbf{T}_{\mathrm{p}}$ : temperatura do pico; $\Delta H$ : variação de entalpia 


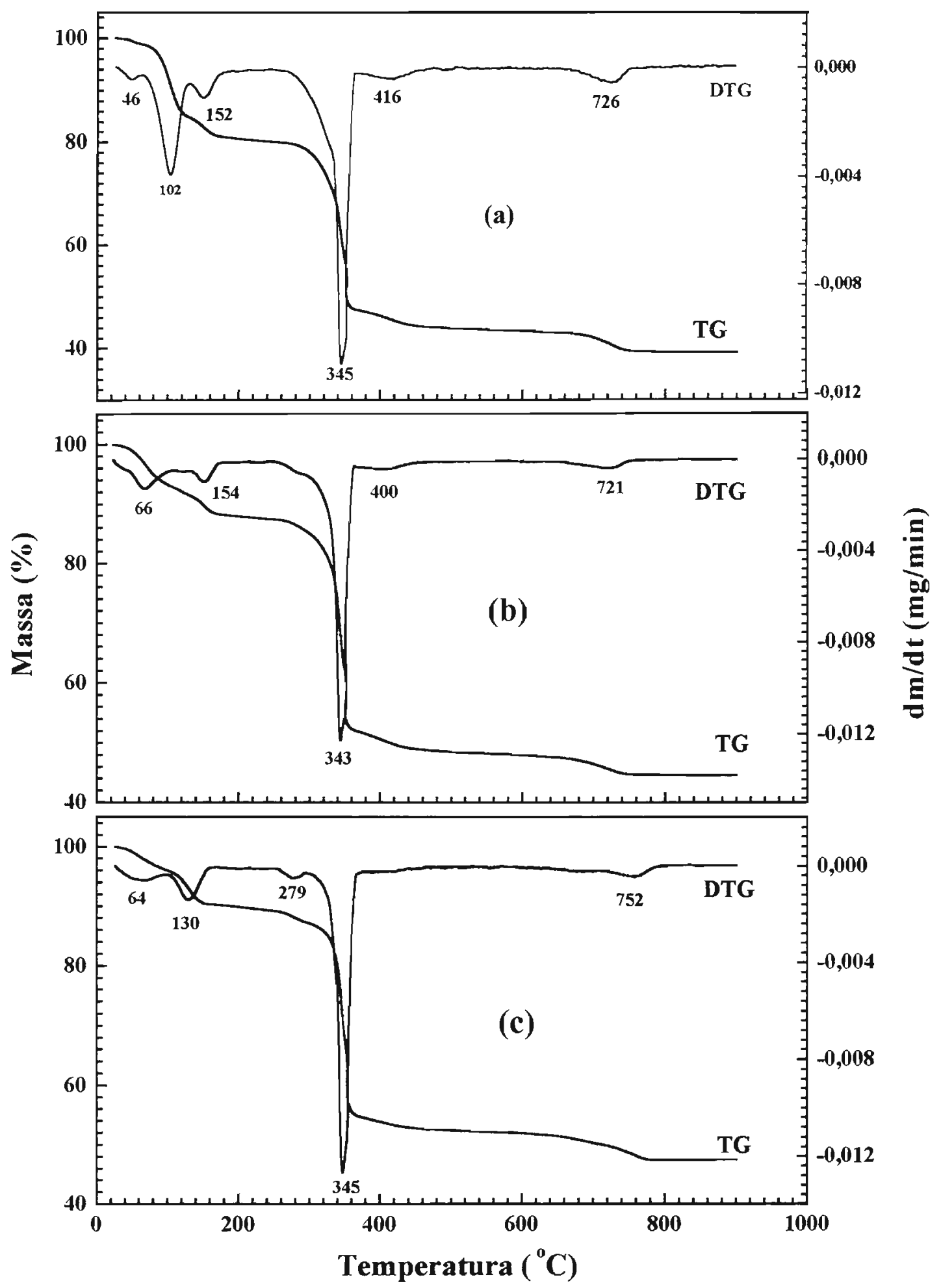

Figura 3.33: Curvas TG/DTG dos sistemas de acetatos binários de lantânio e níquel obtidas sob atmosfera dinâmica de ar $\left(50 \mathrm{~mL} \mathrm{~min}^{-1}\right)$, razão de aquecimento de $10^{\circ} \mathrm{C} \mathrm{min}^{-1}$ e cadinho de platina: (a) $\mathrm{LaNi}\left(\mathrm{CH}_{3} \mathrm{COO}\right)_{5} .5,5 \mathrm{H}_{2} \mathrm{O}, \mathrm{M} . \mathrm{M}$. (m = 5,009 mg); (b) $\mathrm{LaNi}\left(\mathrm{CH}_{3} \mathrm{COO}\right)_{5} .3 \mathrm{H}_{2} \mathrm{O}$, E. S. $(\mathrm{m}=6,413 \mathrm{mg})$; (c) $\mathrm{LaNi}\left(\mathrm{CH}_{3} \mathrm{COO}\right)_{5} \cdot 2,5 \mathrm{H}_{2} \mathrm{O}, \mathrm{C} . \mathrm{A} .(\mathrm{m}=4,990 \mathrm{mg})$. 


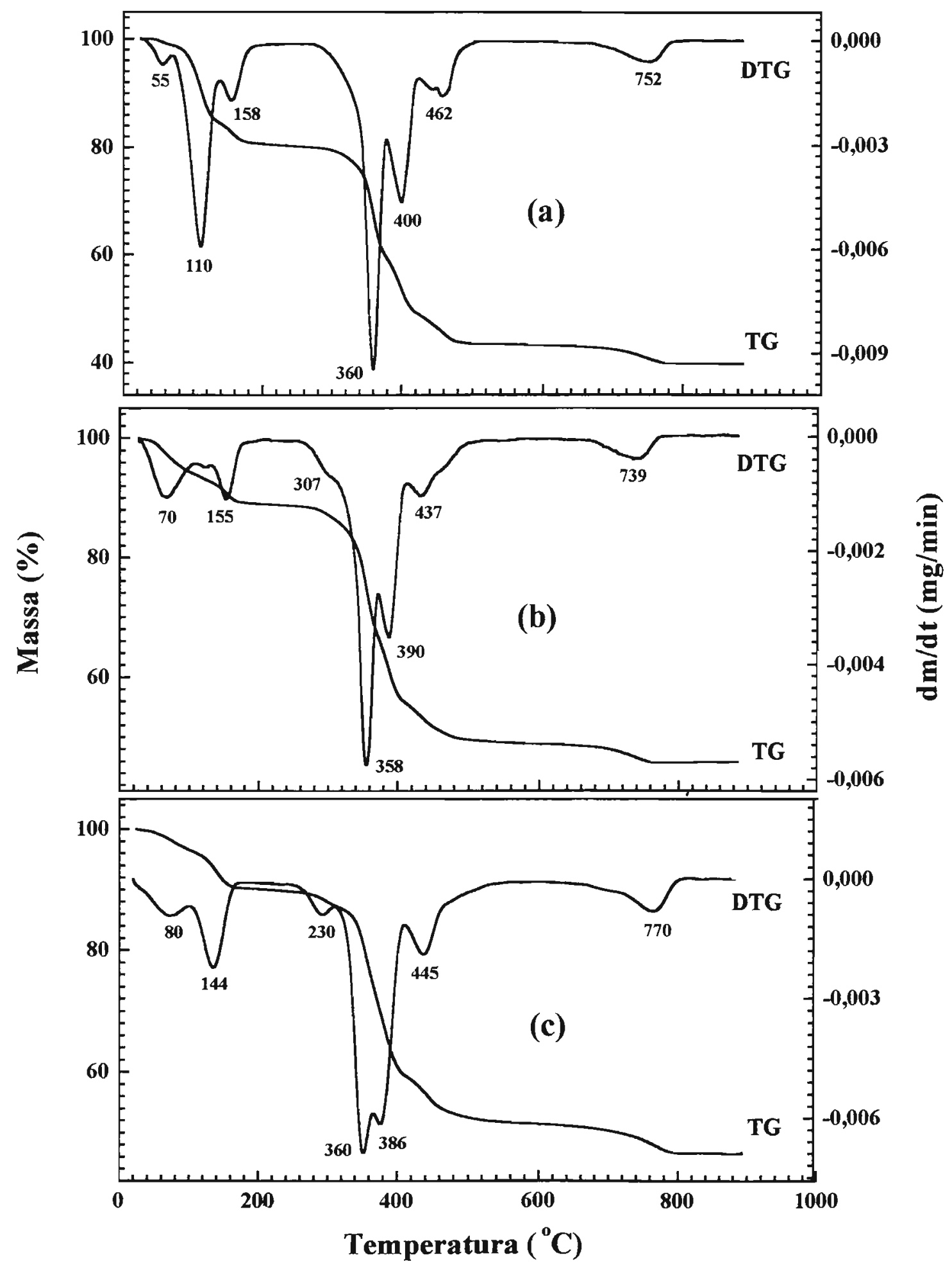

Figura 3.34: Curvas TG/DTG dos sistemas de acetatos binários de lantânio e níquel obtidas sob atmosfera dinâmica de nitrogênio $\left(50 \mathrm{~mL} \mathrm{~min}^{-1}\right)$, razão de aquecimento de $10^{\circ} \mathrm{C} \mathrm{min}^{-1}$ e cadinho de platina: (a) $\mathrm{LaNi}\left(\mathrm{CH}_{3} \mathrm{COO}\right)_{5} .5,5 \mathrm{H}_{2} \mathrm{O}$, M. M. $(\mathrm{m}=5,556 \mathrm{mg})$; (b) $\mathrm{LaNi}\left(\mathrm{CH}_{3} \mathrm{COO}\right)_{5} .3 \mathrm{H}_{2} \mathrm{O}$, E. S. $(\mathrm{m}=5,351 \mathrm{mg}) ;(\mathrm{c}) \mathrm{LaNi}\left(\mathrm{CH}_{3} \mathrm{COO}\right)_{5} \cdot 2,5 \mathrm{H}_{2} \mathrm{O}, \mathrm{C} . \mathrm{A} .(\mathrm{m}=5,403 \mathrm{mg})$. 


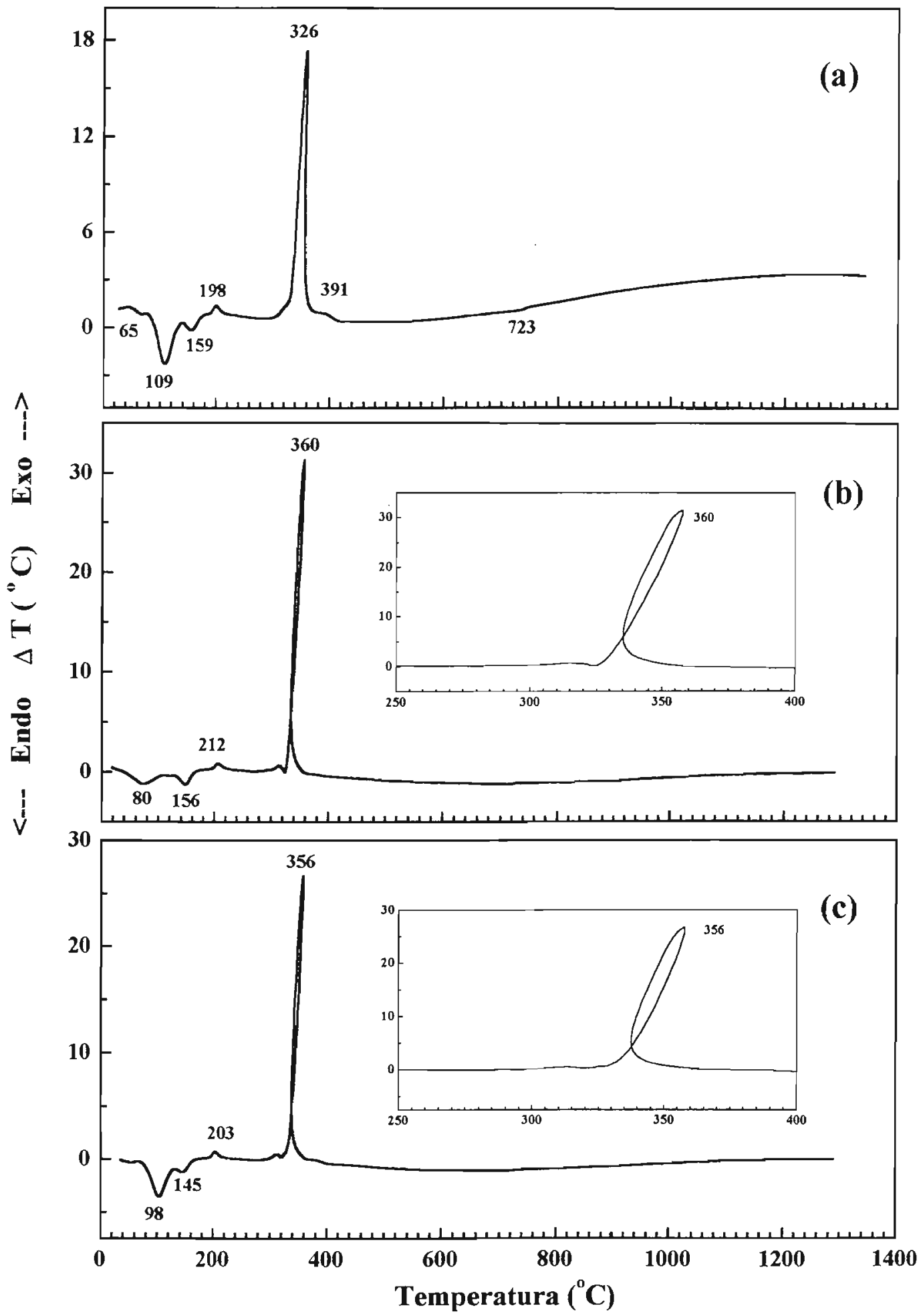

Figura 3.35: Curvas DTA dos sistemas de acetatos binários de lantânio e níquel obtidas sob

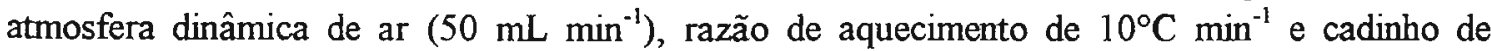
alumina: (a) $\mathrm{LaNi}\left(\mathrm{CH}_{3} \mathrm{COO}\right)_{5} .5,5 \mathrm{H}_{2} \mathrm{O}, \mathrm{M} . \mathrm{M} .(\mathrm{m}=19,22 \mathrm{mg})$; (b) $\mathrm{LaNi}\left(\mathrm{CH}_{3} \mathrm{COO}\right)_{5} \cdot 3 \mathrm{H}_{2} \mathrm{O}$, E. S. $(\mathrm{m}=17,50 \mathrm{mg})$; (c) $\mathrm{LaNi}\left(\mathrm{CH}_{3} \mathrm{COO}\right)_{5} .2,5 \mathrm{H}_{2} \mathrm{O}$, C. A. $(\mathrm{m}=18,30 \mathrm{mg})$. 


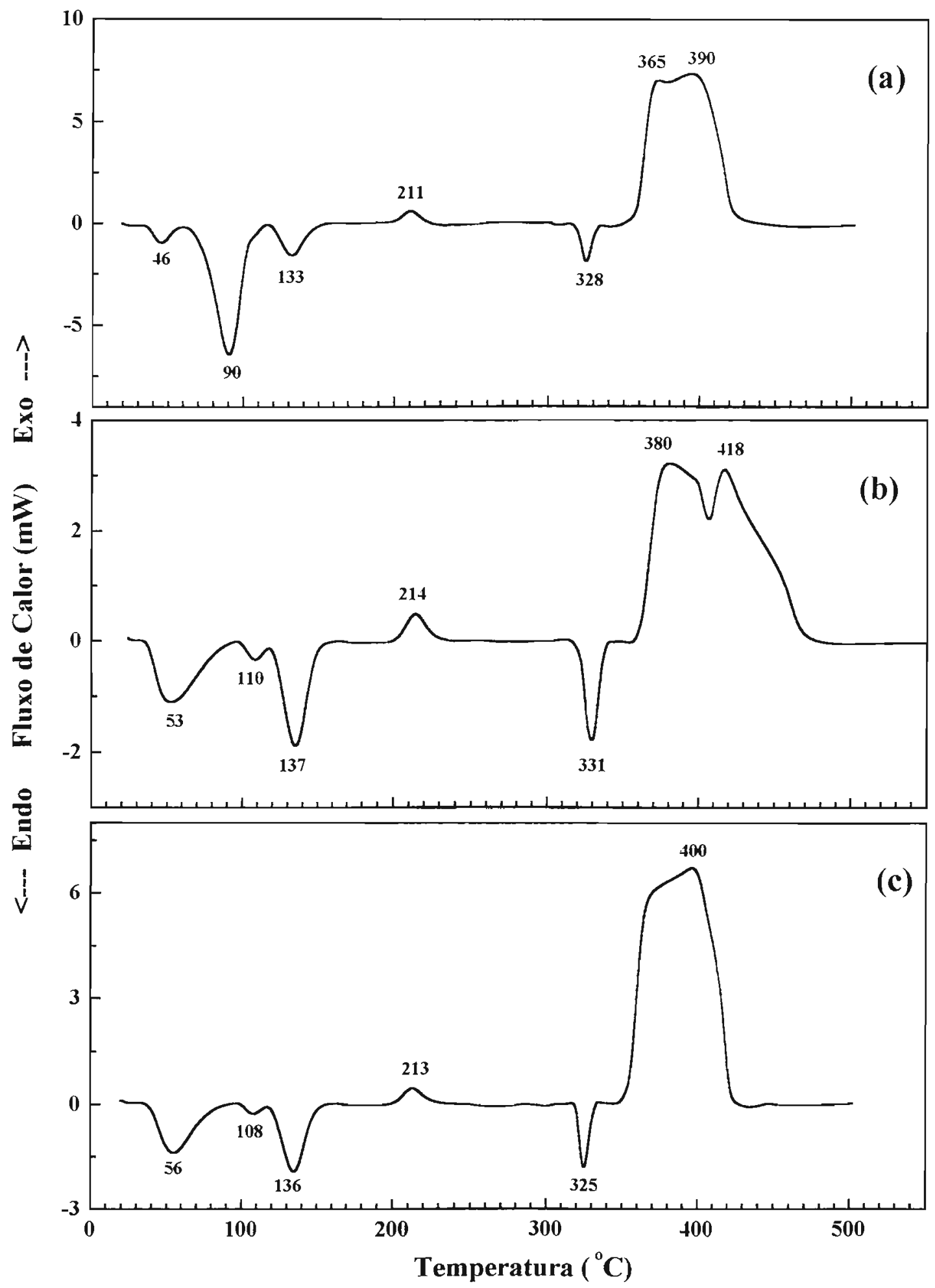

Figura 3.36: Curvas DSC dos sistemas de acetatos binários de lantânio e níquel obtidas sob atmosfera dinâmica de nitrogênio $\left(50 \mathrm{~mL} \mathrm{~min}^{-1}\right)$, razão de aquecimento de $10^{\circ} \mathrm{C} \mathrm{min}{ }^{-1}$ e cápsula de alumínio aberta: (a) $\mathrm{LaNi}\left(\mathrm{CH}_{3} \mathrm{COO}\right)_{5} .5,5 \mathrm{H}_{2} \mathrm{O}, \quad$ M. M. $(\mathrm{m}=2,328 \mathrm{mg})$; (b) $\mathrm{LaNi}\left(\mathrm{CH}_{3} \mathrm{COO}\right)_{5} \cdot 3 \mathrm{H}_{2} \mathrm{O}$, E. S. $(\mathrm{m}=2,260 \mathrm{mg})$; (c) $\mathrm{LaNi}\left(\mathrm{CH}_{3} \mathrm{COO}\right)_{5} \cdot 2,5 \mathrm{H}_{2} \mathrm{O}$, C. A. $(\mathrm{m}=2,096$ $\mathrm{mg}$ ). 


\subsubsection{5- Produtos sólidos da decomposição térmica dos sistemas de acetatos binários de lantânio e níquel}

Os produtos sólidos da decomposição térmica dos sistemas de acetatos binários de lantânio e níquel foram isolados em $900^{\circ} \mathrm{C}$ e submetidos à caracterização por difração de raios X. A análise dos difratogramas foi realizada a partir da comparação com os óxidos simples, obtidos nas mesmas condições de decomposição térmica dos sais precursores.

A Figura 3.37 apresenta os difratogramas de raios $\mathrm{X}$ dos produtos isolados sob atmosfera dinâmica de ar. Para o produto final do sistema $\mathrm{LaNi}\left(\mathrm{CH}_{3} \mathrm{COO}\right)_{5} .5,5 \mathrm{H}_{2} \mathrm{O}$, o difratograma de raios $\mathrm{X}$ apresentou o somatório das linhas de reflexão dos óxidos simples $\mathrm{NiO}$ e $\mathrm{La}_{2} \mathrm{O}_{3}$, sendo observada apenas uma das linhas principais do óxido misto $\mathrm{La}_{2} \mathrm{NiO}_{4}$ em $2 \theta=32,6^{\circ}$. Para os produtos dos sistemas $\mathrm{LaNi}\left(\mathrm{CH}_{3} \mathrm{COO}\right)_{5} \cdot 3 \mathrm{H}_{2} \mathrm{O}$ e $\mathrm{LaNi}\left(\mathrm{CH}_{3} \mathrm{COO}\right)_{5} .2,5 \mathrm{H}_{2} \mathrm{O}$, os difratogramas de raios $\mathrm{X}$ foram muito similares, sendo observado as linhas principais dos óxidos simples e da fase desejada. Este resultado indicou que os dois precursores foram adequados para a obtenção do óxido misto. No entanto, sugere-se que para obter a fase única deste óxido, é necessário submeter o produto à $900^{\circ} \mathrm{C}$ isotermicamente, durante um determinado intervalo de tempo.

A Figura 3.38 apresenta os difratogramas de raios $\mathrm{X}$ dos produtos isolados sob atmosfera dinâmica de nitrogênio. De um modo geral, foram identificadas somente as reflexões pertinentes aos óxidos simples $\mathrm{La}_{2} \mathrm{O}_{3}$ e $\mathrm{NiO}$, e indícios da formação do óxido misto em $2 \theta=32,6^{\circ}$. Dessa forma, observou-se que a atmosfera inerte não conduz na obtenção do óxido misto, $\mathrm{La}_{2} \mathrm{NiO}_{4}$.

Os resultados sugeriram aumentar o tratamento térmico das amostras. Dessa forma, as seguintes condições de sinterização foram utilizadas: atmosfera dinâmica de ar comprimido, vazão aproximada de $50 \mathrm{~mL} \min ^{-1}$, cadinho de alumina, razão de aquecimento de $10^{\circ} \mathrm{C} \mathrm{min}{ }^{-1}$, no intervalo de 25 a $900^{\circ} \mathrm{C}$, mantido isotérmico por uma hora. Nestas condições foi possível obter fase única do óxido misto $\mathrm{La}_{2} \mathrm{NiO}_{4}$, de simetria tetragonal, grupo espacial Bmab [41], a partir dos precursores sintetizados por evaporação do solvente e cristalização com acetona. No entanto, para o óxido obtido a partir da mistura mecânica de acetatos foi observado uma mistura da fase desejada e dos óxidos simples (Figura 3.39). 


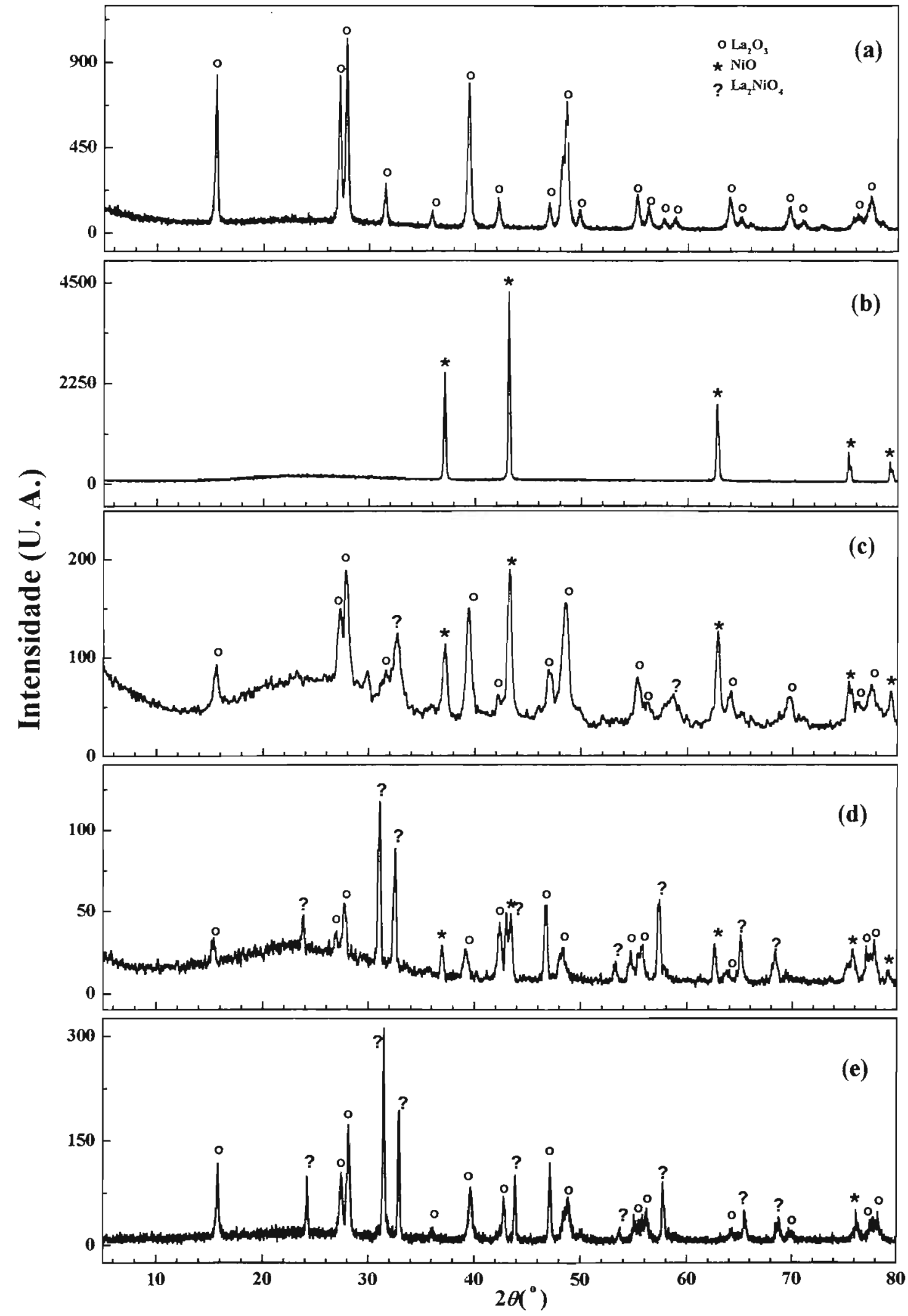

Figura 3.37: Difratogramas de raios $\mathrm{X}$ (método do pó) dos produtos da decomposição térmica a $300^{\circ} \mathrm{C}$, obtidos sob atmosfera dinâmica de ar $\left(50 \mathrm{~mL} \mathrm{~min}^{-1}\right)$, razão de aquecimento de $10^{\circ} \mathrm{C} \mathrm{min}{ }^{-1}$ : cadinho de platina das amostras: $\mathrm{La}\left(\mathrm{CH}_{3} \mathrm{COO}\right)_{3} .1,5 \mathrm{H}_{2} \mathrm{O}$; (b) $\mathrm{Ni}\left(\mathrm{CH}_{3} \mathrm{COO}\right)_{2} \cdot 4 \mathrm{H}_{2} \mathrm{O}$; (c) aNi $\left(\mathrm{CH}_{3} \mathrm{COO}\right)_{5} .5,5 \mathrm{H}_{2} \mathrm{O} \quad$ (M. M.); (d) $\mathrm{LaNi}_{3}\left(\mathrm{CH}_{3} \mathrm{COO}\right)_{5} 3 \mathrm{H}_{2} \mathrm{O} \quad$ (E. S.); $\mathrm{JaNi}\left(\mathrm{CH}_{3} \mathrm{COO}\right)_{5} .2,5 \mathrm{H}_{2} \mathrm{O}$ (C. A.). 


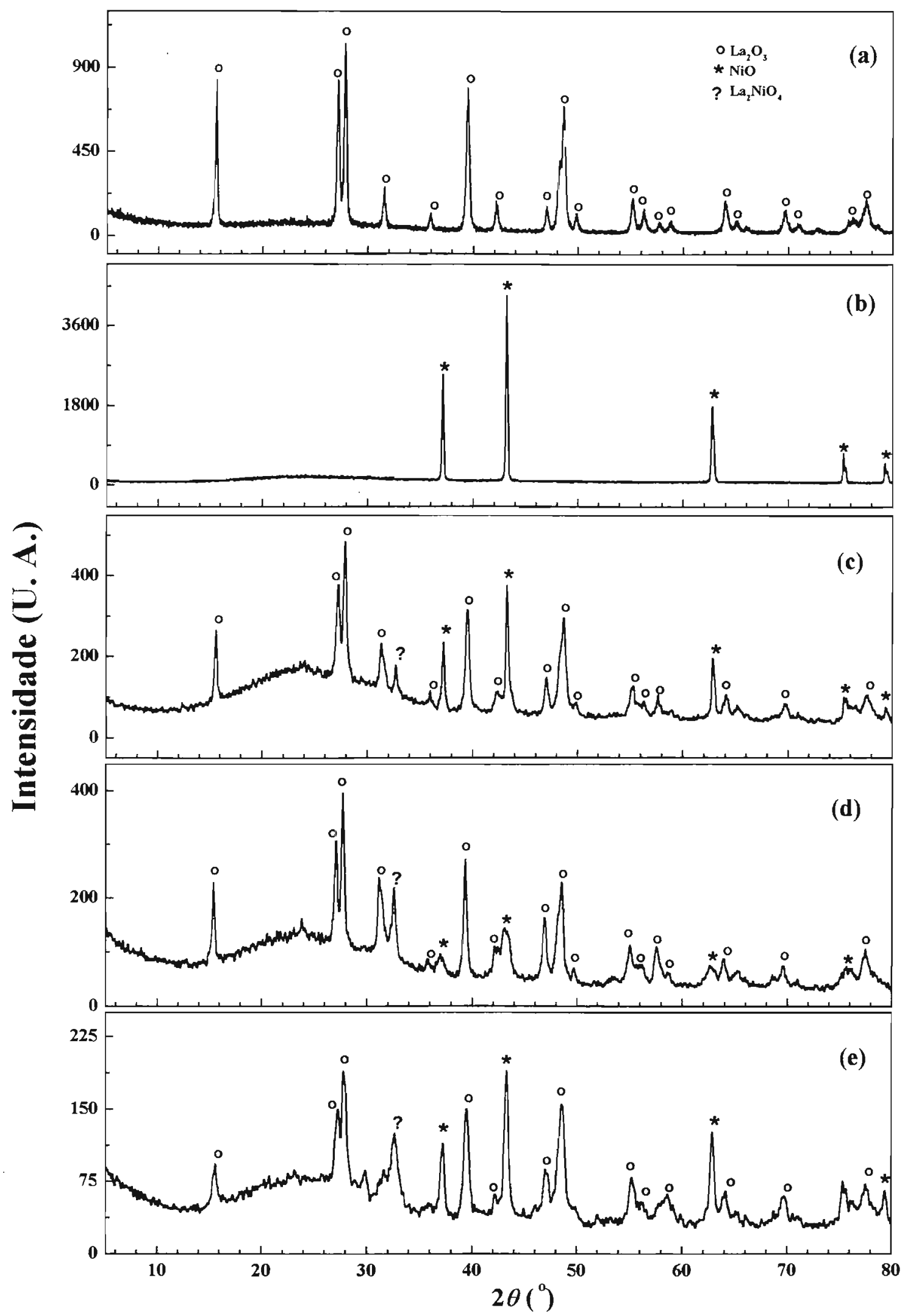

Figura 3.38: Difratogramas de raios $\mathrm{X}$ (método do pó) dos produtos da decomposição térmica a $900^{\circ} \mathrm{C}$, obtidos sob atmosfera dinâmica de nitrogênio $\left(50 \mathrm{~mL} \mathrm{~min}^{-1}\right)$, razão de aquecimento de $10^{\circ} \mathrm{C} \mathrm{min}^{-1}$ e cadinho de platina das amostras: (a) $\mathrm{La}\left(\mathrm{CH}_{3} \mathrm{COO}\right)_{3} .1,5 \mathrm{H}_{2} \mathrm{O}$; (b) $\mathrm{Ni}\left(\mathrm{CH}_{3} \mathrm{COO}\right)_{2} .4 \mathrm{H}_{2} \mathrm{O}$; (c) $\mathrm{LaNi}\left(\mathrm{CH}_{3} \mathrm{COO}\right)_{5} .5,5 \mathrm{H}_{2} \mathrm{O}$ (M. M.); (d) $\mathrm{LaNi}_{2}\left(\mathrm{CH}_{3} \mathrm{COO}\right)_{5} .3 \mathrm{H}_{2} \mathrm{O}$ (E. S.); (e) $\mathrm{LaNi}\left(\mathrm{CH}_{3} \mathrm{COO}\right)_{5} .2,5 \mathrm{H}_{2} \mathrm{O}$ (C. A.). 


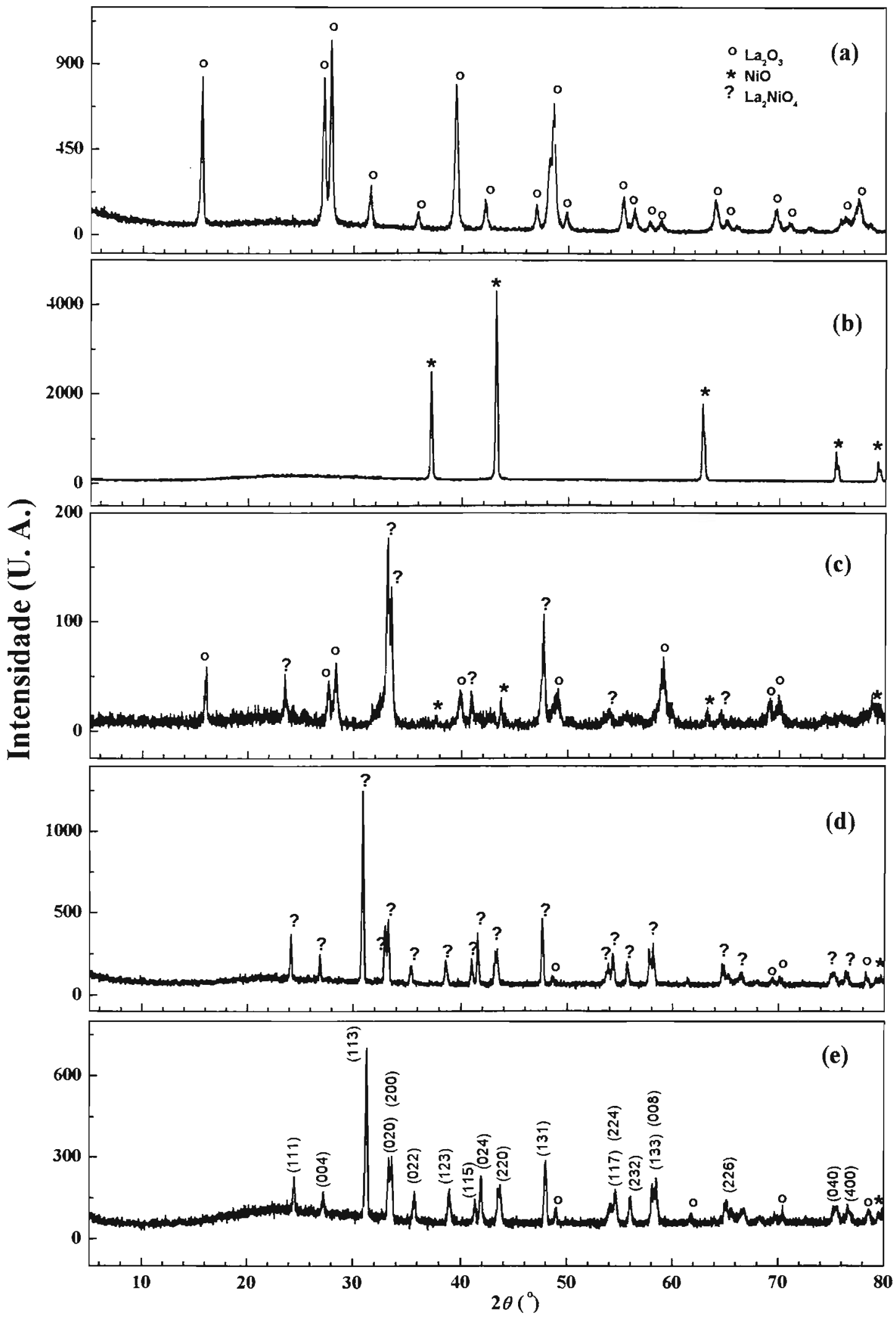

Figura 3.39: Difratogramas de raios $X$ (método do pó) obtidos após tratamento térmico a $900^{\circ} \mathrm{C}$ durante uma hora de aquecimento, sob atmosfera dinâmica de ar $\left(50 \mathrm{~mL} \mathrm{~min}{ }^{-1}\right)$, razão de aquecimento de $10^{\circ} \mathrm{C} \min ^{-1}$ e cadinho de alumina, das amostras: (a) $\mathrm{La}\left(\mathrm{CH}_{3} \mathrm{COO}\right)_{3} .1,5 \mathrm{H}_{2} \mathrm{O}$; (b) $\mathrm{Ni}\left(\mathrm{CH}_{3} \mathrm{COO}\right)_{2} .4 \mathrm{H}_{2} \mathrm{O}$; (c) $\mathrm{LaNi}\left(\mathrm{CH}_{3} \mathrm{COO}\right)_{5} .5,5 \mathrm{H}_{2} \mathrm{O}$ (M. M.); (d) $\mathrm{LaNi}\left(\mathrm{CH}_{3} \mathrm{COO}\right)_{5} .3 \mathrm{H}_{2} \mathrm{O}$ (E. S.); (e) $\mathrm{LaNi}\left(\mathrm{CH}_{3} \mathrm{COO}\right)_{5} \cdot 2,5 \mathrm{H}_{2} \mathrm{O}$ (C. A.). 


\subsubsection{6- Propriedades catalíticas: teste preliminar}

Os óxidos metálicos são materiais muito importantes, do ponto de vista científico e tecnológico. Por exemplo, são usados na indústria química e petroquímica como catalisadores ácidos e /ou básicos em diversos processos para converter hidrocarbonetos a outros compostos. Eles podem ser usados como eletrodos em processos eletroquímicos e na indústria eletrônica para obtenção de filmes condutores.

Entre essas aplicações, o uso em catálise é a mais importante economicamente. Existem três reações modelos com álcoois que podem ser utilizados para avaliação catalítica dos óxidos metálicos: (i) desidratação com formação de alcenos; (ii) desidrogenação com formação de cetonas ou aldeídos e (iii) oxidação com formação de carboxilatos ou óxidos de carbono e redução do óxido [42].

Dessa forma, uma amostra do óxido misto $\mathrm{La}_{2} \mathrm{NiO}_{4+\delta}$ foi submetida a um ensaio catalítico preliminar, para a reação modelo de desidratação (3.13) e/ou desidrogenação (3.14) de isopropanol [43].

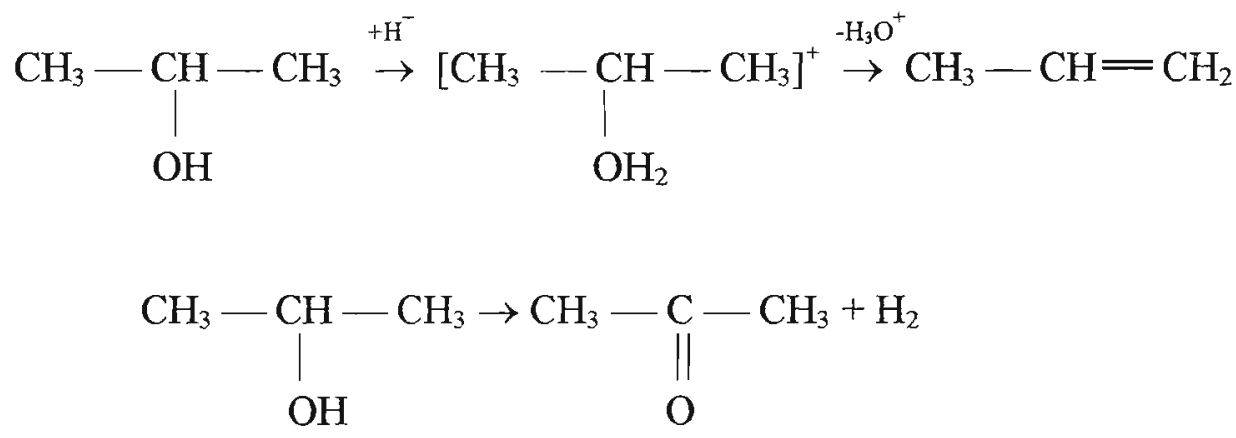

O ensaio foi realizado durante uma hora de reação, em intervalos de $15 \mathrm{~min}$. Os resultados deste ensaio estão apresentados na Tabela 3.16. Observou-se que o óxido misto apresentou boa atividade catalítica para formação de propanona (reação de desidrogenação), porém maior seletividade para formação de propileno (reação de desidratação), apresentando propriedades catalíticas com caráter anfótero. Os centros ácidos dos íons $\mathrm{La}^{3+}$ promovem a reação de desidratação, enquanto os centros básicos dos íons $\mathrm{Ni}^{2+}$ promovem a reação de desidrogenação do isopropanol.

A concentração de propanona variou de 18,46 a 11,26\%, enquanto que a de propileno de 34,33 a $29,70 \%$. A perda da atividade catalítica do óxido, com o decorrer do tempo de reação, foi devida à deposição de coque sobre a sua superficie. 
Tabela 3.16: Concentração molar (\%) dos produtos de reação em função do tempo obtidos do ensaio catalítico do $\mathrm{La}_{2} \mathrm{NiO}_{4}$

\begin{tabular}{|c|c|c|c|c|c|c|c|c|}
\hline \multirow{3}{*}{$\begin{array}{l}\text { Tempo } \\
\text { de reação } \\
\text { (min) }\end{array}$} & \multicolumn{8}{|c|}{ PRODUTOS DA REAÇÃO } \\
\hline & \multicolumn{2}{|c|}{ Propanona } & \multicolumn{2}{|c|}{ 2-propanol } & \multicolumn{2}{|c|}{ Água } & \multicolumn{2}{|c|}{ Propileno } \\
\hline & $\mathrm{C}(\%)$ & $n_{1}$ & $\mathrm{C}(\%)$ & $\mathbf{n}_{2}$ & $C(\%)$ & $\mathbf{n}_{\mathbf{3}}$ & $\mathrm{C}(\%)$ & $\mathrm{n}_{4}$ \\
\hline 5 & 18,46 & 0,7488 & 12,87 & 0,5222 & 34,33 & 1,393 & 34,33 & 4,057 \\
\hline 15 & 18,57 & 0,7172 & 15,20 & 0,5869 & 33,12 & 1,279 & 33,12 & 3,862 \\
\hline 30 & 16,08 & 0,6106 & 18,48 & 0,7015 & 32,72 & 1,242 & 32,72 & 3,796 \\
\hline 45 & 15,10 & 0,5699 & 19,69 & 0,7431 & 32,61 & 1,231 & 32,61 & 3,775 \\
\hline 60 & 14,40 & 0,5008 & 21,19 & 0,7634 & 31,83 & 1,107 & 31,83 & 3,478 \\
\hline 75 & 12,22 & 0,4188 & 27,71 & 0,9499 & 30,05 & 1,030 & 30,05 & 3,428 \\
\hline 90 & 11,26 & 0,3815 & 29,33 & 0,9933 & 29,70 & 1,006 & 29,70 & 3,387 \\
\hline
\end{tabular}

C: concentração molar; n: número de mol 


\subsection{2- Sistema európio - níquel}

Os sistemas de acetatos binários de európio (III) e níquel (II) foram obtidos hidratados, cristalinos e solúveis em água.

\subsubsection{1- Análise elementar}

Os teores de carbono e hidrogênio foram determinados por procedimentos microanalíticos, enquanto que os teores de európio e níquel foram obtidos a partir de cálculos de variação de massa registrados, diretamente, nas curvas TG/DTG sob atmosfera de ar comprimido. Os resultados revelaram a estequiometria dos acetatos binários e estão apresentados na Tabela 3.17.

Tabela 3.17: Resultados de análise elementar para os sistemas de acetatos binários de európio e níquel

\begin{tabular}{l|c|c|c|c|c|c|c|c}
\hline \multirow{2}{*}{ ACETATOS BINÁRIOS } & \multicolumn{3}{|c|}{ \% CALCULADA } & \multicolumn{3}{c}{ \% EXPERIMENTAL } \\
\cline { 2 - 9 } & C & H & Eu & Ni & C & H & Eu & Ni \\
\hline EuNi(Ac) $)_{5} .8 \mathrm{H}_{2} \mathrm{O}^{\text {a }}$ & 18,48 & 4,81 & 23,38 & 9,03 & 18,36 & 4,60 & 23,19 & 8,96 \\
EuNi(Ac) $5.5 \mathrm{H}_{2} \mathrm{O}^{b}$ & 20,15 & 4,23 & 25,50 & 9,85 & 19,18 & 4,09 & 25,42 & 9,82 \\
EuNi(Ac) $5.7 \mathrm{H}_{2} \mathrm{O}^{c}$ & 19,00 & 4,63 & 24,04 & 9,29 & 18,16 & 4,53 & 24,05 & 9,36 \\
\hline
\end{tabular}

Ac: íon acetato $\left(\mathrm{CH}_{3} \mathrm{COO}^{-}\right) ;{ }^{a}$ obtido por mistura mecânica; ${ }^{b}$ obtido por evaporação do solvente; c obtido por cristalização com acetona

\subsubsection{2- Espectroscopia de absorção na região do infravermelho}

Os espectros de absorção na região do infravermelho para os acetatos binários de európio e níquel estão apresentados na Figura 3.40. Para os sistemas EuNi $\left(\mathrm{CH}_{3} \mathrm{COO}\right)_{5} .8 \mathrm{H}_{2} \mathrm{O}$, obtido por mistura mecânica e EuNi $\left(\mathrm{CH}_{3} \mathrm{COO}\right)_{5} .7 \mathrm{H}_{2} \mathrm{O}$, obtido por cristalização com acetona, os espectros $\mathbb{R}$ foram similares e apresentaram o somatório das bandas de absorção dos acetatos de európio e níquel. Estes resultados indicaram que os sais comportam-se como misturas dos acetatos individuais. No entanto, para o sistema EuNi $\left(\mathrm{CH}_{3} \mathrm{COO}\right)_{5} .5 \mathrm{H}_{2} \mathrm{O}$, obtido por evaporação do solvente, o espectro IR apresentou as bandas de absorção nas mesmas freqüências observadas para $o$ 
$\mathrm{Eu}\left(\mathrm{CH}_{3} \mathrm{COO}\right)_{3} .4 \mathrm{H}_{2} \mathrm{O}$, indicando, possivelmente, que estes sais apresentam a mesma estrutura cristalina.

Na Tabela 3.18 estão apresentadas as atribuições das bandas de absorção dos espectros IR para os sistemas de acetatos binários de európio e níquel.

Tabela 3.18: Atribuição das bandas de absorção dos espectros IR dos sistemas de acetatos binários de európio e níquel (número de onda, $\mathrm{cm}^{-1}$ )

\begin{tabular}{|c|c|c|c|}
\hline ATRIBUIÇÃO & $\mathrm{EuNi}(\mathrm{Ac})_{5} .8 \mathrm{H}_{2} \mathrm{O}^{\mathrm{a}}$ & $\mathrm{EuNi}(\mathrm{Ac})_{5} .5 \mathrm{H}_{2} \mathrm{O}^{b}$ & $\mathrm{EuNi}(\mathrm{Ac})_{5} \cdot 7 \mathrm{H}_{2} \mathrm{O}^{\circ}$ \\
\hline$v(\mathrm{O}-\mathrm{H})$ & $\begin{array}{l}3475(\mathrm{~m}) \\
3200(\mathrm{~m})\end{array}$ & $3347(\mathrm{~F})$ & $\begin{array}{l}3476(F) \\
3200(F)\end{array}$ \\
\hline$v_{\text {as. }}(\mathrm{C}-\mathrm{H})$ & $3024(0)$ & $3008(0)$ & n. $\mathrm{o}$. \\
\hline$v_{\text {s. }}(\mathrm{C}-\mathrm{H})$ & $2928(\mathrm{o})$ & $2936(0)$ & $2928(0)$ \\
\hline$\delta(\mathrm{OH})$ & $\begin{array}{c}1680(\mathrm{mf}) \\
1657(\mathrm{f})\end{array}$ & n. 0 . & $\begin{array}{l}1680(\mathrm{o}) \\
1658(\mathrm{~m})\end{array}$ \\
\hline$v_{\text {as. }}\left(\mathrm{COO}^{-}\right)$ & $1544(\mathrm{~m})$ & $1549(\mathrm{mF})$ & $1545(\mathrm{mF})$ \\
\hline$v_{\text {s. }}\left(\mathrm{COO}^{-}\right)$ & $\begin{array}{l}1458(\mathrm{~m}) \\
1421(\mathrm{~m})\end{array}$ & $\begin{array}{c}1455(\mathrm{mF}) \\
1421(\mathrm{~F})\end{array}$ & $\begin{array}{c}1457(\mathrm{mF}) \\
1420(\mathrm{~F})\end{array}$ \\
\hline$\delta_{\mathrm{s} .}\left(\mathrm{CH}_{3}\right)$ & $1353(\mathrm{mf})$ & $1348(\mathrm{~m})$ & $1352(\mathrm{~m})$ \\
\hline$\rho\left(\mathrm{CH}_{3}\right)$ & $\begin{array}{l}1053(\mathrm{mf}) \\
1025(\mathrm{mf})\end{array}$ & $\begin{array}{l}1051(f) \\
1024(f)\end{array}$ & $\begin{array}{l}1054(f) \\
1025(f)\end{array}$ \\
\hline$v(\mathrm{C}-\mathrm{C})$ & $\begin{array}{l}963(f) \\
940(f)\end{array}$ & $\begin{array}{l}959(f) \\
941(f)\end{array}$ & $\begin{array}{l}963(f) \\
941(f)\end{array}$ \\
\hline$\rho\left(\mathrm{H}_{2} \mathrm{O}\right)_{\text {rock }} * *$ & $909(\mathrm{mf})$ & n. o. & 909 (f) \\
\hline$\beta\left(\mathrm{H}_{2} \mathrm{O}\right)_{t w i s t}$ ** & $812(\mathrm{o})$ & n. o. & $816(0)$ \\
\hline$\gamma\left(\mathrm{H}_{2} \mathrm{O}\right)_{\text {wag }} * *$ & $752(\mathrm{o})$ & n. o. & $751(\mathrm{o})$ \\
\hline$\delta\left(\mathrm{COO}^{\circ}\right)$ & $680(f)$ & $680(\mathrm{~m})$ & $680(F)$ \\
\hline $\begin{array}{l}\rho\left(\mathrm{COO}^{-}\right) \\
\text {fora do plano }\end{array}$ & $631(\mathrm{mf})$ & $616(f)$ & $630(\mathrm{~m})$ \\
\hline$\pi\left(\mathrm{COO}^{-}\right)_{n o p l a n o}$ & $\begin{array}{l}554(\mathrm{mf}) \\
470(\mathrm{mf})\end{array}$ & $\begin{array}{l}542(\mathrm{o}) \\
471 \text { (f) }\end{array}$ & $\begin{array}{l}553(\mathrm{~m}) \\
473(\mathrm{o})\end{array}$ \\
\hline
\end{tabular}

* Nomenclatura das bandas segundo Nakamoto [23]; ** Segundo Raghuvanshi et al [32]; Ac: ion acetato $\left(\mathrm{CH}_{3} \mathrm{COO}^{-}\right)$; ${ }^{\text {a }}$ : obtido por mistura mecânica; ${ }^{\mathbf{b}}$ : obtidos por evaporação do solvente; ${ }^{\text {c }}$ obtido por cristalização com acetona; mf: muito fraca (100-85\%); f: fraca (85-60\%); m: média (60-30\%); F: forte (30-10\%); $\mathbf{m F}$ : muito forte (10-0\%); o: ombro; n. o.: não obbservado. 


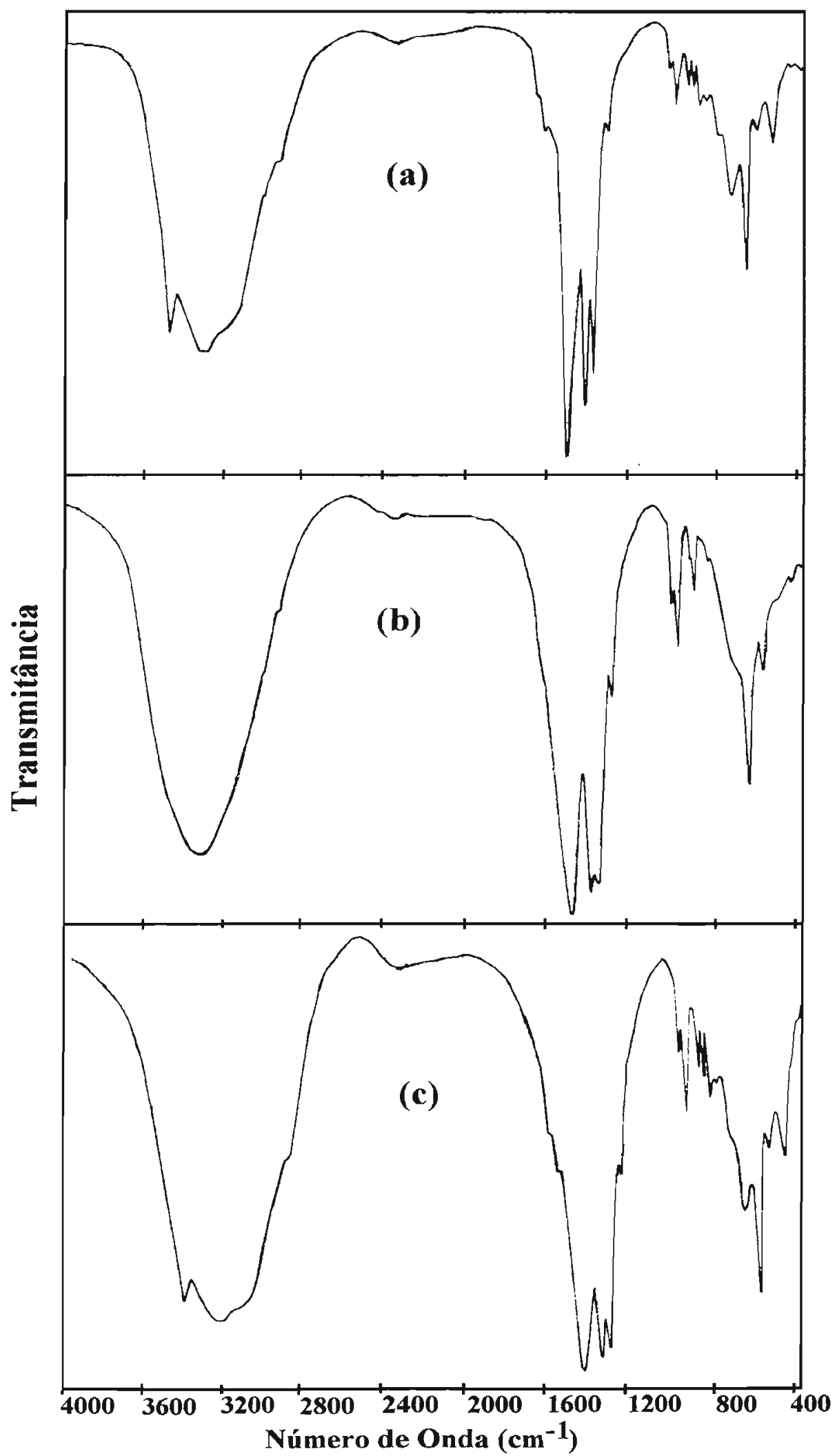

Figura 3.40: Espectros de absorção na região do infravermelho dos sistemas de acetatos binários: (a) $\mathrm{EuNi}\left(\mathrm{CH}_{3} \mathrm{COO}\right)_{5} .8 \mathrm{H}_{2} \mathrm{O}$ (M. M.); (b) $\mathrm{EuNi}\left(\mathrm{CH}_{3} \mathrm{COO}\right)_{5} .5 \mathrm{H}_{2} \mathrm{O}$ (E. S.); (c) $\mathrm{EuNi}\left(\mathrm{CH}_{3} \mathrm{COO}\right)_{5} .7 \mathrm{H}_{2} \mathrm{O}$ (C. A.) 


\subsubsection{3- Difração de raios $X$}

Os difratogramas de raios X, Figura 3.41, para os acetatos binários de európio e níquel foram obtidos com o objetivo de verificar a cristalinidade e observar a formação de novas fases. A avaliação foi realizada a partir da comparação entre as linhas de reflexão dos compostos binários com os acetatos simples (Tabela 3.19).

Similarmente aos resultados da espectroscopia de absorção na região do infravermelho, os difratogramas de raios $\mathrm{X}$ dos sistemas $\mathrm{EuNi}\left(\mathrm{CH}_{3} \mathrm{COO}\right)_{5} .8 \mathrm{H}_{2} \mathrm{O}$ e EuNi $\left(\mathrm{CH}_{3} \mathrm{COO}\right)_{5} .7 \mathrm{H}_{2} \mathrm{O}$, obtidos respectivamente por mistura mecânica e cristalização com acetona, corresponderam à mistura dos acetatos simples, evidenciadas pelas linhas mais intensas do $\mathrm{Eu}\left(\mathrm{CH}_{3} \mathrm{COO}\right)_{3} .4 \mathrm{H}_{2} \mathrm{O}\left(2 \theta=9,6^{\circ}\right)$ e $\mathrm{Ni}\left(\mathrm{CH}_{3} \mathrm{COO}\right)_{2} \cdot 4 \mathrm{H}_{2} \mathrm{O}\left(2 \theta=12,9^{\circ}\right)$. Para o sistema $\mathrm{EuNi}\left(\mathrm{CH}_{3} \mathrm{COO}\right)_{5} \cdot 5 \mathrm{H}_{2} \mathrm{O}$, obtido por evaporação do solvente, foram identificadas no difratograma de raios $X$ algumas linhas de reflexão não observadas nos acetatos simples.

Quanto à cristalinidade dos compostos, observou-se que o sistema sintetizado por evaporação do solvente apresentou-se menos cristalino, em relação aos sistemas de mistura mecânica e cristalização com acetona.

Tabela 3.19: Dados parciais de difração de raios $X$ para os sistemas binários de acetatos binários de európio e níquel

\begin{tabular}{|c|c|c|c|c|c|c|c|c|}
\hline \multicolumn{3}{|c|}{$\mathrm{EuNi}(\mathrm{Ac})_{5} .8 \mathrm{H}_{2} \mathrm{O}^{\mathrm{a}}$} & \multicolumn{3}{|c|}{$\mathrm{EuNi}(\mathrm{Ac})_{5} .5 \mathrm{H}_{2} \mathrm{O}^{b}$} & \multicolumn{3}{|c|}{$\mathrm{EuNi}(\mathrm{Ac})_{5.7 \mathrm{H}_{2} \mathrm{O}^{c}}$} \\
\hline $2 \theta\left(\left(^{\circ}\right)\right.$ & $d(\AA)$ & I//o & $2 \theta\left(\left(^{\circ}\right)\right.$ & d $(\AA)$ & I/Io & $2 \theta\left({ }^{\circ}\right)$ & d $(\AA)$ & I/To \\
\hline 9,6 & 9,22 & 20 & 9,3 & 9,41 & 99 & 9,5 & 9,23 & 75 \\
\hline n. o. & n. o. & n. $o$ & 9,5 & 9,21 & 100 & n. o. & n. o. & n. $o$. \\
\hline 11,2 & 7,88 & 9 & 11,2 & 7,89 & 72 & 11,1 & 7,91 & 33 \\
\hline n. 0 & n. o. & n. $o$. & 11,5 & 7,67 & 51 & n. o. & n. $\mathrm{o}$ & n. $o$. \\
\hline 11,7 & 7,52 & 12 & 11,7 & 7,52 & 91 & 11,7 & 7,53 & 50 \\
\hline n. o. & n. o. & n. o. & 12,5 & 7,02 & 11 & n. o. & n. o. & n. $o$. \\
\hline n. o. & n. o. & n. o. & 12,7 & 6,92 & 17 & n. o. & n. o. & n. $o$. \\
\hline 12,9 & 6,83 & 100 & 13,0 & 6,75 & 23 & 12,9 & 6,84 & 100 \\
\hline n. o. & n. o. & n. o. & 13,3 & 6,61 & 16 & n. o. & n. o. & n. $o$. \\
\hline
\end{tabular}


continuação da tabela 3.19

\begin{tabular}{|c|c|c|c|c|c|c|c|c|}
\hline $2 \theta\left({ }^{\circ}\right)$ & $\mathrm{d}(\AA)$ & I/Io & $2 \theta\left(\left(^{\circ}\right)\right.$ & d $(\AA)$ & І/Іо & $2 \theta\left(\left(^{\circ}\right)\right.$ & d ( $(\AA)$ & I/Io \\
\hline 15,1 & 5,88 & 1 & 15,3 & 5,43 & 24 & 15,0 & 5,88 & 3 \\
\hline 16,6 & 5,32 & 6 & 16,6 & 5,31 & 45 & 16,6 & 5,32 & 31 \\
\hline 16,9 & 5,23 & 1 & 16,9 & 5,22 & 17 & 16,9 & 5,23 & 8 \\
\hline 17,2 & 5,14 & 5 & 17,2 & 5,13 & 53 & 17,2 & 5,13 & 32 \\
\hline 18,6 & 4,76 & 2 & n. $o$. & n. 0 & n. o. & 18,5 & 4,76 & 6 \\
\hline 18,9 & 4,69 & 2 & 19,0 & 4,65 & 22 & 18,8 & 4,70 & 12 \\
\hline 19,7 & 4,49 & 2 & 19,7 & 4,49 & 24 & 19,7 & 4,49 & 18 \\
\hline n. o. & n. 0 & n. $o$ & 20,6 & 4,30 & 3 & n. $o$. & n. o. & n. $o$. \\
\hline 21,1 & 4,20 & 13 & n. o. & n. o. & n. o. & 21,0 & 4,21 & 22 \\
\hline 21,5 & 4,14 & 4 & 21,4 & 4,14 & 44 & 21,3 & 4,15 & 28 \\
\hline 21,6 & 4,06 & 2 & 21,8 & 4,05 & 16 & 21,8 & 4,07 & 12 \\
\hline 22,1 & 4,01 & 2 & n. $o$ & n. $o$ & n. $o$ & 22,1 & 4,01 & 7 \\
\hline 22,4 & 3,95 & 5 & 22,7 & 3,91 & 9 & 22,4 & 3,95 & 7 \\
\hline 23,3 & 3,81 & 1 & 23,5 & 3,78 & 15 & 23,4 & 3,78 & 6 \\
\hline 23,5 & 3,78 & 1 & 24,0 & 3,70 & 8 & n. o. & n. o. & n. $o$. \\
\hline n. o. & n. o. & n. $o$ & 24,5 & 3,61 & 14 & n. $o$. & n. o. & n. $o$. \\
\hline 25,0 & 3,55 & 7 & 25,0 & 3,55 & 34 & 25,0 & 3,55 & 38 \\
\hline 25,7 & 3,46 & 1 & n. $о$ & n. o. & n. o. & 25,7 & 3,46 & 4 \\
\hline 26,3 & 3,38 & 1 & 26,3 & 3,38 & 10 & 26,2 & 3,39 & 5 \\
\hline 26,8 & 3,32 & 3 & 26,7 & 3,32 & 22 & 26,8 & 3,32 & 14 \\
\hline 27,4 & 3,25 & 2 & 27,4 & 3,24 & 21 & 27,3 & 3,25 & 16 \\
\hline
\end{tabular}

Ac: ín acetato $\left(\mathrm{CH}_{3} \mathrm{COO}^{-}\right)$; n. o.: não observado; ${ }^{a}$ obtido por mistura mecânica; ${ }^{\mathrm{b}}$ obtido por evaporação do solvente; ${ }^{c}$ obtido por cristalização com acetona; $2 \theta$ : posição angular; $\mathbf{d}$ : distância interplanar. 


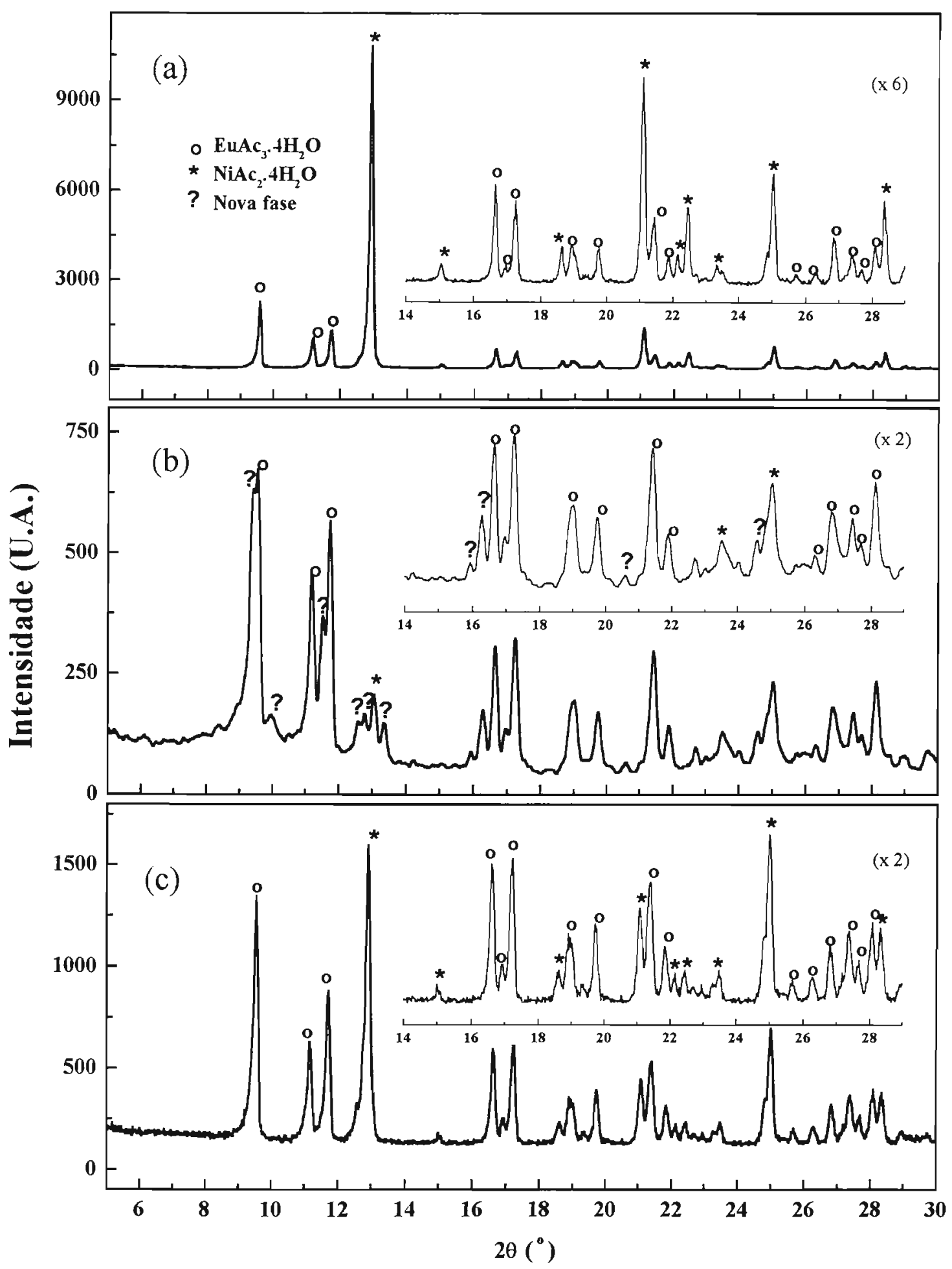

Figura 3.41: Difratogramas de raios $X$ (método do pó) dos sistemas de acetatos binários de európio e níquel:

(a) $\mathrm{EuNi}\left(\mathrm{CH}_{3} \mathrm{COO}\right)_{5} .8 \mathrm{H}_{2} \mathrm{O}$, M. M. (inserido $2 \theta=14$ a $29^{\circ}$, ampliado seis vezes);

(b) EuNi $\left(\mathrm{CH}_{3} \mathrm{COO}\right)_{5} .5 \mathrm{H}_{2} \mathrm{O}$, E. S. (inserido $2 \theta=14$ a $29^{\circ}$, ampliado duas vezes);

(c) $\mathrm{EuNi}\left(\mathrm{CH}_{3} \mathrm{COO}\right)_{5} .7 \mathrm{H}_{2} \mathrm{O}, \mathrm{C}$. A. (inserido $2 \theta=14$ a $29^{\circ}$, ampliado duas vezes). 


\subsubsection{4- Análise Térmica}

De uma maneira geral, o comportamento térmico dos sistemas de acetatos binários de európio e níquel envolveu três eventos principais: desidratação, decomposição com a formação da mistura de $\mathrm{Eu}_{2} \mathrm{O}_{2} \mathrm{CO}_{3}$ e $\mathrm{NiO}$, e produção dos óxidos $\mathrm{Eu}_{2} \mathrm{O}_{3}$ e $\mathrm{NiO}$.

Nas Figuras 3.42 e 3.43 estão representadas as curvas TG/DTG dos acetatos binários, obtidas nas atmosferas dinâmicas de ar comprimido e nitrogênio, respectivamente.

A primeira variação de massa observada nas curvas TG/DTG, no intervalo de temperatura de 25 a $200^{\circ} \mathrm{C}$, corresponde a desidratação dos sistemas em uma etapa, independente da atmosfera utilizada. Para o sistema $\mathrm{EuNi}\left(\mathrm{CH}_{3} \mathrm{COO}\right)_{5} .8 \mathrm{H}_{2} \mathrm{O}$, a variação de massa total foi em torno de $23 \%$, correspondente à libertação de oito mol de água de cristalização, Figuras 3.42 (a) e 3.43 (a). Não foi possível distinguir a perda das moléculas de água relativa a cada acetato simples, uma vez que a desidratação destes sais ocorre no mesmo intervalo de temperatura. Para o $\mathrm{EuNi}\left(\mathrm{CH}_{3} \mathrm{COO}\right)_{5} .5 \mathrm{H}_{2} \mathrm{O}$, a libertação das moléculas de água de cristalização envolveu uma perda de aproximadamente $15 \%$, relativo a libertação de cinco mol de água, Figuras 3.42 (b) e 3.43 (b). Similarmente, o sistema EuNi( $\left(\mathrm{CH}_{3} \mathrm{COO}\right)_{5} .7 \mathrm{H}_{2} \mathrm{O}$, a desidratação envolveu uma etapa, sendo que a variação de massa total foi de aproximadamente $20 \%$ relativo à libertação de sete mol de água de cristalização, Figuras 3.42 (c) e 3.43 (c).

Para todos os sistemas, os valores observados para a etapa de desidratação foram superiores ao valor calculado, segundo a estequiometria proposta. Estes resultados sugerem que ocorre a desidratação, seguida, possivelmente, de hidrólise parcial de grupos acetatos, conduzindo a formação de uma mistura de acetatos básicos anidros de európio e níquel. A perda de massa total dos voláteis, até $200^{\circ} \mathrm{C}$, observada nas curvas TG dos compostos foi de: $\operatorname{EuNi}(\mathrm{Ac})_{5} \cdot 8 \mathrm{H}_{2} \mathrm{O}(\exp .=23,17$ e calc. $=22,17 \%)$; EuNi $(\mathrm{Ac})_{5} .5 \mathrm{H}_{2} \mathrm{O}(\exp .=16,64 \%$ e calc. $=15,12 \%)$ e EuNi $(\mathrm{Ac})_{5} .7 \mathrm{H}_{2} \mathrm{O}(\exp .=21,42 \%$ e calc. $=19,95 \%)$. O valor experimental é a média aritmética dos valores observados nas atmosferas de ar comprimido e nitrogênio.

A decomposição térmica dos intermediários em $200^{\circ} \mathrm{C}$ foi influenciada pela atmosfera atuante. De forma geral, sob atmosfera de ar comprimido, a análise das curvas TG/DTG para os sistemas obtidos por mistura mecânica e cristalização com acetona evidenciaram uma perda de massa rápida e um pico agudo em torno de $360^{\circ} \mathrm{C}$, 
característico de pirólise, Figuras 3.42 (a) e (c). Para o sistema obtido por evaporação do solvente, este evento ocorreu em duas etapas, com temperatura de picos na curva DTG em 319 e $356^{\circ} \mathrm{C}$. Sob atmosfera de nitrogênio, as curvas TG/DTG mostraram que a decomposição térmica ocorreu em duas etapas lentas, caracterizadas por picos largos nas curvas DTG. Para todos os sistemas, os dados de perda de massa calculados nas curvas TG/DTG até $500^{\circ} \mathrm{C}$, sugeriram a formação da mistura $\mathrm{Eu}_{2} \mathrm{O}_{2} \mathrm{CO}_{3}$ e $\mathrm{NiO}$.

A última variação de massa observada nas curvas TG/DTG, independente da atmosfera, correspondeu à libertação de $\mathrm{CO}_{2}$ proveniente do $\mathrm{Eu}_{2} \mathrm{O}_{2} \mathrm{CO}_{3}$, e consequentemente a formação da mistura de $\mathrm{Eu}_{2} \mathrm{O}_{3}$ e $\mathrm{NiO}$ em $900^{\circ} \mathrm{C}$. Por meio desta etapa foi possivel estimar os teores de európio e níquel presentes nos acetatos binários, utilizando-se cálculos estequiométricos. Os valores percentuais calculados e experimentais, dos produtos sólidos da decomposição térmica dos EuNi( $\left.\mathrm{CH}_{3} \mathrm{COO}\right)_{5} \cdot \mathrm{xH}_{2} \mathrm{O}$ estão apresentados na Tabela 3.20.

Tabela 3.20: Dados percentuais dos produtos sólidos da decomposição térmica dos sistemas de acetatos binários de európio e níquel

\begin{tabular}{|c|c|c|c|}
\hline \multirow{2}{*}{ COMPOSTO } & \multirow{2}{*}{ \% CALCULADA } & \multicolumn{2}{|c|}{ \% EXPERIMENTAL } \\
\hline & & $\mathbf{A R}$ & $\mathbf{N}_{2}$ \\
\hline $\mathrm{EuNi}(\mathrm{Ac})_{5} .8 \mathrm{H}_{2} \mathrm{O}^{\mathrm{a}}$ & 100,00 & 100,0 & 100,0 \\
\hline $\mathrm{EuNi}(\mathrm{Ac})_{5}$ & 77,83 & 76,3 & 77,4 \\
\hline $\mathrm{Eu}_{2} \mathrm{O}_{2} \mathrm{CO}_{3} \cdot \mathrm{NiO}$ & 41,94 & 41,6 & 41,9 \\
\hline $\mathrm{Eu}_{2} \mathrm{O}_{3} \cdot \mathrm{NiO}$ & 38,56 & 38,3 & 39,5 \\
\hline $\mathrm{EuNi}(\mathrm{Ac})_{5} .5 \mathrm{H}_{2} \mathrm{O}^{\mathrm{b}}$ & 100,00 & 100,0 & 100,0 \\
\hline $\mathrm{EuNi}(\mathrm{Ac})_{5}$ & 84,88 & 83,3 & 83,4 \\
\hline $\mathrm{Eu}_{2} \mathrm{O}_{2} \mathrm{CO}_{3} \cdot \mathrm{NiO}$ & 45,75 & 45,6 & 45,7 \\
\hline $\mathrm{Eu}_{2} \mathrm{O}_{3} \cdot \mathrm{NiO}$ & 42,06 & 41,9 & 42,3 \\
\hline $\mathrm{EuNi}(\mathrm{Ac})_{5} \cdot 7 \mathrm{H}_{2} \mathrm{O}^{\mathrm{c}}$ & 100,00 & 100,0 & 100,0 \\
\hline $\operatorname{EuNi}(\mathrm{Ac})_{5}$ & 80,05 & 78,6 & 78,6 \\
\hline $\mathrm{Eu}_{2} \mathrm{O}_{2} \mathrm{CO}_{3} \cdot \mathrm{NiO}$ & 43,14 & 43,5 & 43,4 \\
\hline $\mathrm{Eu}_{2} \mathrm{O}_{3} \cdot \mathrm{NiO}$ & 39,66 & 40,0 & 39,9 \\
\hline
\end{tabular}

Ac: íon acetato $\left(\mathrm{CH}_{3} \mathrm{COO}\right)$; ${ }^{\mathbf{a}}$ : obtido por mistura mecânica; ${ }^{\mathbf{b}}$ : obtido por evaporação do solvente; ${ }^{c}$ : obtido por cristalização com acetona 
Nas Figuras 3.44 e 3.45 estão apresentadas as curvas DTA e DSC para os acetatos binários de európio e níquel, respectivamente. Similarmente, aos acetatos de terras raras e acetato de níquel, os valores das temperaturas dos picos observados nessas curvas estão deslocados para valores menores (curvas DSC) e maiores (curvas DTA), em relação aos picos das curvas DTG.

Para os sistemas EuNi $\left(\mathrm{CH}_{3} \mathrm{COO}\right)_{5} .8 \mathrm{H}_{2} \mathrm{O}$ e EuNi $\left(\mathrm{CH}_{3} \mathrm{COO}\right)_{5} .7 \mathrm{H}_{2} \mathrm{O}$, as curvas DTA apresentaram dois picos endotérmicos, em 120 e $180^{\circ} \mathrm{C}$, relativos a etapa de desidratação, Figura 3.44 (a) e (c). Apesar das curvas DTG apresentarem somente uma perda de massa para esta etapa, as curvas DTA sugerem e existência de moléculas de água ligadas de forma diferentes, relativas aos acetatos de európio e níquel. No entanto, para o composto $\mathrm{EuNi}\left(\mathrm{CH}_{3} \mathrm{COO}\right)_{5} .5 \mathrm{H}_{2} \mathrm{O}$, a desidratação foi evidenciada por um evento endotérmico em $110^{\circ} \mathrm{C}$, Figura 3.44 (b). Este resultado sugere a existência de apenas um tipo de água ligada no sal.

Após desidratação os compostos apresentaram um evento exotérmico, caracterizado por um pico agudo, entre 280 e $420^{\circ} \mathrm{C}$, que pode estar associado ao fenômeno de pirólise. Este fenômeno é uma indicação que a decomposição térmica dos acetatos binários é rápida, o que facilita a formação dos óxidos em temperaturas mais baixas. Para todos os sistemas, a última etapa da decomposição térmica, relativa à libertação de $\mathrm{CO}_{2}$, proveniente do $\mathrm{Eu}_{2} \mathrm{O}_{2} \mathrm{CO}_{3}$ e formação da mistura de $\mathrm{Eu}_{2} \mathrm{O}_{3} \cdot \mathrm{NiO}$, foi evidenciada por um evento endotérmico em torno de $650^{\circ} \mathrm{C}$.

$\mathrm{Na}$ Figura 3.45 estão apresentadas as curvas DSC, obtidas sob atmosfera dinâmica de nitrogênio, para os acetatos binários de európio e níquel. Estas curvas são concordantes com as curvas DTA, para a etapa de desidratação. Esta etapa foi evidenciada por dois eventos endotérmicos consecutivos em torno de 70 e $90^{\circ} \mathrm{C}$, para os sistemas obtidos por mistura mecânica e cristalização com acetona, Figuras 3.45 (a) e (c). No entanto, para o sistema obtido por evaporação do solvente, a desidratação foi evidenciada apenas por um evento endotérmico em $69^{\circ} \mathrm{C}$, Figuras 3.45 (b). Em virtude da pequena massa de amostra usada nos experimentos, ca. $2 \mathrm{mg}$, observou-se os que os eventos ocorreram em temperaturas inferiores, em relação as curvas DTA.

Para todos os sistemas, a etapa de decomposição térmica foi evidenciada por um evento endotérmico, em torno de $310^{\circ} \mathrm{C}$, seguido de um evento exotérmico, caracterizado por um pico largo em aproximadamente $380^{\circ} \mathrm{C}$. Esse resultado sugere que 
a decomposição ocorre lentamente, mas com liberação de energia e a atmosfera gerada influência na obtenção dos óxidos finais.

Os perfis das curvas DSC permitiram calcular as entalpias de reação $(\Delta H)$ referentes às etapas de desidratação e decomposição dos sistemas. Na Tabela 3.21 estão apresentados os resultados de DSC, para os EuNi $\left(\mathrm{CH}_{3} \mathrm{COO}\right)_{5} \cdot \mathrm{XH}_{2} \mathrm{O}$, sintetizados pelos três métodos em estudo.

Tabela 3.21: Dados de DSC para as etapas de desidratação e decomposição térmica dos sistemas de acetatos binários de európio e níquel

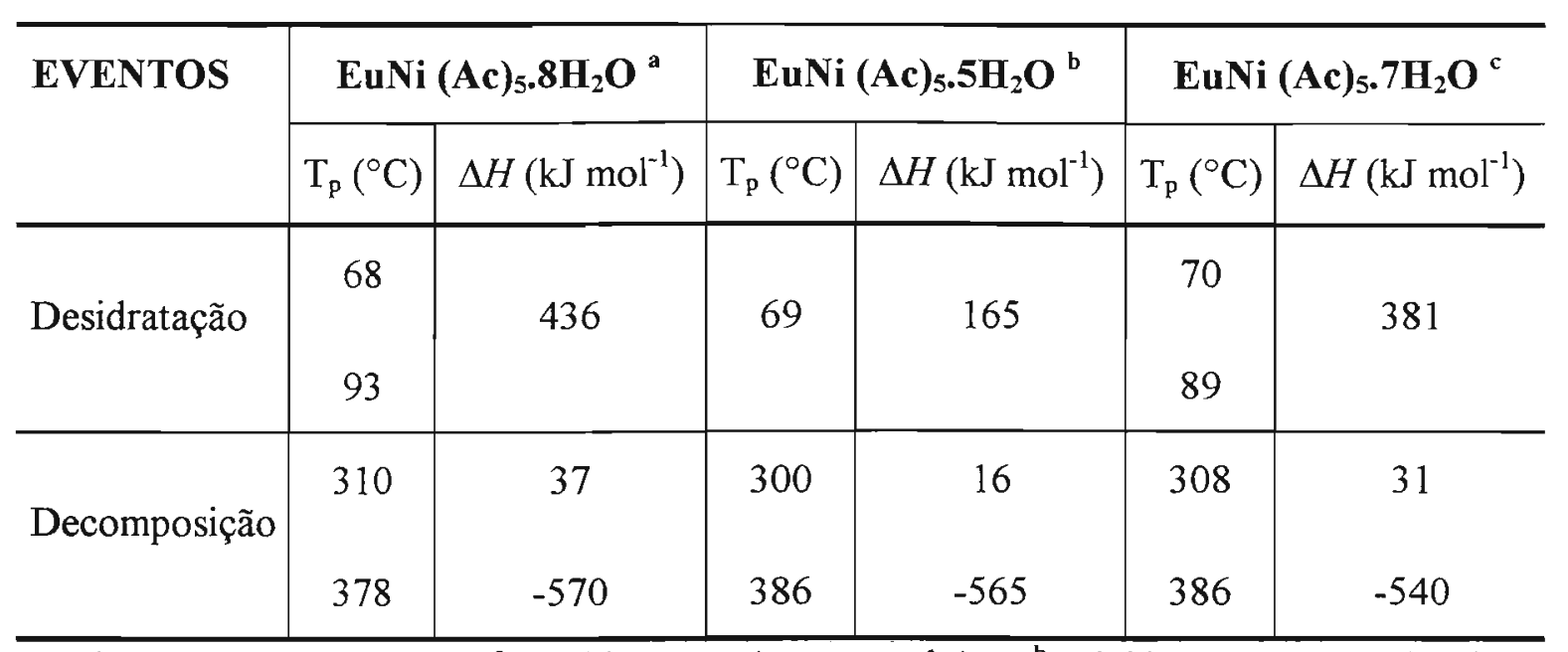

Ac: íon acetato $\left(\mathrm{CH}_{3} \mathrm{COO}^{-}\right)$; ${ }^{\mathbf{a}}$ : obtido por mistura mecânica; ${ }^{\mathbf{b}}$ : obtido por evaporação do

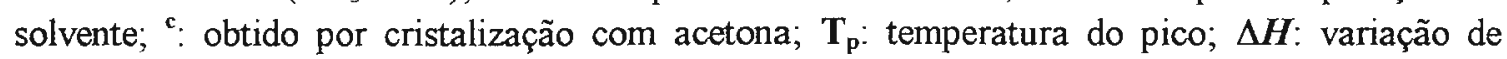
entalpia 


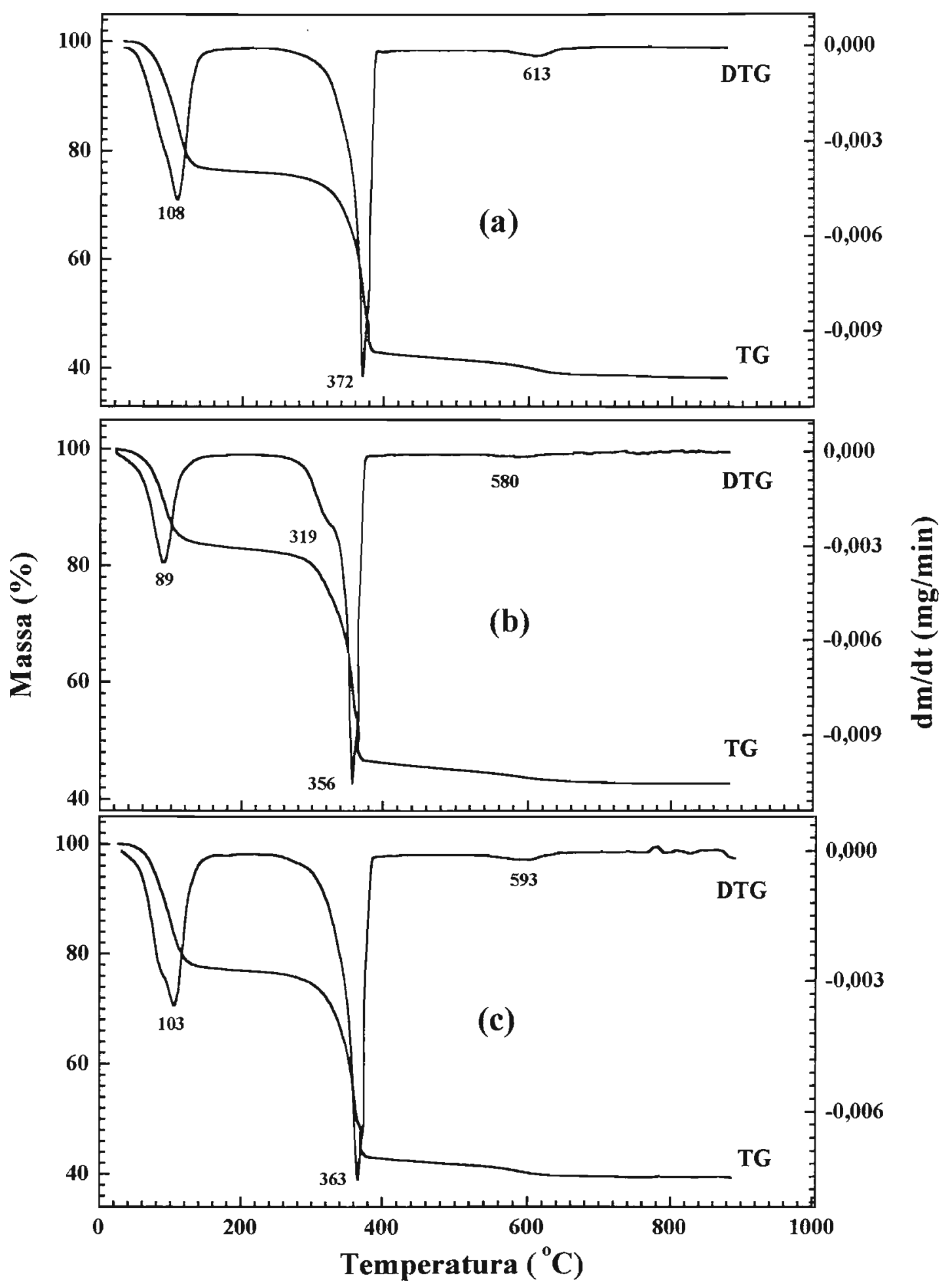

Figura 3.42: Curvas TG/DTG dos sistemas de acetatos binários de európio e níquel obtidas sob atmosfera dinâmica de ar $\left(50 \mathrm{~mL} \mathrm{~min}{ }^{-1}\right)$, razão de aquecimento de $10^{\circ} \mathrm{C} \mathrm{min}{ }^{-1}$ e cadinho de platina: (a) $\mathrm{EuNi}\left(\mathrm{CH}_{3} \mathrm{COO}\right)_{5} .8 \mathrm{H}_{2} \mathrm{O}, \mathrm{M} . \mathrm{M} .\left(\mathrm{m}=5,673 \mathrm{mg}\right.$ ); (b) $\mathrm{EuNi}\left(\mathrm{CH}_{3} \mathrm{COO}\right)_{5} .5 \mathrm{H}_{2} \mathrm{O}$, E. S. $(\mathrm{m}=5,305 \mathrm{mg})$; (c) $\mathrm{EuNi}\left(\mathrm{CH}_{3} \mathrm{COO}\right)_{\mathrm{s}} .7 \mathrm{H}_{2} \mathrm{O}$, C. A. $(\mathrm{m}=4,519 \mathrm{mg})$. 


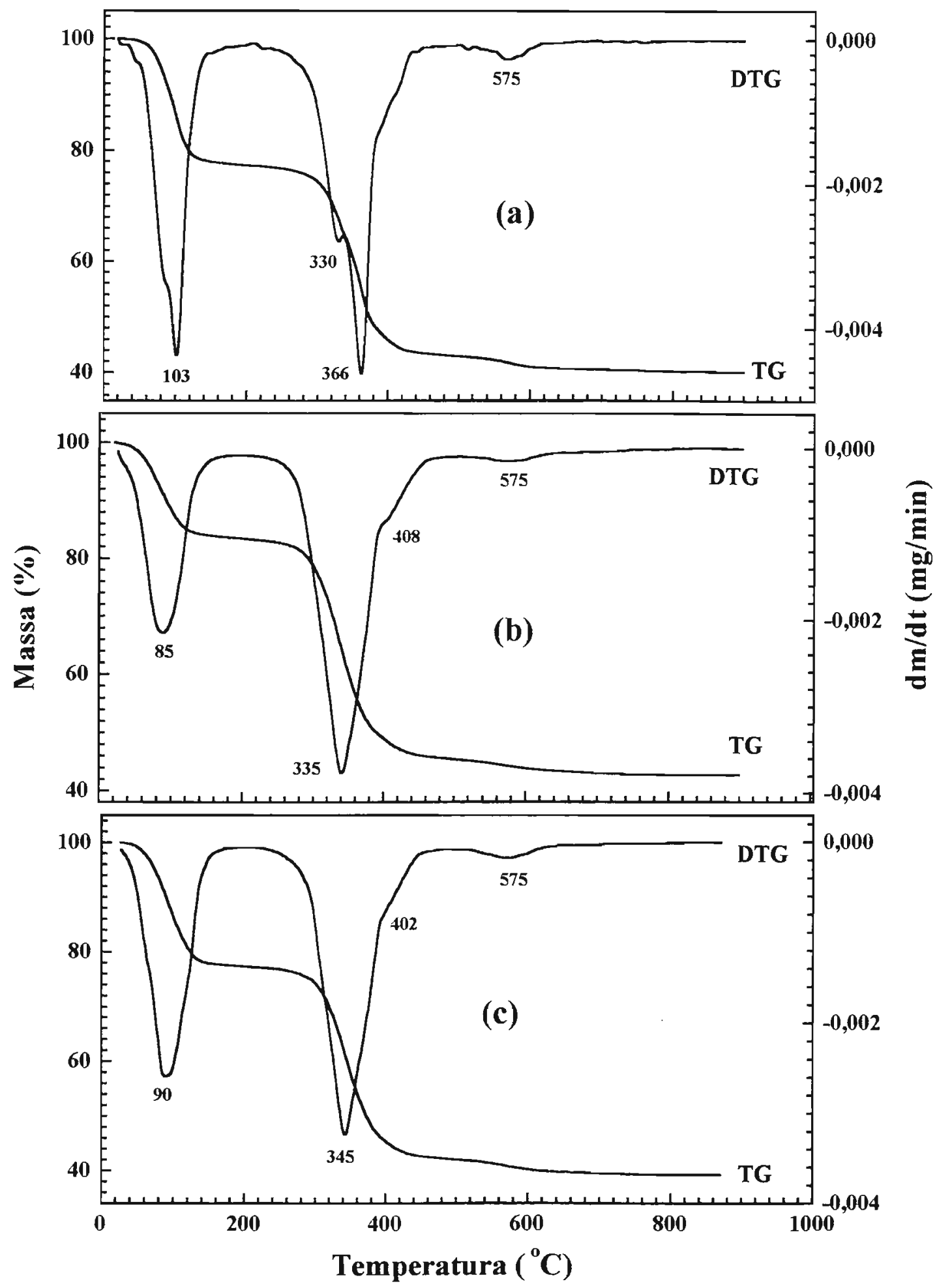

Figura 3.43: Curvas TG/DTG dos sistemas de acetatos binários de európio e níquel obtidas sob atmosfera dinâmica de nitrogênio $\left(50 \mathrm{~mL} \mathrm{~min}^{-1}\right)$, razão de aquecimento de $10^{\circ} \mathrm{C} \mathrm{min}^{-1}$ e cadinho de platina: (a) EuNi( $\left.\mathrm{CH}_{3} \mathrm{COO}\right)_{5} .8 \mathrm{H}_{2} \mathrm{O}$, M. M. (m = 4,164 mg); (b) $\mathrm{EuNi}\left(\mathrm{CH}_{3} \mathrm{COO}\right)_{5} .5 \mathrm{H}_{2} \mathrm{O}$, E. S. $(\mathrm{m}=4,971 \mathrm{mg})$; (c) $\mathrm{EuNi}\left(\mathrm{CH}_{3} \mathrm{COO}\right)_{5} .7 \mathrm{H}_{2} \mathrm{O}$, C. A. $(\mathrm{m}=4,287 \mathrm{mg})$. 

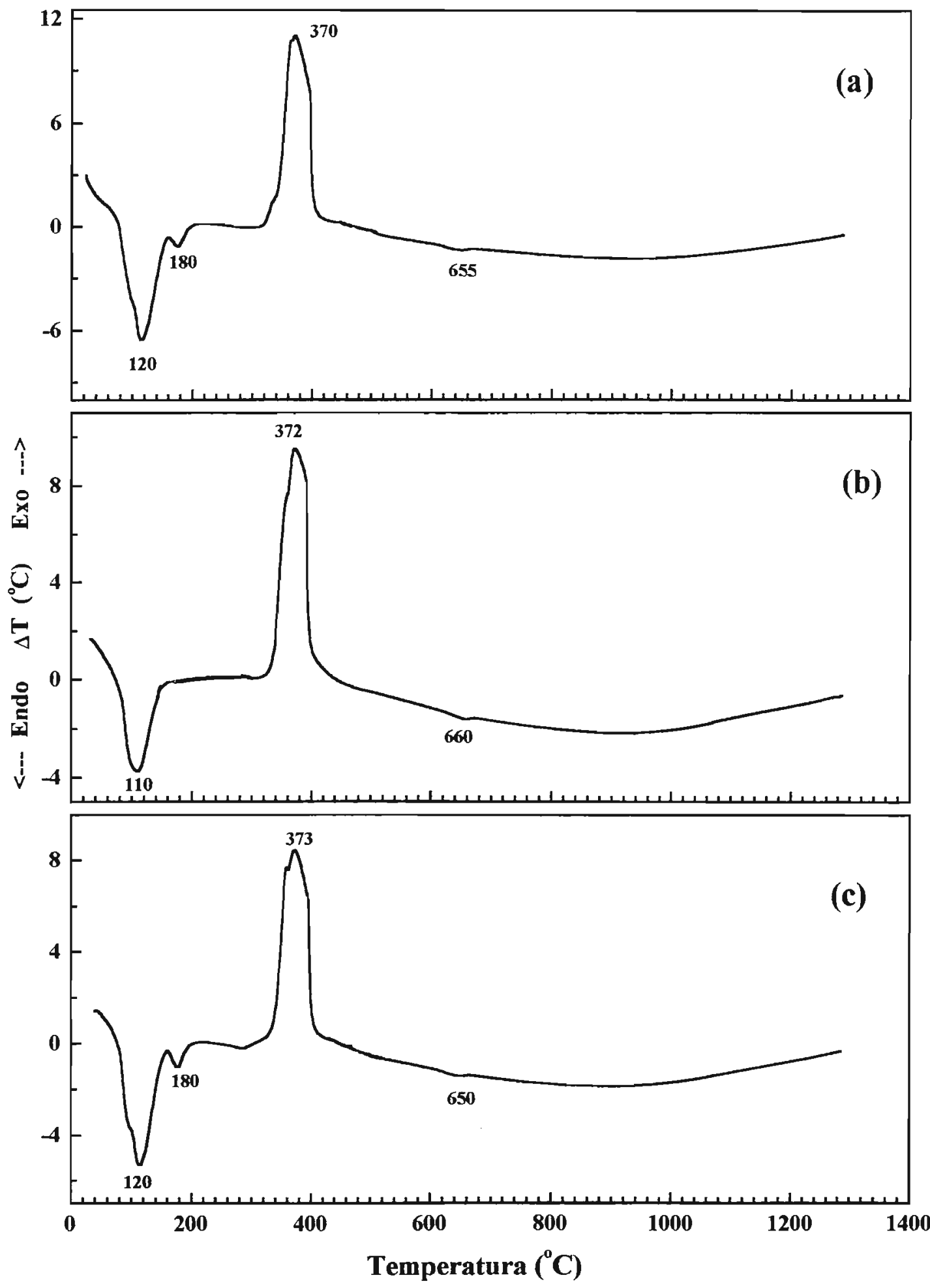

Figura 3.44: Curvas DTA dos sistemas de acetatos binários de európio e níquel obtidas sob atmosfera dinâmica de ar $\left(50 \mathrm{~mL} \mathrm{~min}{ }^{-1}\right)$, razão de aquecimento de $10^{\circ} \mathrm{C} \mathrm{min}$ - $^{-1}$ e cadinho de alumina: (a) $\mathrm{EuNi}\left(\mathrm{CH}_{3} \mathrm{COO}\right)_{3} .8 \mathrm{H}_{2} \mathrm{O}, \mathrm{M}$. M. $(\mathrm{m}=19,50 \mathrm{mg})$; (b) $\mathrm{EuNi}\left(\mathrm{CH}_{3} \mathrm{COO}\right)_{5} .5 \mathrm{H}_{2} \mathrm{O}$, E. S. (m = 18,68 mg); (c) EuNi( $\left.\mathrm{CH}_{3} \mathrm{COO}\right)_{5} .7 \mathrm{H}_{2} \mathrm{O}$, C. A. $(\mathrm{m}=19,02 \mathrm{mg})$. 


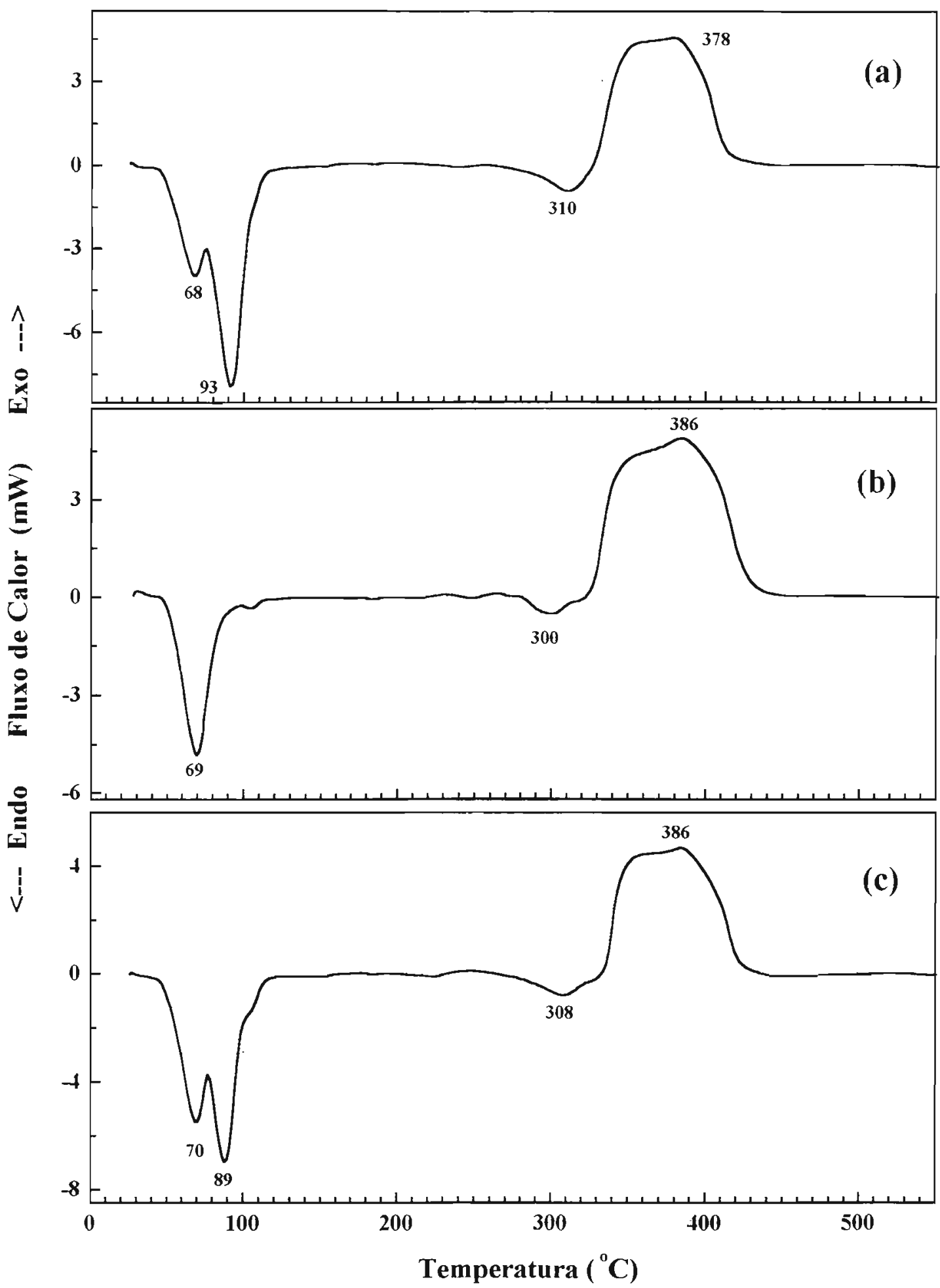

Figura 3.45: Curvas DSC dos sistemas de acetatos binários de európio e níquel obtidas sob atmosfera dinâmica de nitrogênio $\left(50 \mathrm{~mL} \mathrm{~min}{ }^{-1}\right)$, razão de aquecimento de $10^{\circ} \mathrm{C} \mathrm{min}^{-1}$ e cápsula de alumínio aberta: (a) $\mathrm{EuNi}\left(\mathrm{CH}_{3} \mathrm{COO}\right)_{5} .8 \mathrm{H}_{2} \mathrm{O}, \quad$ M. M. $(\mathrm{m}=2,105 \mathrm{mg}) ;$ (b) $\mathrm{EuNi}\left(\mathrm{CH}_{3} \mathrm{COO}\right)_{5} .5 \mathrm{H}_{2} \mathrm{O}$, E. S. $(\mathrm{m}=2,305 \mathrm{mg})$; (c) $\mathrm{EuNi}\left(\mathrm{CH}_{3} \mathrm{COO}\right)_{5} \cdot 3 \mathrm{H}_{2} \mathrm{O}$, C. A. $(\mathrm{m}=2,225$ $\mathrm{mg}$ ). 


\subsubsection{5- Produtos sólidos da decomposição térmica dos acetatos binários de európio e niquel}

Os produtos sólidos da decomposição térmica dos sistemas de acetatos binários de európio e níquel isolados a $900^{\circ} \mathrm{C}$ foram submetidos à caracterização por difração de raios X. A análise dos difratogramas foi realizada a partir da comparação com os óxidos simples, obtidos nas mesmas condições de decomposição térmica dos sais precursores.

Nas Figuras 3.46 e 3.47 estão apresentados os difratogramas de raios X dos produtos isolados sob atmosferas dinâmicas de ar e nitrogênio, respectivamente. Independente do método de síntese, os produtos consistiram da mistura dos óxidos simples, ou seja, somente foi observado o somatório das linhas de reflexão dos óxidos $\mathrm{Eu}_{2} \mathrm{O}_{3}$ e $\mathrm{NiO}$. A intensidade relativa das linhas variou, mas não foi observado nenhum indício da formação do óxido misto desejado.

Este resultado sugere que o tratamento térmico utilizado não foi adequado para a obtenção de óxido misto, sendo necessário manter o produto a $900^{\circ} \mathrm{C}$, durante um intervalo de tempo maior.

Na Figura 3.48 estão apresentados os difratogramas de raios $\mathrm{X}$ dos produtos após tratamento térmico nas seguintes condições: atmosfera dinâmica de ar, vazão aproximada de $50 \mathrm{~mL} \mathrm{~min}{ }^{-1}$, cadinho de alumina, razão de aquecimento de $10^{\circ} \mathrm{C} \mathrm{min}^{-1}$, no intervalo de 25 a $900^{\circ} \mathrm{C}$, mantido isotérmico por uma hora.

Nestas condições foi observado que os produtos dos sistemas EuNi $\left(\mathrm{CH}_{3} \mathrm{COO}\right)_{5} .8 \mathrm{H}_{2} \mathrm{O}$ e EuNi $\left(\mathrm{CH}_{3} \mathrm{COO}\right)_{5} .7 \mathrm{H}_{2} \mathrm{O}$ corresponderam à mistura dos óxidos simples. Os difratogramas de raios $\mathrm{X}$ evidenciaram que esses produtos apresentaram baixa cristalinidade e possivelmente, estão em processo de formação de uma nova fase, Figuras 3.48 (c) e (e). No entanto, para o produto isolado do sistema $\mathrm{EuNi}\left(\mathrm{CH}_{3} \mathrm{COO}\right)_{5} .5 \mathrm{H}_{2} \mathrm{O}$, o difratograma de raios $\mathrm{X}$ evidenciou linhas do óxido misto $\mathrm{Eu}_{2} \mathrm{NiO}_{4}$ e algumas linhas dos óxidos simples $\mathrm{Eu}_{2} \mathrm{O}_{3}$ e $\mathrm{NiO}$, Figura 3.48 (d). Esse produto apresentou-se altamente cristalino, mas ainda não foi possivel isolar o material como monofásico, mesmo aumentando o tempo do tratamento térmico.

Dessa forma, o precursor sintetizado por evaporação do solvente constituiu-se naquele que proporcionou a obtenção do melhor óxido misto, quando comparado aos outros dois precursores. Isto se deve, possivelmente, a forma de cristalização do material de partida. 


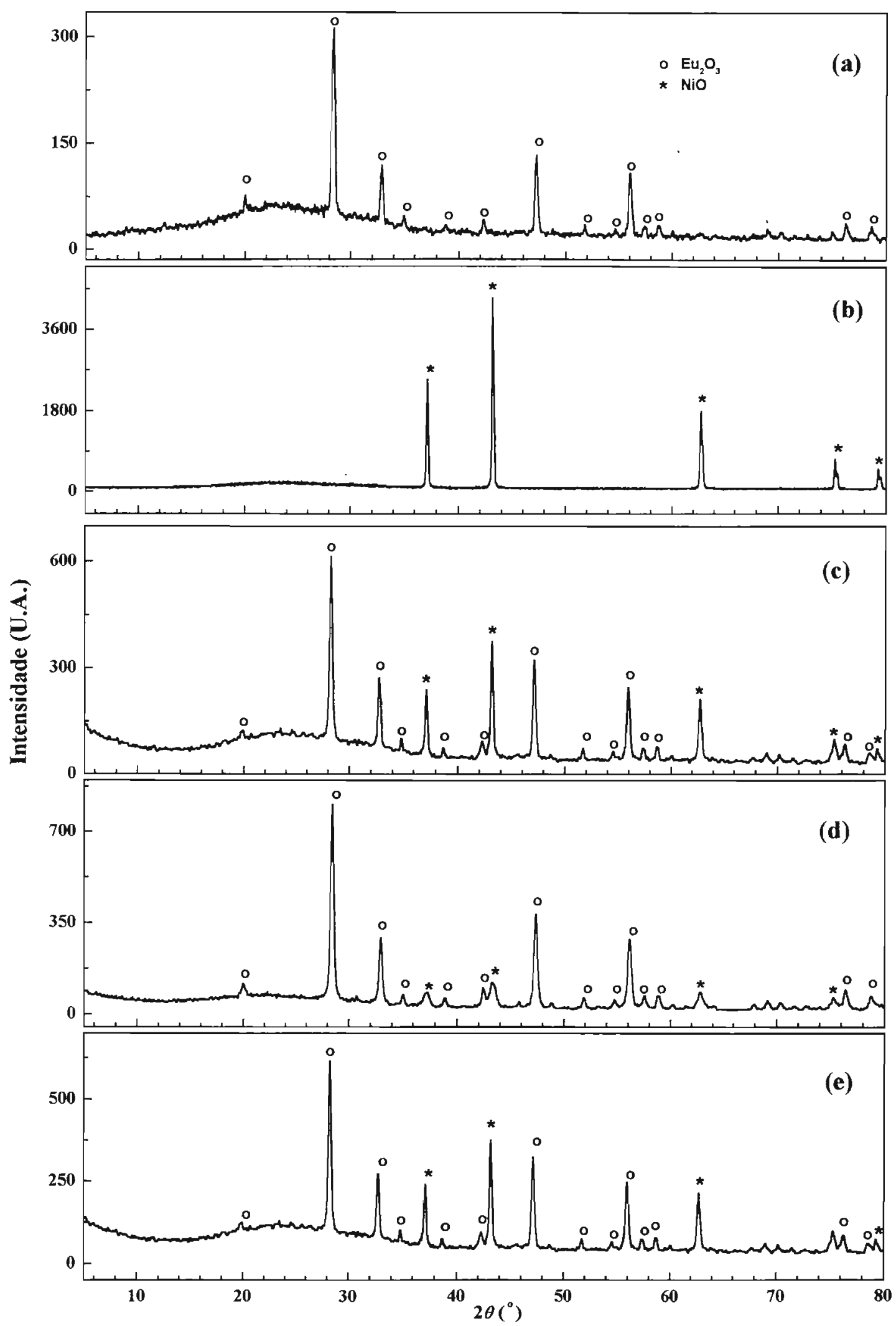

Figura 3.46: Difratogramas de raios $X$ (método do pó) dos produtos da decomposição térmica a $900^{\circ} \mathrm{C}$, obtidos sob atmosfera dinâmica de ar $\left(50 \mathrm{~mL} \mathrm{~min}^{-1}\right)$, razão de aquecimento de $10^{\circ} \mathrm{C} \mathrm{min}{ }^{-1}$ e cadinho de platina das amostras: (a) $\mathrm{Eu}\left(\mathrm{CH}_{3} \mathrm{COO}\right)_{3} \cdot 4 \mathrm{H}_{2} \mathrm{O}$; (b) $\mathrm{Ni}\left(\mathrm{CH}_{3} \mathrm{COO}\right)_{2} \cdot 4 \mathrm{H}_{2} \mathrm{O}$; (c) $\mathrm{EuNi}\left(\mathrm{CH}_{3} \mathrm{COO}\right)_{5} .8 \mathrm{H}_{2} \mathrm{O}$ (M. M.); (d) $\mathrm{EuNi}\left(\mathrm{CH}_{3} \mathrm{COO}\right)_{5} .5 \mathrm{H}_{2} \mathrm{O}$ (E. S.); (e) $\mathrm{EuNi}\left(\mathrm{CH}_{3} \mathrm{COO}\right)_{5} .7 \mathrm{H}_{2} \mathrm{O}$ (C. A.). 


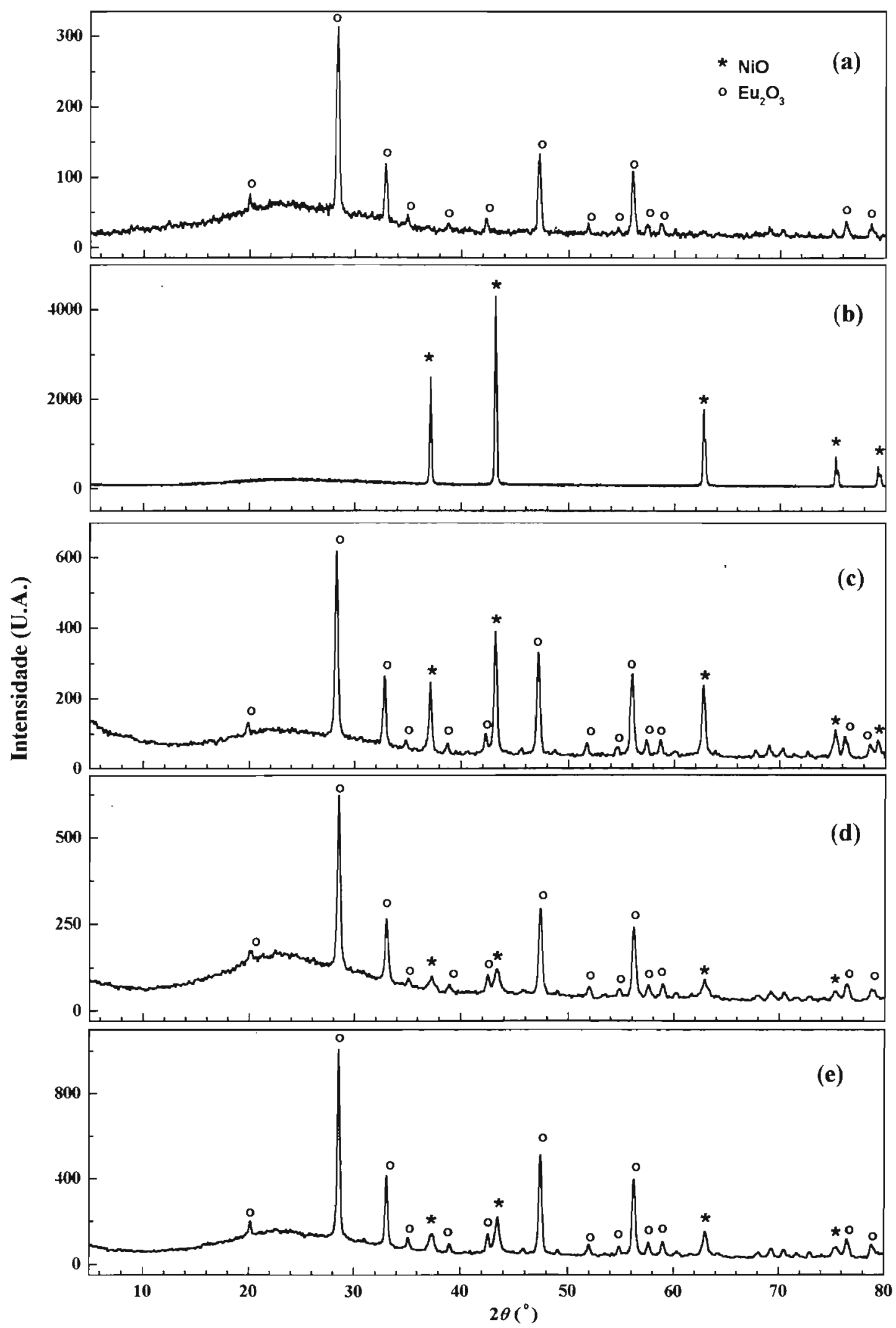

Figura 3.47: Difratogramas de raios $\mathrm{X}$ (método do pó) dos produtos da decomposição térmica a $900^{\circ} \mathrm{C}$, obtidos sob atmosfera dinâmica de nitrogênio $\left(50 \mathrm{~mL} \mathrm{~min}{ }^{-1}\right)$, razão de aquecimento de $10^{\circ} \mathrm{C} \min ^{-1}$ e cadinho de platina das amostras: (a) $\mathrm{Eu}\left(\mathrm{CH}_{3} \mathrm{COO}\right)_{3} \cdot 4 \mathrm{H}_{2} \mathrm{O}$; (b) $\mathrm{Ni}\left(\mathrm{CH}_{3} \mathrm{COO}\right)_{2} .4 \mathrm{H}_{2} \mathrm{O}$; (c) $\mathrm{EuNi}\left(\mathrm{CH}_{3} \mathrm{COO}\right)_{5} .8 \mathrm{H}_{2} \mathrm{O}$ (M. M.); (d) $\mathrm{EuNi}\left(\mathrm{CH}_{3} \mathrm{COO}\right)_{5} .5 \mathrm{H}_{2} \mathrm{O}$ (E. S.); (e) $\mathrm{EuNi}\left(\mathrm{CH}_{3} \mathrm{COO}\right)_{5} .7 \mathrm{H}_{2} \mathrm{O}$ (C. A.). 


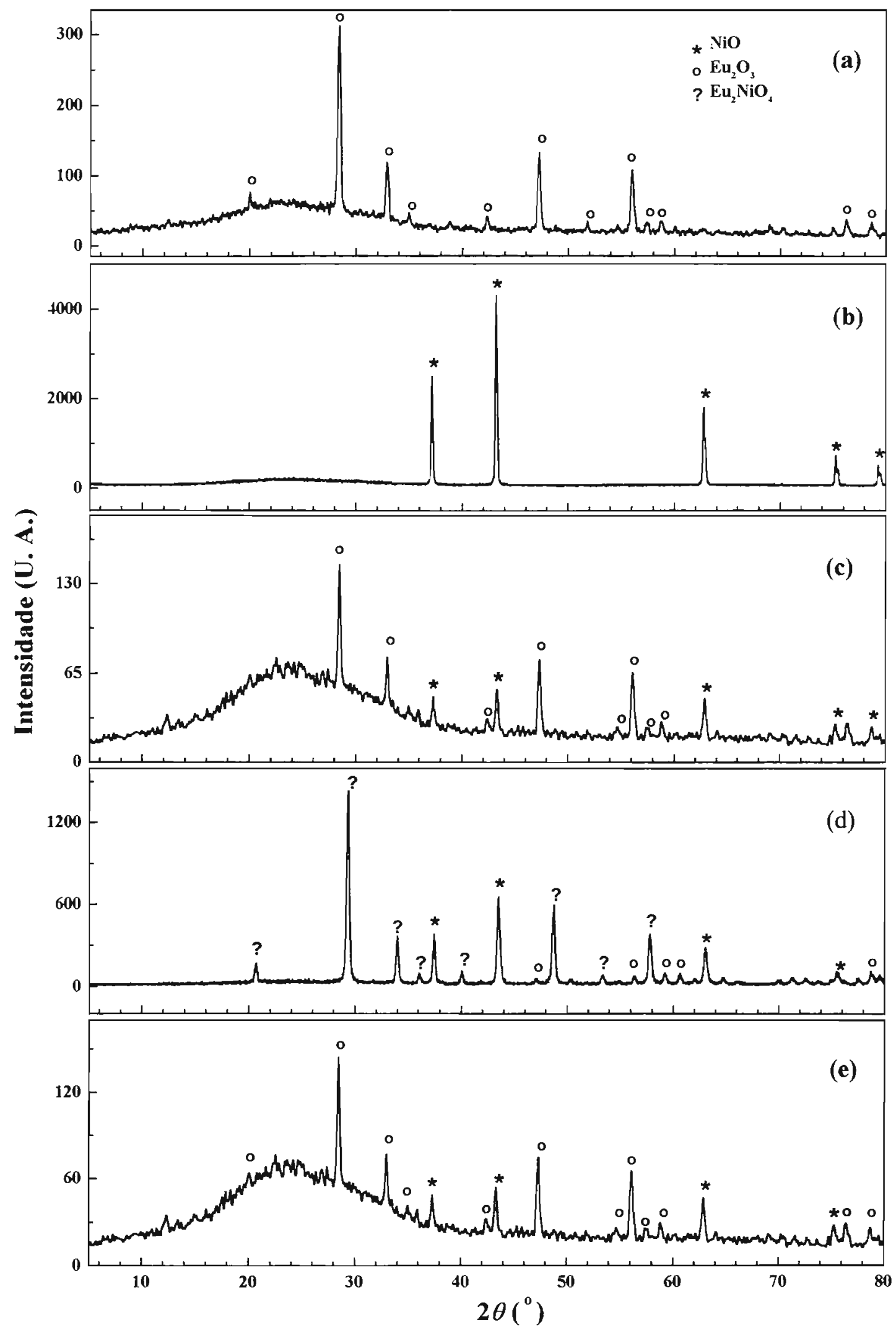

Figura 3.48: Difratogramas de raios $X$ (método do pó) obtidos após tratamento térmico a $900^{\circ} \mathrm{C}$ durante uma hora de aquecimento, sob atmosfera dinâmica de ar $\left(50 \mathrm{~mL} \min ^{-1}\right)$, razão de aquecimento de $10^{\circ} \mathrm{C} \mathrm{min}^{-1}$ e cadinho de alumina das amostras: (a) $\mathrm{Eu}\left(\mathrm{CH}_{3} \mathrm{COO}\right)_{3} .4 \mathrm{H}_{2} \mathrm{O}$; (b) $\mathrm{Ni}\left(\mathrm{CH}_{3} \mathrm{COO}\right)_{2} .4 \mathrm{H}_{2} \mathrm{O}$; (c) $\mathrm{EuNi}\left(\mathrm{CH}_{3} \mathrm{COO}\right)_{5} .8 \mathrm{H}_{2} \mathrm{O}$ (M. M.); (d) $\mathrm{EuNi}\left(\mathrm{CH}_{3} \mathrm{COO}\right)_{5} .5 \mathrm{H}_{2} \mathrm{O}$ (E. S.); (e) $\mathrm{EuNi}\left(\mathrm{CH}_{3} \mathrm{COO}\right)_{5} .7 \mathrm{H}_{2} \mathrm{O}$ (C. A.). 


\subsection{3- Sistema ítrio - níquel}

Os sistemas de acetatos binários de ítrio (III) e níquel (II) foram obtidos hidratados, cristalinos e solúveis em água.

\subsubsection{1- Análise elementar}

Os teores de carbono e hidrogênio foram determinados por procedimentos microanalíticos, enquanto que os teores de ítrio e níquel foram obtidos por espectrometria de emissão atômica com plasma de argônio indutivamente acoplado (ICP-AES). Os resultados revelaram a estequiometria dos acetatos binários e estão apresentados na Tabela 3.22 .

Tabela 3.22: Resultados de análise elementar para os sistemas de acetatos binários de ítrio e níquel

\begin{tabular}{l|c|c|c|c|c|c|c|c}
\hline \multirow{2}{*}{ COMPOSTO } & \multicolumn{4}{c}{ \% CALCULADA } & \multicolumn{3}{c}{ \% EXPERIMENTAL } \\
\cline { 2 - 8 } (Sistemas binários) & C & H & Y & Ni & C & H & Y & Ni \\
\hline $\mathrm{YNi}(\mathrm{Ac})_{5} .8 \mathrm{H}_{2} \mathrm{O}^{3}$ & 20,48 & 5,33 & 15,17 & 9,89 & 20,38 & 4,88 & 15,25 & 9,05 \\
$\mathrm{YNi}(\mathrm{Ac})_{5} .3 \mathrm{H}_{2} \mathrm{O}^{\mathrm{b}}$ & 24,20 & 4,27 & 17,93 & 11,68 & 23,02 & 3,92 & 16,80 & 11,10 \\
$\mathrm{YNi}(\mathrm{Ac})_{5} .2 \mathrm{H}_{2} \mathrm{O}^{\mathrm{c}}$ & 25,11 & 4,01 & 18,16 & 12,12 & 25,06 & 3,81 & 18,76 & 12,35 \\
\hline
\end{tabular}

Ac: íon acetato $\left(\mathrm{CH}_{3} \mathrm{COO}^{-}\right)$; ${ }^{a}$ obtido por mistura mecânica; ${ }^{\mathbf{b}}$ obtido por evaporação do solvente; c obtido por cristalização com acetona

\subsubsection{2- Espectroscopia de absorção na região do infravermelho}

Os espectros de absorção na região do infravermelho para os acetatos binários de ítrio e níquel estão apresentados na Figura 3.49. Os espectros foram obtidos com o objetivo de verificar a formação de acetatos duplos ou misturas dos acetatos simples.

Para os sistemas $\mathrm{YNi}\left(\mathrm{CH}_{3} \mathrm{COO}\right)_{5} .3 \mathrm{H}_{2} \mathrm{O}$, obtido por evaporação do solvente e $\mathrm{YNi}\left(\mathrm{CH}_{3} \mathrm{COO}\right)_{5} \cdot 2 \mathrm{H}_{2} \mathrm{O}$, obtido por cristalização com acetona, os espectros $\mathbb{R}$ foram similares e apresentaram praticamente as bandas de absorção nas mesmas freqüências do $\mathrm{Y}\left(\mathrm{CH}_{3} \mathrm{COO}\right)_{3} .4 \mathrm{H}_{2} \mathrm{O}$. Este resultado indicou que os sais cristalizaram, possivelmente, 
com a mesma estrutura cristalina. No entanto, para o composto $\mathrm{YNi}\left(\mathrm{CH}_{3} \mathrm{COO}\right)_{5} .8 \mathrm{H}_{2} \mathrm{O}$, obtido por mistura mecânica, espectro $\mathbb{R}$ apresentou o somatório das bandas de absorção relativas aos acetatos simples, indicando que este sal se comporta como uma mistura física dos respectivos acetatos.

$\mathrm{Na}$ Tabela 3.23 estão apresentadas as atribuições das bandas de absorção dos espectros $\mathrm{IR}$ para os acetatos binários de ítrio e níquel.

Tabela 3.23: Atribuição das bandas de absorção dos espectros IR dos sistemas de acetatos binários de ítrio e níquel (número de onda, $\mathrm{cm}^{-1}$ ) *

\begin{tabular}{|c|c|c|c|}
\hline ATRIBUIÇÃO & $\mathrm{YNi}(\mathrm{Ac})_{5} .8 \mathrm{H}_{2} \mathrm{O}^{\mathrm{a}}$ & $\mathrm{YNi}(\mathrm{Ac})_{5} .3 \mathrm{H}_{2} \mathrm{O}^{\mathrm{b}}$ & $\mathrm{YNi}(\mathrm{Ac})_{5 \cdot} \cdot 2 \mathrm{H}_{2} \mathrm{O}^{\mathrm{c}}$ \\
\hline$v(\mathrm{O}-\mathrm{H})$ & $\begin{array}{l}3476(\mathrm{~m}) \\
3200(\mathrm{~m})\end{array}$ & $3407(\mathrm{~m})$ & $3399(\mathrm{~m})$ \\
\hline$v_{\text {as. }}(\mathrm{C}-\mathrm{H})$ & $3056(0)$ & $3015(\mathrm{o})$ & $3028(0)$ \\
\hline$v_{\mathrm{s}}(\mathrm{C}-\mathrm{H})$ & n. $o$. & 2938 (o) & $2928(0)$ \\
\hline$\delta(\mathrm{OH})$ & $\begin{array}{l}1696(\mathrm{~m}) \\
1658(\mathrm{~m})\end{array}$ & n. 0 . & n. $o$. \\
\hline$v_{\text {as. }}\left(\mathrm{COO}^{-}\right)$ & $1544(\mathrm{~m})$ & $1557(\mathrm{mF})$ & $1579(\mathrm{mF})$ \\
\hline$v_{\mathrm{s} .}\left(\mathrm{COO}^{-}\right)$ & $\begin{array}{l}1458(\mathrm{~m}) \\
1421(\mathrm{~m})\end{array}$ & $1422(\mathrm{~F})$ & $\begin{array}{l}1451(\mathrm{~F}) \\
1425(\mathrm{~F})\end{array}$ \\
\hline$\delta_{\text {s. }}\left(\mathrm{CH}_{3}\right)$ & $1353(\mathrm{mf})$ & $1347(\mathrm{~m})$ & $1346(\mathrm{~m})$ \\
\hline$\rho\left(\mathrm{CH}_{3}\right)$ & $\begin{array}{c}1055(\mathrm{f}) \\
1027(\mathrm{~m})\end{array}$ & $\begin{array}{l}1051(f) \\
1024(f)\end{array}$ & $\begin{array}{l}1050(f) \\
1024(f)\end{array}$ \\
\hline$v(\mathrm{C}-\mathrm{C})$ & $\begin{array}{l}966(\mathrm{~m}) \\
946(\mathrm{~m})\end{array}$ & $948(\mathrm{f})$ & $949(\mathrm{mf})$ \\
\hline$\rho\left(\mathrm{H}_{2} \mathrm{O}\right)_{\text {rock }}$ * * & $909(\mathrm{mf})$ & n. $o$ & n. $o$. \\
\hline$\beta\left(\mathrm{H}_{2} \mathrm{O}\right)_{\text {twist }}$ ** & $813(\mathrm{~m})$ & n. o. & n. $o$. \\
\hline$\gamma\left(\mathrm{H}_{2} \mathrm{O}\right)_{\text {wag }}$ * * & $749(\mathrm{~F})$ & n. $o$. & n. $o$. \\
\hline$\delta\left(\mathrm{COO}^{-}\right)$ & $681(\mathrm{mF})$ & $681(\mathrm{~m})$ & $681(f)$ \\
\hline$\rho\left(\mathrm{COO}^{*}\right)_{\text {fora do plano }}$ & $628(\mathrm{mf})$ & $617(f)$ & $616(f)$ \\
\hline$\pi\left(\mathrm{COO}^{-}\right)_{\text {no plano }}$ & $553(\mathrm{~m})$ & 475 (f) & $\begin{array}{l}555(\mathrm{~m}) \\
473(\mathrm{o})\end{array}$ \\
\hline
\end{tabular}

* Nomenclatura das bandas segundo Nakamoto [23]; ** Segundo Raghuvanshi et al [32];

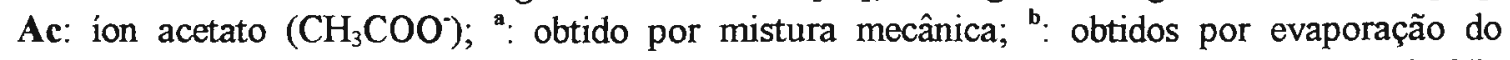
solvente; ${ }^{\text {c }}$ obtido por cristalização com acetona; mf: muito fraca (100-85\%); f: fraca (85-60\%); m: média $(60-30 \%)$; F: forte $(30-10 \%)$; mF: muito forte $(10-0 \%)$; o: ombro; n. o.: não obbservado. 


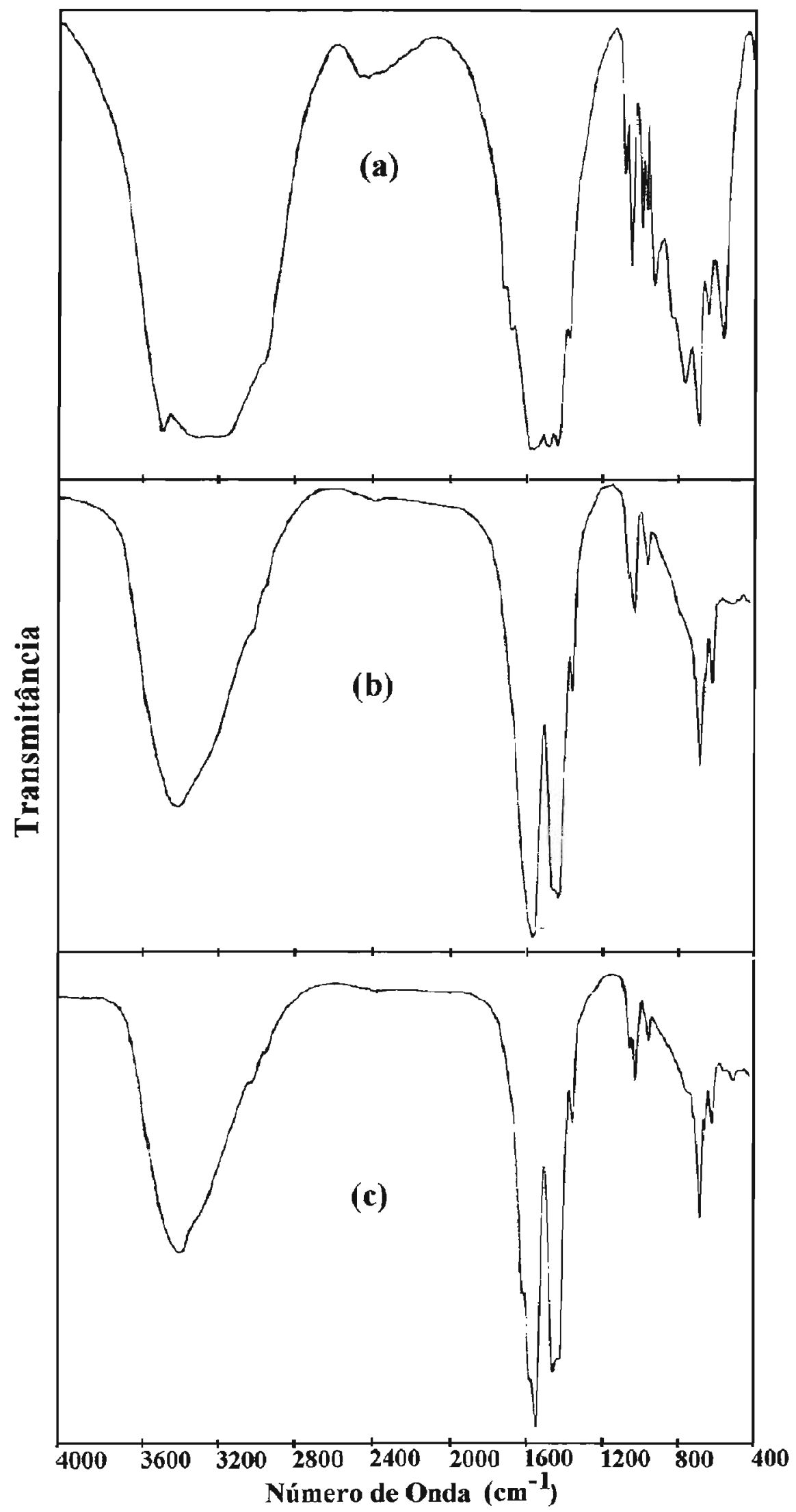

Figura 3.49: Espectros de absorção na região do infravermelho dos sistemas de acetatos binários: (a) $\mathrm{YNi}\left(\mathrm{CH}_{3} \mathrm{COO}\right)_{5} .8 \mathrm{H}_{2} \mathrm{O} \quad$ (M. M.); (b) $\mathrm{YNi}\left(\mathrm{CH}_{3} \mathrm{COO}\right)_{5} .3 \mathrm{H}_{2} \mathrm{O} \quad$ (E. S.); (c) $\mathrm{YNi}\left(\mathrm{CH}_{3} \mathrm{COO}\right)_{5} .2 \mathrm{H}_{2} \mathrm{O}$ (C. A.). 


\subsubsection{3- Difração de raios $X$}

Os difratogramas de raios $\mathrm{X}$, Figura 3.50, para os acetatos binários de ítrio e níquel foram obtidos com os objetivos de verificar a cristalinidade e observar a formação de novas fases. A avaliação foi realizada por meio de comparações entre as linhas de reflexão dos compostos binários com os acetatos simples (Tabela 3.24).

Similarmente aos resultados da espectroscopia de absorção na região do infravermelho, foi observado que o difratograma de raios $\mathrm{X}$ do sistema obtido por mistura mecânica, $\mathrm{YNi}\left(\mathrm{CH}_{3} \mathrm{COO}\right)_{5} .8 \mathrm{H}_{2} \mathrm{O}$ correspondeu a mistura dos acetatos simples,

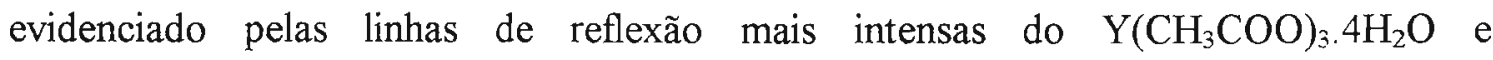
$\mathrm{Ni}\left(\mathrm{CH}_{3} \mathrm{COO}\right)_{2} \cdot 4 \mathrm{H}_{2} \mathrm{O}$, em $2 \theta=9,6$ e $12,9^{\circ}$, respectivamente. Para os sistemas obtidos por evaporação do solvente, $\mathrm{YNi}\left(\mathrm{CH}_{3} \mathrm{COO}\right)_{5} \cdot 3 \mathrm{H}_{2} \mathrm{O}$, e cristalização com acetona, $\mathrm{YNi}\left(\mathrm{CH}_{3} \mathrm{COO}\right)_{5} \cdot 2 \mathrm{H}_{2} \mathrm{O}$, os difratogramas de raios $\mathrm{X}$ apresentaram alguma linhas de reflexão não observadas nos acetatos simples e diferentes das linhas do $\mathrm{YNi}\left(\mathrm{CH}_{3} \mathrm{COO}\right)_{5} .8 \mathrm{H}_{2} \mathrm{O}$.

Quanto a cristalinidade dos sistemas, observou-se que aquele sintetizado por evaporação do solvente apresentou baixa cristalinidade, em relação aos sistemas de mistura mecânica e cristalização com acetona.

Tabela 3.24: Dados parciais de difração de raios $X$ dos sistemas de acetatos binários de itrio e níquel

\begin{tabular}{|c|c|c|c|c|c|c|c|c|}
\hline \multicolumn{3}{|c|}{$\mathrm{YNi}(\mathrm{Ac})_{5} \cdot 8 \mathrm{H}_{2} \mathrm{O}^{\text {a }}$} & \multicolumn{3}{|c|}{$\mathrm{YNi}(\mathrm{Ac})_{5} \cdot 3 \mathrm{H}_{2} \mathrm{O}^{b}$} & \multicolumn{3}{|c|}{$\mathrm{YNi}(\mathrm{Ac})_{5 \cdot} \cdot 2 \mathrm{H}_{2} \mathrm{O}^{c}$} \\
\hline $2 \theta\left(^{\circ}\right)$ & d $(\AA)$ & I/Io & $2 \theta\left({ }^{\circ}\right)$ & d $(\AA)$ & I//o & $2 \theta\left({ }^{\circ}\right)$ & $\mathrm{d}(\AA)$ & I/To \\
\hline n. $o$. & n. o. & n. o. & n. $o$. & n. o. & n. o. & 8,2 & 10,78 & 35 \\
\hline 9,6 & 9,18 & 20 & 9,7 & 9,06 & 100 & 9,6 & 9,16 & 7 \\
\hline n. $o$ & n. $o$. & n. $o$. & n. $o$. & n. $o$. & n. o. & 10,7 & 8,25 & 36 \\
\hline 11,2 & 7,88 & 9 & 11,3 & 7,78 & 49 & 11,2 & 7,85 & 5 \\
\hline 11,7 & 7,50 & 13 & 11,9 & 7,43 & 65 & 11,8 & 7,44 & 100 \\
\hline 12,9 & 6,85 & 100 & 12,8 & 6,90 & 12 & 12,9 & 6,83 & 2 \\
\hline n. o. & n. o. & n. o. & 13,2 & 6,66 & 22 & n. o. & n. o. & n. o. \\
\hline 15,0 & 5,89 & 1 & n. $o$. & n. o. & n. $o$. & 15,8 & 5,57 & 7 \\
\hline
\end{tabular}


continuação da tabela 3.24

\begin{tabular}{|c|c|c|c|c|c|c|c|c|}
\hline $2 \theta\left({ }^{\circ}\right)$ & $\mathrm{d}(\AA)$ & I/Io & $2 \theta\left(^{\circ}\right)$ & d $(\AA)$ & I/Io & $2 \theta\left({ }^{\circ}\right)$ & d $(\AA)$ & I/Io \\
\hline 16,7 & 5,30 & 8 & 16,8 & 5,24 & 27 & 16,7 & 5,29 & 9 \\
\hline 17,3 & 5,11 & 5 & 17,4 & 5,07 & 29 & 17,2 & 5,14 & 8 \\
\hline 18,5 & 4,76 & 5 & n. 0. & n. $\mathrm{o}$ & n. o. & n. o. & n. o. & n. 0. \\
\hline 19,1 & 4,62 & 2 & 19,3 & 4,59 & 18 & 19,2 & 4,60 & 6 \\
\hline 19,8 & 4,46 & 3 & 19,9 & 4,44 & 16 & n. o. & n. o. & n. $o$. \\
\hline 21,0 & 4,21 & 13 & n. $o$ & n. o. & n. $o$. & n. $o$. & n. o. & n. 0. \\
\hline 21,5 & 4,12 & 7 & 21,6 & 4,11 & 36 & 21,5 & 4,12 & 5 \\
\hline 22,0 & 4,02 & 4 & 22,1 & 4,01 & 14 & 22,4 & 3,96 & 10 \\
\hline 22,4 & 3,96 & 5 & 22,9 & 3,87 & 4 & n. o. & n. o. & n. $o$. \\
\hline 23,2 & 3,82 & 2 & n. o. & n. o. & n. o. & 23,5 & 3,77 & 8 \\
\hline 23,9 & 3,56 & 6 & 23,8 & 3,72 & 9 & 23,9 & 3,71 & 6 \\
\hline 25,2 & 3,52 & 5 & 25,3 & 3,50 & 47 & 24,8 & 3,59 & 48 \\
\hline 27,2 & 3,26 & 3 & 27,0 & 3,29 & 15 & 26,6 & 3,34 & 13 \\
\hline n. o. & n. $o$. & n. $o$ & 27,7 & 3,210 & 19 & 27,0 & 3,29 & 6 \\
\hline 28,3 & 3,14 & 3 & 28,2 & 3,15 & 19 & 28,5 & 3,12 & 10 \\
\hline
\end{tabular}

Ac: íon acetato $\left(\mathrm{CH}_{3} \mathrm{COO}^{-}\right) ;{ }^{\mathbf{a}}$ obtido por mistura mecânica; ${ }^{\mathbf{b}}$ obtido por evaporação do solvente; ${ }^{~}$ obtido por cristalização com acetona; $2 \theta$ : posição angular; $\mathbf{d}$ : distância interplanar. 


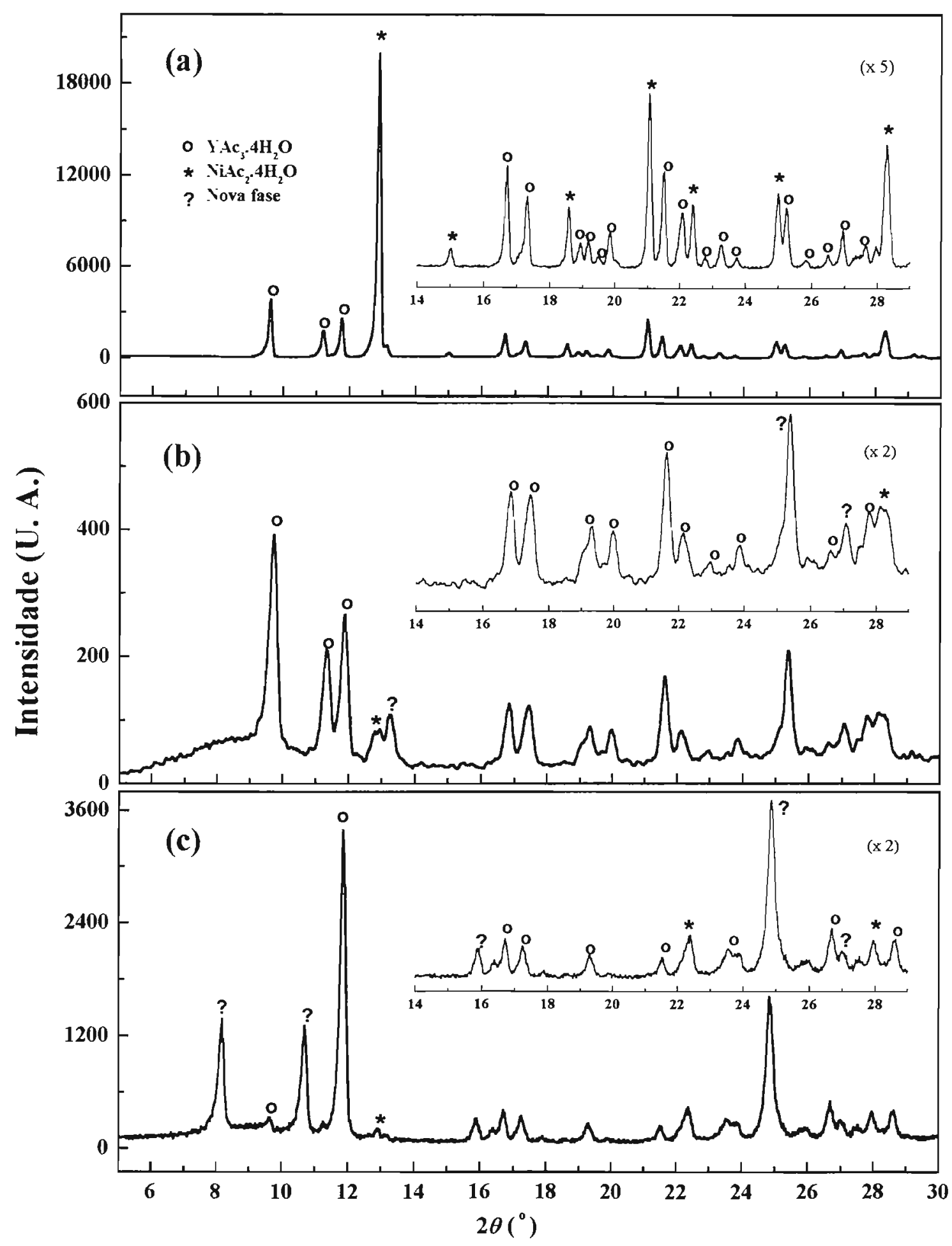

Figura 3.50: Difratogramas de raios $X$ (método do pó) dos sistemas de acetatos binários de itrio e niquel:

(a) $\mathrm{YNi}\left(\mathrm{CH}_{3} \mathrm{COO}\right)_{5} .8 \mathrm{H}_{2} \mathrm{O}, \mathrm{M}$. M. (inserido $2 \theta=14$ a $29^{\circ}$, ampliado cinco vezes);

(b) $\mathrm{YNi}\left(\mathrm{CH}_{3} \mathrm{COO}\right)_{5} \cdot 3 \mathrm{H}_{2} \mathrm{O}$, E. S. (inserido $2 \theta=14$ a $29^{\circ}$, ampliado duas vezes);

(c) $\mathrm{YNi}\left(\mathrm{CH}_{3} \mathrm{COO}\right)_{5} .2 \mathrm{H}_{2} \mathrm{O}$, C. A. (inserido $2 \theta=14$ a $29^{\circ}$, ampliado duas vezes). 


\subsubsection{4- Análise térmica}

De uma forma geral, o comportamento térmico dos sistemas de acetatos binários de ítrio e níquel, independente do método de síntese, envolveu dois eventos principais: desidratação e formação da mistura $\mathrm{Y}_{2} \mathrm{O}_{2} \mathrm{CO}_{3}$ e NiO. Nas Figuras 3.51 e 3.52 estão apresentadas as curvas TG/DTG, obtidas nas atmosferas dinâmicas de ar e nitrogênio, respectivamente.

A desidratação dos sais ocorreu no intervalo de 25 a $180^{\circ} \mathrm{C}$, independente da atmosfera utilizada. A Figura 3.51 (a) apresenta as curvas TG/DTG sob atmosfera de ar do sistema $\mathrm{YNi}\left(\mathrm{CH}_{3} \mathrm{COO}\right)_{5} .8 \mathrm{H}_{2} \mathrm{O}$. A desidratação ocorreu em uma etapa, sendo observado na curva DTG dois picos em 93 e $110^{\circ} \mathrm{C}$, indicativos da existência de moléculas de água ligadas de forma diferentes. No entanto, na curva DTG sob atmosfera de nitrogênio, Figura 3.52 (a), foi observado somente um pico largo em $110^{\circ} \mathrm{C}$ para a etapa de desidratação. Os cálculos de variação de massa foram de aproximadamente $27 \%$, sugerindo a perda de oito mol de água de cristalização. Para o sistema $\mathrm{YNi}\left(\mathrm{CH}_{3} \mathrm{COO}\right)_{5} .3 \mathrm{H}_{2} \mathrm{O}$, a desidratação ocorreu em uma etapa, independente da atmosfera atuante, com temperatura de pico nas curvas DTG em $72^{\circ} \mathrm{C}$, Figuras 3.51 (b) e 3.52 (b). A perda de massa foi de $13 \%$ relativo a libertação de três mol de água de cristalização. Por outro lado, o sistema $\mathrm{YNi}\left(\mathrm{CH}_{3} \mathrm{COO}\right)_{5} \cdot 2 \mathrm{H}_{2} \mathrm{O}$, a desidratação envolveu duas etapas lentas e consecutivas, com temperatura de picos nas curvas DTG em 70 e $120^{\circ} \mathrm{C}$. O cálculo de perda de massa total foi de $10 \%$, correspondente a saída de dois mol de água de cristalização.

Para todos os sistemas, os dados de perda de massa observados experimentalmente em $200^{\circ} \mathrm{C}$, foram maiores que os esperados para a desidratação dos sais. Esses resultados indicaram que similarmente ao acetato de níquel, ocorre hidrólise de grupos acetatos conduzindo na formação de uma mistura de acetatos básicos anidros de ítrio e níquel. A perda de massa total dos voláteis libertados, até $200^{\circ} \mathrm{C}$, observada nas curvas TG foram de: $\mathrm{YNi}\left(\mathrm{CH}_{3} \mathrm{COO}\right)_{5} .8 \mathrm{H}_{2} \mathrm{O}(\exp .=26,73 \%$ e calc. $=24,55 \%)$; $\mathrm{YNi}\left(\mathrm{CH}_{3} \mathrm{COO}\right)_{5} \cdot 3 \mathrm{H}_{2} \mathrm{O}(\exp .=12,54 \%$ e calc. $=10,88 \%)$ e $\mathrm{YNi}\left(\mathrm{CH}_{3} \mathrm{COO}\right)_{5} \cdot 2 \mathrm{H}_{2} \mathrm{O}(\exp$. $=10,20 \%$ e calc. $=7,52 \%$ ). O valor experimental é a média aritmética dos valores observados nas atmosferas de ar e nitrogênio. 
A decomposição térmica dos intermediários dos sistemas em $250^{\circ} \mathrm{C}$ foi influenciada pela atmosfera atuante. Sob atmosfera dinâmica de ar, as curvas TG/DTG evidenciaram uma perda de massa rápida e um pico agudo na curva DTG em torno de $370^{\circ} \mathrm{C}$, característico de pirólise (Figura 3.51). Porém, sob atmosfera de nitrogênio, as curvas TG/DTG mostram que a decomposição ocorre lentamente. Para o sistema obtido por mistura mecânica, a decomposição ocorreu em duas etapas consecutivas, com temperatura de picos na curva DTG em 329 e $370^{\circ} \mathrm{C}$, Figura 3.52 (a). Similarmente, o sistema obtido por cristalização com acetona também sofreu decomposição em duas etapas, em 330 e $370^{\circ} \mathrm{C}$, Figura 3.52 (c). No entanto, o sistema obtido por evaporação do solvente sofreu decomposição em uma etapa, evidenciada por um pico largo na curva DTG em $372^{\circ} \mathrm{C}$, Figura 3.52 (b).

Para todo os sistemas, independente do método e atmosfera atuante, os cálculos de variação de massa indicaram a formação da mistura de $\mathrm{Y}_{2} \mathrm{O}_{3}$ e $\mathrm{NiO}$ em $900^{\circ} \mathrm{C}$. Para estes sistemas de acetatos binários de ítrio e níquel, não foram observados a formação da mistura de $\mathrm{Y}_{2} \mathrm{O}_{2} \mathrm{CO}_{3}$ e NiO. Este comportamento concorda com os observados nos hidroxicarbonato e acetato de ítrio, pois, a estabilidade térmica de dioxicarbonatos de terras raras decresce, à medida que diminui o raio do íon $\mathrm{TR}^{3+}$.

Dessa forma, tornou-se dificil calcular os teores de ítrio e níquel nos acetatos binários diretamente das curvas TG/DTG. Na Tabela 3.25 estão apresentados os valores percentuais calculados e experimentais, dos produtos sólidos da decomposição térmica dos $\mathrm{YNi}\left(\mathrm{CH}_{3} \mathrm{COO}\right)_{5} \cdot \mathrm{xH}_{2} \mathrm{O}$, nas atmosferas de ar comprimido e nitrogênio. 
Tabela 3.25: Dados percentuais dos intermediários sólidos da decomposição térmica dos sistemas de acetatos binários de ítrio e níquel

\begin{tabular}{|c|c|c|c|}
\hline \multirow{2}{*}{ COMPOSTO } & \multirow{2}{*}{$\%$ CALCULADA } & \multicolumn{2}{|c|}{ \% EXPERIMENTAL } \\
\hline & & $\mathbf{A R}$ & $\mathbf{N}_{2}$ \\
\hline $\mathrm{YNi}(\mathrm{Ac})_{5} .8 \mathrm{H}_{2} \mathrm{O}^{\mathrm{a}}$ & 100,00 & 100,0 & 100,0 \\
\hline $\mathrm{YNi}(\mathrm{Ac})_{5}$ & 75,44 & 73,5 & 73,1 \\
\hline $\mathrm{Y}_{2} \mathrm{O}_{3} . \mathrm{NiO}$ & 31,96 & 31,7 & 31,8 \\
\hline $\mathrm{YNi}(\mathrm{Ac})_{5} \cdot 3 \mathrm{H}_{2} \mathrm{O}^{\mathrm{b}}$ & 100,00 & 100,0 & 100,0 \\
\hline $\mathrm{YNi}(\mathrm{Ac})_{5}$ & 89,12 & 87,0 & 87,9 \\
\hline $\mathrm{Y}_{2} \mathrm{O}_{3}, \mathrm{NiO}$ & 38,53 & 39,1 & 39,8 \\
\hline $\mathrm{YNi}(\mathrm{Ac})_{5} \cdot 2 \mathrm{H}_{2} \mathrm{O}^{\mathrm{c}}$ & 100,00 & 100,0 & 100,0 \\
\hline $\mathrm{YNi}(\mathrm{Ac})_{5}$ & 92,48 & 89,6 & 90,0 \\
\hline $\mathrm{Y}_{2} \mathrm{O}_{3} \cdot \mathrm{NiO}$ & 39,18 & 39,2 & 40,1 \\
\hline
\end{tabular}

Ac: íon acetato $\left(\mathrm{CH}_{3} \mathrm{COO}^{-}\right)$; ${ }^{\text {a }}$ : obtido por mistura mecânica; ${ }^{\text {b: }}$ obtido por evaporação do solvente; $\mathbf{c}$ : obtido por cristalização com acetona

Nas Figuras 3.53 e 3.54 estão apresentadas as curvas DTA e DSC para os acetatos binários de ítrio e níquel, respectivamente. Similarmente, aos acetatos de terras raras e acetato de níquel, os valores das temperaturas dos picos observados nessas curvas estão deslocados para valores menores nas curvas DSC e maiores nas curvas DTA, em relação às temperaturas dos picos das curvas DTG.

Para o sistema $\mathrm{YNi}\left(\mathrm{CH}_{3} \mathrm{COO}\right)_{5} .8 \mathrm{H}_{2} \mathrm{O}$ foi evidenciado na curva DTA um evento endotérmico em $115^{\circ} \mathrm{C}$ relativo a etapa de desidratação, Figura 3.53 (a). Similarmente, para o sistema $\mathrm{YNi}\left(\mathrm{CH}_{3} \mathrm{COO}\right)_{5} .3 \mathrm{H}_{2} \mathrm{O}$, esta etapa foi evidenciada por um pico largo endotérmico em $95^{\circ} \mathrm{C}$, Figura 3.53 (b). No entanto, para o sistema $\mathrm{YNi}\left(\mathrm{CH}_{3} \mathrm{COO}\right)_{5} .2 \mathrm{H}_{2} \mathrm{O}$, a curva DTA evidenciou dois eventos endotérmicos em $100 \mathrm{e}$ $138^{\circ} \mathrm{C}$, Figura 3.53 (c).

De uma maneira geral, após desidratação os sistemas apresentaram um evento endotérmico em torno de $320^{\circ} \mathrm{C}$, seguido de um forte evento exotérmico em $372^{\circ} \mathrm{C}$, que pode estar associado ao fenômeno de pirólise. 
Na Figura 3.54 estão apresentadas as curvas DSC, obtidas sob atmosfera dinâmica de nitrogênio, dos acetatos binários de ítrio e níquel. Para o sistema $\mathrm{YNi}\left(\mathrm{CH}_{3} \mathrm{COO}\right)_{5} .8 \mathrm{H}_{2} \mathrm{O}$, a curva DSC evidenciou dois eventos endotérmicos consecutivos em 75 e $91^{\circ} \mathrm{C}$, indicando que as moléculas de água estão ligadas de forma diferente, Figura 3.54 (a). A decomposição deste sistema foi evidenciada por dois eventos endotérmicos em 305 e $342^{\circ} \mathrm{C}$, seguido de um forte e largo pico exotérmico em $376^{\circ} \mathrm{C}$. Para o sistema $\mathrm{YNi}\left(\mathrm{CH}_{3} \mathrm{COO}\right)_{5} \cdot 3 \mathrm{H}_{2} \mathrm{O}$, as etapas de desidratação e decomposição foram evidenciadas, respectivamente, por eventos endotérmico em $68^{\circ} \mathrm{C}$ e exotérmico em $342^{\circ} \mathrm{C}$. No entanto, para o sistema $\mathrm{YNi}\left(\mathrm{CH}_{3} \mathrm{COO}\right)_{5} \cdot 2 \mathrm{H}_{2} \mathrm{O}$, a etapa de desidratação foi evidenciada por dois eventos endotérmicos, em 60 e $104^{\circ} \mathrm{C}$, similarmente ao resultado de DTA. Entretanto, a decomposição foi evidenciada somente por um largo evento exotérmico em $380^{\circ} \mathrm{C}$.

Os perfis das curvas DSC permitiram calcular as entalpias de reação $(\Delta H)$ referentes às etapas de desidratação e decomposição dos sistemas. Na Tabela 3.26 estão apresentados os resultados de DSC, para os $\mathrm{YNi}\left(\mathrm{CH}_{3} \mathrm{COO}\right)_{5} \cdot \mathrm{xH}_{2} \mathrm{O}$, sintetizados pelos três métodos em estudo.

Tabela 3.26: Dados de DSC para as etapas de desidratação e decomposição térmica dos sistemas de acetatos binários de ítrio e níquel

\begin{tabular}{|c|c|c|c|c|c|c|}
\hline \multirow{2}{*}{ EVENTOS } & \multicolumn{2}{|c|}{$\mathrm{YNi}(\mathrm{Ac})_{5} .8 \mathrm{H}_{2} \mathrm{O}^{\mathrm{a}}$} & \multicolumn{2}{|c|}{$\mathrm{YNi}(\mathrm{Ac})_{5 \cdot} \cdot 3 \mathrm{H}_{2} \mathrm{O}^{b}$} & \multicolumn{2}{|c|}{$\mathrm{YNi}(\mathrm{Ac})_{5} \cdot 2 \mathrm{H}_{2} \mathrm{O}^{\mathrm{c}}$} \\
\hline & $\mathrm{T}_{\mathrm{p}}\left({ }^{\circ} \mathrm{C}\right)$ & $\Delta H\left(\mathrm{~kJ} \mathrm{~mol}^{-1}\right)$ & $\mathrm{T}_{\mathrm{p}}\left({ }^{\circ} \mathrm{C}\right)$ & $\Delta H\left(\mathrm{~kJ} \mathrm{~mol}^{-1}\right)$ & $\mathrm{T}_{\mathrm{p}}\left({ }^{\circ} \mathrm{C}\right)$ & $\Delta H\left(\mathrm{~kJ} \mathrm{~mol}^{-1}\right)$ \\
\hline \multirow[t]{2}{*}{ Desidratação } & 75 & 515 & 68 & 169 & 60 & \\
\hline & 91 & & & & 104 & 36 \\
\hline \multirow{3}{*}{ Decomposição } & 305 & 40 & \multirow{3}{*}{342} & \multirow{3}{*}{911} & & \\
\hline & 342 & 26 & & & & \\
\hline & 376 & 622 & & & 380 & 622 \\
\hline
\end{tabular}

Ac: íon acetato $\left(\mathrm{CH}_{3} \mathrm{COO}^{-}\right)$; ${ }^{\text {a }}$ : obtido por mistura mecânica; ${ }^{\text {b: }}$ obtido por evaporação do solvente; ${ }^{c}$ : obtido por cristalização com acetona; $\mathbf{T}_{\mathrm{p}}$ : temperatura do pico; $\Delta \boldsymbol{H}$ : variação de entalpia 


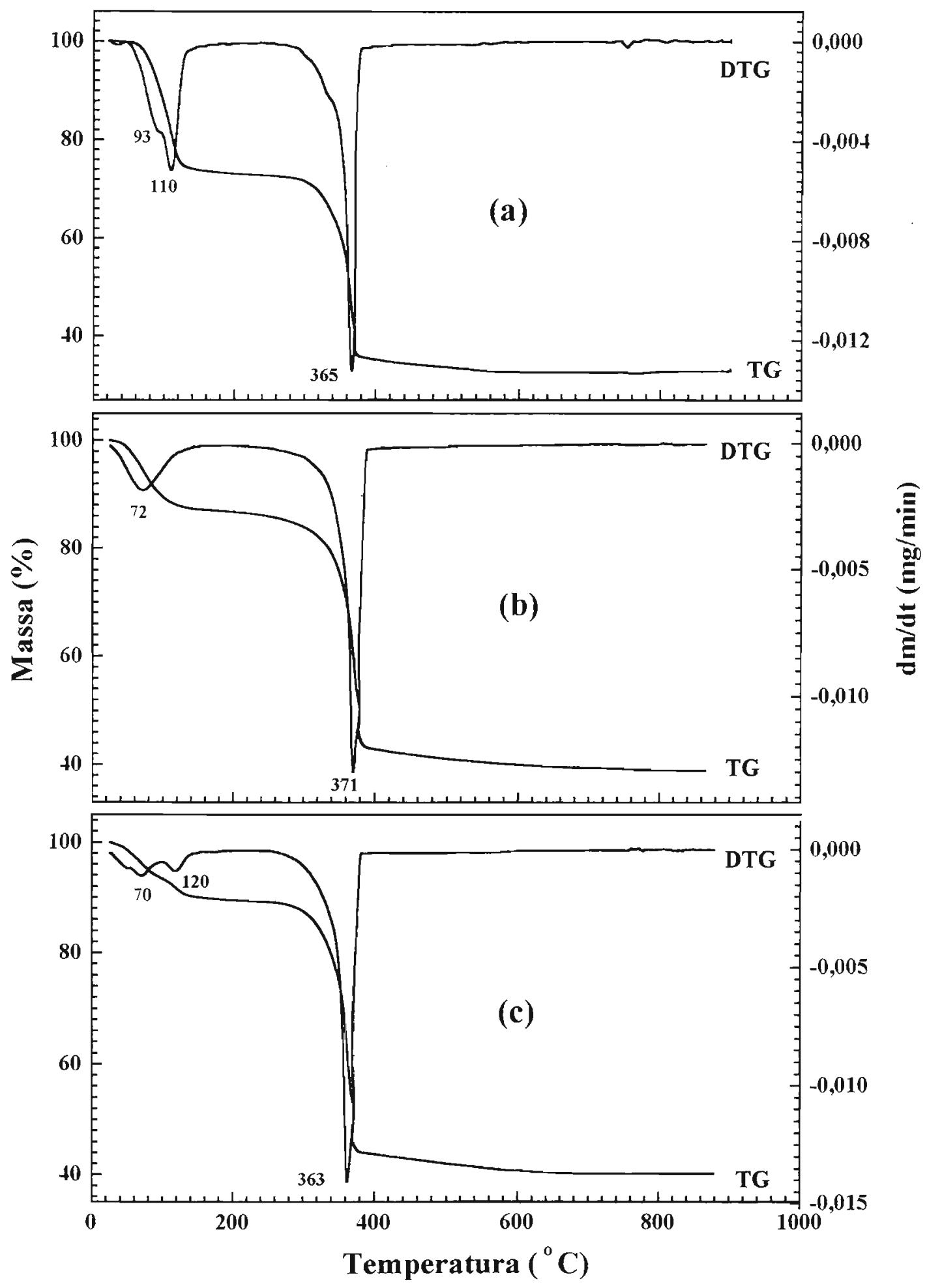

Figura 3.51: Curvas TG/DTG dos sistemas de acetatos binários de ítrio e níquel obtidas sob atmosfera dinâmica de ar $\left(50 \mathrm{~mL} \mathrm{~min}{ }^{-1}\right)$, razão de aquecimento de $10^{\circ} \mathrm{C} \mathrm{min}{ }^{-1}$ e cadinho de platina: (a) $\mathrm{YNi}\left(\mathrm{CH}_{3} \mathrm{COO}\right)_{5} .8 \mathrm{H}_{2} \mathrm{O}$, M. M. (m $=4,826 \mathrm{mg}$ ); (b) $\mathrm{YNi}\left(\mathrm{CH}_{3} \mathrm{COO}\right)_{5} .3 \mathrm{H}_{2} \mathrm{O}$, E. S. (m $=5,070 \mathrm{mg}$ ); (c) $\mathrm{YNi}\left(\mathrm{CH}_{3} \mathrm{COO}\right)_{5} \cdot 2 \mathrm{H}_{2} \mathrm{O}$, C.A. $(\mathrm{m}=4,931 \mathrm{mg})$. 


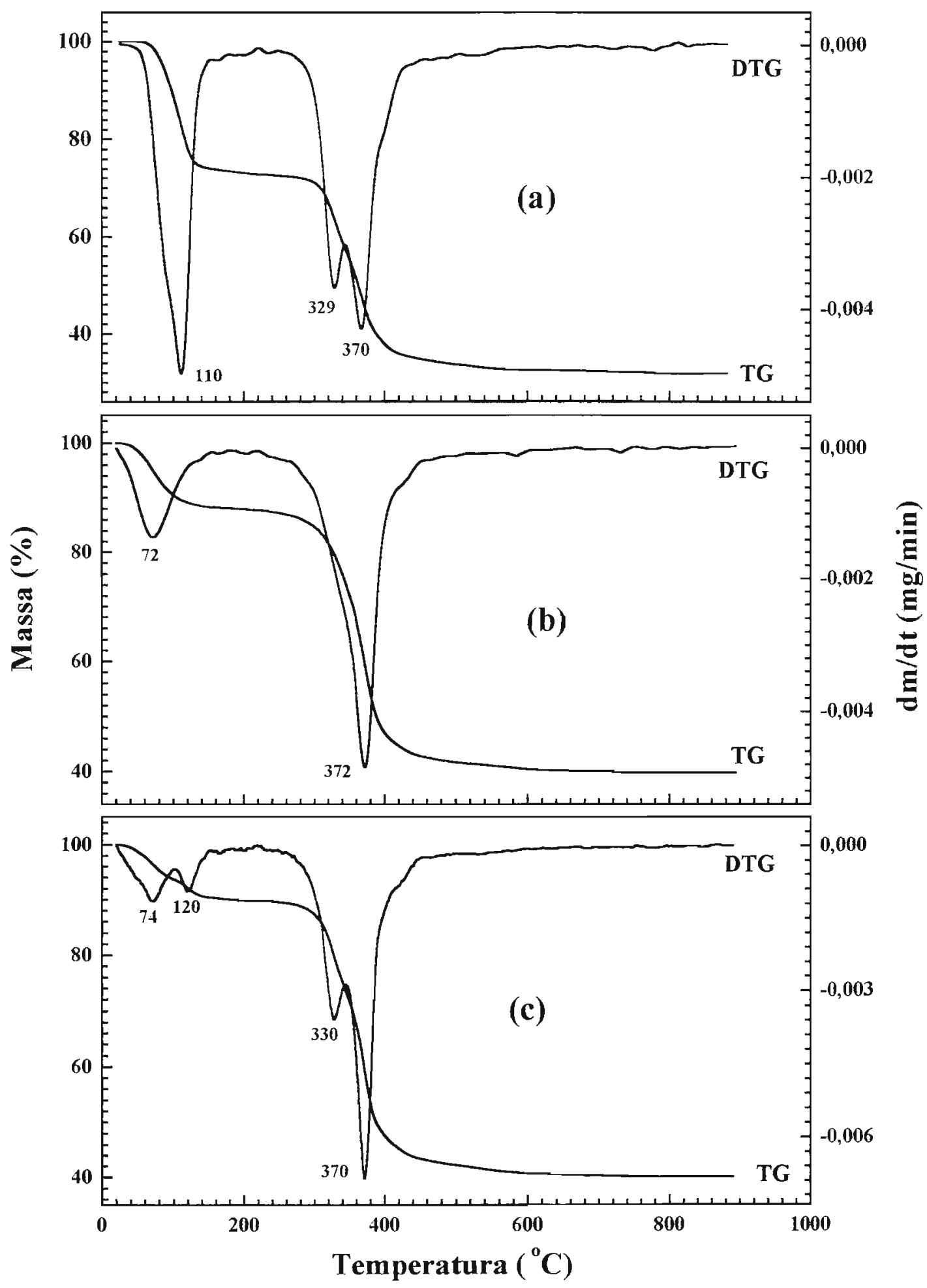

Figura 3.52: Curvas TG/DTG dos sistemas de acetatos binários de ítrio e níquel obtidas sob atmosfera dinâmica de nitrogênio $\left(50 \mathrm{~mL} \mathrm{~min}^{-1}\right)$, razão de aquecimento de $10^{\circ} \mathrm{C} \mathrm{min}^{-1}$ e cadinho de platina: (a) $\mathrm{YNi}\left(\mathrm{CH}_{3} \mathrm{COO}\right)_{5} .8 \mathrm{H}_{2} \mathrm{O}$, M. M. $\left(\mathrm{m}=5,117 \mathrm{mg}\right.$ ); (b) $\mathrm{YNi}\left(\mathrm{CH}_{3} \mathrm{COO}\right)_{5} .3 \mathrm{H}_{2} \mathrm{O}$, E. S. $(\mathrm{m}=4,075 \mathrm{mg})$; (c) $\mathrm{YNi}\left(\mathrm{CH}_{3} \mathrm{COO}\right)_{5} .2 \mathrm{H}_{2} \mathrm{O}$, C. A. $(\mathrm{m}=5,073 \mathrm{mg})$. 


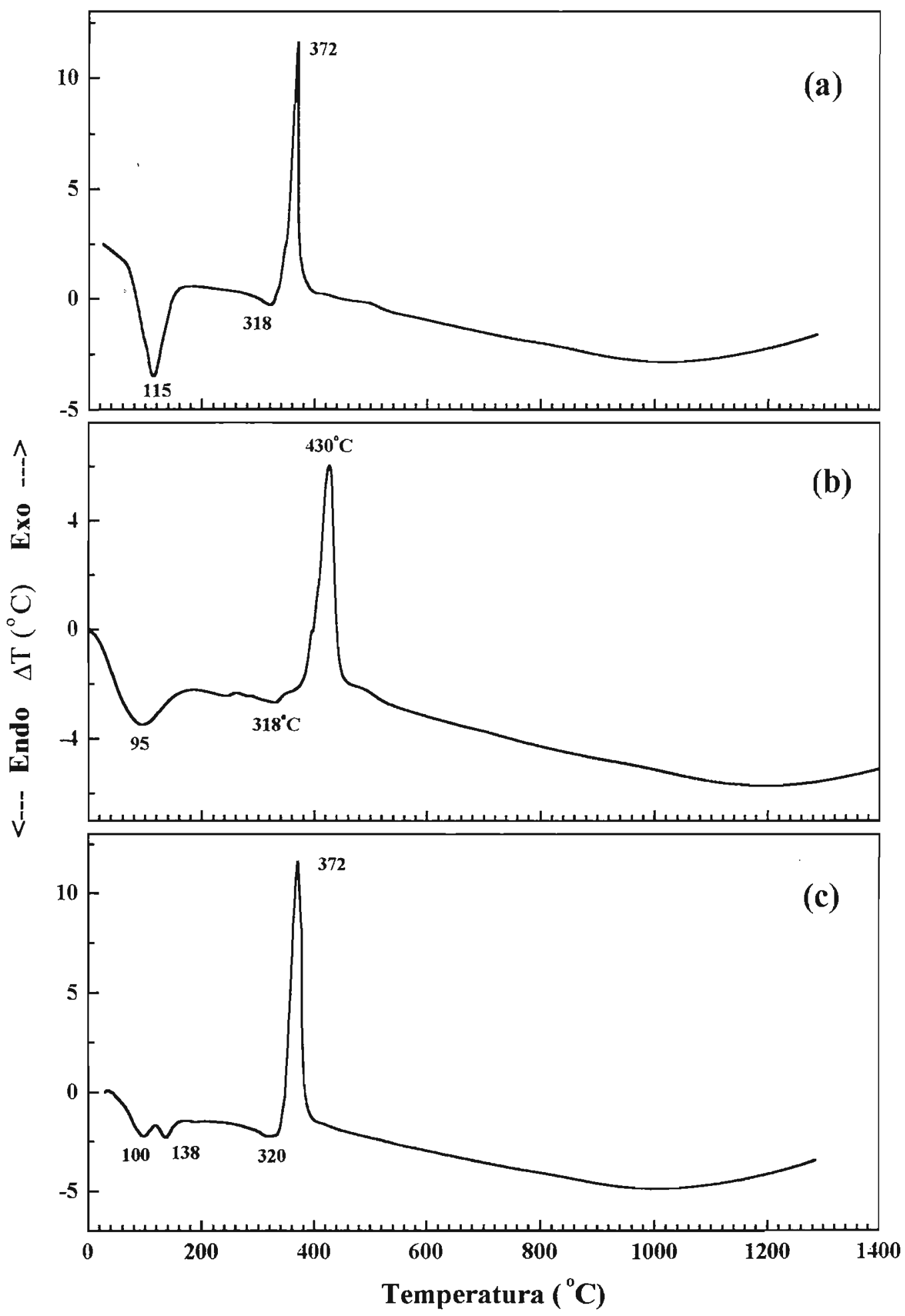

Figura 3.53: Curvas DTA dos sistemas de acetatos binários de ítrio e niquel obtidas sob atmosfera dinâmica de ar $\left(50 \mathrm{~mL} \mathrm{~min}{ }^{-1}\right)$, razão de aquecimento de $10^{\circ} \mathrm{C} \mathrm{min}^{-1}$ e cadinho de alumina: (a) $\mathrm{YNi}\left(\mathrm{CH}_{3} \mathrm{COO}\right)_{3} .8 \mathrm{H}_{2} \mathrm{O}$, M. M. (m=19,22 mg); (b) $\mathrm{YNi}\left(\mathrm{CH}_{3} \mathrm{COO}\right)_{5} \cdot 3 \mathrm{H}_{2} \mathrm{O}$, E. S. (m $=17,50 \mathrm{mg})$; (c) $\mathrm{YNi}\left(\mathrm{CH}_{3} \mathrm{COO}\right)_{5} \cdot 2 \mathrm{H}_{2} \mathrm{O}, \mathrm{C} . \mathrm{A} .(\mathrm{m}=18,30 \mathrm{mg})$. 


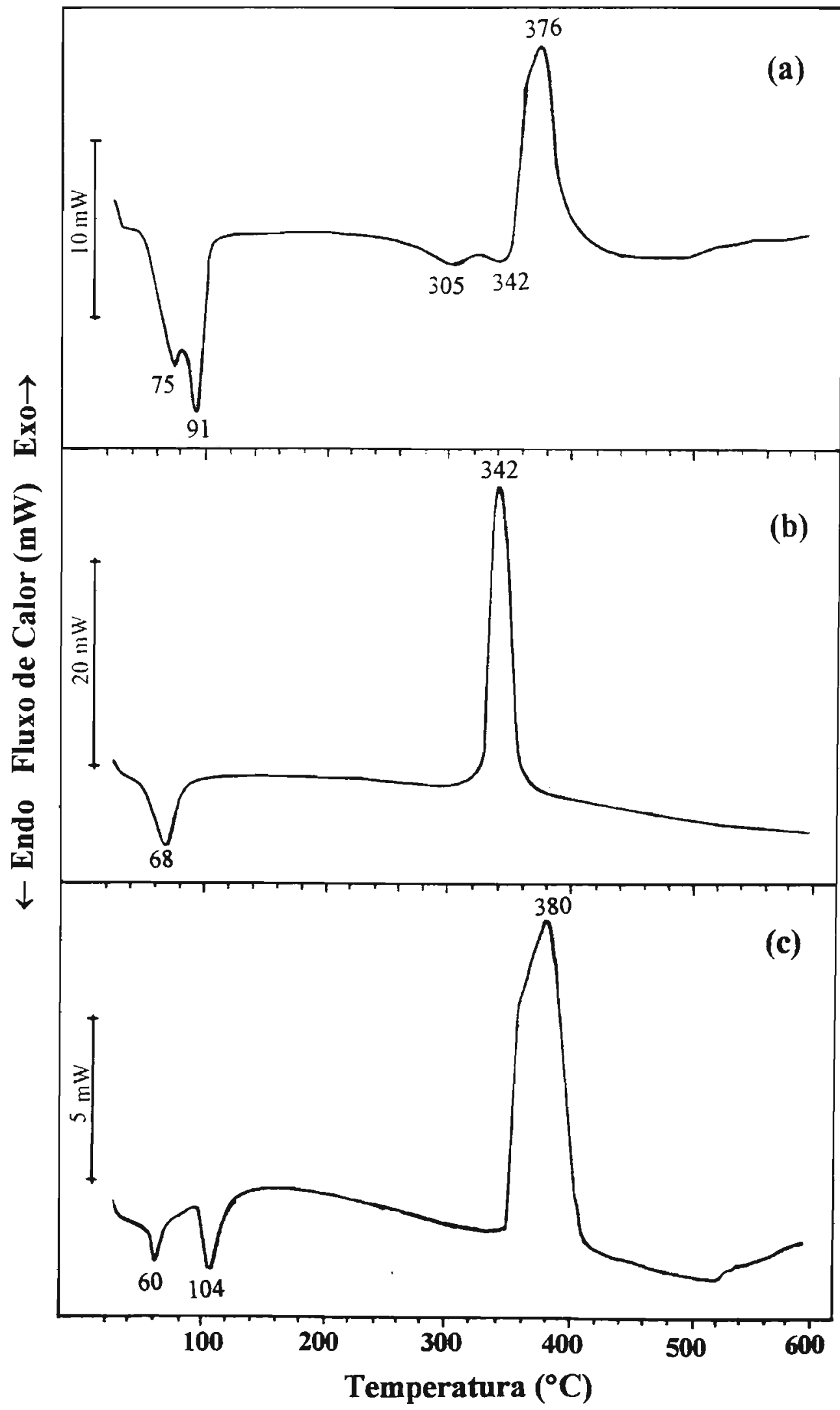

Figura 3.54: Curvas DSC dos sistemas de acetatos binários de ítrio e níquel obtidas sob atmosfera dinâmica de nitrogênio $\left(50 \mathrm{~mL} \mathrm{~min}^{-1}\right)$, razão de aquecimento de $10^{\circ} \mathrm{C} \min ^{-1}$ e cápsula de alumínio aberta: (a) $\mathrm{YNi}\left(\mathrm{CH}_{3} \mathrm{COO}\right)_{5} \cdot 8 \mathrm{H}_{2} \mathrm{O}, \quad \mathrm{M}$. M. $(\mathrm{m}=2,045 \mathrm{mg}) ;$ (b) $\mathrm{YNi}\left(\mathrm{CH}_{3} \mathrm{COO}\right)_{5} .3 \mathrm{H}_{2} \mathrm{O}$, E. S. $(\mathrm{m}=2,021 \mathrm{mg})$; (c) $\mathrm{YNi}\left(\mathrm{CH}_{3} \mathrm{COO}\right)_{5} \cdot 2 \mathrm{H}_{2} \mathrm{O}$, C. A. $(\mathrm{m}=2,041 \mathrm{mg})$. 


\subsubsection{5- Produtos sólidos da decomposição térmica dos acetatos binários de ítrio e níquel}

Os produtos sólidos da decomposição térmica dos acetatos binários de ítrio e níquel foram isolados a $900^{\circ} \mathrm{C}$ e submetidos à caracterização por difração de raios $\mathrm{X}$. A avaliação dos difratogramas foi realizada a partir da comparação com os óxidos simples, obtidos nas mesmas condições de decomposição térmica dos sais precursores.

$\mathrm{Na}$ Figuras 3.55 estão apresentados os difratogramas de raios $\mathrm{X}$ dos produtos isolados sob atmosfera de ar comprimido. No caso dos sistemas $\mathrm{YNi}\left(\mathrm{CH}_{3} \mathrm{COO}\right)_{5} .8 \mathrm{H}_{2} \mathrm{O}$ (M. M.) e $\mathrm{YNi}\left(\mathrm{CH}_{3} \mathrm{COO}\right)_{5} .2 \mathrm{H}_{2} \mathrm{O}$ (C. A.), os produtos consistiram da mistura dos óxidos individuais, ou seja, somente foi observado o somatório das linhas de reflexão dos óxidos $\mathrm{Y}_{2} \mathrm{O}_{3}$ e NiO. A intensidade das linhas variou, mas não foi observado nenhum indício da formação do óxido misto desejado. No entanto, o difratograma de raios $\mathrm{X}$ do produto da decomposição térmica do $\mathrm{YNi}\left(\mathrm{CH}_{3} \mathrm{COO}\right)_{5} .3 \mathrm{H}_{2} \mathrm{O}$ (E. S.) apresentou algumas linhas não observadas nos óxidos simples. Este resultado sugere indícios da formação da fase desejada.

Os difratogramas de raios $X$ dos produtos isolados sob atmosfera de nitrogênio estão apresentados na Figura 3.56. De um modo geral, foram identificadas somente as reflexões pertinentes aos óxidos simples, independente do método de síntese utilizado. Este resultado sugere que a atmosfera inerte não é adequada para a obtenção do óxido misto $\mathrm{Y}_{2} \mathrm{NiO}_{4}$.

A partir dos resultados acima, sugere-se que o tratamento térmico não foi adequado para a obtenção do óxido misto, sendo necessário submeter os produtos isolados a $900^{\circ} \mathrm{C}$, nesta temperatura, durante um determinado intervalo de tempo. Dessa forma, as seguintes condições foram usadas para otimizar a formação do óxido misto: atmosfera dinâmica de ar comprimido, vazão de $50 \mathrm{~mL} \mathrm{~min}^{-1}$, no intervalo de 25 a $900^{\circ} \mathrm{C}$, mantido isotérmico por uma hora. Os difratogramas de raios $\mathrm{X}$ das amostras tratadas nestas condições estão apresentados na Figura 3.57. Para o produto do precursor de mistura mecânica, foi observado indícios da fase desejada, prevalecendo as linhas dos óxidos simples, Figura 3.57 (c). Porém, para os produtos dos precursores de cristalização com acetona e evaporação do solvente, observou-se uma mistura dos óxidos simples e da fase desejada, Figuras 3.57 (d) e (e). Para este sistema, os métodos de síntese e/ou os tratamentos térmicos empregados, não foram adequados para a obtenção de óxido misto de ítrio e níquel monofásico. 


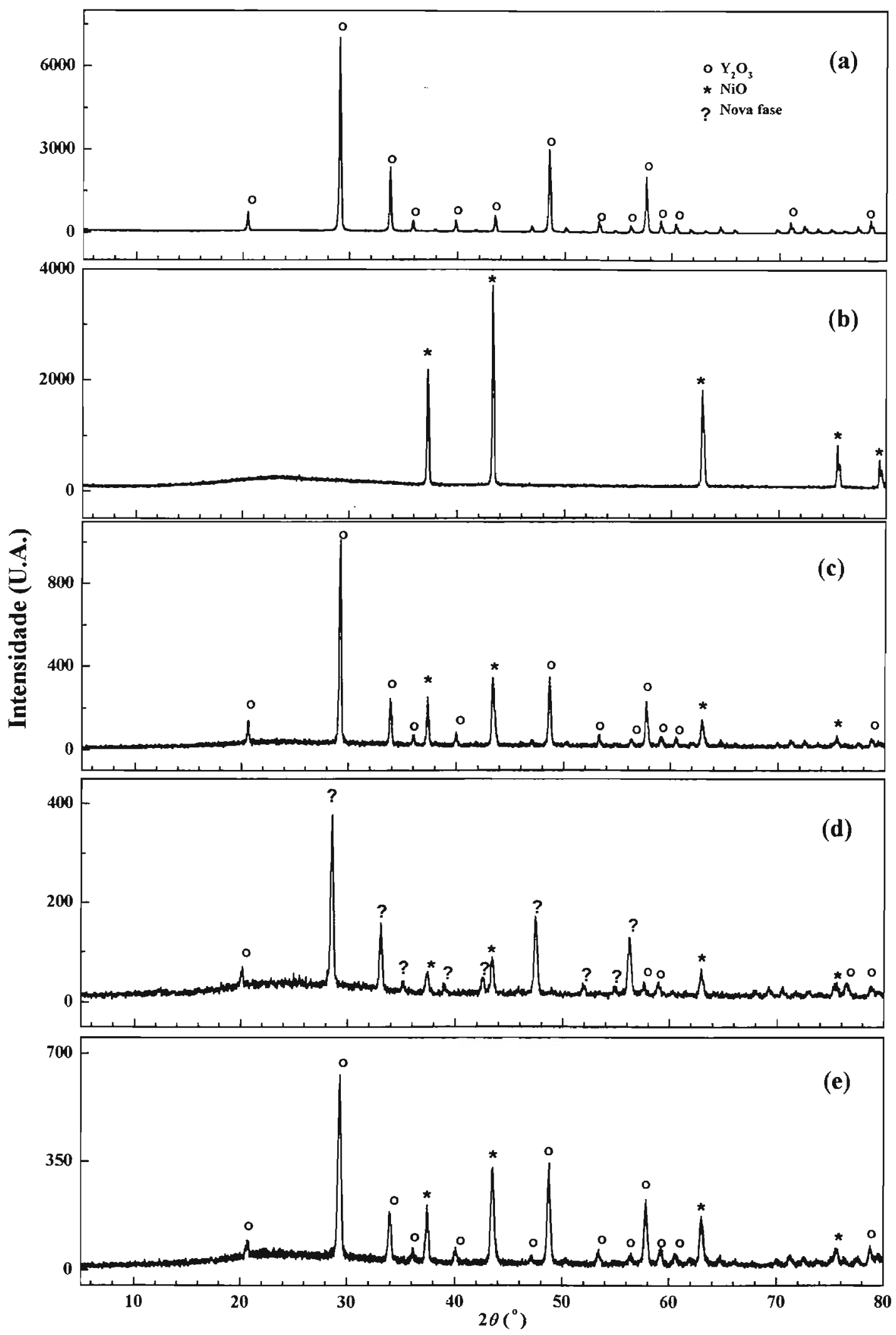

Figura 3.55: Difratogramas de raios $\mathrm{X}$ (método do pó) dos produtos da decomposição térmica a $900^{\circ} \mathrm{C}$, obtidos sob atmosfera dinâmica de ar $\left(50 \mathrm{~mL} \min ^{-1}\right)$, razão de aquecimento de $10^{\circ} \mathrm{C} \mathrm{min}{ }^{-1}$ e cadinho de platina das amostras: (a) $\mathrm{Y}\left(\mathrm{CH}_{3} \mathrm{COO}\right)_{3} \cdot 4 \mathrm{H}_{2} \mathrm{O}$; (b) $\mathrm{Ni}\left(\mathrm{CH}_{3} \mathrm{COO}\right)_{2} \cdot 4 \mathrm{H}_{2} \mathrm{O}$; (c) $\mathrm{YNi}\left(\mathrm{CH}_{3} \mathrm{COO}\right)_{5} .8 \mathrm{H}_{2} \mathrm{O}$ (M. M.); (d) $\mathrm{YNi}\left(\mathrm{CH}_{3} \mathrm{COO}\right)_{5} .3 \mathrm{H}_{2} \mathrm{O}$ (E. S.); (e) $\mathrm{YNi}\left(\mathrm{CH}_{3} \mathrm{COO}\right)_{5} .2 \mathrm{H}_{2} \mathrm{O}$ (C. A.). 


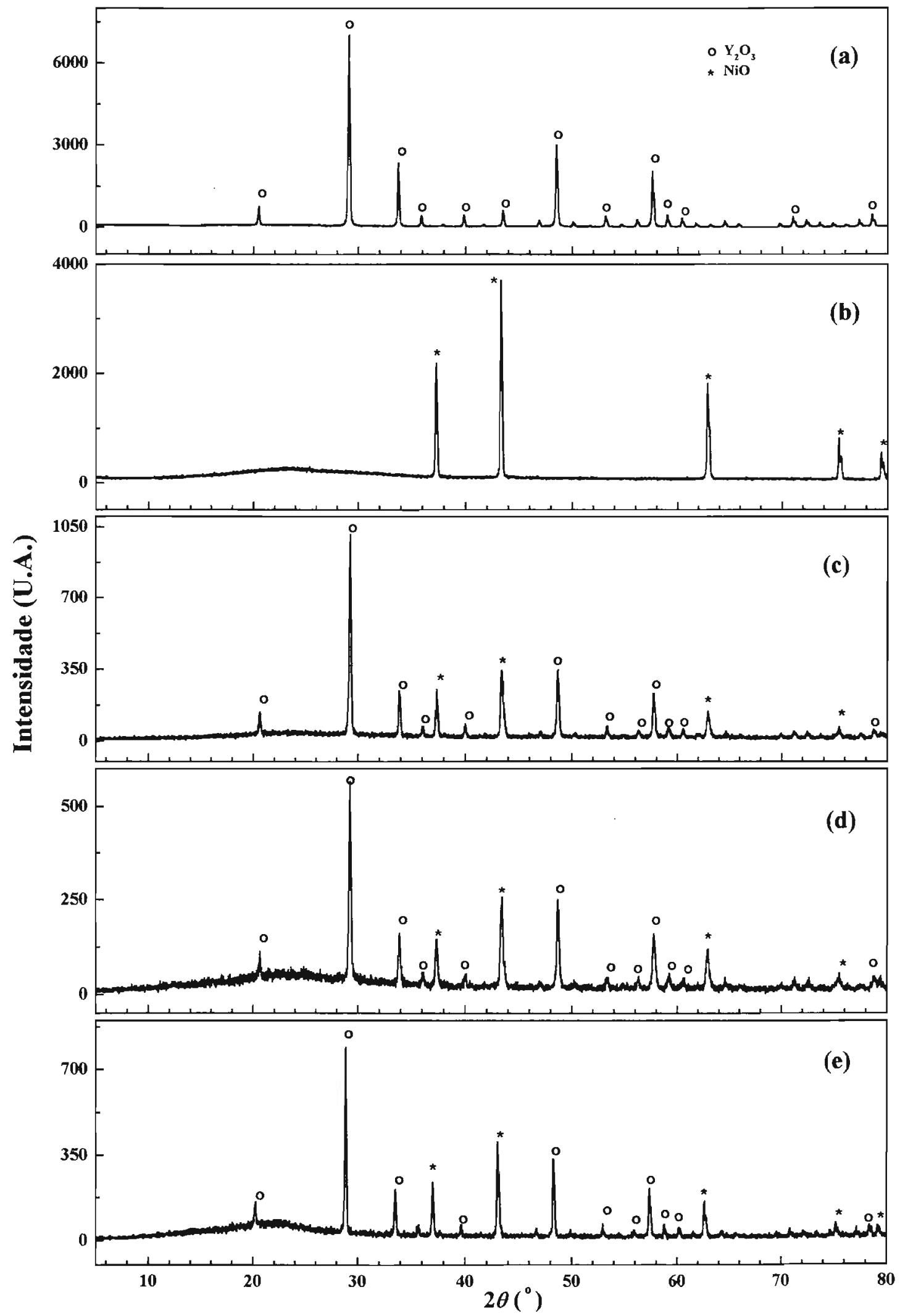

Figura 3.56: Difratogramas de raios $\mathrm{X}$ (método do pó) dos produtos da decomposição térmica a $900^{\circ} \mathrm{C}$, obtidos sob atmosfera dinâmica de nitrogênio $\left(50 \mathrm{~mL} \mathrm{~min}{ }^{-1}\right)$, razão de aquecimento de $10^{\circ} \mathrm{C}$ min $^{-1}$ e cadinho de platina das amostras: (a) $\mathrm{Y}\left(\mathrm{CH}_{3} \mathrm{COO}\right)_{3} .4 \mathrm{H}_{2} \mathrm{O}$; (b) $\mathrm{Ni}\left(\mathrm{CH}_{3} \mathrm{COO}\right)_{2} .4 \mathrm{H}_{2} \mathrm{O}$; (c) $\mathrm{YNi}\left(\mathrm{CH}_{3} \mathrm{COO}\right)_{5} .8 \mathrm{H}_{2} \mathrm{O}$ (M. M.); (d) $\mathrm{YNi}\left(\mathrm{CH}_{3} \mathrm{COO}\right)_{5} .3 \mathrm{H}_{2} \mathrm{O}$ (E. S.); (e) $\mathrm{YNi}\left(\mathrm{CH}_{3} \mathrm{COO}\right)_{5} .2 \mathrm{H}_{2} \mathrm{O}$ (C. A.). 


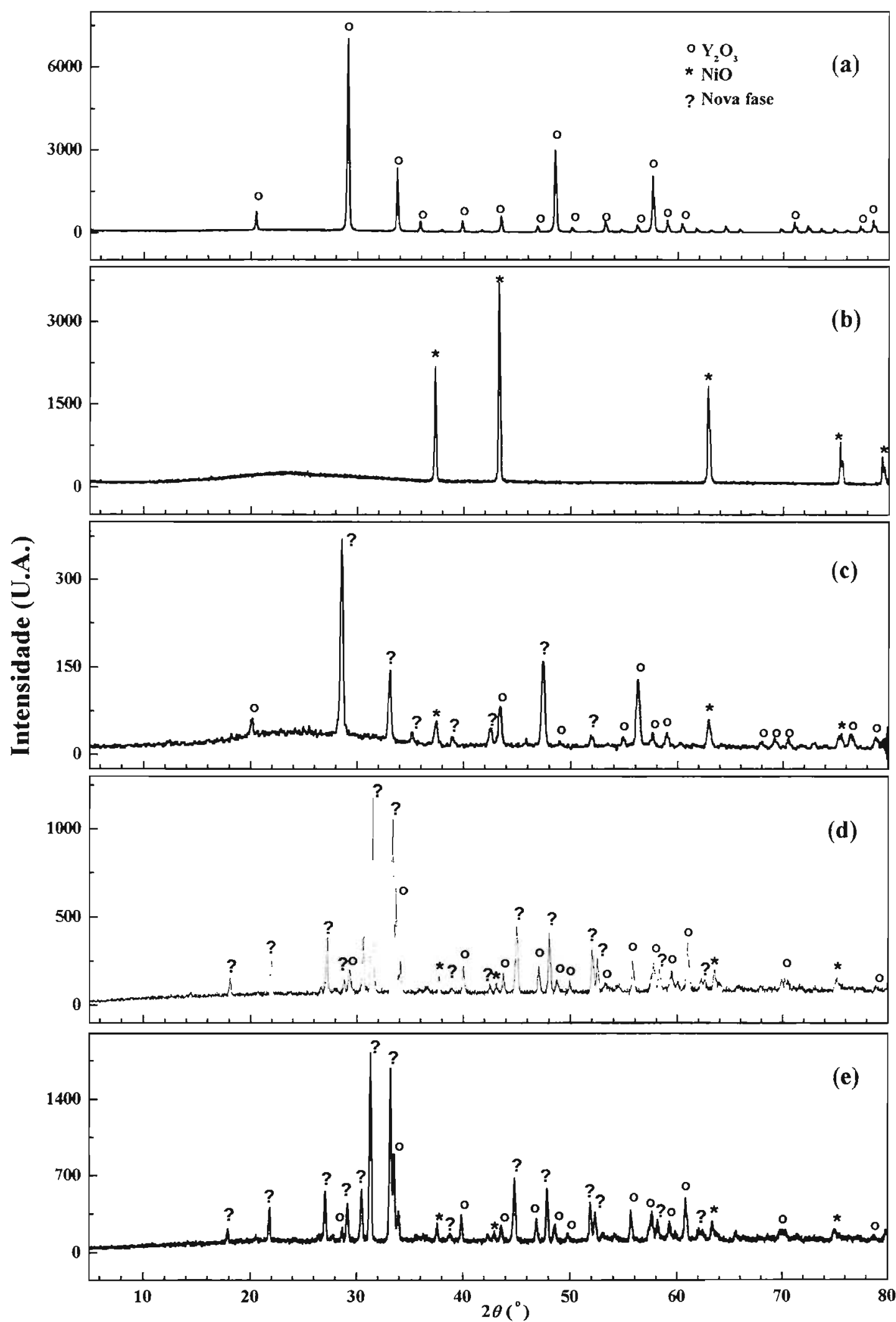

Figura 3.57: Difratogramas de raios $X$ (método do pó) obtidos após tratamento térmico a $900^{\circ} \mathrm{C}$, durante uma hora de aquecimento, sob atmosfera dinâmica de ar $\left(50 \mathrm{~mL} \min ^{-1}\right)$, razão de

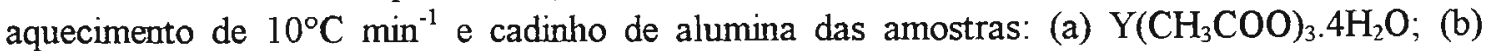
$\mathrm{Ni}\left(\mathrm{CH}_{3} \mathrm{COO}\right)_{2} .4 \mathrm{H}_{2} \mathrm{O}$; (c) $\mathrm{YNi}\left(\mathrm{CH}_{3} \mathrm{COO}\right)_{5} .8 \mathrm{H}_{2} \mathrm{O}$ (M. M.); (d) $\mathrm{YNi}\left(\mathrm{CH}_{3} \mathrm{COO}\right)_{5} .3 \mathrm{H}_{2} \mathrm{O}$ (E. S.); (e) $\mathrm{YNi}\left(\mathrm{CH}_{3} \mathrm{COO}\right)_{5} .2 \mathrm{H}_{2} \mathrm{O}$ (C. A.). 


\section{PARTE 2}

Os óxidos $\mathrm{TRNiO}_{3}[\mathrm{TR}=\mathrm{Pr}, \mathrm{Nd}$ e $\mathrm{Sm}$ (III)] foram preparados através de três métodos diferentes: (1) mistura de óxidos; (2) precipitação simultânea de hidróxidos de $\mathrm{TR}^{3+}$ e $\mathrm{Ni}^{3+}$ e (3) processo sol-gel. Esta parte do trabalho foi realizada em colaboração com o Prof. Dr. Renato F. Jardim e aluna Márcia T. Escote, ambos do departamento de Física e Mecânica de Materiais do IF-USP [44].

A formação dos óxidos foi avaliada variando-se a temperatura, tempo e pressão de oxigênio durante o processo de calcinação. As amostras foram tratadas termicamente no intervalo de 750 a $1000^{\circ} \mathrm{C}$, sob pressão de 40 a 70 atm de oxigênio, por períodos de no máximo $48 \mathrm{~h}$. As condições para a obtenção dos óxidos foram avaliadas por difração de raios $X$, que permitiu obter informações precisas acerca da estrutura cristalina, a presença ou ausência de fases indesejadas, tamanho médio dos cristalitos, etc.

Os resultados obtidos para cada sistema são discutidos separadamente a seguir.

\section{6- Sistema neodímio - níquel}

\subsection{1- Caracterização}

A determinação das melhores condições para a obtenção de $\mathrm{NdNiO}_{3}$ foi conseguida com o acompanhamento por análise de difração de raios X. Os precursores sintetizados por mistura de óxidos, hidróxidos binários e sol-gel foram submetidos aos mesmos tratamentos térmicos, sendo observado que se utilizando temperatura de $900^{\circ} \mathrm{C}$, sob pressão de 50 atm de oxigênio, obtém-se a fase desejada. Na Figura 3.58 estão representados os difratogramas de raios $\mathrm{X}$ das amostras tratadas nestas condições.

A Figura 3.58 (a) mostra o difratograma de raios $\mathrm{X}$ da amostra obtida por mistura de óxidos. Foi possível identificar as reflexões mais intensas dos óxidos de $\mathrm{Nd}_{2} \mathrm{O}_{3}$ e $\mathrm{NiO}$, que ocorrem em posições angulares diferentes do $\mathrm{NdNiO}_{3}$. No entanto, foram observadas algumas reflexões da fase desejada, por exemplo, na posição angular $2 \theta=33,1$ e $59,3^{\circ}$. A presença dos óxidos simples sugere que a interdifusão não foi total, e o óxido misto $\mathrm{NdNiO}_{3}$ ainda está em processo de formação. 
Para a amostra obtida por hidróxidos binários, as reflexões pertinentes aos óxidos $\mathrm{Nd}_{2} \mathrm{O}_{3}$ e $\mathrm{NiO}$ não foram perceptíveis, Figura 3.58 (b). As reflexões relativas a fase $\mathrm{NdNiO}_{3}$ são menos intensas do que as observadas pelo método anterior, indicando um menor grau de cristalinidade.

$\mathrm{O}$ difratograma de raios $\mathrm{X}$ para a amostra $\mathrm{NdNiO}_{3}$ preparada pelo método solgel é mostrado na Figura 3.58 (c). O resultado revelou um estreitamento apreciável das reflexões da fase desejada e o material obtido foi monofásico.

A largura e intensidade das linhas de difração são características dos dominios cristalinos presentes no material. Em geral, quando os domínios são pequenos, as reflexões de Bragg tendem a ser largas e podem estar associadas com o processo de cristalização do material, como observado no caso da amostra de mistura de óxidos [45].

As amostras obtidas por hidróxidos e sol-gel apresentaram-se monofásicas. Observou-se um estreitamento das reflexões de Bragg pertencentes ao $\mathrm{NdNiO}_{3}$ e maior grau de cristalinidade para a mostra obtida por sol-gel. Uma maneira mais precisa para observar este estreitamento é através da largura da meia altura (FWHM) das reflexões da fase desejada. Por exemplo, para os planos (200)/(020) verifica-se que o valor de FWHM diminui de $0,50^{\circ}$ no óxido obtido por hidróxidos, para $0,25^{\circ}$ no óxido obtido por sol-gel. Esta diferença corresponde a um decréscimo de $50 \%$, ou seja, uma redução significativa.

As reflexões observadas nos difratogramas de raios $\mathrm{X}$ foram indexadas (hkl) e utilizadas para calcular os parâmetros de rede $a, \mathrm{~b}$ e $c$ da estrutura ortorrômbica, com seus respectivos desvios, Tabela 3.27 .

Tabela 3.27: Parâmetros de rede $a$, b e $c$ calculados para as amostras de $\mathrm{NdNiO}_{3}$ obtidas por diferentes métodos de síntese

\begin{tabular}{l|c|c|c}
\hline MÉTODO & $\mathbf{a}(\boldsymbol{\AA})$ & $\mathbf{b}(\boldsymbol{\AA})$ & $\mathbf{c}(\mathbf{\AA})$ \\
\hline Teórico & 5,3891 & 5,3816 & 7,6101 \\
Mistura de óxidos & $5,397(20)$ & $5,386(15)$ & $7,677(21)$ \\
Hidróxidos & $5,392(2)$ & $5,383(2)$ & $7,622(4)$ \\
Sol-gel & $5,390(2)$ & $5,381(2)$ & $7,616(3)$ \\
\hline
\end{tabular}


Os resultados de parâmetros de rede para a amostra preparada por mistura de óxidos foram maiores do que os obtidos nas amostras preparadas pelos outros dois métodos. Por exemplo, o desvio associado ao parâmetro de rede $a(\Delta \mathrm{a})$, com o valor de $0,020 \AA$, obtido na amostra em questão é aproximadamente uma ordem de grandeza maior que os desvios observados nas amostras preparadas por hidróxidos e sol-gel $(\Delta \mathrm{a}=$ $0,002 \AA$ ). Isto significa que a amostra de $\mathrm{NdNiO}_{3}$ obtida por mistura de óxidos foi inferior em relação aos outros dois métodos.

Estes resultados também revelaram que os parâmetros de rede obtidos estão muito próximos dos valores encontrados na literatura $[46,47]$. Dentre os valores listados na Tabela 3.27, aqueles referentes ao óxido produzido por sol-gel foram os que mais se aproximaram, indicando que este método pode ser considerado, neste caso, o melhor para a obtenção de $\mathrm{NdNiO}_{3}$.

As observações de microscopia eletrônica de varredura forneceram informações sobre o tamanho médio dos grãos e a morfologia dos óxidos em estudo. Estas informações foram importantes para uma associação com os resultados de difração de raios $\mathrm{X}$.

Na Figura 3.59 estão representados os resultados desta técnica para as amostras de $\mathrm{NdNiO}_{3}$. As micrografias, apesar de não terem um contraste excelente, possibilitaram verificar que as amostras, de uma maneira geral, apresentaram grãos com diâmetros médios muito pequenos, variando de $2 \mu \mathrm{m}$ para amostra obtida por mistura de óxidos até valores inferiores a $1 \mu \mathrm{m}$ nos compostos preparados pelos outros dois métodos. $\mathrm{O}$ desenvolvimento microestrutural depende do tamanho inicial do grão, sendo este menor para a amostra obtida por hidróxidos binários.

A variação do tamanho médio dos grãos influencia a microestrutura destes materiais. Conforme pode ser observado nas micrografias, a amostra obtida por mistura de óxidos foi mais porosa que as outras. Sua microestrutura consistiu de grãos grandes que foram relativamente separados uns dos outros por regiões de porosidade. No entanto, as amostras preparadas pelos outros dois métodos apresentaram uma microestrutura composta de grãos pequenos e com alta densidade de agrupamento. Algumas características adicionais sobre a morfologia destes óxidos não foram visíveis, devido ao fato à dificuldade em acertar o contraste na aquisição das micrografias. 


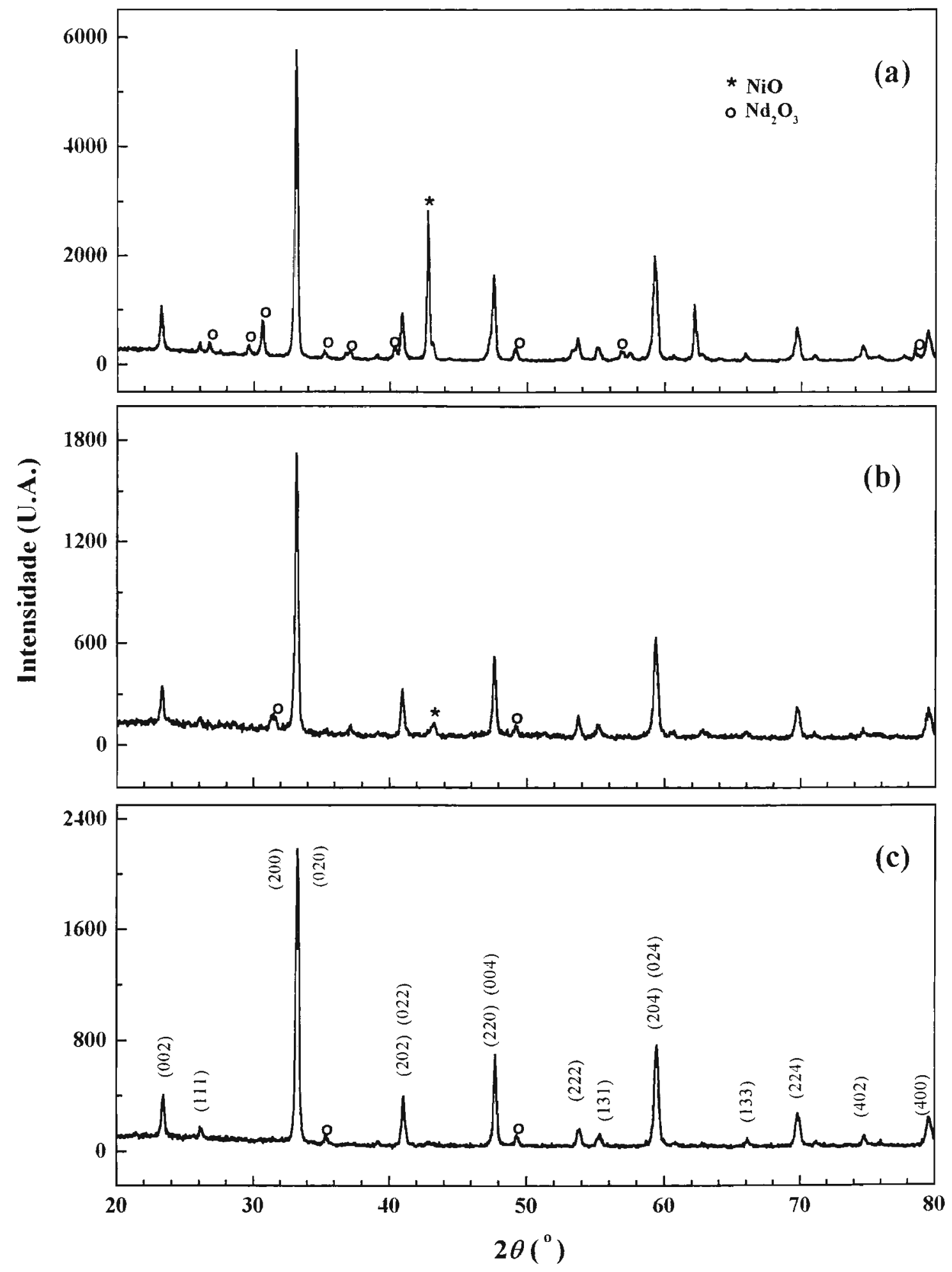

Figura 3.58: Comparação dos difratogramas de raios $\mathrm{X}$ (método do pó) das amostras de $\mathrm{NdNiO}_{3}$, tratadas a $900^{\circ} \mathrm{C}$ sob pressão de $50 \mathrm{~atm}$ de oxigênio durante $48 \mathrm{~h}$ de aquecimento e preparadas por: (a) mistura de óxidos; (b) hidróxidos binários e (c) processo sol-gel. 


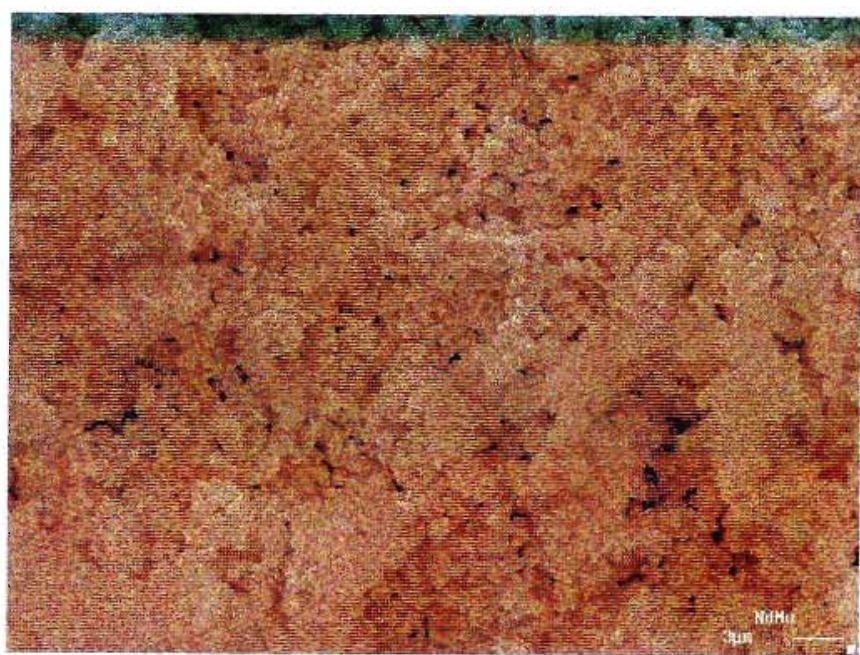

(a)

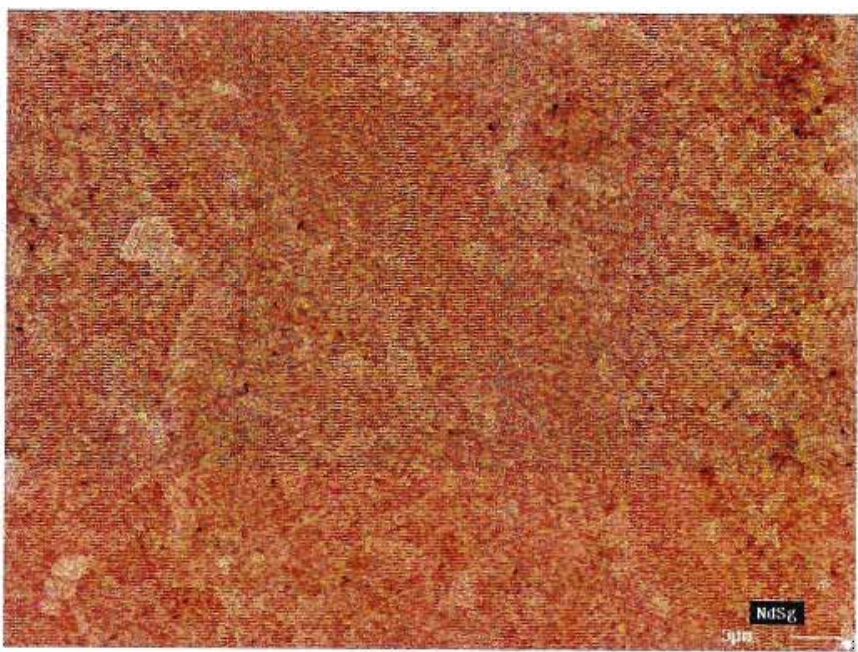

(b)

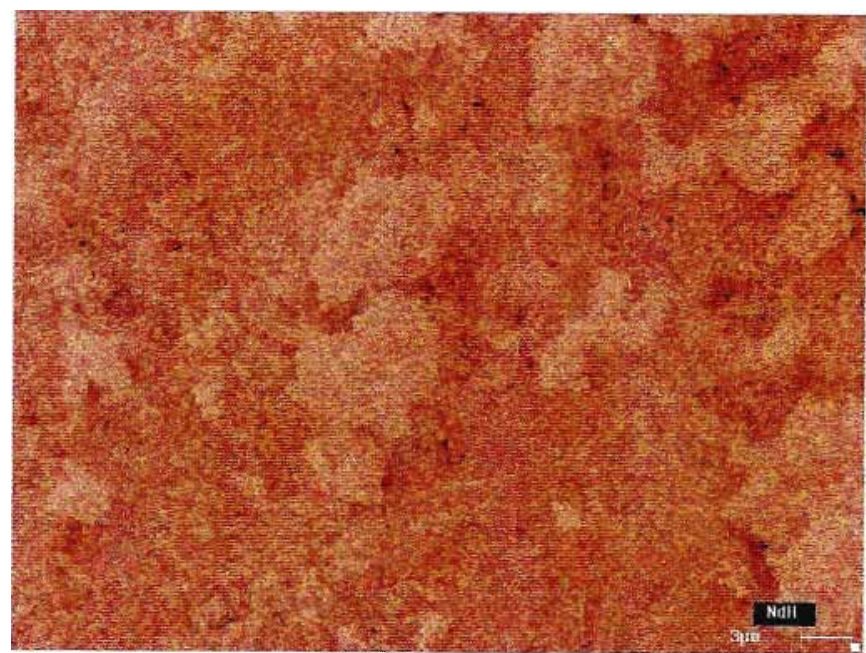

(c)

Figura 3.59: Comparação das micrografias das amostras de $\mathrm{NdNiO}_{3}$, tratadas a $900^{\circ} \mathrm{C}$ sob pressão de 50 atm de oxigênio, durante $48 \mathrm{~h}$ de aquecimento, preparadas por; (a) mistura de óxidos; (b) hidróxidos binários e (c) processo sol-gel. 


\subsection{2- Propriedades}

A determinação da temperatura de transição de fase metal-isolante $\left(\mathrm{T}_{\mathrm{MI}}\right)$ assim como um estudo das propriedades elétricas podem ser feitas com medidas de resistividade elétrica em função da temperatura $\rho(\mathrm{T})$.

A Figura 3.60 apresenta uma comparação entre as curvas de $\rho(T)$ em função da temperatura das amostras de $\mathrm{NdNiO}_{3}$ sintetizadas pelos três métodos. A $\mathrm{T}_{\mathrm{MI}}$ foi caracterizada por uma repentina mudança no comportamento na resistividade elétrica quando a amostra atingiu esta temperatura (inserido na Figura 3.60). Acima desta temperatura o material comportou-se como um condutor e abaixo como semicondutor. Esta temperatura foi determinada através do valor mínimo de $\rho(T)$, ou seja, a temperatura na qual o material perdeu seu caráter metálico.

Nesta figura são mostrados os resultados de $\rho(T)$ no intervalo de -170 a $-25^{\circ} \mathrm{C}$ e um detalhe acerca da definição da $T_{M}$. Para o óxido obtido por mistura de óxidos o valor foi de $-75^{\circ} \mathrm{C}$, enquanto para os outros dois métodos foi de $-73^{\circ} \mathrm{C}$. Estes valores foram muito próximos ao relatado na literatura que é de $-73^{\circ} \mathrm{C}$ [47-49]. Pode-se observar que a transição é mais abrupta na amostra preparada pelo método sol-gel.

Os diferentes valores de $\rho(T)$ na região metálica $\left(T>T_{M}\right)$ dependem do método utilizado na preparação dos materiais. Esta região da curva é linear, descrita por uma relação $\rho(\mathrm{T})=\rho_{0}+\mathrm{BT}$, e o coeficiente angular foi praticamente o mesmo para as amostras obtidas pelos três métodos. Sendo assim, as diferenças nos valores de $\rho(T)$ devem ser determinadas pelos valores de $\rho_{0}$, o qual está relacionado com imperfeições estruturais e morfologia das amostras.

Nas curvas apresentadas na Figura 3.60, verificou-se que os valores de $\rho(T)$ para o óxido $\mathrm{NdNiO}_{3}$ obtido por hidróxidos foram maiores que os observados para amostras de sol-gel e misturas de óxidos. Este resultado foi concordante com as observações de microscopia que revelaram uma microestrutura com grãos muito pequenos, que contribui para um maior espalhamento eletrônico, aumentando consideravelmente o valor da resistividade residual. A combinação dos resultados sugere que a amostra preparada pelo método sol-gel apresentou menor valor de $\rho_{o}$, seguido da amostra obtida por mistura de óxidos e finalmente por hidróxidos binários. 
Na região isolante $\left(T<T_{M I}\right)$ observou-se que os valores de $\rho(T)$ das amostras também variaram com o método utilizado. $O$ valor de $\rho(T)$ depende do volume da fase isolante, homogeneidade e cristalinidade da amostra.

Sendo assim, os resultados confirmaram aqueles obtidos por difração de raios $\mathrm{X}$, indicando que o método sol-gel produziu melhores amostras de $\mathrm{NdNiO}_{3}$.

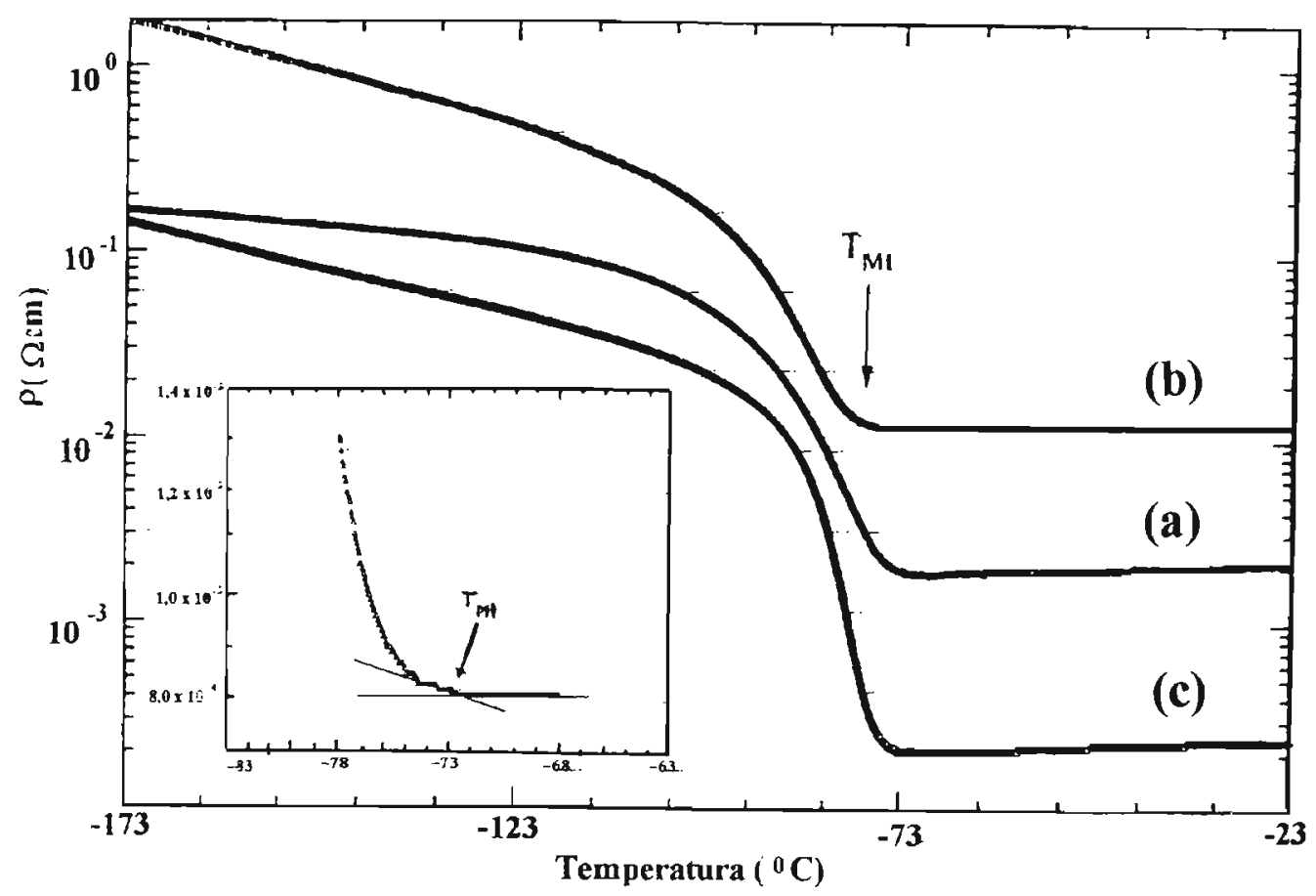

Figura 3.60: Medidas de resistividade elétrica em função da temperatura das amostras $\mathrm{NdNiO}_{3}$ obtidas por: (a) mistura de óxidos; (b) hidróxidos binários e (c) processo sol-gel. Detalhe da região próxima a transição de fase metal-isolante $T_{M}$.

A $\mathrm{T}_{\mathrm{MI}}$ também foi determinada por medidas de calorimetria exploratória diferencial (DSC). Os resultados apresentados na Figura 3.61 foram difíceis de serem obtidos, devido a limitações do instrumento DSC-50, na região de interesse, isto é, T<$50^{\circ} \mathrm{C}$

A primeira observação importante nos resultados de DSC, foi a ligeira diferença de temperatura onde ocorre a transição. A $T_{M I}$ foi evidenciada por um evento endotérmico nas curvas DSC. Com a ampliação da escala de temperatura, foi observado 
um aumento na temperatura de transição do óxido $\mathrm{NdNiO}_{3}$, ao mudar o método de síntese.

A temperatura do pico para a amostra obtida por sol-gel foi de $-83^{\circ} \mathrm{C}$, hidróxidos binários de $-79^{\circ} \mathrm{C}$ e mistura de óxidos de $-76^{\circ} \mathrm{C}$. Estas temperaturas diferem entre si de $7^{\circ} \mathrm{C}$, estando muito próximas considerando as limitações instrumentais. Estes resultados aproximaram-se dos encontrados por medidas de resistividade elétrica e concordaram com os resultados citados na literatura $[47,49,50]$.

A largura do intervalo de temperatura de transição de fase $\Delta T_{M I}$ também variou com o método de síntese utilizado para a obtenção do óxido misto $\mathrm{NdNiO}_{3}$. Os valores de $\Delta \mathrm{T}_{\mathrm{MI}}$ para as amostras preparadas por mistura de óxidos, hidróxidos binários e solgel, foram de 7,16 e $13{ }^{\circ} \mathrm{C}$, respectivamente.

Uma outra observação importante foi o calor envolvido na transição de fase. Para essas amostras, na mesma ordem citada acima, os valores $\Delta H$ foram de $18,311 \mathrm{e}$ $284 \mathrm{~J} \mathrm{~mol}^{-1}$, respectivamente. As diferenças observadas nestes valores são devidas aos grau de cristalinidade das amostras e à fração volumétrica da fase $\mathrm{NdNiO}_{3}$, ou seja, quanto maior o volume da fase, maior o valor de $\Delta H$. A baixa intensidade do pico observada na transição de fase metal-isolante da amostra obtida por mistura de óxidos, pode estar associada ao fato deste composto não ser monofásico e apresentar baixa cristalinidade. Os outros dois métodos apresentaram valores muito próximos e a diferença de $5 \%$, está dentro dos erros experimentais, não sendo considerada significativa.

Desta forma, a calorimetria exploratória diferencial pode ser considerada como uma técnica alternativa para a determinação da temperatura de transição metal-isolante. 


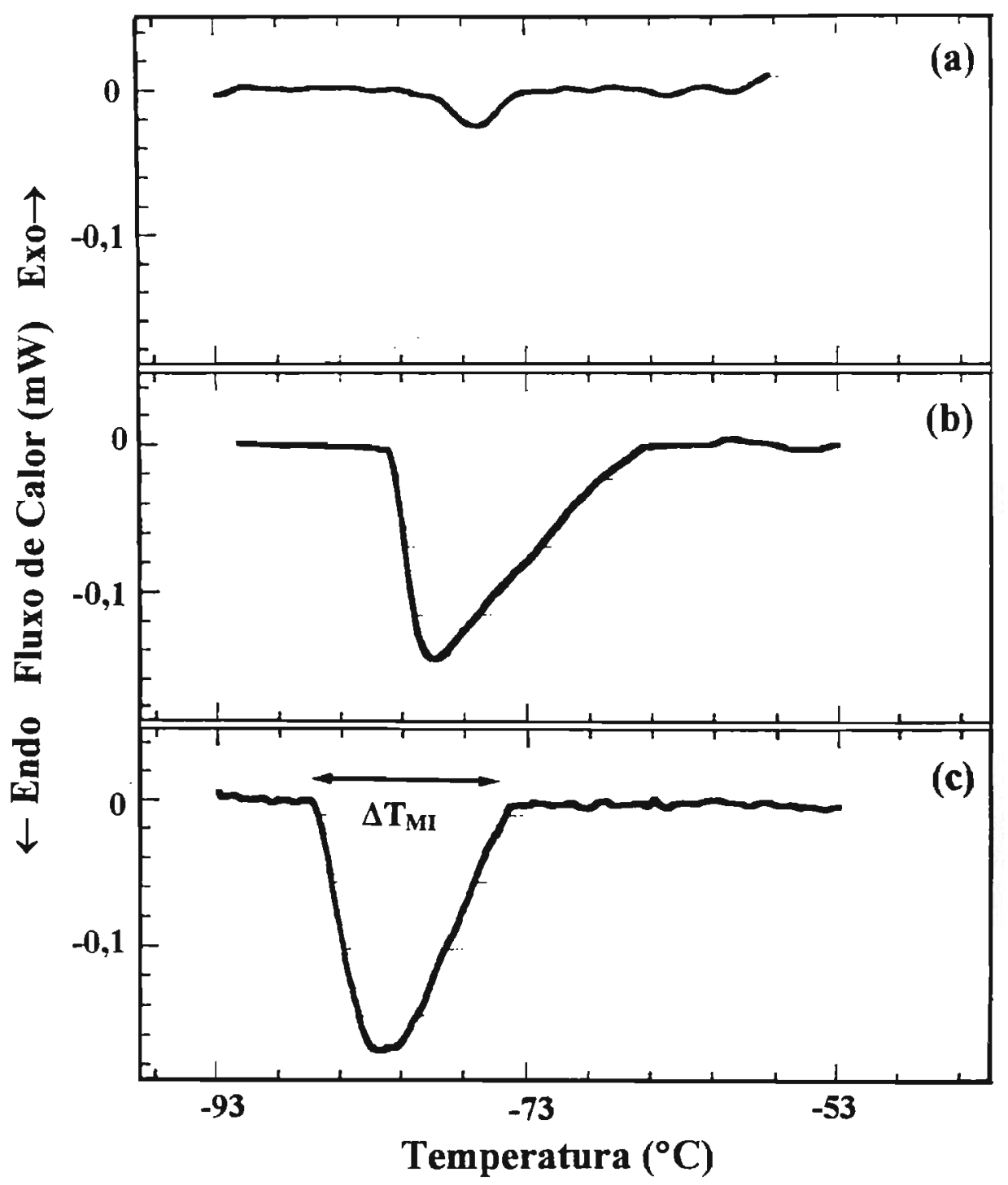

Figura 3.61: Curvas DSC das amostras de $\mathrm{NdNiO}_{3}$ obtidas sob atmosfera dinâmica de nitrogênio (50 $\left.\mathrm{mL} \mathrm{min}^{-1}\right)$, razão de aquecimento de $2^{\circ} \mathrm{C} \min ^{-1}$ e cápsula de alumínio fechada: (a) mistura óxidos ( $\mathrm{m}=40,36 \mathrm{mg}$ ); (b) hidróxidos binários $(\mathrm{m}=39,78 \mathrm{mg})$ e (c) processo sol-gel $(\mathrm{m}=41,27 \mathrm{mg})$. 


\section{7- Sistema samário - níquel}

\subsection{1- Caracterização}

Similarmente ao óxido $\mathrm{NdNiO}_{3}$, a formação do $\mathrm{SmNiO}_{3}$ sintetizados por mistura de óxidos, hidróxidos binários e sol-gel foi avaliada variando-se as condições de tratamento térmico, para a obtenção deste material.

A produção deste óxido foi muito dificil e verificou-se que empregando temperatura de $900^{\circ} \mathrm{C}$, sob pressão de 50 atm de oxigênio, obtém-se uma mistura da fase desejada e dos óxidos simples. Desta forma foi necessário modificar as condições do tratamento térmico

A Figura 3.62 representa os difratogramas de raios $\mathrm{X}$ das amostras tratadas $1000^{\circ} \mathrm{C}$, sob pressão de $70 \mathrm{~atm}$ de oxigênio por $48 \mathrm{~h}$ de aquecimento. Nestas condições, a amostra obtida por mistura de óxidos apresentou as reflexões dos óxidos simples (NiO e $\mathrm{Sm}_{2} \mathrm{O}_{3}$ ), de dioxicarbonato de samário e algumas da fase desejada, por exemplo $2 \theta=$ $33,5^{\circ}$, correspondente a reflexão do plano (020) do $\mathrm{SmNiO}_{3}$, Figura 3.62 (a).

A presença de dioxicarbonato de samário não era esperada, em virtude da alta temperatura e pressão utilizadas. Isto ocorreu provavelmente devido ao fato da reação entre os óxidos simples ter sido incompleta, e o óxido de samário tende a absorver água e gás carbônico da atmosfera durante o processo de resfriamento [51].

$\mathrm{O}$ difratograma de raios $\mathrm{X}$ do óxido obtido por hidróxidos binários está mostrado na Figura 3.62(b). O resultado revelou a presença das reflexões pertencentes ao $\mathrm{SmNiO}_{3}$ intensas e estreitas. Foram observadas também algumas reflexões de baixa intensidade do $\mathrm{NiO}$. A amostra obtida por este método apresentou maior grau de cristalinidade do que a obtida por mistura de óxidos.

Para a amostra obtida pelo método sol-gel, Figura 3.62(c), o difratograma de raios $\mathrm{X}$ revelou um estreitamento apreciável das reflexões do $\mathrm{SmNiO}_{3}$, o qual apresentou-se monofásico

As reflexões observadas nos difratogramas de raios $\mathrm{X}$ foram indexadas (hkl) e utilizadas para calcular os parâmetros de rede $a, b$ e $c$ da estrutura ortorrômbica, com seus respectivos desvios, Tabela 3.28. 
Tabela 3.28: Parâmetros de rede $a, b$ e $c$ calculados para as amostras de $\mathrm{SmNiO}_{3}$ obtidas por diferentes métodos de síntese

\begin{tabular}{l|c|c|c}
\hline MÉTODO & $\mathbf{a}(\AA)$ & $\mathbf{b}(\AA)$ & $\mathbf{c}(\AA)$ \\
\hline Teórico & 5,3252 & 5,4247 & 7,560 \\
Mistura de Óxidos & $5,345(13)$ & $5,448(12)$ & $7,586(11)$ \\
Hidróxidos & $5,337(8)$ & $5,440(8)$ & $7,579(12)$ \\
Sol gel & $5,329(10)$ & $5,433(10)$ & $7,572(9)$ \\
\hline
\end{tabular}

Os resultados de parâmetros de rede para a amostra preparada por mistura de óxidos foram maiores do que os obtidos para as amostras preparadas pelos outros dois métodos. Por exemplo, o desvio do parâmetro de rede $a(\Delta \mathrm{a})$ para esta amostra foi de $0,013 \AA$, enquanto que para amostras obtidas por hidróxidos e sol gel foram de $0,008 \mathrm{e}$ $0,010 \AA$, respectivamente.

Estes resultados foram muito próximos aos valores encontrados na literatura [46, 47]. Dentre os valores listados na Tabela 3.28, aqueles referentes ao óxido produzido por sol-gel foram os que mais se aproximaram do valor teórico, indicando que este método pode ser considerado o melhor para a obtenção do $\mathrm{SmNiO}_{3}$.

As observações de microscopia eletrônica de varredura forneceram informações sobre o tamanho dos grãos e a morfologia dos óxidos em estudo. As micrografias deste sistema, em relação ao sistema neodímio - níquel, foram mais fáceis de serem obtidas e estão apresentadas na Figura 3.63. De uma maneira geral, o tamanho médio dos grãos foi maior para a amostra obtida por mistura de óxidos, que também apresentaram maior porosidade, seguida da amostra de hidróxidos e o menor tamanho foi observado pela amostra obtida pelo processo sol-gel.

A variação do tamanho médio dos grãos influência na microestrutura destes materiais. A amostra obtida por mistura de óxidos apresentou microestrutura constituída de grãos grandes, separados uns dos outros por regiões de porosidade. As amostras preparadas pelos outros dois métodos apresentaram uma microestrutura composta de grãos pequenos e com alta densidade de agrupamento.

Estas observações preliminares foram relevantes para a discussão sobre os diferentes métodos de síntese. $\mathrm{O}$ tamanho médio dos grãos nas amostras de hidróxidos e sol-gel, do ponto de vista microestrutural, indicam materiais de boa qualidade no que concerne a possíveis aplicações tecnológicas. 


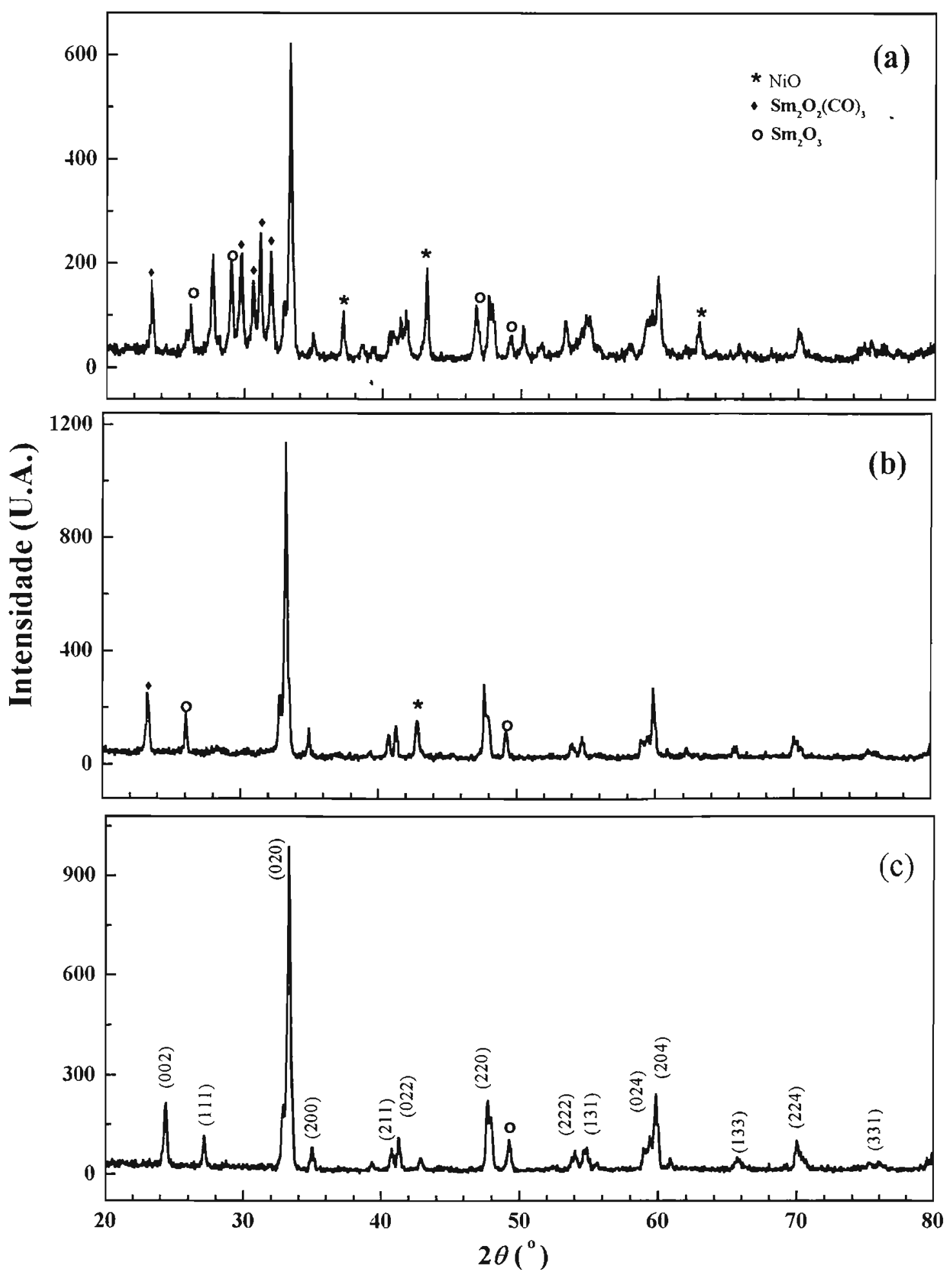

Figura 3.62: Comparação dos difratogramas de raios $X$ (método do pó) das amostras de $\mathrm{SmNiO}_{3}$, tratadas a $1000^{\circ} \mathrm{C}$ sob pressão de $70 \mathrm{~atm}$ de oxigênio durante $48 \mathrm{~h}$ de aquecimento e preparadas por: (a) mistura de óxidos; (b) hidróxidos binários; (c) processo sol-gel. 


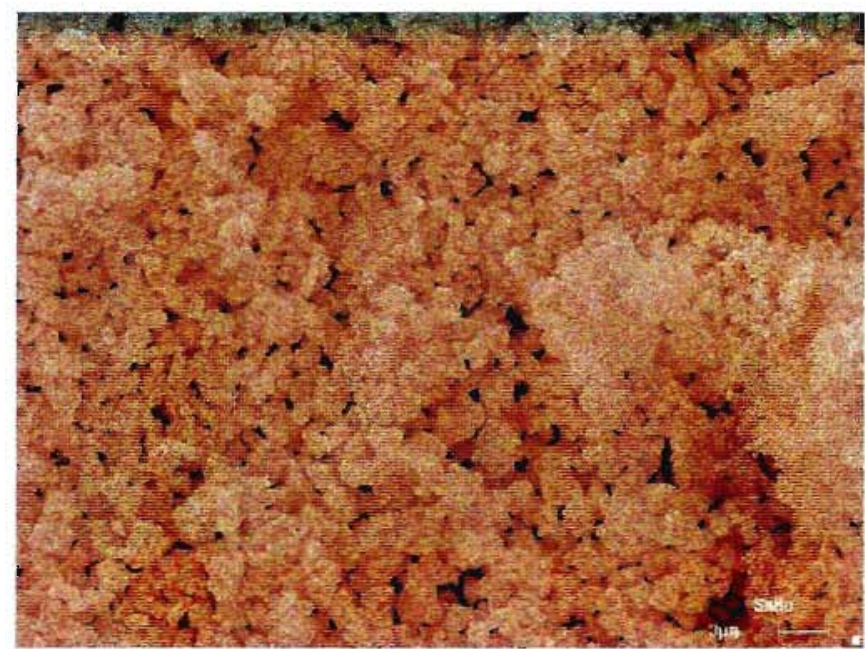

(a)

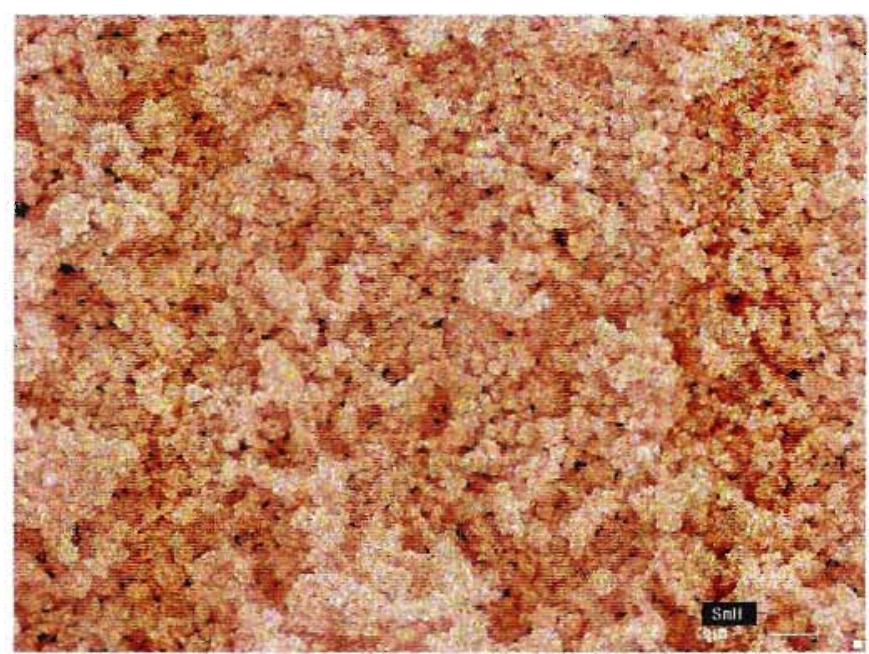

(b)

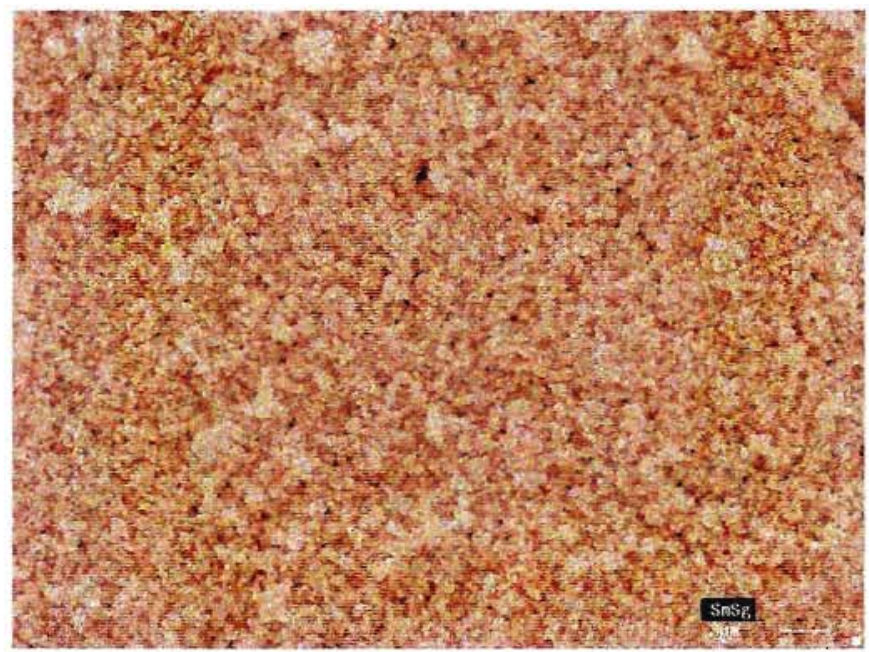

(c)

Figura 3.63: Comparação das micrografias das amostras de $\mathrm{SmNiO}_{3}$, tratadas a $1000^{\circ} \mathrm{C}$, sob pressão de $70 \mathrm{~atm}$ de oxigênio, durante $48 \mathrm{~h}$ de aquecimento, preparadas por: (a) mistura de óxidos; (b) hidróxidos binários e (c) processo sol-gel. 


\subsection{2- Propriedades}

A determinação da temperatura de transição de fase metal-isolante $\left(T_{M I}\right)$ para as amostras de $\mathrm{SmNiO}_{\Sigma}$, foi feita por medidas de resistividade elétrica e por calorimetria exploratória diferencial.

$\mathrm{Na}$ Figura 3.64 estão apresentadas uma comparação entre as curvas de $\rho(\mathrm{T}) \mathrm{em}$ função da temperatura. O valor da temperatura de transição metal-isolante para todas as amostras de $\mathrm{SmNiO}_{3}$, independente do método utilizado, foi de $127^{\circ} \mathrm{C}$ e correspondem exatamente aos valores relatados na literatura $[47,48]$

Na região isolante $\left(T<T_{M}\right)$ observaram-se diferenças nos valores de $\rho(T)$, análogas as relatadas para os óxidos $\mathrm{NdNiO}_{3}$. Para a amostra obtida por mistura de óxidos, a resistividade elétrica cresce aproximadamente duas ordens e meia de grandeza. No entanto, para as amostras obtidas por hidróxidos binários e sol-gel, esta medida aumenta aproximadamente três ordens de grandeza.

Similarmente as amostras de $\mathrm{NdNiO}_{3}$, a $\mathrm{T}_{\mathrm{M}}$ também foi determinada por DSC. Esta transição é de primeira ordem e identificada por medidas de DSC por eventos endotérmicos, durante o processo de aquecimento, e exotérmico no resfriamento. $\mathrm{Na}$ Figura 3.65 estão representadas as curvas DSC de aquecimento e resfriamento, das amostras de $\mathrm{SmNiO}_{3}$ obtidas pelos três métodos de síntese

Para a amostra obtida por mistura de óxidos, Figura 3.65 (a), o valor de $\mathrm{T}_{\mathrm{MI}}$ durante o processo de aquecimento foi de $129^{\circ} \mathrm{C}$, não sendo possível observar a temperatura durante o processo de resfriamento. Para as amostras obtidas por hidróxidos e sol-gel, os valores de $T_{M I}$ durante o processo de aquecimento foram de 128 e $127^{\circ} \mathrm{C}$, e no resfriamento de 125 e $123^{\circ} \mathrm{C}$, respectivamente, Figuras 3.65 (b) e (c). As diferenças observadas nas temperaturas é devido ao aparecimento de histerese, evidenciando o caráter de primeira ordem da transição metal-isolante. A histerese térmica está associada com uma região onde acredita-se que as duas fases, metálica e isolante, coexistam no material.

A variação de temperatura de transição de fase metal-isolante $\left(\Delta \mathrm{T}_{\mathrm{MI}}\right)$ foi muito próxima nos óxidos obtidos pelos três métodos de síntese, e correspondeu a $35^{\circ} \mathrm{C}$. O calor envolvido na transição $\Delta H$, durante o processo de aquecimento, das amostras de $\mathrm{SmNiO}_{3}$ por mistura de óxidos, hidróxidos e sol gel foram de 57,345 e $275 \mathrm{~J} \mathrm{~mol}^{-1}$, respectivamente. 


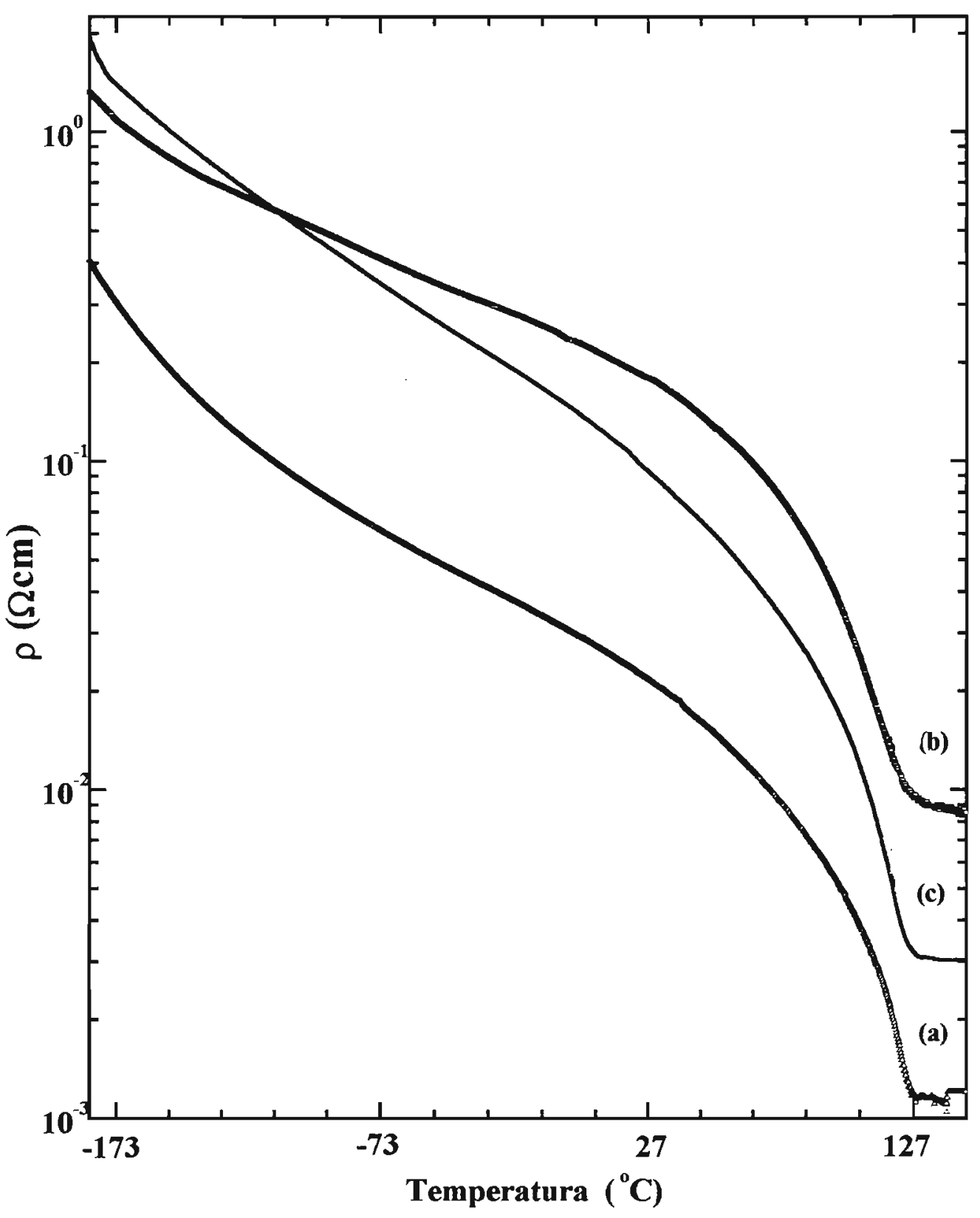

Figura 3.64: Medidas de resistividade elétrica em função da temperatura das amostras de $\mathrm{SmNiO}_{3}$ obtidas por: (a) mistura de óxidos; (b) hidróxidos binários; (c) processo sol-gel. 


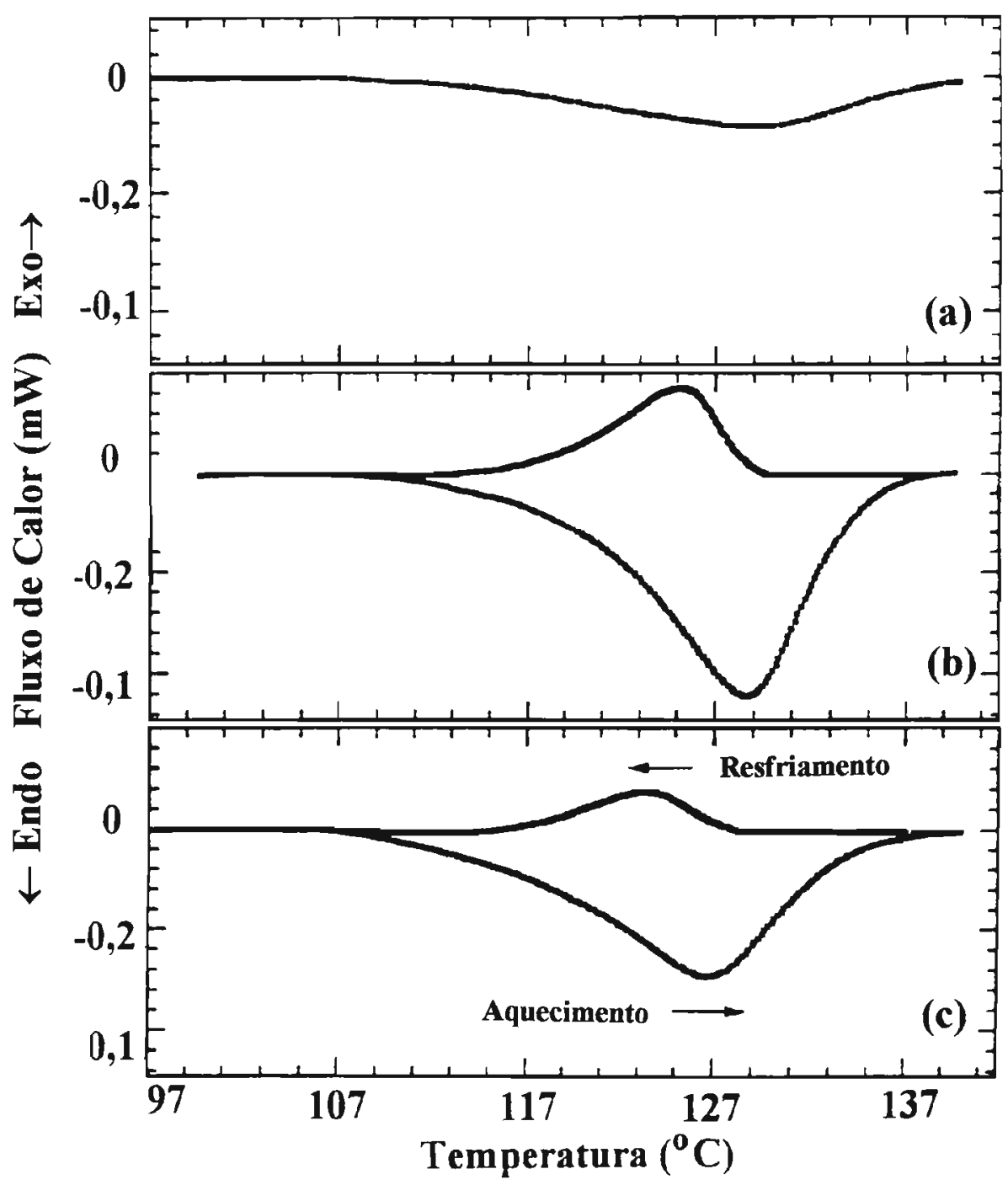

Figura 3.65: Curvas DSC das amostras de $\mathrm{SmNiO}_{3}$ obtidas sob atmosfera dinâmica de nitrogênio $\left(50 \mathrm{~mL} \mathrm{~min}{ }^{-1}\right)$, razão de aquecimento e resfriamento de $10^{\circ} \mathrm{C} \min ^{-1}$ e cápsula de alumínio fechada: (a) mistura de óxidos $(\mathrm{m}=20,15 \mathrm{mg})$; (b) hidróxidos binários $(\mathrm{m}=22,10 \mathrm{mg}$ ); (c) processo sol-gel $(\mathrm{m}=21,30 \mathrm{mg})$. 


\section{8- Sistema praseodímio - níquel}

\subsection{1- Caracterização}

A obtenção do óxido $\mathrm{PrNiO}_{3}$ apresentou um grau de dificuldade maior em relação aos óxidos $\mathrm{NdNiO}_{3}$ e $\mathrm{SmNiO}_{3}$. Algumas dificuldades foram encontradas na identificação das suas reflexões, uma vez que estas ocorrem em posições angulares muito próximas ao óxido $\mathrm{Pr}_{6} \mathrm{O}_{11}$ [46].

Na Figura 3.66 estão representados os difratogramas de raios $\mathrm{X}$ das amostras tratadas a $1000^{\circ} \mathrm{C}$, sob pressão de $70 \mathrm{~atm}$ de oxigênio, durante $48 \mathrm{~h}$ de aquecimento. Nestas condições, a amostra obtida por mistura de óxidos apresentou as principais reflexões dos óxidos $\mathrm{NiO}$ e $\operatorname{Pr}_{6} \mathrm{O}_{11}$, e algumas da fase desejada, Figura 3.66 (a). Este resultado sugeriu que o óxido ainda está em fase de formação e necessário prolongar o tratamento térmico.

$\mathrm{O}$ difratograma de raios $\mathrm{X}$ do óxido obtido por hidróxidos binários está mostrado na Figura 3.66 (b). O resultado revelou a presença das reflexões pertencentes ao $\mathrm{PrNiO}_{3}$, coexistindo com algumas dos óxidos simples.

A Figura 3.66 (c) representa o difratograma de raios X para amostra preparada pelo processo sol-gel. Os resultados são diferentes em relação aos casos anteriores e confirmam a presença da fase $\mathrm{PrNiO}_{3}$.

As reflexões observadas nos difratogramas de raios $\mathrm{X}$ foram indexadas (hkl) e utilizadas para calcular os parâmetros de rede $a, b$ e $c$ da estrutura ortorrômbica, com seus respectivos desvios, Tabela 3. 29.

Tabela 3.29: Parâmetros de rede $a, b$ e $c$ calculados para as amostras $\mathrm{PrNiO}_{3}$ obtidas por diferentes métodos

\begin{tabular}{l|c|c|c}
\hline MÉTODO & $\mathbf{a}(\boldsymbol{\AA})$ & $\mathbf{b}(\boldsymbol{\AA})$ & $\mathbf{c}(\boldsymbol{\AA})$ \\
\hline Teórico & 5,4093 & 5,3801 & 7,6263 \\
Mistura de Óxidos & $5,423(13)$ & $5,389(7)$ & $7,629(13)$ \\
Hidróxidos & $5,409(6)$ & $5,381(4)$ & $7,614(7)$ \\
Sol gel & $5,403(4)$ & $5,382(4)$ & $7,619(6)$ \\
\hline
\end{tabular}


Os resultados de parâmetros de rede para a amostra preparada por mistura de óxidos foram maiores do que os obtidos para aquelas preparadas pelos outros dois métodos. Por exemplo, o desvio do parâmetro de rede $a(\Delta \mathrm{a})$ para esta amostra foi de $0,013 \AA$, enquanto que para amostras obtidas pelos métodos dos hidróxidos e sol-gel foram de 0,006 e $0,004 \AA$, respectivamente.

Os parâmetros de rede calculados através do refinamento de pelo menos dez reflexões, estão próximos aos valores encontrados na literatura $[46,50]$. Dentre os valores listados na Tabela 3.29, aqueles referentes ao óxido produzido pelo método dos hidróxidos foram os que mais se aproximaram do valor teórico. Entretanto, o processo sol-gel foi o método de síntese que produziu óxido $\mathrm{PrNiO}_{3}$ monofásico, isto é, não foi observado a presença de traços dos óxidos simples.

\subsection{2- Propriedades}

A temperatura de transição de fase $\left(T_{M}\right)$ para as amostras de $\mathrm{PrNiO}_{3}$, apenas foi determinada por medidas de resistividade elétrica em função da temperatura. Não foi possível determiná-la por DSC, devido a problemas instrumentais de estabilização da célula em temperaturas inferiores a $-100^{\circ} \mathrm{C}$.

A amostra obtida por mistura de óxidos não proporcionou resultados satisfatórios, uma vez que este método gerou misturas polifásicas de óxidos. No entanto, para as amostras preparadas tanto por hidróxidos binários, quanto pelo processo sol-gel, Figuras 3.67 (a) e (b), a temperatura de transição de fase metal-isolante foi de $-138^{\circ} \mathrm{C}$, coincidindo com os valores relatados na literatura $[47,48]$.

Nesta figura são mostrados os resultados de $\rho(\mathrm{T})$ no intervalo de $-185 \mathrm{a}-23^{\circ} \mathrm{C}$. $\mathrm{Na}$ região metálica $\left(\mathrm{T}>\mathrm{T}_{\mathrm{MI}}\right)$, a curva é linear, e o coeficiente angular foi praticamente o mesmo para as amostras obtidas por hidróxidos binários e sol-gel. Na região isolante ( $\mathrm{T}$ $<\mathrm{T}_{\mathrm{MI}}$ ), foi observado que os valores de $\rho(\mathrm{T})$ possuem a mesma ordem de grandeza. Os valores da resistividade dependem do volume da fase isolante, homogeneidade e cristalinidade da amostra. De uma maneira geral, o óxido obtido por sol-gel apresentou menor valor de resistividade elétrica e intervalo de temperatura, em relação ao óxido obtido a partir de hidróxidos binários. A combinação de todos os dados sugeriram que o método sol-gel é o mais adequado para a síntese do óxido misto $\mathrm{PrNiO}_{3}$. 


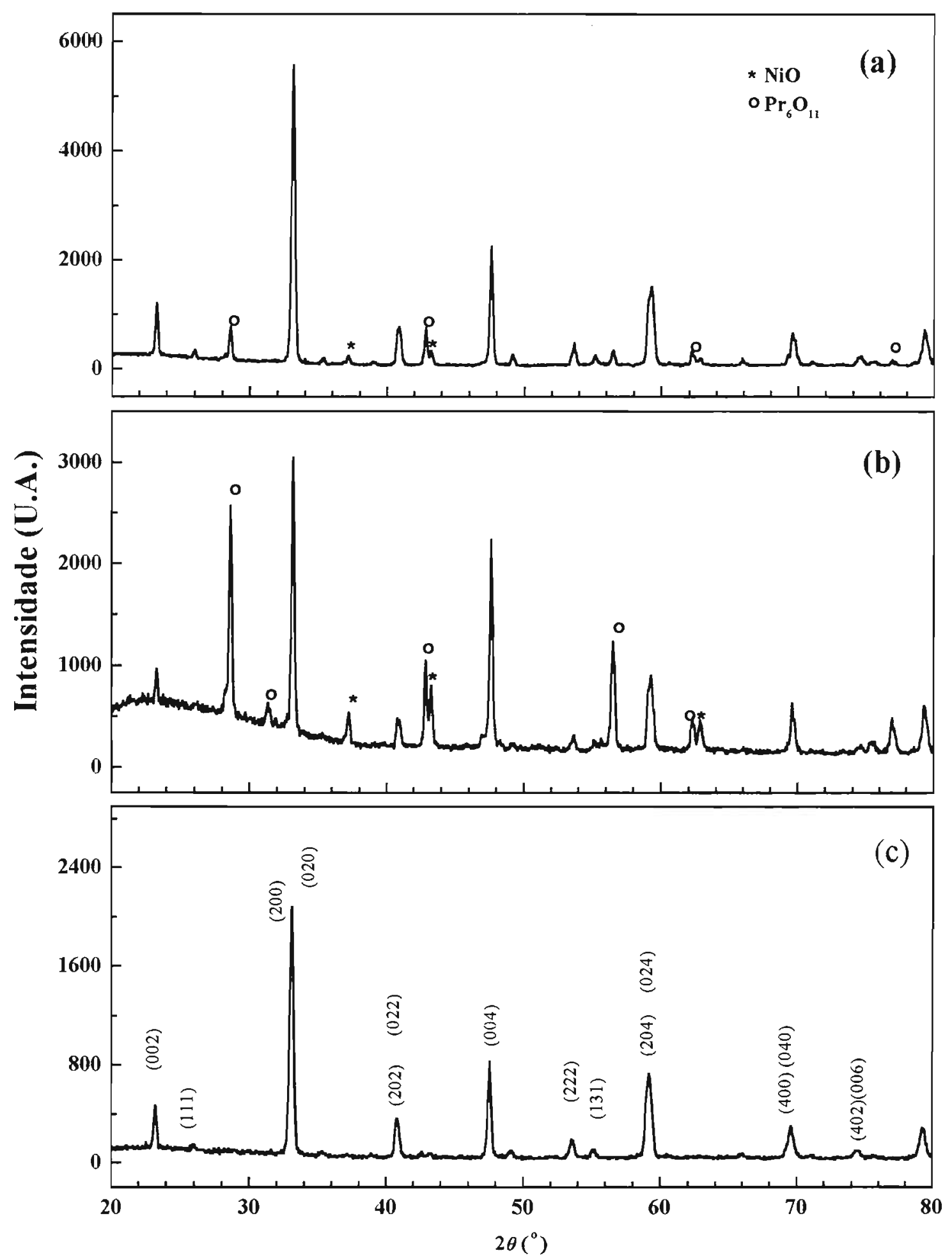

Figura 3.66: Comparação dos difratogramas de raios $\mathrm{X}$ (método do pó) das amostras de $\mathrm{PrNiO}_{3}$, tratadas a $1000^{\circ} \mathrm{C}$ sob pressão de $70 \mathrm{~atm}$ de oxigênio durante $48 \mathrm{~h}$ de aquecimento e preparadas por: (a) misturas de óxidos; (b) hidróxidos binários; (c) processo sol-gel. 


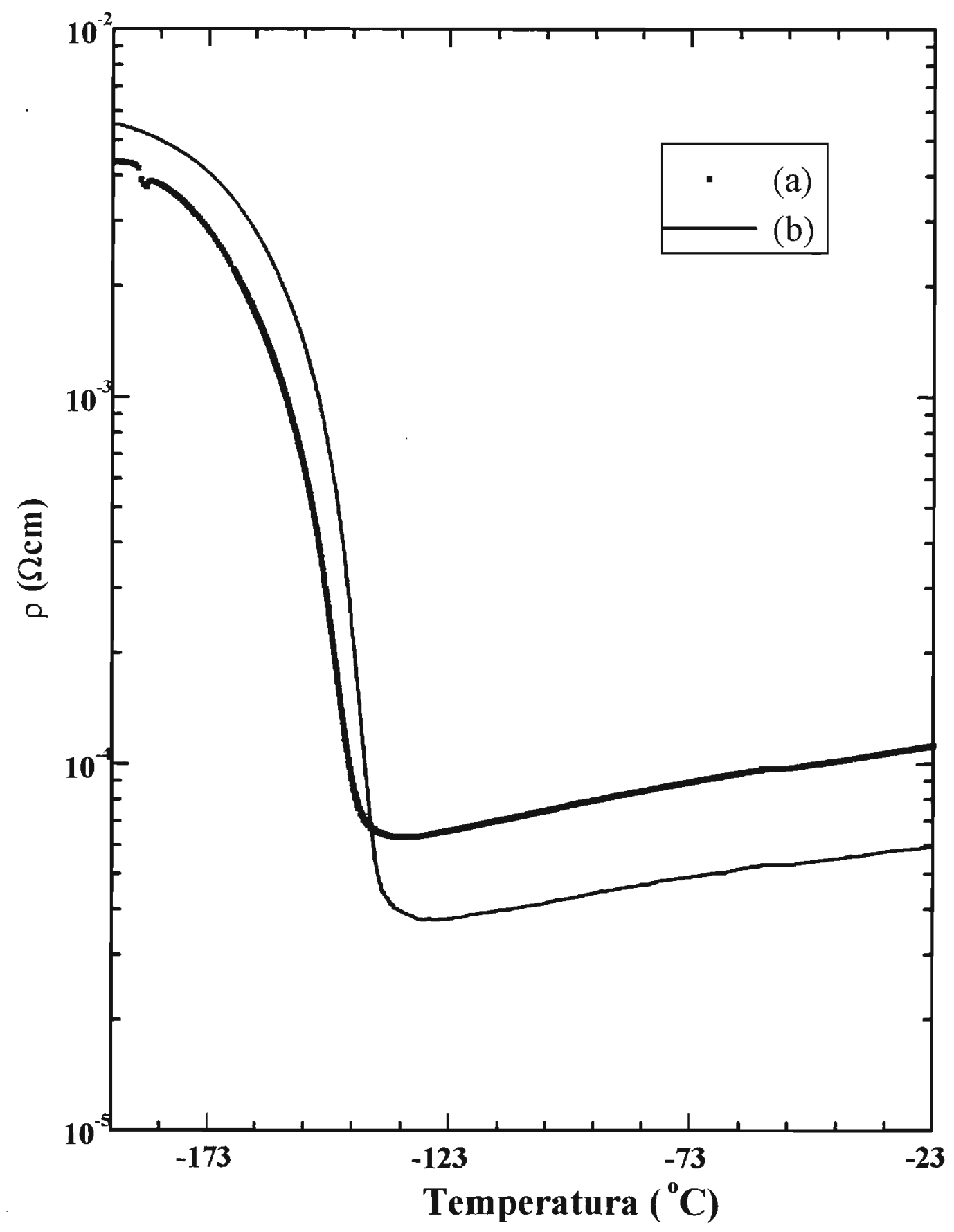

Figura 3.67: Medidas de resistividade elétrica em função da temperatura das amostras $\mathrm{PrNiO}_{3}$ obtidas por: (a) hidróxidos binários; (b) processo sol-gel. 


\section{9- Referências bibliográficas}

1- M. L. Salutsky, L. L. Quiil, J. Am. Chem. Soc. 72, 3306 (1950).

2- $\quad$ R. G. Charles, J. Inorg. Nucl. Chem. 27, 1489 (1965).

3- $\quad$ R. L. N. Sastry, R. S. Yoganarasimhan, P. N. Mehrotra, C. N. R. Rao, J. Inorg. Nucl. Chem. 28, 1165 (1966).

4- H. Hinode, R. Sharma, L. Eyring, J. Solid State Chem. 84, 102 (1990).

5- $\quad$ L. M. D’Assunção, I. Giolito, M. Ionashiro, Thermochim. Acta 137, 319 (1989).

6- L. M. D’Assunção, M. Ionashiro, , I. Giolito, D. E. Rasera, Thermochim. Acta 219, 225 (1993).

7- J. M. Luiz, "Hidroxicarbonatos de terras raras: estudo termoanalítico de sistemas simples e binários". Tese de Doutoramento - Instituto de Química - USP, 1985.

8- Powder Diffraction File of the Joint Commitee on Powder Diffraction Data (International Centre for Diffraction Data, Swarthmore, 1995).

9- K. Nakamoto, F. Fujita, S. Tanaka, M. Kobayashi, J.Am. Chem. Soc. 79, 4904 (1957).

10- J. A. Seaton, F. G. Sherif, L. F. Audrieth, J. Inorg. Nucl. Chem. 9, 222 (1959).

11- J. R. Witt, E. I. Onstott, J. Inorg. Nucl. Chem. 24, 637 (1962).

12- A. I. Grigor'ev, Russ. J. Inorg. Chem. 8, 409 (1963).

13- A. I. Grigor'ev, V. N. Maksimov, Russ. J. Inorg. Chem. 9, 580 (1964).

14- P. G. Manning, Can. J. Chem. 43, 3476 (1965).

15- K. C. Patil, G. V. Chandrashekhar, M. V. George, C. N. R. Rao, Can. J. Chem. 46, 57 (1968).

16- D. A. Edwards, R. N. Hayward, Can. J. Chem. 46, 3443 (1968).

17- C. Oldham, Progress in Inorganic Chemistry, vol 10, F. A. Cotton, Ed. Interscience, New York, 1968.

18- D. G. Karraker, J. Inorg. Nucl. Chem. 31, 2815 (1969).

19- N. W. Alcock, V. M. Tracy, T.C. Waddington, J. Chem. Soc. Dalton 2243 (1976).

20- G. B. Deacon, R. J. Phillips, Coord. Chem. Rev. 33, 227 (1980).

21- J. E. Tackett, Appl. Spectrosc. 43 (3), 483 (1989).

22- F. Ribot, P. Toledano, C. Sanchez, Inorg. Chim. Acta 185, 239 (1991). 
23- K. Nakamoto, Infrared spectra of inorganic and coordination compounds, (1986). John Wiley and Sons, New York.

24- I. Mayer, F. Kassierer, J. Inorg. Nucl. Chem. 28, 2430 (1966)

25- G. Adachi, E. A. Secco, Can. J. Chem. 50, 3100 (1972).

26- M. Hussein, J. Thermal. Anal. 42, 1091 (1994).

27- B. Kvapil, Mater Res. Bull. 8, 807 (1973).

28- B. Kvapil, Mater Res. Bull. 6, 865 (1971).

29- J. N. Van Niekerk, F. R. L. Shoening, Acta Cryst. 6, 609 (1953).

30- T. C. Downie, W. Harrison, E. S. Raper, Acta Cryst. B 27, 706 (1971).

31- G. S. Raghuvanshi, M. Pal, M. B. Patel, H. D. Bist, J. Mol. Struct. 7, 101 (1983).

32- G. S. Raghuvanshi, D. P. Khandelwal, H. D. Bist, Spectrochim. Acta Part A 41, $391(1985)$.

33- P. Baraldi, G. Fabbri, Spectrochim. Acta 37A, 89 (1981).

34- P. Baraldi, Spectrochim. Acta 38A (1), 51 (1982).

35- R. I. Bickley, H. G. M. Edwards, S. J. Rose, R. Gustar, J. Mol. Struct. 238, 15 (1990).

36- R. J. Meyer (Ed.), Gmelin's Handbuch der Anorganischen Chemie, 57 B/3, Weinheim, 1966, p. 860.

37- S. K. Siddhanta, S. M. Banjeree, J. Chem. Phys. 13, 419 (1958).

38- J. Leicester, M. J. Redman, J. Appl. Chem. 12, 357 (1962).

39- G. A. M. Hussein, A. K. H. Nohman, K. M. A. Attyia, J. Thermal. Anal. 42, 1155 (1994)

40- A. M. L. Silva, M. F. V. Moura, L. P. Mercuri, A. M. E. Santo, J. R. Matos, An. Assoc. Bras. Quim. 47(2), 133 (1998).

41- A. Golub, Phys. Rev. B 49, 563 (1994).

42- T. Ono, M. Anpo, Y. Kubokawa, J. Phys. Chem. 90, 4780 (1986).

43- H. H. Kung, Transition Metal Oxides: Surface Chemistry and Catalysis, (1989). Elsevier Science Publisher B.V. E. W. Nuffield, X-Ray Diffraction Methods, (1966). John Wiley and Sons, Inc.

44- M. T. Escote, "Produção e caracterização de compostos $\mathrm{LnNiO}_{3}$ e nd1-xLnxNiO3, $\mathrm{Ln}=\operatorname{Pr}, \mathrm{Nd}, \mathrm{Sm}, \mathrm{Eu}, \mathrm{Gd}, \mathrm{Er}, \mathrm{Yb}(0 \leq \mathrm{x} \leq 1)$ : um estudo da transição metalisolante". Dissertação de Mestrado - Instituto de Física - USP, 1997. 
45- E. W. Nuffield, X-Ray Diffraction Methods (1966). John Wiley and Sons, Inc

46- Powder Diffraction File of the Joint Commitee on Powder Diffraction Data (International Centre for Diffraction Data, Swarthmore, PA, 1992).

47- P. Lacorre, J. B. Torrance, J. Pannetier, A. I. Nazzal, P. W. Wang, T. C. Huang, J. Solid State Chem. 91, 225 (1991).

48- J. L. García-Muñoz, J. R. Carvajal, P. Lacorre, J. B. Torrance, Phys. Rev .B 46, 44414 (1992).

49- G. Frand, O. Bonhnke, P. Lacorre, J. L. Fourquet, A. Carré, B. Eid, J. Théobald, A. Gire, J. Solid State Chem. 120, 157 (1995).

50- X. Granados, J. Fontcuberta, X. Obradors, L. Manõsa, J. B. Torrance, Phys. Rev.B 48, 11666 (1993).

51- M. L. Medarde, J. Phys. Condens. Matter 9, 1679 (1997). 


\section{Capítulo}

\section{4}

Considerações Finais

Este capitulo finaliza o trabalho e aborda resumidamente, as principais considerações sobre os diferentes precursores utilizados para a obtenção dos óxidos mistos $\mathrm{TR}_{2} \mathrm{NiO}_{4}$ $[\mathrm{TR}=\mathrm{La}, \mathrm{Eu}$ e $\mathrm{Y}(\mathrm{III})]$ e $\mathrm{TRNiO}_{3}[\mathrm{TR}=\mathrm{Pr}$, $\mathrm{Nd}$ e Sm (III)]. 


\section{4- CONSIDERAÇÕES FINAIS}

Neste trabalho foi estudado diferentes métodos de síntese para a obtenção de óxidos mistos de niquel e terras raras.

A primeira parte do trabalho envolveu a síntese de hidroxicarbonatos de terras raras, $\mathrm{TROHCO}_{3} \cdot \mathrm{xH}_{2} \mathrm{O}(\mathrm{TR}=\mathrm{La}, \mathrm{Eu}$ e $\mathrm{Y})$, utilizados como materiais de partida para a preparação dos respectivos acetatos. Em seguida, os acetatos de terras raras, $\mathrm{TR}\left(\mathrm{CH}_{3} \mathrm{COO}\right)_{3} \cdot \mathrm{xH}_{2} \mathrm{O}$, juntamente com o acetato de níquel, $\mathrm{Ni}\left(\mathrm{CH}_{3} \mathrm{COO}\right)_{2} \cdot 4 \mathrm{H}_{2} \mathrm{O}$, foram caracterizados por análise elementar, espectroscopia de absorção na região do infravermelho, difração de raios X e técnicas termoanalíticas (TG/DTG, DTA e DSC). A caracterização destes sais foi fundamental, pois os mesmos foram utilizados como precursores de sistemas binários.

Dessa forma, os sistemas de acetatos binários envolvendo os acetatos de terras raras e níquel, foram sintetizados por três métodos diferentes: (1) mistura mecânica; (2) evaporação do solvente e (3) cristalização com acetona. Similarmente aos acetatos simples, estes sais foram caracterizados e estudou-se o comportamento térmico por técnicas termoanalíticas, variando-se a atmosfera atuante. A caracterização destes sais possibilitou obter resultados interessantes, por exemplo, a formação de acetatos duplos ou mistos, diferentes da mistura fisica dos acetatos simples.

A partir da decomposição térmica dos acetatos binários foi verificado que a formação de óxido misto é influenciada tanto pela atmosfera atuante, quanto pelo método de síntese empregado.

De uma maneira geral, os óxidos $\mathrm{TR}_{2} \mathrm{NiO}_{4}[\mathrm{TR}=\mathrm{La}, \mathrm{Eu}$ e $\mathrm{Y}$ (III)] foram isolados a partir da decomposição térmica dos acetatos binários obtidos por evaporação do solvente e/ou cristalização com acetona. Quando utilizaram-se tratamentos térmicos a $900^{\circ} \mathrm{C}$, sob atmosfera dinâmica de ar comprimido durante uma hora de aquecimento, obteve-se o óxido misto desejado. A atmosfera de nitrogênio não propicia a formação de $\mathrm{TR}_{2} \mathrm{NiO}_{4}$. Em adição, o método da mistura mecânica de acetatos possibilitou obter, somente, os óxidos simples, independente da atmosfera utilizada.

A segunda parte do trabalho envolveu a obtenção de óxidos mistos $\mathrm{TRNiO}_{3}$ [TR $=\operatorname{Pr}, \mathrm{Nd}$ e $\mathrm{Sm}(\mathrm{II})]$, utilizando três métodos de síntese: (1) mistura de óxidos; (2) hidróxidos binários e (3) processo sol-gel. 
$\mathrm{O}$ óxido $\mathrm{NdNiO}_{3}$ foi o mais fácil de ser obtido, isto é, a sua formação ocorreu em condições menos drásticas de temperatura e pressão, do que as necessárias à obtenção dos óxidos $\mathrm{SmNiO}_{3}$ e $\mathrm{PrNiO}_{3}$, independente do método de síntese empregado.

Comparando-se os três procedimentos sintéticos, isto é, mistura de óxidos, hidróxidos binários e processo sol-gel, o último apresentou-se mais adequado uma vez que foram obtidas amostras monofásicas e com alto grau de cristalinidade, quando tratadas nas mesmas condições de temperatura e pressão.

As amostras de $\mathrm{SmNiO}_{3}$ e $\mathrm{PrNiO}_{3}$ foram obtidas como fase única, somente quando se utilizou o método sol-gel e ainda foi necessário empregar alta temperatura $\left(1000^{\circ} \mathrm{C}\right)$ e pressão de oxigênio relativamente elevada(70 atm).

$\mathrm{O}$ óxido $\mathrm{PrNiO}_{3}$ não foi obtido como monofásico, quando se utilizou o método de hidróxidos binários, mas este apresentou-se mais adequado do que a da mistura de óxidos. As amostras quando submetidas a tratamentos térmicos a altas temperaturas $\mathrm{e}$ pressões de oxigênio, favorecem a formação de $\operatorname{Pr}^{4+}$ ao invés de $\operatorname{Pr}^{3+}$.

O tamanho médio dos grãos dos materiais precursores é uma característica muito importante na síntese térmica dos óxidos mistos. Neste estudo, o método que apresentou menor tamanho foi o de hidróxidos binários, onde a precipitação dos cátions ocorreu de forma lenta e gradativa, facilitando o processo de difusão. O favorecimento da fase desejada, isto é $\mathrm{TRNiO}_{3}$, depende do raio iônico da terra rara envolvida. Por exemplo, no $\mathrm{NdNiO}_{3}$ o raio iônico do $\mathrm{Nd}^{3+}$ é $1,109 \AA$, sendo este o composto mais fácil de ser produzido. Para $\mathrm{SmNiO}_{3}$ o raio iônico do $\mathrm{Sm}^{\hat{2}+}$ é $1,079 \AA$, sendo este ligeiramente menor que o neodímio, apresentou maior dificuldade para obtenção de materiais monofásicos.

As medidas de resistividade elétrica e DSC revelaram que estes óxidos mistos apresentaram transição de fase do tipo metal - isolante $\left(\mathrm{T}_{\mathrm{MI}}\right)$ nas temperaturas de -138, 73 e $127^{\circ} \mathrm{C}$, para $\mathrm{PrNiO}_{3}, \mathrm{NdNiO}_{3}$ e $\mathrm{SmNiO}_{3}$, respectivamente. 
Capítulo

Perspectivas de

trabalhos futuros 


\section{5- PERSPECTIVAS FUTURAS}

Embora as propriedades fisicas e químicas de óxidos mistos vêm sendo largamente estudada nos últimos dez anos, existe a possibilidade de ampliação, por exemplo na área de catálise heterogênea.

De uma maneira geral, alguns aspectos sobre este trabalho precisam de uma maior abordagem. Por exemplo:

1- O teor de oxigênio nos óxidos $\mathrm{La}_{2} \mathrm{NiO}_{4+\delta}$ pode ser determinado por $\mathrm{TG}$, utilizando atmosfera redutora (mistura $\mathrm{N}_{2} / \mathrm{H}_{2}, 90 / 10$ ) e razões de aquecimento muito baixas.

2- Submeter os precursores de acetatos binários de ítrio e níquel, a tratamentos térmicos envolvendo maior temperatura e pressão, uma vez que somente foram obtidos os resíduos da decomposição térmica sob fluxo de ar comprimido.

3- Escolher um sistema, por exemplo lantânio e níquel, estudar diferentes precursores sintéticos, com o objetivo de obter óxidos com diferentes estequiometria.

4- Ampliar os estudos sobre acetatos duplos, envolvendo outros elementos terras raras e metais de transição, bem como dos compostos estudados neste trabalho.

5- Ampliar os estudos envolvendo propriedades catalíticas.

6- Otimizar as condições da síntese térmica de óxidos mistos, que envolvam diferentes estados de oxidação, por exemplo $\mathrm{PrNiO}_{3}$. 